UNIVERSIDADE DE SÃO PAULO

ESCOLA POLITÉCNICA

\title{
ANÁLISE DO COMPORTAMENTO ESTRUTURAL DE SISTEMAS DE DRENAGEM VIÁRIA CONSTITUÍDOS POR TUBOS PLÁSTICOS FLEXÍVEIS ENVOLVIDOS COM AREIA
}

Texto apresentado à Escola Politécnica da Universidade de São Paulo para concorrer ao Título de Mestre, pelo curso de Pós-Graduação em Engenharia - Área de concentração: Engenharia de Transportes.

São Paulo 


\section{Schmitz, Cristiane Salerno}

Análise do comportamento estrutural de sistemas de drenagem viária constituídos por tubos plásticos flexíveis envolvidos com areia / Cristiane Salerno Schmitz. -- São Paulo, 2002.

$170 \mathrm{p}$.

Dissertação (Mestrado) - Escola Politécnica da Universidade de São Paulo. Departamento de Engenharia de Transportes.

1.Drenagem viária 2.Pavimentos \{Ensaios\} 3.Carregamento cíclico 4.Tubos flexíveis I.Universidade de São Paulo. Escola Politécnica. Departamento de Engenharia de Transportes II.t. 
UNIVERSIDADE DE SÃO PAULO

ESCOLA POLITÉCNICA

\section{ANÁLISE DO COMPORTAMENTO ESTRUTURAL DE SISTEMAS DE DRENAGEM VIÁRIA CONSTITUÍDOS POR TUBOS PLÁSTICOS FLEXÍVEIS ENVOLVIDOS COM AREIA}

Texto apresentado à Escola Politécnica da Universidade de São Paulo para concorrer ao Título de Mestre, pelo curso de Pós-Graduação em Engenharia - Área de concentração: Engenharia de Transportes.

Orientadora: Prof ${ }^{a}$ Dr $^{a}$ Liedi Légi Bariani Bernuci

São Paulo 
Data da Defesa: 13/12/2002

\section{Banca Examinadora}

$\operatorname{Prof}^{a} \operatorname{Dr}^{a}$ Liedi Légi Bariani Bernucci

Julgamento:

Assinatura:

Prof Dr Washington Pérez Nuñez

Julgamento:

Assinatura:

Prof $^{a}$ Dr $^{a}$ Maria Eugênia Gimenez Boscov

Julgamento:

Assinatura: 
Aos meus pais Ruben e Diná pelo esforço que fizeram para que eu pudesse chegar onde estou. 


\section{AGRADECIMENTOS}

A Deus por me capacitar a fazer coisas que eu jamais pensei que fosse capaz de fazer e por Seu constante amor e cuidado durante a temporada em que estive distante da família e dos amigos.

À minha família pelo apoio mesmo à distância. Permito-me mencionar a tia Milka, o tio Selmo, o Cristiano, o Cícero e a Clarissa, sempre presentes em ligações telefônicas carinhosas e confortadoras.

Aos meus amigos que mesmo de longe continuaram me apoiando. Também agradeço pelo ombro dos amigos Dani e Lídia, sempre disponíveis para ouvir minhas queixas e lamúrias. E aos integrantes da Gang do Apolônio: Vinícius, Henrique, Cícero, Oliver, Fabiano e agregados, amizades que nasceram durante a faculdade e continuarão para o resto de nossas vidas. Ainda há muitos outros que mereceriam ser citados, pena que o espaço não me permita, mas não posso deixar de acrescentar o Salin.

Às amigas Jack, Vanessa e Rosângela, que foram minha família em São Paulo, também integrada pelo Eduardo, pelo Ramon e pelo Adelson, mais recentemente. Obrigado por todos os momentos que passamos juntos.

Ao Mestre Edson de Moura, grande companheiro das horas boas e ruins do trabalho e de uma paciência poucas vezes vista. Ao calmo Daniel que também foi um grande companheiro e amigo das horas difíceis nos primeiros meses de trabalho, me fazendo acreditar que eu era capaz de transpor as barreiras que se colocavam a minha frente Agradeço também aos demais colegas do LTP - Márcia, Simonne, Lucia, Helder e Erasmo.

Aos amigos do Departamento de Engenharia de Transportes: Simone, Edson, Cidinha, Flávio e Conceição, que me permitiam momentos de descontração e amizade durante os intervalos, além de estarem sempre dispostos a ajudar. 
Aos colegas do Departamento de Estruturas e Fundações: José João, André e a grande amiga Adriane e seu esposo Christian. Agradeço também aos professores, sempre acessíveis, e aos laboratoristas Joaquim e Antônio.

À minha orientadora Prof ${ }^{a}$ Dr $^{a}$ Liedi Légi Bariani Bernucci sempre preocupada com o meu bem-estar. Obrigado pela orientação durante o trabalho e pelos conselhos sempre bem vindos.

Aos professores Dr Jorge Augusto Pereira Ceratti e Washington Pérez Nuñez e ao engenheiro José Augusto Oliveira pelo apoio técnico e científico durante o experimento de campo.

À equipe de funcionários, bolsistas e alunos de pós-graduação da Área de Pesquisas e Testes de Pavimentos, destacando meus fiéis escudeiros: Helena, Vinicius e Croaci, e demais colegas: Seu Ivo, Rodrigo, Thiago, Max, Ivan, Luciano, Mirtes e Fernando pelo apoio e coleguismo.

À FAPESP pelo apoio financeiro desburocratizado à pesquisa.

Ao meu amado Elias pelos momentos divididos no último ano, período no qual se tornou um grande amigo e companheiro. 
SUMÁRIO

LISTA DE FIGURAS _ IX

LISTA DE TABELAS ___ XIII

LISTA DE ABREVIATURAS___ XIV

RESUMO _ XV

ABSTRACT_ XVI

1. INTRODUÇÃO

1.1 Importância dos Sistemas Solo-Tubo para Drenagem Viária ___ 1

1.2 Objetivos 3

2. PRojeto Estrutural dos Sistemas Solo-Tubo Flexível

2.1 Interação Solo-Tubo __ 4

2.2 Tipos de Solicitação __ 6

2.2.1 Carregamento Permanente - Teoria de Marston-Spangler _ 7

2.2.2 Sobrecargas - Solução pela Formulação de Boussinesq__ 9

2.2.3 Cálculo dos Deslocamentos dos Tubos pela Fórmula de Iowa__ 12

2.2.4 Cálculo dos Deslocamentos dos Tubos pela Fórmula de Iowa

Modificada 14

2.3 Rigidez Anular _ 15

2.3.1. Determinação Teórica da Rigidez Anular ___ 16

2.3.2 Determinação Experimental da Rigidez Anular pela ISO 9969__ 16

2.3.3 Determinação Experimental da Rigidez Anular pela NBR 9053_ 17

2.4 Critérios de Projeto - Modos de Ruptura do Tubo 19

2.4.1 Deformação diametral excessiva__ 20

2.4.2 Reversão de curvatura _L 21

2.4.3 Esmagamento da parede do tubo__22

2.4.4 Flambagem da parede do tubo _ 23

2.4.5 Deformação excessiva da parede do tubo__ 24

2.5 Critérios para Seleção de Materiais de Envolvimento _ 25

2.6 Materiais de Berço, Fundação e Reaterro _ 28

2.6.1 Fundação _ 28

2.6.2 Material do Berço _ 29

2.6.3 Material de Reaterro__ 30

2.7 Aspectos Geométricos das Valas _ 30

2.7.1 Largura das Valas _ 30

2.7.2 Profundidade das Valas __ 31

3. BREVE HISTÓRICO DO USO DE TUBOS FLEXÍVEIS ENTERRADOS

3.1 Evolução para o Uso de Tubos Flexíveis de Parede Estruturada __ 33

3.2 Experimentos 36 
4.1 Concepção e Descrição do Experimento___ 48

4.2 Materiais__ $\mathbf{5 0}$

4.2.1 Tubos plásticos flexíveis de parede estruturada em PVC _ 50

4.2.2 Materiais de Envolvimento__ 52

4.3 Métodos 53

4.3.1 Métodos de seleção de materiais__ 53

4.3.2 Métodos de compactação _ 53

4.3.3 Métodos de controle de compactação_ 54

4.4 Construção e Instrumentação das Valas-Teste___ 64

4.4.1 Processo de Instalação do Tubo na Vala e Compactação dos Materiais

de Envolvimento e Reaterro___ 65

4.4.2 Instalação dos LVDT's___ 68

4.4.3 Sistema de Aquisição de Dados _ 69

5. ENSAIOS REALIZADOS E RESULTADOS_ 71

5.1 Ensaios de Laboratório _ 71

5.2 Ensaio de Campo - Controle de Compactação__ 74

5.2.1 Cones de Penetração Dinâmica _ 74

5.2.2 Equipamento de Impacto Clegg__ 87

5.3 Simulação de Campo___ 89

5.3.1 Instalaçções e Carregamentos Empregados __ 89

5.3.2 Deslocamentos Medidos _ 90

5.3.3 Discussão sobre Registros e Dificuldades do Experimento___ 97

5.4 Avaliação das Valas após a Aplicação de Carga __ 98

5.4.1 Procedimentos e Medidas Realizadas após a Simulação de Carga _ 98

5.4.2 Afundamentos em Trilhas de Rodas_ 99

5.4.3 Medidas realizadas no interior dos tubos 101

5.4.4 Controle de Compactação da Areia Após a Simulação de Carga__ 103

6. ANÁLISE DOS RESULTADOS

6.1 Controle de Compactação___ 105

6.1.1 Compactação do Berço _ 105

6.1.2 Variação da Resistência das Areias Dependendo do Estado __ 106

6.2 Módulo de Reação E’ _ 113

6.2.1. Carregamentos e Deslocamentos Considerados _ 113

6.2.2. Interpretação dos Resultados da Retroanálise___ 114

7. CONCLUSÕES E SUGESTÕES ___ 118

REFERÊNCIAS BIBLIOGRÁFICAS___ 121

ANEXO I 126

ANEXO II__ 128

ANEXO III _ 132 
ANEXO IV 135 ANEXO V 138 ANEXO VI 141

ANEXO VII 148 ANEXO VIII 157 ANEXO IX 164 


\section{LISTA DE FigURAS}

Figura 2.1 - Representação gráfica de um tubo enterrado (Moser, 1990) 5

Figura 2.2 - Distribuição comparativa de tensões ao redor de um tubo rígido e de um flexivel enterrados e sujeitos a carregamentos iguais (adaptado de Watkins, 1966) 6

Figura 2.3 - Tensões verticais atuantes sobre o plano tangente à geratriz superior do tubo LTP-PTREPUSP/Tigre (1998b) 12

Figura 2.4 - Elemento estrutural da parede do tubo Rib Loc ${ }^{T M}$ 16

Figura 2.5 - Deflexão em um tubo flexivel 20

Figura 2.6 - Reversão de curvatura em um tubo de PVC causada por deflexão excessiva 21

Figura 2.7 - Esmagamento da parede de um tubo flexivel 22

Figura 2.8 - Flambagem da parede de um tubo flexivel_ 23

Figura 2.9 - Cunha de esforcos (Monge, 1996) 31

Figura 3.1 - Seção típica do perfil do tubo Rib Loc ${ }^{T M}$ - com as paredes estruturadas com almas e mesas de enrijecimento e encaixes nas extremidades tipo macho-fêmea 35

Figura 3.2 - Tubo plástico flexivel de parede estruturada sendo enrolado helicoidalmente em canteiro de obra no Brasil 35

Figura 3.3 - Influência da densidade do solo em testes com tubos com rigidez anular de $69 \mathrm{kN} / \mathrm{m}^{2}$ (10 psi), onde $A, B$ e C são os graus de compactação do material de envolvimento relativo à Energia Normal (Moser et al., 1985)

Figura 3.4 - Influência do tipo de solo de envolvimento em testes com tubos com rigidę. anular de 69 kN/m2 (10 psi) (Moser et al., 1985)

Figura 3.5- Perfis típicos das paredes dos tubos (segundo o eixo longitudinal) utilizados por Sargand et al. (1995) 40

Figura 3.6 - Deflexões dos tubos de PVC-1 (a) e de PVC-2 (b) durante os testes de campo realizados por Sargand et al (1995) 42

Figura 4.1 - Perfis fabricados no Brasil 50

Figura 4.2 - Localização dos componentes do perfil (Tabela 1) ${ }^{9}$ 51

Figura 4.3 - Deformação diametral em função da carga permanente para $\mathrm{R} A=1000$ Pa e $\mathrm{R} A$ nula (LTP-PTR-EPUSP/Tigre, 1998b) 52

Figura 4.4 - Compactador utilizado na área de testes 54 
Figura 4.5 - Localização esquemática das valas e dos pontos de controle de compactação 56

Figura 4.6 - Penetrômetro Dinâmico de Cone (cedido por Trichês e Cardoso) 57

Figura 4.7 - Vista geral do Penetrômetro Dinâmico Leve UFV -II e detalhes das pontas de $30^{\circ}$ e $60^{\circ}$ (Röhm, 1984) 61

Figura 4.8 - Equipamento de Impacto Clegg (Trevor Deakin Consultants Ltd) 63

Figura 4.9 - Vista geral das valas-teste 65

Figura 4.10 - Algumas observações sobre a instalação do tubo na vala pertinentes ao projeto estrutural (LTP-PTR-EPUSP/Tigre, 1998) 66

Figura 4.11 - Falhas no preenchimento das valas provocadas pela chuva 67

Figura 4.12 - Detalhes da fixação dos sensores tipo LVDT dentro dos tubos 68

Figura 4.13 - Vista geral das instalações internas de um tubo preparado para a execução do ensaio e registro dos deslocamentos 69

Figura 5.1 - Curva granulométrica da areia 72

Figura 5.2 - Curva de compactação da areia 73

Figura 5.3 - Variação do valor de CBR com a compacidade relativa 74

Figura 5.4 - Ensaio com o DCP para controle de compactação das valas-teste na Área de Pesquisas e Testes de Pavimentos UFRGS/DAER-RS 75

Figura 5.5 - Ensaio com o UFV-II para controle de compactação das valas-teste na Área de Pesquisas e Testes de Pavimentos UFRGS/DAER-RS

Figura 5.6 - Resultados dos ensaios de penetração dinâmica com DCP no solo de fundação da vala profunda compactada 76

Figura 5.7 - Resultados dos ensaios de penetração dinâmica com DCP no solo de fundação da vala rasa compactada 77

Figura 5.8 - Resultados dos ensaios de penetração dinâmica com DCP no solo de fundação da vala rasa não compactada 77

Figura 5.9 - Resultados dos ensaios de penetração dinâmica com DCP no solo de fundação da vala profunda não compactada 78

Figura 5.10 - Resultados de controle de compactação com DCP na superfície da Vala Profunda Compactada antes da simulação de tráfego 79

Figura 5.11 - Resultados de controle de compactação com UFV-II na sexta camada da Vala Profunda Compactada antes da simulação de tráfego 79

Figura 5.12 - Resultados de controle de compactação com DCP na superfície da Vala Rasa Compactada antes da simulação de tráfego 80 
Figura 5.13 - Resultados de controle de compactação com UFV-II na superficie da V ala Rasa Compactada antes da simulação de tráfego 80

Figura 5.14 - Resultados de controle de compactação com DCP na Vala Profunda Compactada após a simulação de tráfego

Figura 5.15 - Resultados de controle de compactação com UFV-II na V ala Profunda Compactada após a simulação de tráfego 82

Figura 5.16 - Resultados de controle de compactação com DCP na Vala Rasa Compactada após a simulação de tráfego

Figura 5.17 - Resultados de controle de compactação com UFV-II na V ala Rasa Compactada após a simulação de tráfego 83

Figura 5.18 - Resultados de controle de compactação com DCP na Vala Rasa Não Compactada após a simulação de tráfego 84

Figura 5.19 - Resultados de controle de compactação com UFV-II na Vala Rasa Não Compactada após a simulação de tráfego 85

Figura 5.20 - Resultados de controle de compactação com DCP na V ala Profunda Não Compactada após a simulação de tráfego

Figura 5.21 - Resultados de controle de compactação com UFV-II na V ala Profunda Não

Compactada após a simulação de tráfego 86

Figura 5.22 - Ensaio com o Equipamento de Impacto Clegg para controle de compactação das valasteste na Área de Pesquisas e Testes de Pavimentos UFRGS/DAER-RS 87

Figura 5.23 - Simulador de Tráfego UFRGS/DAER-RS 89

Figura 5.24 - Resultados de deslocamento com carga de 3,0 tfpara na Vala Profunda Compactada91

Figura 5.25 - Resultados de deslocamento com carga de 4,5 tfpara na V ala Profunda Compactada91

Figura 5.26 - Resultados de deslocamento com carga de 6,0 tfpara na Vala Profunda Compactada92

Figura 5.27 - Resultados de deslocamento com carga de 3,0 tfpara na Vala Rasa Compactada_ 92

Figura 5.28 - Resultados de deslocamento com carga de 4,0 tfpara na Vala Rasa Compactada_ 93

Figura 5.29 - Resultados de deslocamento com carga de 5,0 tfpara na Vala Rasa Compactada_ 93

Figura 5.30 - Resultados de deslocamento com carga de 6,0 tfpara na V ala Rasa Compactada_ 94

Figura 5.31 - Resultados de deslocamento com carga de 3,0 tfpara na Vala Rasa Não Compactada

Figura 5.32 - Resultados de deslocamento com carga de 4,0 tfpara na Vala Rasa Não Compactada 
Figura 5.33 - Resultados de deslocamento com carga de 5,0 tfpara na Vala Rasa Não Compactada

Figura 5.34 - Resultados de deslocamento com carga de 3,0 tf para na Vala Profunda Não

Compactada 96

Figura 5.35 - Resultados de deslocamento com carga de 4,5 tfpara na V ala Profunda Não

Compactada 96

Figura 5.36 - Resultados de deslocamento com carga de 6,0 tf para na Vala Profunda Não

Compactada 97

Figura 5.37 - Superfície das valas-teste após a simulação de tráfego 100

Figura 5.38 - Evolução do diâmetro interno do tubo na V ala Profunda Compactada 102

Figura 5.39 - Evolução do diametro interno do tubo na Vala Rasa Compactada 102

Figura 5.40 - Evolução do diâmetro interno do tubo na Vala Rasa Não Compactada 102

Figura 5.41 - Evolução do diâmetro interno do tubo na V ala Profunda Não Compactada 103

Figura 6.1 - Comparação entre grau de compactação e compacidade relativa 107

Figura 6.2 - Influência da posição de uma determinada camada com relação à superfície na resistência medida por meio do DCP

Figura 6.3 - Influência da posição de uma determinada camada com relação à superfície na resistência medida por meio do UFV-II 109

Figura 6.4 - Valores de CBR (\%) e Mini-CBR (\%) obtidos de correlações com DCP (mm/golpe) de vários autores 


\section{LISTA DE TABELAS}

Tabela 2.1 - Valores típicos de Ke $\boldsymbol{\mu}^{\prime}$ 8

Tabela 2.2 - Valores de $C_{s}$ 11

Tabela 2.3 - Valores da constante de assentamento K (Moser, 1990) 13

Tabela 2.4 - Materiais de envolvimento (Moser, 1990) 26

Tabela 3.1 - Características dos tubos estudados por Sargand et al. (1995) 40

Tabela 3.2 - Características dos testes realizados por Moser (1996) 44

Tabela 3.3 - Variação do valor de E' em função do grau de compactação (Moser, 1996) 44

Tabela 3.4 - Resultados dos testes realizados por Moser (1998) 46

Tabela 4.1 - Principais características geométricas e mecânicas dos perfis" 51

Tabela 4.2 - Limites válidos para as leituras de valor de impacto 64

Tabela 5.1 - Resultados de CBR obtidos através da correlação de Clegg (1983) 88

Tabela 5.2 - Cargas aplicadas em cada vala 90

Tabela 5.3 - Afundamento em trilha de roda medido após o ensaio 100

Tabela 5.4 - Grau de compactação da areia em diversas profundidades 104

Tabela 6.1 - Valores de CBR e Mini-CBR obtidos da correlação com o UFV-II estabelecida por Röhm (1984) 110

Tabela 6.2 - Valores de CBR antes da simulação de tráfego para as camadas 111

abaixo de $30 \mathrm{~cm}$ da superficie livre 111

Tabela 6.3 - Valores de CBR antes da simulação de tráfego para a camada 111

Superficial de 20 a $30 \mathrm{~cm}$ de espessura 111

Tabela 6.4 - Valores de CBR após da simulação de tráfego 112

Tabela 6.5 - Deslocamentos e valores de Módulo de Reação (E') obtidos com o carregamento permanente e a sobrecarga do ensaio dinâmico com 3,0 tf 


\section{Lista DE ABREVIATURAS}

$\begin{array}{ll}\text { AASHTO } & \text { American Association of State Highway and Transportation Officials } \\ \text { ABS } & \text { Acrylonitrile-Butadiene-Stirene } \\ \text { ASTM } & \text { American Society for Testing and Materials } \\ \text { DAER-RS } & \text { Depertamento Autônomo de Estradas de Rodagem do Estado do Rio } \\ & \text { Grande do Sul } \\ \text { FAPESP } & \text { Fundação de Amparo a Pesquisa do estado de São Paulo } \\ \text { HDPE } & \text { High Density Polyethylene } \\ \text { LMS-USP } & \text { Laboratório de Mecânica dos Solos da Escola Politécnica da USP } \\ \text { LTP-PTR-EPUSP } & \text { Laboratório de Tecnologia de Pavimentação do Departamento de } \\ & \text { Engenharia de Transportes da Escola Politécnica da USP } \\ \text { LVDT } & \text { Linear Variable Differential Transformer } \\ \text { MDPE } & \text { Medium Density Polyethylene } \\ \text { NCHRP } & \text { National Cooperative Highway Research Program } \\ \text { Ohio DOT } & \text { Ohio Department of Transportation } \\ \text { PC } & \text { Vala Profunda Compactada } \\ \text { PNC } & \text { Vala Profunda Não Compactada } \\ \text { PVC } & \text { Polyvinyl Chloride } \\ \text { RC } & \text { Vala Rasa Compactada } \\ \text { RNC } & \text { Vala Rasa Não Compactada } \\ \text { RPM } & \text { Reinforced Plastic Mortar } \\ \text { UFRGS } & \text { Universidade Federal do Rio Grande do Sul } \\ \text { USP } & \end{array}$




\section{RESUMO}

Este trabalho objetivou o conhecimento do comportamento estrutural de um sistema solo-tubo plástico flexível de paredes estruturadas frente a cargas permanentes sobre a tubulação e carregamentos móveis, como os provenientes de tráfego de veículos. Para o estudo, foram construídas valas em verdadeira grandeza na Área de Pesquisas e Testes de Pavimentos DAER-RS/UFRGS em Porto Alegre, RS, onde se dispõe de um equipamento simulador de tráfego, utilizado para aplicação de cargas estáticas e cíclicas na superfície dos sistemas solo-tubo. As variáveis independentes controladas são o grau de compactação do material que envolve o tubo e altura do mesmo material sobre o tubo. As variáveis medidas são a deflexão do tubo sob carregamento do simulador e o deslocamento permanente causado pela carga de solo sobre o tubo. O controle de compactação do material de envolvimento do tubo foi realizado com três equipamentos diferentes e os resultados foram comparados. Os resultados de deflexão e deslocamento pemanente foram utilizados para cálculo dos valores de módulo de reação E' do maerial de envolvimento do tubo e foram comparados com os encontrados na literatura. Constatou-se o comportamento elástico dos tubos sob carregamento repetido, e no caso em que o tubo é instalado muito próximo da superfície, as deflexões no sistema são de tal magnitude que chegam a ser prejudiciais ao pavimento construído sobre a vala. Ficou comprovada a importância da cuidadosa compactação do material de envolvimento do tubo para o bom desempenho estrutural do sistema solo-tubo flexível. 


\section{AbStRaCT}

This work aimed at the knowledge of the structural behavior of a ribbed flexible plastic buried pipe system undergoing permanent loads on the piping and mobile loads, as the ones deriving from the traffic of vehicles. For this study, full scale ditches were built at the DAER-RS/UFRGS Pavement Research and Test Area in Porto Alegre, RS, where there is a equipment for simulating traffic, used for applying both static and cyclic loads on the ditch surface. The controled independent variables are the involving material density and the height of this material on the pipe. The variables measured are the pipe deflection under simulator load and the permanent displacement caused by the soil load on the pipe. The compaction control of involving material was carried out with three different types of equipment and results were compared. The results for pemanent deflection and displacement were used to calculate the Modulus of Soil Reaction (E') values of the involving material and these were compared to the ones found in the literature. The pipe elastic behavior under repeated load was observed, and where the pipe is installed too close to the surface, the system deflections are of such magnitude that they affect the pavement built over the ditch. The careful compaction of the involving material proved to be of paramount importance to a good structural performance of the flexible buried pipe system. 


\section{INTRODUÇÃO}

\subsection{Importância dos Sistemas Solo-Tubo para Drenagem Viária}

Foi lançada recentemente no Brasil tubulação plástica flexível de parede estruturada ${ }^{1}$ para drenagem viária. A tecnologia desse tubo foi especialmente desenvolvida para ser utilizada em instalações enterradas, em conduto livre ou a baixas pressões. A experiência mundial, abrangendo atualmente mais de 40 países, tem comprovado a eficiência construtiva e o bom desempenho dos tubos plásticos flexíveis de parede estruturada em drenagem viária ${ }^{2}$.

A tubulação plástica apresenta uma série de vantagens em comparação com tubulações de materiais convencionais como:

- Maleabilidade na opção de comprimento e diâmetro graças à possibilidade de produção em canteiro de obras, uma vez que a tubulação é formada por tiras ou bandas plásticas de paredes estruturadas que são enroladas helicoidalmente e conectadas umas às outras por encaixes colados do tipo macho-fêmea;

- O perfil pode ser enrolado em local diferente de onde foi extrudado, permitindo economia em termos de transporte e estocagem;

- O tubo pode ser produzido com grandes diâmetros, no Brasil atualmente são produzidos com diâmetros de $300 \mathrm{~mm}$ a cerca de 1,5 metros; há a possibilidade de

\footnotetext{
${ }^{1}$ Este produto foi patenteado pela Tigre S.A. Tubos e Conexões em 1998, com a designação de Rib $\operatorname{Loc}^{\mathrm{TM}}$.

2 Tigre Rib Loc: A solução mais ágil e flexível em drenagem pluvial - manual. Tigre S.A. Tubos e Conexões, Joinvile-SC, sem data.
} 
atingir até cerca de 3,0 metros com o uso de tiras metálicas de enrijecimento sobre as almas e mesas ${ }^{3}$;

- O tubo tem baixo peso, gerando economia com equipamentos de transporte vertical na obra e facilitando o seu manuseio e assentamento nas valas;

- Grande rapidez de frente de obra;

- O material que constitui o tubo, PVC no caso brasileiro, oferece baixa rugosidade interna, resistência química ao ataque agressivo de produtos presentes na água e resistência à abrasão, oferecendo, portanto, grande durabilidade;

- As seções transversais dos tubos plásticos flexíveis de parede estruturada apresentam saliências externas devido ao recurso do uso de alma e mesa, fazendo com que o momento de inércia da parede do tubo seja muito mais elevado em comparação com a de um tubo de parede não corrugada, não estruturada, com pouco dispêndio de material.

Para o funcionamento estrutural, o sistema conta significativamente com a resistência do material de envolvimento dos tubos, uma vez que estes últimos são flexíveis, apresentando um deslocamento vertical com redução do diâmetro nesta direção, e portanto, um aumento do diâmetro horizontalmente, frente à solicitação de cargas, seja do tráfego, como do peso próprio sobre o tubo. Este último é devido ao peso do material de cobrimento/envolvimento sobre o tubo, do material de reaterro das valas e, eventualmente quando existir, da estrutura do pavimento ou da infra-estrutura e superestrutura ferroviária.

Tradicionalmente são utilizados como material de envolvimento solos granulares ou materiais britados, sem finos ou com poucos finos, graças à sua grande resistência ao cisalhamento, quando confinados, e mobilização de empuxo passivo.

Em 1997, por solicitação da Tigre, o Laboratório de Tecnologia de Pavimentação do Departamento de Transportes da Escola Politécnica da USP propôs uma pesquisa a ser realizada por meio de um convênio entre ambas as partes a fim de estudar o comportamento estrutural do sistema solo-tubo. Em 1998 foi apresentado à Tigre, na

\footnotetext{
${ }^{3}$ Este produto é conhecido por Rib Steel ${ }^{\mathrm{TM}}$ no mercado brasileiro, produzido igualmente pela Tigre S.A.
} 
oportunidade do lançamento do Rib $\operatorname{Loc}^{\mathrm{TM}}$, relatório final composto por quatro cadernos. No texto desta dissertação as informações desse relatório são utilizadas por diversas vezes, sendo empregada a designação "LTP-PTR-EPUSP/Tigre, 1998” para referenciá-la.

\subsection{Objetivos}

Objetiva-se estudar o comportamento de tubos plásticos flexíveis de paredes estruturadas envolvidos com areia, analisando o desempenho mecânico do sistema solotubo frente a aplicações de carga estática e dinâmica. O principal objetivo do trabalho reside na possibilidade de relacionar essas respostas à natureza e ao estado do material de envolvimento dos tubos, atribuindo valores de resistência de projeto a esse material.

A importância desse estudo é destacada no sentido de pesquisar em verdadeira grandeza o comportamento estrutural do sistema solo-tubo flexível de parede estruturada envolvido com areia, material comumente encontrado no Brasil e de uso corrente nos países onde essa tecnologia vem sendo empregada. Tal experimento possibilitará a comparação dos resultados obtidos em campo com valores estipulados pela literatura internacional, propiciando o uso destes parâmetros de resistência nos projetos brasileiros de forma mais realista e mais segura. 


\section{Projeto Estrutural dos SiSTEMAS Solo-Tubo FLEXívEL}

Neste capítulo são apresentadas as características dos tubos flexíveis de paredes estruturadas e seus modos de ruptura, assim como os critérios de seleção dos solos para envolverem esses tubos, bem como suas propriedades requeridas para que se garanta um funcionamento adequado do sistema solo-tubo.

\subsection{Interação Solo-Tubo}

Os sistemas enterrados solo-tubo são constituídos pelos tubos flexíveis de paredes estruturadas e por diversos materiais que cumprem a função de envolvimento, de berço, e de reaterro das valas, cujo arranjo geométrico pode ser visto esquematicamente na Figura 2.1. 


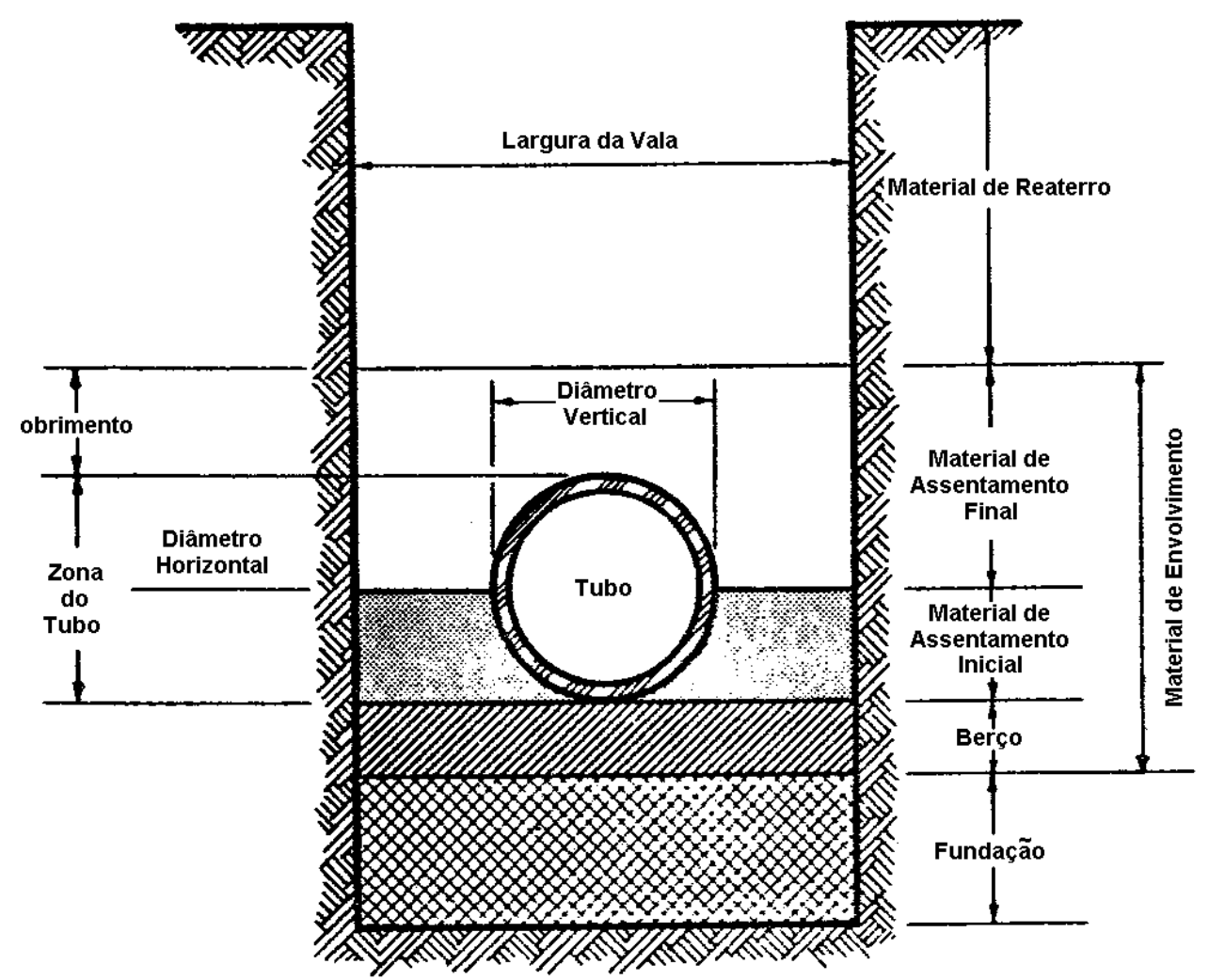

Figura 2.1 - Representação gráfica de um tubo enterrado (Moser, 1990)

Os tubos rígidos diferem dos flexíveis em sua resposta frente à solicitação proveniente das cargas atuantes, sendo que as tensões resistivas mobilizadas nos tubos e nos solos de envolvimento são particularmente diversas, tanto em intensidade quanto na forma de distribuição. Uma tubulação rígida não pode sofrer grandes deslocamentos sem que haja prejuízo estrutural, traduzido por fissuras e até mesmo pela ruptura do tubo. Por outro lado, uma tubulação de PVC pode deformar-se consideravelmente sem sofrer danos estruturais que comprometam a resistência do sistema. O comportamento ante a ação das cargas de tubulações rígidas e flexíveis é ilustrado na Figura 2.2.

O deslocamento vertical de um tubo flexível devido à ação de carregamentos, causando a redução de seu diâmetro nessa direção e extensão na horizontal, provoca a mobilização de pressões nos solos de envolvimento, chamadas de empuxo passivo, que colaboram para suportar a carga solicitante. 


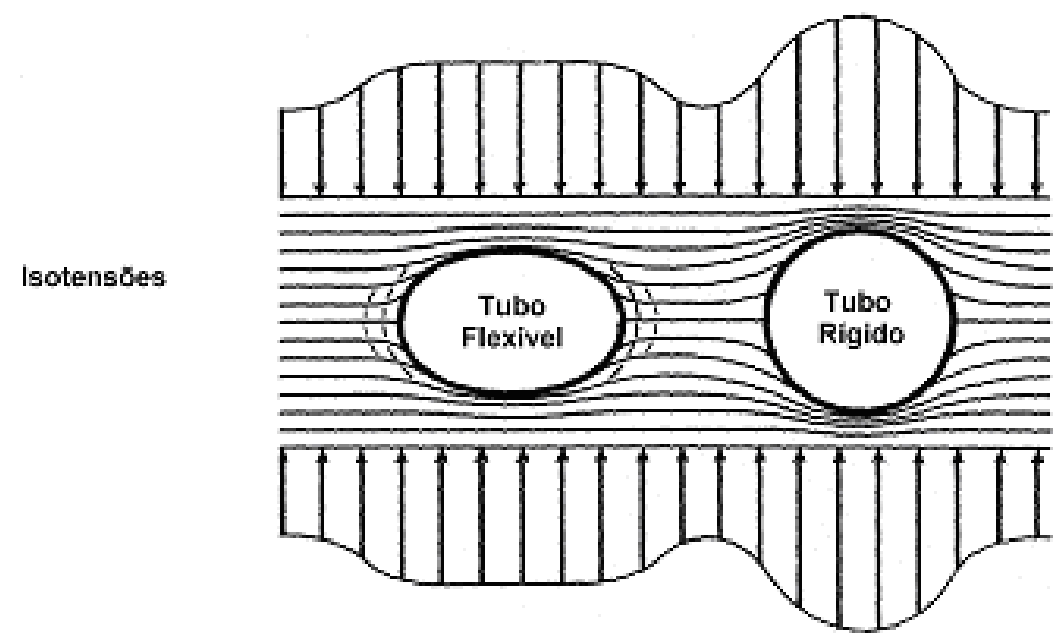

Figura 2.2 - Distribuição comparativa de tensões ao redor de um tubo rígido e de um flexível enterrados e sujeitos a carregamentos iguais (adaptado de Watkins, 1966)

Conforme explicação dada em LTP-PTR-EPUSP/Tigre (1998b), o empuxo passivo pode ser visto como a resultante das tensões horizontais desenvolvidas no solo, atuantes na superfície de uma estrutura que se deslocou empurrando a massa de solo, no estado limite de ruptura; nessa situação, as tensões horizontais no solo são superiores às tensões horizontais em repouso. As tensões horizontais efetivas no estado de empuxo passivo dependem do coeficiente de empuxo passivo, função do ângulo de atrito do solo, e da coesão do solo. Portanto, o solo que envolve o tubo atua no sistema solotubo flexível como material estruturalmente resistente, diferentemente dos tubos rígidos, onde esse material não tem função estrutural.

\subsection{Tipos de Solicitação}

Devem ser calculadas solicitações sobre o tubo devidas a dois tipos principais de cargas:

- Carga permanente sobre o tubo devida ao peso do solo e, quando houver, pavimento;

口 Cargas móveis relativas ao tráfego de veículos sobre a vala.

Outras solicitações a serem calculadas são as advindas da expansão e adensamento dos solos de envolvimento e de reaterro, segundo considerações em LTP-PTREPUSP/Tigre (1998b). Essas solicitações podem causar redistribuição das tensões sobre o tubo, modificando os deslocamentos diametrais verticais previstos; seus efeitos, no 
entanto, podem ser minimizados com a escolha adequada de materiais. O congelamento dos solos de envolvimento e reaterro acarreta solicitações adicionais no tubo, mas é inexistente no Brasil.

A seguir, serão apresentados métodos e critérios de aceitação corrente, relativos à determinação de carregamentos a que estão sujeitas as tubulações enterradas, tais como galerias e canalizações em geral. Além disso são abordadas as formas para cálculo de deslocamentos dos tubos devido à atuação dos carregamentos.

\subsubsection{Carregamento Permanente - Teoria de Marston-Spangler}

No início do século XX Anson Marston desenvolveu um método para calcular a carga de terra à qual um tubo rígido enterrado estaria sujeito ao longo de sua vida de serviço (Monge, 1996). Esse método, a Teoria de Carga de Marston, serve para prever a capacidade de suporte de tubos rígidos sob várias condições e é expressa por:

$$
W_{d}=C_{d} \cdot \gamma \cdot B_{d}{ }^{2}
$$

Onde:

$W_{d}=$ carga sobre o tubo por unidade de comprimento $\left(\mathrm{kN} / \mathrm{m}^{2} / \mathrm{m}\right)$;

$C_{d}=$ coeficiente de carga do tubo, função do coeficiente de empuxo passivo de Rankine do solo que envolve o tubo, altura de cobrimento sobre o tubo, largura da vala e coeficiente de atrito do solo que envolve o tubo com a parede da vala e do peso específico aparente do solo;

$\gamma=$ peso específico do solo $\left(\mathrm{kN} / \mathrm{m}^{3}\right)$;

$B_{d}=$ largura da vala sobre o tubo $(\mathrm{m}) ;$

$$
C_{d}=\frac{1-e^{-2 K \mu^{\prime}\left(H / B_{d}\right)}}{2 K \mu^{\prime}}
$$

$K=$ coeficiente de empuxo passivo de Rankine;

$\mathrm{H}=$ altura de solo sobre o tubo $(\mathrm{m})$;

$\mu^{\prime}=$ coeficiente de atrito entre o material de envolvimento e as paredes da vala.

Os valores típicos de $K$ e $\mu$ ' foram determinados experimentalmente por Marston e são dados na Tabela 2.1 (Moser, 1990). 
Tabela 2.1 - Valores típicos de $K$ e $\mu$ '

\begin{tabular}{|c|c|c|c|}
\hline Tipo de Solo & $\begin{array}{c}\text { Peso } \\
\text { Unitário } \\
\mathrm{Lb} / \mathrm{ft}^{3}\end{array}$ & $\begin{array}{c}\text { Relação de } \\
\text { Rankine } \\
\text { K }\end{array}$ & $\begin{array}{c}\text { Coeficiente } \\
\text { de Atrito } \\
\mu\end{array}$ \\
\hline Solo superior úmido parcialmente compactado & 90 & 0,33 & 0,50 \\
\hline Solo superior saturado & 110 & 0,37 & 0,40 \\
\hline Argila úmida parcialmente compactada & 100 & 0,33 & 0,40 \\
\hline Argila saturada & 120 & 0,37 & 0,30 \\
\hline Areia seca & 100 & 0,33 & 0,50 \\
\hline Areia úmida & 120 & 0,33 & 0,50 \\
\hline
\end{tabular}

Fonte: Moser (1990)

M. G. Spangler, trabalhando com Marston, desenvolveu uma teoria específica para projetos de tubos flexíveis (Monge, 1996). A teoria de Marston-Spangler foi desenvolvida originalmente para tubos rígidos. Para o caso especial em que o solo que envolve o tubo e este último têm a mesma rigidez, obtém-se pela teoria de Marston a seguinte equação simplificada, conhecida como a formulação de Marston e Spangler para tubos flexíveis:

$$
W_{d}=C \cdot \gamma \cdot D_{e} \cdot B
$$

Onde:

$$
D_{e}=\text { diâmetro externo do tubo (m) }
$$

Para tubos flexíveis pode-se também adotar a distribuição de tensões solicitantes prismática, que corresponde a uma carga uniformemente distribuída na largura da vala, no plano horizontal que tangencia a geratriz superior do tubo, com módulo igual à pressão devida ao peso do prisma (paralelepípedo) de solo existente sobre o tubo, ou seja:

$$
W_{d}=B \cdot H \cdot \gamma
$$

Esse método é mais conservador, portanto leva a valores maiores do que os calculados pela Teoria de Marston. 
Multiplicando a carga do prisma pelo diâmetro do tubo expressa-se a carga em força/unidade de comprimento do tubo, como na Teoria de Carga de Marston.

\subsubsection{Sobrecargas - Solução pela Formulação de Boussinesq}

Tubulações enterradas estão sujeitas a cargas provenientes da passagem de tráfego, denominadas sobrecargas ou cargas móveis. A distribuição de tensões em um espaço elástico semi-infinito devida à uma carga pontual aplicada em uma superfície foi calculada pelo matemático francês Boussinesq. Essa solução assume que o meio é elástico, homogêneo e isotrópico, o que o solo certamente não é. Entretanto, experimentos têm mostrado que a solução clássica de Boussinesq, quando devidamente aplicada, fornece em alguns casos uma boa aproximação das tensões reais que ocorrem.

A tensão vertical segundo a formulação de Boussinesq, em um ponto a uma profundidade z. exatamente abaixo do ponto de aplicação da carga (vertical e pontual) é dada por

$$
\sigma_{v}=\frac{0,48 \cdot Q}{z^{2}}
$$

Onde:

$$
\begin{aligned}
& \sigma_{v}=\text { tensão vertical em ponto a profundidade } \mathrm{z}\left(\mathrm{kN} / \mathrm{m}^{2}\right) ; \\
& Q=\text { carga concentrada aplicada na superfície }(\mathrm{kN}) ; \\
& z=\text { profundidade considerada }(\mathrm{m}) .
\end{aligned}
$$

Love integrou a solução de Boussinesq para calcular o acréscimo de tensão em pontos ao longo de uma vertical passando pelo centro de uma área circular uniformemente carregada.

$$
\sigma_{v}=\sigma_{0}\left\{1-\left[\frac{1}{1+\left(\frac{R}{z}\right)^{2}}\right]^{3 / 2}\right\}
$$

Onde: 
$\sigma_{0}=$ tensão aplicada na superfície $\left(\mathrm{kN} / \mathrm{m}^{2}\right)$;

$\mathrm{R}=$ raio da área carregada $(\mathrm{m})$.

Hall e Newmark integraram a solução de Boussinesq para obter coeficientes de carga. A integração desenvolvida por Hall para $\mathrm{C}_{\mathrm{s}}$ é usada para calcular cargas concentradas e é dada pela fórmula:

$$
W_{s c}=C_{s}\left(\frac{P F^{\prime}}{L}\right)
$$

Onde:

$W_{s c}=$ carga por unidade de comprimento atuante sobre o tubo $(\mathrm{kN} / \mathrm{m})$

$P=$ carga concentrada (roda de veículo, por exemplo) aplicada na superfície do solo segundo a vertical do centro do tubo $(\mathrm{kN})$

$F^{\prime}=$ fator de impacto

$L=$ comprimento efetivo $^{4}$ do conduto $(\mathrm{m})$

$C_{s}=$ coeficiente de carga, função de $\mathrm{D}_{\mathrm{e}} /(2 \mathrm{H})$ e $\mathrm{L} /(2 \mathrm{H})$, onde $H=$ altura de material sobre o tubo, e $D_{e}=$ diâmetro externo do tubo.

A integração desenvolvida por Newmark é usada para calcular cargas distribuídas e é dada por:

$$
W_{s d}=C_{s} p F^{\prime} D_{e}
$$

Onde:

$$
p=\text { carga uniformemente distribuída }\left(\mathrm{kN} / \mathrm{m}^{2}\right) .
$$

$\mathrm{O}$ coeficiente de carga $C_{s}$ é função de $\mathrm{D} /(2 \mathrm{H})$ e $\mathrm{M} /(2 \mathrm{H})$, onde $\mathrm{D}$ e $\mathrm{M}$ são respectivamente a largura e o comprimento da área sobre a qual a carga distribuída atua. O coeficiente de carga $C_{s}$ pode ser determinado com o auxílio da Tabela 2.2, onde as medidas $\mathrm{D}$ e $\mathrm{M}$ devem entrar em ft.

4Para aplicações práticas recomenda-se adotar como comprimento efetivo o valor de $0,90 \mathrm{~m}$ ou menos. (Moser, 1990) 
Tabela $2.2-$ Valores de $C_{s}$

\begin{tabular}{|c|c|c|c|c|c|c|c|c|c|c|c|c|c|c|}
\hline \multirow{2}{*}{$\begin{array}{c}\mathrm{D} / 2 \mathrm{H} \\
\text { ou } \\
\mathrm{B}_{\mathrm{c}} / 2 \mathrm{H}\end{array}$} & \multicolumn{14}{|c|}{$\mathrm{M} / 2 \mathrm{H}$ ou $\mathrm{L} / 2 \mathrm{H}$} \\
\hline & 0,1 & 0,2 & 0,3 & 0,4 & 0,5 & 0,6 & 0,7 & 0,8 & 0,9 & 1,0 & 1,2 & 1,5 & 2,0 & 5,0 \\
\hline 0,1 & 0,019 & 0,037 & 0,053 & 0,067 & 0,079 & 0,089 & 0,097 & 0,103 & 0,108 & 0,112 & 0,117 & 0,121 & 0,124 & 0,128 \\
\hline 0,2 & 0,037 & 0,072 & 0,103 & 0,131 & 0,155 & 0,174 & 0,189 & 0,202 & 0,211 & 0,219 & & 0,238 & 0,244 & 0,248 \\
\hline 0,3 & 0,053 & 0,103 & 0,149 & 0,190 & 0,224 & 0,252 & 0,274 & 0,292 & 0,306 & 0,318 & 0,333 & 0,345 & 0,355 & 0,360 \\
\hline 0,4 & 067 & 0,131 & 0,190 & 0,241 & 0,284 & 0,320 & 0,349 & 0,373 & 0,391 & 0,405 & 0,425 & 0,440 & 0,454 & 0,460 \\
\hline 0,5 & 0,079 & 0,155 & 0,224 & 0,284 & 0,336 & 0,379 & 0,414 & 0,441 & 0,463 & 0,481 & 0,505 & 0,525 & 0,540 & 0,548 \\
\hline 0,6 & 0,089 & 0,174 & 0,252 & 0,320 & 0,379 & 0,428 & 0,467 & 0,499 & 0,524 & 0,544 & 0,572 & 0,596 & 0,613 & 0,624 \\
\hline 0,7 & 0,097 & 0,189 & 0,274 & 0,349 & 0,414 & 0,467 & 0,511 & 0,546 & 0,584 & 0,597 & 0,628 & 0,650 & 0,674 & 0,688 \\
\hline 0,8 & 0,103 & 0,202 & 0,272 & 0,373 & 0,441 & 0,499 & 0,546 & 0,584 & 0,615 & 0,639 & 0,674 & 0,703 & 0,725 & 0,740 \\
\hline 0,9 & 0,108 & 0,211 & 0,306 & 0,391 & 0,463 & 0,524 & 0,574 & 0,615 & 0,647 & 0,673 & 0,711 & 0,742 & 0,766 & 0,784 \\
\hline 1,0 & 0,112 & 0,219 & 0,318 & 0,405 & 0,481 & 0,544 & 0,597 & 0,639 & 0,673 & 0,701 & 0,740 & 0,774 & 0,800 & 0,816 \\
\hline 1,2 & 0,117 & 0,229 & 0,333 & 0,425 & 0,505 & 0,572 & 0,628 & 0,674 & 0,711 & 0,740 & 0,783 & 0,820 & 0,849 & 0,868 \\
\hline 1,5 & 0,121 & 0,238 & 0,345 & 0,440 & 0,525 & 0,596 & 0,650 & 0,703 & 0,742 & 0,774 & 0,820 & 0,861 & 0,894 & 0,916 \\
\hline 2,0 & 0,124 & 0,244 & 0,355 & 0,454 & 0,540 & 0,613 & 0,674 & 0,725 & 0,766 & 0,800 & 0,849 & 0,894 & 0,930 & 0,956 \\
\hline
\end{tabular}

Fonte: Moser (1990)

As expressões 2.8 e 2.9 pressupõem o coeficiente de impacto, $F$, igual à unidade para cargas estáticas. Para cargas móveis, como rodas de veículos, o valor de F dependerá da velocidade do veículo, dos efeitos dinâmicos (vibrações, efeito de sustentação de asas nos aviões, etc.) e, principalmente, características de rugosidade da superfície de rolamento. Segundo Zaidler (1983), os valores geralmente aceitos são:

- Rodovias - 1,50;

ㄱerrovias - 1,75;

․ Aeroportos - 1,00 a 1,50.

Para ilustração da magnitude dos carregamentos e da importância de cada um dos fatores no total solicitante, na Figura 2.3, constante em LTP-PTR-EPUSP/Tigre (1998b), apresenta-se a composição de tensões verticais resultantes das cargas permanentes (devida ao peso próprio) e móveis (carga legal brasileira de caminhões) atuantes sobre o tubo em diferentes profundidades de assentamento. 


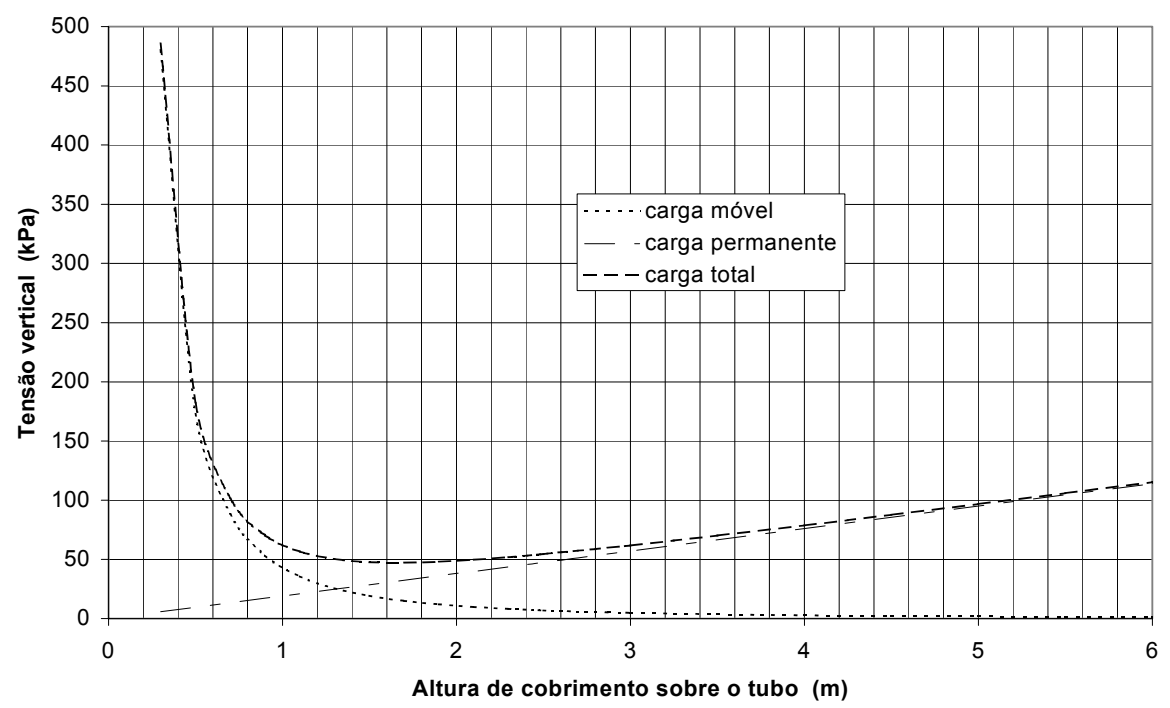

Figura 2.3 - Tensões verticais atuantes sobre o plano tangente à geratriz superior do tubo LTP-PTR-EPUSP/Tigre (1998b)

\subsubsection{Cálculo dos Deslocamentos dos Tubos pela Fórmula de Iowa}

Spangler observou que a teoria de Marston não era adequada para o cálculo de cargas sobre tubos flexíveis (Moser, 1990). Seus estudos e testes levaram à Fórmula de Iowa, publicada em $1941^{5}$ apud Moser (1990), para cálculo dos deslocamentos horizontais sofridos por tubos em que a carga vertical atuante é calculada pela teoria de Marston e corrigida por um fator tempo igual a 1,5 para levar em consideração a redistribuição de tensões ao redor do tubo que ocorre ao longo do tempo.

$$
\Delta x=\frac{D_{L} \cdot K \cdot W_{d} \cdot r^{3}}{E \cdot I+0,061 \cdot e \cdot r^{4}}
$$

Onde:

$\Delta x=$ deslocamento diametral horizontal $(\mathrm{m}) ;$

$D_{L}=$ fator tempo;

$K=$ constante de assentamento;

$W_{d}=$ carga sobre o tubo por unidade de comprimento, de Marston $(\mathrm{kN} / \mathrm{m})$;

$r=$ raio médio do tubo $(\mathrm{m})$;

$E=$ módulo de elasticidade do material do tubo $\left(\mathrm{kN} / \mathrm{m}^{2}\right)$;

5 Spangler, M. G., 1941. The Structural Design of Flexible Pipe Culverts, Bulletin 153, Iowa Engineering Experiment Station, Ames, Iowa. 
$I=$ momento de inércia da parede do tubo por unidade de comprimento $\left(\mathrm{m}^{4} / \mathrm{m}\right)$;

$e=$ módulo de resistência passiva do material de envolvimento $\left(\mathrm{kN} / \mathrm{m}^{2} / \mathrm{m}\right)$.

As cargas permanentes sobre a tubulação podem ser calculadas tanto considerando a carga do prisma (eq 2.4) quanto pela teoria de Marston (eq. 2.1). Sabe-se que a carga que realmente atua sobre o tubo é um valor intermediário entre a carga de Marston e a carga do prisma. Entretanto, a longo prazo a carga tende a alcançar os valores máximos calculados, ou seja, a carga do prisma (Monge, 1996). Recomenda-se utilizar fator de tempo igual a 1,0 quando se utiliza a carga do prisma e igual a 1,5 quando se utiliza a carga de Marston. Segundo as investigações de Spangler a deflexão final se dá somente quando o solo está completamente consolidado, ou seja, quando o valor da carga alcança o valor da carga do prisma de solo acima do tubo (Monge, 1996).

A constante de assentamento, $K$, representa a resposta do material de fundação ou berço, que está sob o tubo, à carga solicitante sobre o mesmo. O ângulo de apoio do tubo define a área resistente da camada do berço; se o ângulo é maior, a área resistente também é maior e a deformação é, conseqüentemente, menor, graças à melhor distribuição das tensões, diminuindo a intensidade destas. A Tabela 2.3 contém uma lista de constantes de assentamento, dependentes do ângulo de assentamento do tubo, que foi determinada teoricamente por Spangler. Como regra geral, adota-se $\mathrm{K}=0,1$.

Tabela 2.3 - Valores da constante de assentamento K (Moser, 1990)

\begin{tabular}{cc}
\hline Ângulo de apoio $\left(^{\mathbf{}}\right)$ & $\mathbf{K}$ \\
\hline 0 & 0,110 \\
\hline 30 & 0,108 \\
\hline 45 & 0,105 \\
\hline 60 & 0,102 \\
\hline 90 & 0,096 \\
\hline 120 & 0,090 \\
\hline 180 & 0,083 \\
\hline
\end{tabular}




\subsubsection{Cálculo dos Deslocamentos dos Tubos pela Fórmula de Iowa}

\section{Modificada}

Em 1958, Reynold K. Watkins, um estudante de graduação de Spangler, percebeu que o parâmetro $e$ não era uma propriedade intrínseca do solo e, por análise dimensional modificou a fórmula de Spangler. Definiu-se então outro parâmetro, o módulo de reação do solo E'. A equação corrigida foi chamada de equação de Iowa Modificada e é expressa por:

$$
\Delta x=\frac{D_{L} \cdot K \cdot W_{d}}{\frac{E \cdot I}{r^{3}}+0,061 \cdot E^{\prime}}
$$

Outra observação do estudo de Watkins que deve ser citada é que o deslocamento diametral do tubo não deve ser o único critério de projeto.

O módulo de reação do solo E' é o termo da equação (2.10) mais difícil de ser determinado e depende de experiências de laboratório e de campo. É função não apenas do tipo do material de envolvimento, mas também do estado deste material e da presença de lençol freático, assim como da geometria e rigidez do tubo, sendo na verdade, um módulo de interação solo-tubo.

Um grande número de variações da fórmula de Iowa Modificada vem sendo propostas. Entretanto, todas elas podem ser representadas, de maneira simplificada, por

$$
\text { Deslocamento diametral }=\frac{\text { carga }(\text { permanente }+ \text { móvel })}{\text { rigidez do tubo }+ \text { cons } \tan t e \cdot \text { rigidez do solo }}
$$

A fim de facilitar a comparação entre os valores calculados e os valores medidos em testes mecânicos laboratoriais e em campo, o deslocamento diametral passou a ser considerado na direção vertical, $\Delta y$. Supõe-se que os deslocamentos diametrais máximos, vertical e horizontal, tenham o mesmo valor, ou seja, que o deslocamento ocorrido na vertical gerando diminuição do diâmetro seja igual ao alongamento horizontal do diâmetro. Tal hipótese é válida para pequenos deslocamentos e quando outra forma de ruptura não estiver ocorrendo. 
Neste trabalho a Fórmula de Iowa Modificada será adotada para cálculo do deslocamento diametral vertical do tubo, expressa por:

$$
\Delta y=\frac{D_{L} \cdot K \cdot(p+q)}{8 \cdot R A+0,061 \cdot E^{\prime}}
$$

Onde:

$\Delta y=$ deslocamento diametral vertical do tubo $(\mathrm{m})$

$D_{L}=$ fator tempo

$K=$ constante de assentamento

$p=$ tensão vertical distribuída no plano tangente à geratriz superior do tubo devida à carga permanente (carga/unidade de comprimento, Teoria de Carga de Marston) $\left(\mathrm{kN} / \mathrm{m}^{2} / \mathrm{m}\right)$

$q=$ tensão vertical distribuída no plano tangente à geratriz superior do tubo devida a cargas móveis (carga/unidade de comprimento, Teoria de Carga de Marston) $\left(\mathrm{kN} / \mathrm{m}^{2} / \mathrm{m}\right)$

$\mathrm{R} A=$ rigidez anular do tubo (carga/área) $\left(\mathrm{kN} / \mathrm{m}^{2}\right)$

$E^{\prime}=$ módulo de reação do solo (carga/área) $\left(\mathrm{kN} / \mathrm{m}^{2}\right)$

A determinação da rigidez anular do tubo será tratada adiante, no item 2.3.

\subsection{Rigidez Anular}

O princípio de funcionamento dos tubos de parede estruturada se baseia em projetar a forma da parede para que esta tenha um elevado momento de inércia sem grande aumento de peso. A Figura 2.4 mostra um elemento típico de um tubo Rib Loc ${ }^{\mathrm{TM}}$. 


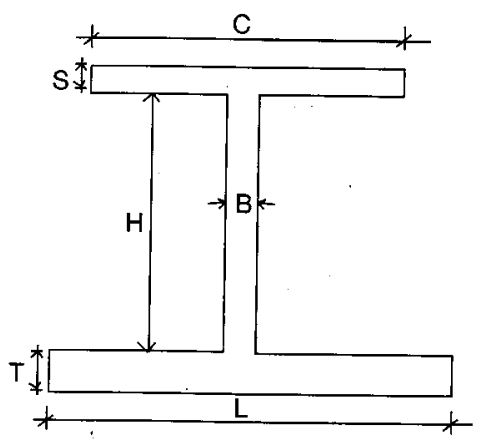

Figura 2.4 - Elemento estrutural da parede do tubo Rib Loc ${ }^{\mathrm{TM}}$

A rigidez anular pode ser determinada por dois modos, por cálculo ou por ensaio em laboratório. A seguir, são mostrados ambos procedimentos.

\subsubsection{Determinação Teórica da Rigidez Anular}

De posse do momento de inércia, do módulo de elasticidade do PVC, e do diâmetro do tubo, pode-se calcular a rigidez anular $(\mathrm{RA})$ do tubo em $\mathrm{MPa}$, relacionada à sua resistência aos diversos modos de ruptura possíveis:

$$
R A=\frac{E \cdot I}{D^{3}}
$$

Onde:

$E=$ módulo de elasticidade do material do tubo (MPa);

$I=$ momento de inércia da parede do tubo por unidade de comprimento $\left(\mathrm{m}^{4} / \mathrm{m}\right)$;

$D=$ diâmetro médio inicial do tubo (m).

\subsubsection{Determinação Experimental da Rigidez Anular pela ISO 9969}

O ensaio é realizado em uma prensa com duas placas paralelas que pressionam uma amostra de tubo. A velocidade de deslocamento diametral de compressão aplicada é de $20 \mathrm{~mm} / \mathrm{min}$. Sendo que os dados coletados são a força aplicada e o deslocamento diametral correspondente, contínua e automaticamente. 
A amostra ensaiada deve apresentar um comprimento mínimo de $300 \pm 10 \mathrm{~mm}$; no caso de parede estruturada a amostra deve conter um número inteiro mínimo de nervuras, corrugações ou outras estruturas que satisfaçam a exigência de comprimento. Para a determinação do diâmetro interno da amostra toma-se a média de três leituras.

A rigidez anular é calculada pela relação entre a força de compressão diametral que gera uma deformação diametral de 3\% e o deslocamento diametral correspondente. São realizados ensaios em três amostras de tubo (1, 2 e 3), sendo que a rigidez anular é a média dos resultados obtidos, calculados segundo a expressão:

$$
R A=\frac{R A_{1}+R A_{2}+R A_{3}}{3}
$$

Sendo,

$$
R A_{i}=\frac{\left(0,0186+\frac{0,025 \cdot y_{i}}{D_{i}}\right) \cdot F_{i}}{L_{i} \cdot y_{i}}
$$

Onde:

$$
\begin{aligned}
& \mathrm{R} A_{i}=\text { rigidez anular da amostra } i\left(\mathrm{kN} / \mathrm{m}^{2}\right) ; \\
& y_{i}=\text { deslocamento diametral da amostra } i \text {, medido na direção de aplicação da } \\
& \quad \text { carga, correspondente a } 3 \% \text { de deformação diametral }(\mathrm{m}) ; \\
& D_{i}=\text { diâmetro interno inicial médio da amostra } i(\mathrm{~m}) ; \\
& F_{i}=\text { força aplicada capaz de provocar uma deformação de } 3 \% \text { na direção de } \\
& \quad \text { aplicação da carga, na amostra } i(\mathrm{kN}) ; \\
& L_{i}=\text { comprimento da amostra } i(\mathrm{~m}) .
\end{aligned}
$$

\subsubsection{Determinação Experimental da Rigidez Anular pela NBR 9053}

O ensaio para determinação da rigidez anular segundo a NBR 9053 também é realizado em uma prensa com dois pratos paralelos. Entretanto, a velocidade de deslocamento diametral de compressão é de $12 \mathrm{~mm} / \mathrm{min}$, sendo anotadas a força e o deslocamento diametral contínua e automaticamente.

Segundo esta norma a amostra deve apresentar um comprimento médio de $150 \mathrm{~mm}$. O ensaio deve ser executado até a deformação diametral de 40\%. 
A rigidez anular é determinada experimentalmente pelo coeficiente angular de uma reta interpolada entre as deformações diametrais de 0 e $12 \%$, no gráfico força vs deslocamento diametral vertical, e calculada pela expressão:

$$
R A=\frac{0,0186 \cdot \frac{F}{L}}{Y}
$$

Onde:

$\mathrm{R} A=$ rigidez anular da amostra $\left(\mathrm{kN} / \mathrm{m}^{2}\right)$;

$Y=$ deslocamento diametral da amostra, medido na direção de aplicação da carga, correspondente a 12\%de deformação diametral (m);

$F=$ força aplicada capaz de provocar uma deformação diametral de $12 \%$ na amostra, na direção de aplicação da mesma $(\mathrm{kN})$;

$L=$ comprimento da amostra ensaiada $(\mathrm{m})$.

O Laboratório de Tecnologia de Pavimentação da Escola Politécnica da Universidade de São Paulo realizou ensaios comparando os métodos propostos pelas duas normas citadas (LTP-PTR-EPUSP/Tigre, 1998a). Esta equipe considerou conveniente calcular os resultados que seriam obtidos pela NBR 9053 tomando-se o valor da força correspondente à uma deformação diametral de $3 \%$.

Como resultado do trabalho, a equipe técnica do LTP-EPUSP chegou a algumas conclusões, dentre elas as mais relevantes para o assunto em consideração são:

- Os valores obtidos para rigidez anular segundo a ISO9969 (a 3\% de deformação diametral) é maior do que o valor obtido seguindo-se o procedimento da NBR 9053 (a 12\% de deformação diametral), o que se justifica pelo valor de deformação adotado no cálculo, pela inclusão de um valor de segunda ordem na expressão adotada pela ISO 9969, pelo comprimento da amostra e pela velocidade do ensaio;

- Ao comparar os valores de rigidez anular obtidos pela ISO 9969 e pela NBR 9053 a 3\% de deformação diametral, nota-se que a ISO 9969 fornece valores maiores, fato 
que também é justificado pelo fator de segunda ordem, pelo comprimento da amostra e pela velocidade do ensaio;

a Estimando-se teoricamente as deformações que poderiam ocorrer em campo, a rigidez anular determinada segundo a ISO 9969 aproxima-se mais do provável valor real;

- Recomenda-se que o valor da rigidez anular de um tubo seja obtido através da média de três determinações, em três amostras, conforme recomenda a ISO 9969, ainda que sejam pouco elevados os desvios-padrão dos ensaios realizados;

- A velocidade do ensaio não representa o carregamento a que está exposto um tubo enterrado em sistemas de drenagem viária, tanto considerando cargas de solo (pois serão certamente menores do que as preconizadas para o ensaio por ambas as normas), quanto para as cargas móveis advindas do tráfego (terão velocidades de aplicação geralmente mais elevadas);

\ É recomendável executar o ensaio até a deformação diametral da ordem de 40 ou $50 \%$, conforme recomendação da NBR 9053, para se tenha mais informações sobre o comportamento do tubo e formas de colapso.

\subsection{Critérios de Projeto - Modos de Ruptura do Tubo}

Os critérios de projeto estrutural do sistema solo-tubo para drenagem viária utilizando tubos plásticos com parede estruturada são:

- Deformação diametral excessiva,

\ Reversão de curvatura,

- Esmagamento da parede do tubo,

- Flambagem da parede do tubo, e

\ Deformação excessiva da parede do tubo. 


\subsubsection{Deformação diametral excessiva}

Tubos plásticos flexíveis tem a deflexão ${ }^{6}$ (deslocamento na direção vertical dada em m ou deformação vertical dada em $\mathrm{m} / \mathrm{m}$ ou em porcentagem) como um limite de projeto (Figura 2.5). Esse valor de projeto não é um limite do desempenho do tubo, mas é freqüentemente baseado em um limite de desempenho majorado por um coeficiente de segurança. Tubos de PVC, por exemplo, não começarão a reverter a curvatura antes de estarem próximos de uma deflexão de 30\%. Assim, a deflexão de projeto é calculada com um coeficiente de segurança igual a 4, ou seja, a deflexão de projeto tem sido considerada de 7,5\% (LTP-PTR-EPUSP/Tigre, 1998b).

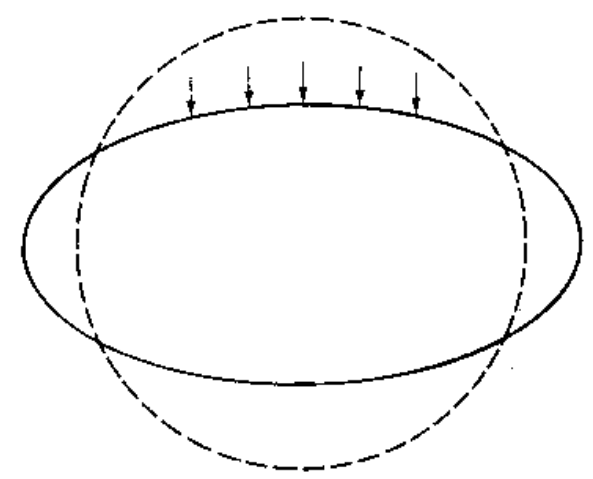

Figura 2.5 - Deflexão em um tubo flexível

Tubos considerados semi-rígidos ou semiflexíveis também tem a deflexão como um limite de projeto, assim como os tubos flexíveis. Alguns desses produtos são freqüentemente citados como sendo possuidores apenas dos atributos positivos tanto dos tubos rígidos quanto dos flexíveis. No entanto, testes mostraram que esses tubos podem e efetivamente exibem uma combinação dos limites de desempenho de ambos os tubos, rígidos e flexíveis, o que leva a uma análise de projeto mais complexa (Moser, 1990).

\footnotetext{
${ }^{6} \mathrm{O}$ termo deflexão tem sido empregado mundialmente, apesar de não ser teoricamente correta sua utilização para tal finalidade. Seria mais correta a denominação de deformação vertical, dada $\mathrm{em} \mathrm{m} / \mathrm{m}$ ou em porcentagem. Dado seu uso de forma generalizada, optou-se por seguir a denominação mais comumente empregada.
} 
Esse limite de projeto é o critério mais importante e pode ser calculado por vários métodos. Tradicionalmente, a fórmula de Iowa modificada (eq. 2.12), desenvolvida por Spangler e apresentada no item 2.2.4, tem sido utilizada para tal finalidade.

\subsubsection{Reversão de curvatura}

A reversão de curvatura é um fenômeno relacionado com a deflexão e não ocorrerá se a mesma for relativamente baixa (Figura 2.6). Tubos de PVC enterrados sofrem deflexões quando expostos a cargas externas e passam a apresentar reversão de curvatura quando a deflexão está próxima a 30\%. Levando em consideração as características dos tubos de PVC, o limite de 7,5\% para a deflexão, recomendado como limite na norma ASTM D3034, é bastante seguro e significativamente inferior àquele que provoca a reversão de curvatura, sendo portanto um tipo de falência estrutural que não ocorrerá se forem mantidos os limites de projeto.

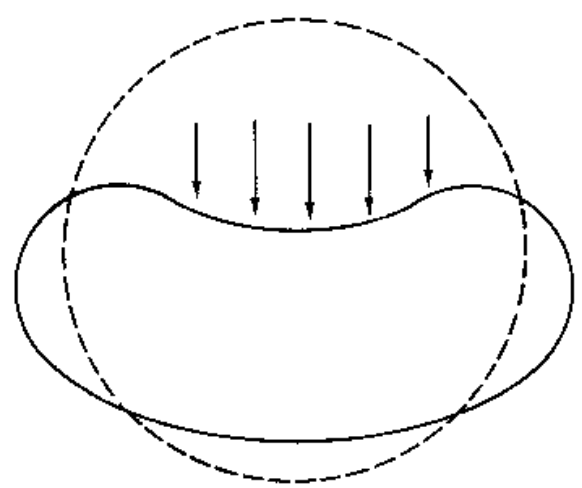

Figura 2.6 - Reversão de curvatura em um tubo de PVC causada por deflexão excessiva

Mesmo sem colapso estrutural, com o tubo ainda suportando as cargas solicitantes, a transferência das tensões resultantes do tubo para o solo que o envolve diminui a partir do momento em que inicia a reversão de curvatura. Ocorre a perda do perfil elíptico da seção transversal do tubo, e todo o princípio estrutural do projeto de tubos plásticos enterrados perde o sentido. 


\subsubsection{Esmagamento da parede do tubo}

Esmagamento de parede é uma terminologia utilizada para descrever um defeito localizado em materiais dúcteis ou fissuras em materiais frágeis. Em materiais dúcteis, caso do PVC, esse defeito corresponde a uma plastificação localizada. Este limite de desempenho é atingido quando as tensões na parede do tubo atingem a tensão de plastificação do material do tubo. A tensão de compressão na seção transversal da parede do tubo é a contribuição principal para este limite de desempenho. Os locais de ocorrência mais provável desse tipo de defeito são as posições três e nove do relógio, conforme ilustrado na Figura 2.7.

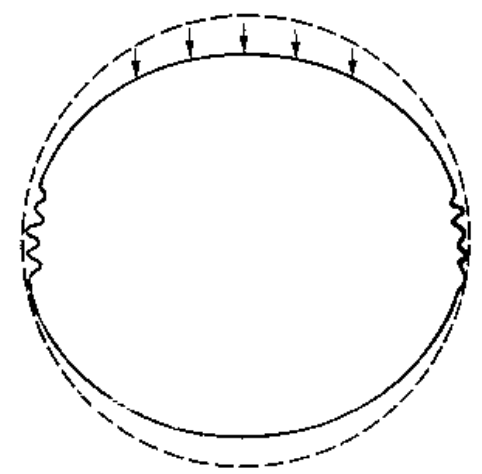

Figura 2.7 - Esmagamento da parede de um tubo flexível

A tensão de compressão na parede do tubo pode ser calculada por:

$$
\sigma_{c}=\frac{(p+q) \cdot D}{2 \cdot A}
$$

Onde:

$\sigma_{c}=$ tensão de compressão na parede do tubo $(\mathrm{MPa})$;

$p=$ tensão vertical distribuída no plano tangente à geratriz superior do tubo devida à carga permanente $(\mathrm{MPa})$;

$q=$ tensão vertical distribuída no plano tangente à geratriz superior do tubo devida a cargas móveis $(\mathrm{MPa})$;

$D=$ diâmetro externo do tubo (pode-se aproximar pelo diâmetro interno) (m);

$A=$ área da seção transversal da parede do tubo por unidade de comprimento $\left(\mathrm{m}^{2} / \mathrm{m}\right)$. 
O esmagamento da parede do tubo geralmente não ocorre em tubos plásticos com parede estruturada, por sua flexibilidade, mas deve ser verificado quando a instalação for executada em grandes profundidades. Além disso, tubos com rigidez mais elevada também estão mais sujeitos ao fenômeno.

\subsubsection{Flambagem da parede do tubo}

A flambagem da parede do tubo não é um limite de resistência, mas ocorre quando a rigidez do tubo é insuficiente para resistir às solicitações. É resultante da combinação da inércia da parede do tubo com o diâmetro utilizado. É um risco para tubos com baixa rigidez enterrados em solos firmes e/ou condições de pressão elevada - Figura 2.8.

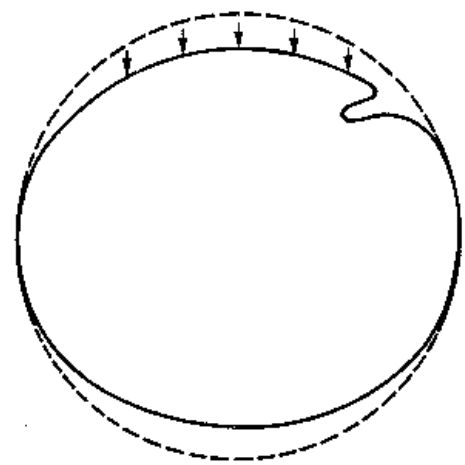

Figura 2.8 - Flambagem da parede de um tubo flexível

Para uma pressão hidrostática externa aplicada a um tubo livre, o carregamento limite para evitar a flambagem é dado por:

$$
p_{f l}=\frac{3 \cdot E \cdot I}{R^{3} \cdot\left(1-v^{2}\right)}
$$

Onde:

$p_{f l}=$ tensão que leva à flambagem um tubo livre $(\mathrm{MPa})$;

$E=$ módulo de elasticidade do material do tubo $(\mathrm{MPa})$;

$I=$ momento de inércia da parede do tubo, por unidade de comprimento $\left(\mathrm{m}^{4} / \mathrm{m}\right)$;

$R$ = raio médio do tubo (pode-se aproximar pelo raio interno) $(\mathrm{m})$;

$v=$ coeficiente de Poisson do material do tubo. 
No caso de um tubo enterrado, o efeito enrijecedor do solo de envolvimento deve ser considerado. Dessa forma, o carregamento que leva à flambagem de um anel circular rodeado por solo pode ser expresso por:

$$
p_{f l s}=1,15 \cdot \sqrt{p_{f l} \cdot E^{\prime}}
$$

Onde:

$p_{f / s}=$ carregamento que leva a flambagem um tubo envolvido por solo $(\mathrm{MPa})$;

$E^{\prime}=$ módulo de reação do solo $(\mathrm{MPa})$;

$p_{f l}=$ carregamento que leva a flambagem um tubo livre $(\mathrm{MPa})$.

Extremos cuidados devem ser tomados com tubos de grandes diâmetros. As equações mostradas assumem que a pressão externa (ou vácuo interno) é constante ao longo do tubo. Tal condição não é facilmente encontrada quando tubos de grandes diâmetros são instalados abaixo do nível do lençol freático. Nesse caso, a pressão hidrostática pode variar substancialmente do topo à parte inferior do tubo.

\subsubsection{Deformação excessiva da parede do tubo}

O deslocamento diametral do tubo, assunto tratado na seção 2.4.1, causa deformações na seção transversal da parede do tubo. Por isso, deve-se verificar se a deformação de tração admissível é maior ou igual à tensão a que o tubo estará submetido.

A deformação total de tração na parede do tubo devida à flexão pode ser calculada por:

$$
\varepsilon=\frac{(p+q) \cdot D}{2 \cdot t \cdot E}+\frac{t}{D} \cdot \frac{3 \cdot \Delta Y / D}{1-2 \cdot \Delta Y / D}
$$

Onde:

$\varepsilon=$ deformação total de tração devida à flexão do tubo;

$p=$ tensão vertical distribuída no plano tangente à geratriz superior do tubo devida à carga permanente $(\mathrm{MPa})$;

$q=$ tensão vertical distribuída no plano tangente à geratriz superior do tubo devida a cargas móveis $(\mathrm{MPa})$;

$t=$ espessura da parede do tubo $(\mathrm{m}) ;$

$D=$ diâmetro externo do tubo (pode-se aproximar pelo diâmetro interno) (m); 


$$
\begin{aligned}
& E=\text { módulo de elasticidade do material do tubo }(\mathrm{MPa}) \\
& \Delta y=\text { deslocamento diametral vertical }(\mathrm{m}) .
\end{aligned}
$$

Normalmente, deformações na parede do tubo, causadas por deflexão (deformação diametral vertical) de até $20 \%$, não causam colapso.

\subsection{Critérios para Seleção de Materiais de Envolvimento}

O material de envolvimento é o material que fica diretamente em contato com o tubo e deve ser capaz de suportar as cargas atuantes, ou seja, o material de envolvimento atua no sistema solo-tubo flexível como material estruturalmente resistente. A estabilidade de um tubo flexível enterrado é significativamente controlada pelas propriedades do material de envolvimento. Sob carregamento vertical, a seção transversal do tubo flexível tende a deformar-se, com redução do diâmetro vertical e aumento do diâmetro horizontal. O movimento horizontal do tubo contra o solo desenvolve neste o empuxo passivo, como visto anteriormente no item 2.1.

As propriedades do solo que envolve uma tubulação influenciam fortemente o desempenho estrutural do sistema solo-tubo. Do mesmo modo, a forma do berço (apoio inferior do tubo) pode reduzir as concentrações de tensão dos solos sobre tubos rígidos. O emprego de materiais adequados e a obtenção de uma densidade adequada (compactação eficiente) do solo em torno de tubos flexíveis podem limitar as deflexões a valores aceitáveis para sistemas enterrados.

O módulo de resistência passiva do solo E' expressa uma relação existente entre o solo ao redor do tubo e a deflexão (deslocamento diametral) deste. O método mais utilizado envolve a determinação das deflexões de um tubo cujas condições de instalação são conhecidas; o valor efetivo de E' é encontrado através de retroanálise utilizando-se a fórmula de Iowa Modificada. Este procedimento assume os valores de carga, constante de assentamento e fator tempo.

Howard (1977) reuniu informações sobre valores de E' publicados para o United States Burean of Reclamation. Howard usou dados de laboratório e de testes de campo para 
compilar uma tabela de valores médios de E’ para vários tipos de solo e densidades (Tabela 2.4). Foram assumidos valores de $E$ ', $K$ e $W_{c}$ e aplicada à fórmula de Iowa Modificada para calcular um valor de deflexão teórico. Essa deflexão teórica foi comparada com deflexões medidas em instalações existentes.

Tabela 2.4 - Materiais de envolvimento (Moser, 1990)

\begin{tabular}{ccc}
\hline E' (MPa) & Material de Envolvimento & Condições de Compactação \\
\hline & Material essencialmente granular, sem & \\
& finos. USCS* : GW, GP, SW e SP. Ex: & Bem compactado: GC ${ }^{* *} \geq 90 \%$ da \\
brita graduada simples, bica corrida, & Energia Normal (Proctor normal) \\
areia bem graduada, areia pura. & \\
\hline & Material essencialmente granular, sem & Compactação mais leve: GC entre \\
& finos. USCS: GW, GP, SW e SP. Ex: & 85\% e 90\% da Energia Normal \\
& brita graduada simples, bica corrida, & (Proctor normal) \\
& areia bem graduada, areia pura. &
\end{tabular}

Material granular com finos (entre $12 \mathrm{e}$

$25 \%$ ) não expansivos. USCS: GM, GC, SM e SC. Ex: pedregulho argiloso, 7 pedregulho arenoso, areia argilosa, Bem compactado: GC $\geq 90 \%$ da Energia Normal (Proctor normal) areia siltosa, solo-brita.

Material granular com finos (entre $12 \mathrm{e}$

25\%) não expansivos. USCS: GM, GC, Compactação mais leve: GC entre SM e SC. Ex: pedregulho argiloso, $\quad$ 85\% e 90\% da Energia Normal 2,8 pedregulho arenoso, areia argilosa, (Proctor normal) areia siltosa, solo-brita.

Material essencialmente granular, sem finos. USCS: GW, GP, SW e SP. Ex: 1,4 brita graduada simples, bica corrida, areia bem graduada, areia pura.

\footnotetext{
* USCS: Sistema Unificado de Classificação de Solos.

** GC: Grau de compactação.
} 
Howard observou que a variação entre as deflexões medidas e as previstas, usando os valores de E' da tabela do Bureau of Reclamation para a fórmula de Iowa e o valor da constante de assentamento $K=0,1$, parece ser afetada mais pelo grau de compactação do que por qualquer outro fator.

Em qualquer caso, os dados da Tabela 2.4 são consistentes com os dados de campo e de laboratório coletados ao longo de um período de 20 anos na Universidade Estadual de Utah, Estados Unidos, se a carga for calculada como um prisma e o fator tempo igual a 1,0. Embora a maioria dos dados do estudo realizado por Howard haver sido coletada em testes com tubos de aço e de RPM com diâmetros maiores de 24", as informações são úteis para guiar os projetistas de tubos flexíveis, inclusive de PVC.

Howard alerta para a precaução que deve ser tomada para o uso de valores de E' da tabela do Bureau of Reclamation quando o solo natural da vala é muito mais compressível do que o material de envolvimento. Nestas condições, um mínimo de dois diâmetros deve ser escavado em cada lado da tubulação e o material de envolvimento deverá ter alto grau de compactação, assim a resistência do sistema solo-tubo não dependerá do solo da vala (Howard, 1977).

Os materiais de envolvimento mais utilizados correspondem aos materiais de classificação GW, GP, SW, SP, GM e SM pelo Sistema Unificado de Classificação de Solos, assim como brita graduada, pedrisco, areia e outros, conforme apresentado na Tabela 2.4.

Deve-se utilizar preferencialmente materiais granulares com grãos de formato cúbico com arestas; agregados lamelares somente serão permitidos na quantidade de 10\%, em peso, ou na ausência de cúbicos. Se forem disponíveis apenas seixos rolados, utilizar preferencialmente a britagem da fração retida na peneira de $4,8 \mathrm{~mm}$, desde que pelo menos 25\% dessa fração contenham agregados com duas faces fraturadas (Moser, 1990).

Ao utilizar-se solo granular como material de envolvimento tem-se a vantagem de drenar as águas subterrâneas, aliviando a pressão neutra causada pela saturação do solo. 
Nestas condições de saturação, impõe-se ao tubo uma carga dupla: a carga devida ao solo mais a carga hidrostática. Porém o problema maior se relaciona principalmente à redução de resistência do solo de envolvimento devido à pressão neutra.

Os valores constantes da Tabela 2.4 vêm da observação prática de pesquisadores, como Atkins, Howard, Moser e outros; têm sido adotados tradicionalmente em normas e especificações de projeto dos países que utilizam a tecnologia de tubos plásticos com parede estruturada (Moser, 1990).

É interessante, quando da compactação do material de envolvimento, que se provoque um acréscimo no diâmetro vertical de $2 \%$, para que este venha a compensar o deslocamento provocado posteriormente pelas cargas atuantes sobre o tubo. A espessura de solo de envolvimento sobre o tubo deve ser de aproximadamente 0,20 metro.

O desempenho estrutural do tubo depende basicamente do grau de compactação do material de envolvimento obtido no campo. Recomenda-se o uso de sapo mecânico ou soquete manual para a compactação.

Nas situações em que há possibilidade de migração de finos do solo natural da vala para o material de envolvimento, o projetista deve considerar a utilização de geotêxtil, ou aplicar os critérios de filtro de Terzaghi para selecionar o material de envolvimento.

\subsection{Materiais de Berço, Fundação e Reaterro}

Os materiais usados no berço, na fundação e no reaterro da vala não têm a mesma importância estrutural para o sistema solo-tubo. Mas são de vital importância para bom desempenho do pavimento sob o qual passa a tubulação de drenagem com tubo flexível.

2.6.1 Fundação

O material que compõe a fundação deve ser suficientemente resistente para suportar as cargas atuantes no sistema solo-tubo sem apresentar recalque excessivo ou diferencial. 
Nesse contexto, materiais como argilas muito moles, expansivas, materiais de resistência irregular, entre outros, são impróprios.

No caso de locais onde o solo natural esteja saturado e for expansivo deve-se proceder a um reforço da fundação, que consiste em uma camada adicional de areia compactada de aproximadamente $0,10 \mathrm{~m}$ entre o berço e a fundação. Esta camada tem a função de dar suporte ao berço e evitar a contaminação deste pelo solo de fundação. Quando há rocha ou pedregulho com diâmetro superior a $40 \mathrm{~mm}$ no fundo da vala o procedimento indicado é escavar mais 0,10 $\mathrm{m}$ abaixo do nível de assentamento do tubo e preencher com material apropriado para o berço LTP-PTR-EPUSP/Tigre (1998b).

Em caso de presença de solo natural orgânico ou mole, pode-se considerar a utilização de geotêxtil para evitar a contaminação do berço e do material de envolvimento.

\subsection{2 \\ Material do Berço}

O material que constitui o berço deve apresentar resistência suficiente para responder com uma reação oposta e de igual valor à força advinda das cargas atuantes sobre o sistema solo-tubo e propiciar um bom assentamento geométrico do tubo.

Os materiais utilizados devem ter alta capacidade de suporte, ser essencialmente granulares, bem compactados e preferencialmente de granulometria densa ou bem graduado. Se o fundo da vala for instável, pode ser requerido um berço especial, como por exemplo, uma base de concreto.

Após a compactação, a espessura final do berço deve ficar entre 0,10 e 0,20 m aproximadamente. Para a compactação é recomendado o uso de sapo mecânico ou soquete manual, o grau de compactação deve ser maior ou igual a 90\% correspondente à Energia Normal (LTP-PTR-EPUSP/Tigre, 1998b). 
A função do material usado como reaterro é preencher a vala até a superfície do terreno. Não é recomendado o uso de materiais expansivos o que adensem muito, pois haverá redistribuição das tensões ao redor do tubo, modificando o deslocamento diametral vertical previsto. Não se deve esquecer que o reaterro será a fundação ou o subleito das camadas de pavimento assentadas sobre ele.

A estrutura de pavimento que eventualmente venha a constar da parcela superior do reaterro deve atender ao projeto geométrico da via e ao projeto de pavimentação.

\subsection{Aspectos Geométricos das Valas}

\subsubsection{Largura das Valas}

O diâmetro do tubo foi definido no projeto hidráulico e é um dos fatores que definem a largura da vala. Além disso, são relevantes as especificações de serviços dos órgãos responsáveis pela drenagem viária, dos equipamentos disponíveis na região e do tipo de escoramento adotado.

O valor limite mínimo de largura da vala deve permitir o acesso dos equipamentos de compactação disponíveis na região, fornecer espaço para a execução de juntas, garantir segurança durante a realização da obra e acomodar os sistemas de suporte das paredes da vala, caso seja necessário.

Segundo LTP-PTR-EPUSP/TIGRE (1998b), recomenda-se que para instalações de tubos plásticos de parede estruturada, em que o material de envolvimento é compactado por equipamento mecânico (sapo) ou por soquete manual, a largura mínima da vala seja o menor valor entre o diâmetro externo do tubo mais $0,4 \mathrm{~m}$ e o diâmetro externo do tubo vezes 1,25 mais $0,3 \mathrm{~m}$.

Quando o solo em que será aberta a vala é plástico, a espessura do material de envolvimento nas laterais do tubo deve ser tal que a cunha de esforços não atinja a 
parede da vala. Garante-se tal condição se a mínima espessura lateral for igual à metade do diâmetro. Usando um material de envolvimento cujo ângulo de atrito seja igual ou superior a $30^{\circ}$, a espessura poderá ser reduzida de maneira a garantir que a parede da vala não seja atingida pela cunha de esforços. Não deve ser prescindida, porém, a consideração de um fator de segurança que garanta tal condição - Figura 2.9 (Monge, 1996).

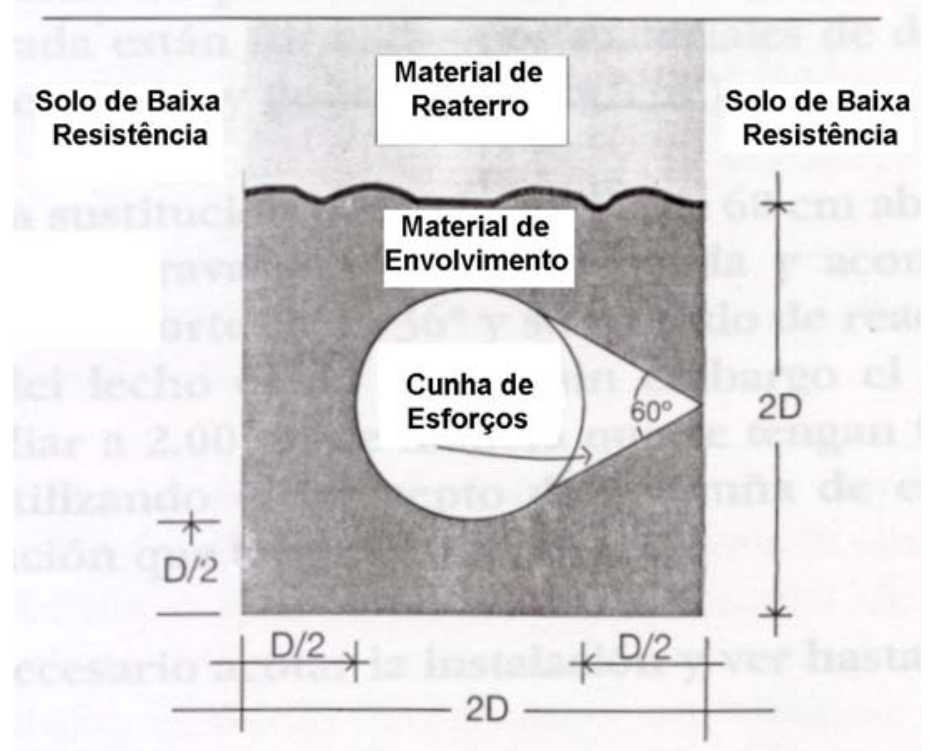

Figura 2.9 - Cunha de esforços (Monge, 1996)

Este é, sem dúvidas, o limite geométrico mais importante para o bom desempenho estrutural do sistema solo-tubo. A profundidade da vala é definida no projeto hidráulico, mas não deve ultrapassar as profundidades máxima e mínima permitidas para cada tipo de tubo. Essas profundidades dependem do tipo de solo bem como das cargas atuantes, incluindo o tipo de tráfego a que a via está submetida. No caso de não ser possível modificar a profundidade de assentamento do tubo, deve-se modificar ou a rigidez do tubo ou a rigidez do material de envolvimento do tubo.

A mínima espessura de cobrimento é estabelecida para prevenir danos ao tubo e problemas com o material de envolvimento, que deve estar confinado para oferecer boa capacidade de suporte no caso de material granular. Não deve ser permitido tráfego de 
veículos ou equipamentos de construção sobre a instalação sem que esta esteja devidamente protegida.

É recomendado pelo LTP-PTR-EPUSP/Tigre (1998b) que a espessura mínima de cobrimento sobre o tubo seja determinada em projeto, pois depende da rigidez do tubo, do material de envolvimento e do tipo de carga atuante. Na ausência de projeto, deve-se

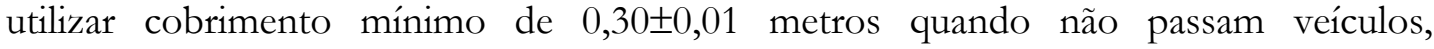
associado à rigidez anular do tubo de no mínimo 1000 Pa. Onde há passagem de veículos, é necessário haver projeto estrutural. 


\section{BREVE HistóRICO do USO DE Tubos FleXíveis ENTERRAdos}

Neste capítulo enfoca-se o uso de tubos flexíveis e sua evolução para tubulações de grandes diâmetros. São citados experimentos realizados com tubos flexíveis em vários países, mostrando alguns resultados e conclusões, com vistas a fundamentar a presente pesquisa.

\subsection{Evolução para o Uso de Tubos Flexíveis de Parede Estruturada}

A prática de uso de tubos plásticos foi introduzida no mercado inicialmente para sistemas de esgoto subterrâneos, utilizando principalmente o PVC. No mercado sueco este emprego data do final da década de 60, e desde então apresentou um forte crescimento, passando a ser a principal alternativa para tubos de concreto e de manilhas cerâmicas até o diâmetro de $630 \mathrm{~mm}$. Atualmente, tubos de polietileno de alta densidade (HDPE) e de polietileno de média densidade (MDPE) têm sido usados para sistemas de esgoto com diâmetros de até 1600 mm (Janson, 1996).

Chambers et al. (1980) reportam uma pesquisa feita durante as fases iniciais do estudo do NCHRP, que proporcionou uma visão geral do uso de tubos plásticos para drenagem viária. Um questionário foi enviado a 50 membros do comitê de materiais da AASHTO, sendo que as respostas revelaram que (1) aproximadamente a metade dos estados norte-americanos não tinha experiência com tubos plásticos até o início da década de 80; e (2) sete estados haviam instalado tubos plásticos com pequena extensão 
de rede; muitos desses estados haviam instalado apenas tubos de polietileno de paredes corrugadas para drenos longitudinais de vias; um estado havia instalado um tubo de parede compósita em ABS (Acrylonitrile-Butadiene-Stirene) para drenagem pluvial, e um estado havia instalado bueiros de RPM (Reinforced Plastic Mortar) com a mesma finalidade.

O ABS apresenta propriedades similares ao PVC, embora sua resistência química seja menor do que a do PVC, sendo sensível inclusive a hidrocarbonetos. O RPM, um tipo de argamassa plástica reforçada, apresenta boa resistência a ataques por agentes químicos, incluindo os encontrados em solos agressivos. Ainda segundo Chambers et al. (1980), a aplicação mais interessante para tubos plásticos pelas agências de transporte americanas tem sido em drenagem subterrânea, com tubos de parede corrugada, sendo polietileno o material mais utilizado. Somente a partir de 1978, os Estados da Georgia, Illinois e Michigan permitiram tubos de polietileno perfurados como uma alternativa para drenos enterrados.

Tubos de PVC foram largamente utilizados em sistemas de esgotamento sanitário e em sistemas de drenagem pluvial, em saída de gases de aterros de lixo, em abastecimento de água, como condutos para cabos de telecomunicação, e em alguns casos como oleodutos e linhas de água salgada (Chambers et al., 1980). A mais larga utilização deu-se em sistemas de esgoto municipais e em drenos subterrâneos em rodovias; usuários e consultores relataram desempenho satisfatório para ambas aplicações. Milhares de quilômetros foram instalados, muitos dos quais haviam sido instalados há até 12 anos, tendo como referência o relato do ano de 1980 de Chambers et al. Alta resistência à abrasão, aos impactos advindos do tráfego e a solos agressivos, além de custo de instalação competitivo foram as razões principais para sua seleção e seu emprego.

O tubo Rib Loc ${ }^{\mathrm{TM}}$ foi patenteado e introduzido no mercado australiano em 1981. Um produto similar é manufaturado nos Estados Unidos, mas confeccionado a quente, para produzir tubos com rigidez muito mais elevada (Chapman, 1990), sem os encaixes macho-fêmea existentes nas tubulações do tubo Rib $\operatorname{Loc}^{\mathrm{TM}}$.

Em 1997, a Tigre Tubos e Conexões S.A. adquiriu a patente do Rib Loc ${ }^{\mathrm{TM}}$ para sua produção e comercilização no Brasil. Esses tubos plásticos flexíveis de parede 
estruturada são constituídos por perfis extrudados de PVC ou polietileno, compostos externamente por tiras em forma de T e por encaixes tipo macho-fêmea nas pontas Figura 3.1.

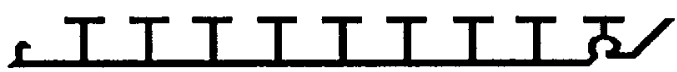

Figura 3.1 - Seção típica do perfil do tubo Rib $\operatorname{Loc}^{\mathrm{TM}}$ - com as paredes estruturadas com almas e mesas de enrijecimento e encaixes nas extremidades tipo macho-fêmea

O perfil é enrolado helicoidalmente a frio in situ (nos depósitos, nos canteiros de obra ou ainda na frente de execução), com diâmetro ajustável, usando maquinaria relativamente simples - Figura 3.2. Os encaixes promovem a vedação do tubo mecanicamente e são reforçados por uma solda química, selando o tubo nestes pontos.

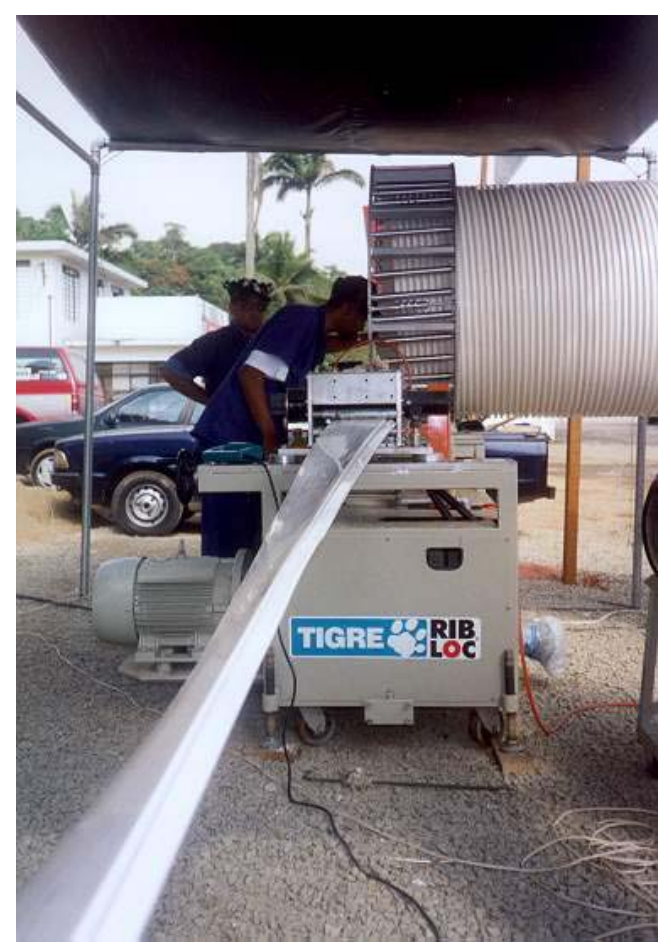

Figura 3.2 - Tubo plástico flexível de parede estruturada sendo enrolado helicoidalmente em canteiro de obra no Brasil 


\subsection{Experimentos}

Vários experimentos e estudos realizados em campo podem ser citados, entre eles Howard (1974), Parmelee \& Corotis (1974), Duncan \& Jeyapalan (1982), Kay (1984), Alferink (1990), Bauer (1990), Moser (1990), Watkins (1990), Kuraoka et al. (1996), entre outros. Nesse texto serão relatados apenas os mais relevantes para a comparação e compreensão dos resultados do experimento deste estudo. De todos os experimentos citados nesta dissertação e listados nas referências bibliográficas pode-se notar que todos eles fizeram avaliações dos tubos sob cargas estáticas, simulando sobrecargas de solo sobre o tubo.

Em 1985, Moser et al. publicaram os resultados de um estudo norte-americano que já vinha sendo realizado há três anos na Utah State University. O estudo foi realizado com tubos de fibra de vidro enterrados, cujos valores de rigidez anular eram de 69, 138, 276, 688 e $1379 \mathrm{kN} / \mathrm{m}^{2}(10,20,40,100$ e 200 psi). Vários tipos de solos e materiais de envolvimento foram usados em diferentes combinações.

O experimento de Moser et al. consiste em um arranjo experimental que compreende a instalação de tubos curtos, com até $1,5 \mathrm{~m}$ de comprimento e $600 \mathrm{~mm}$ de diâmetro, e tubos longos, com $6 \mathrm{~m}$ de comprimento e 1,5 m de diâmetro. Foram utilizados no primeiro caso para a aplicação da carga dezesseis cilindros hidráulicos, quatro em cada braço, exercendo pressão vertical sobre um prato de 1,2 x 1,5 m, instalado na superfície. Uma pressão máxima de $12411 \mathrm{kN} / \mathrm{m}^{2}$ (1.800 psi) foi aplicada pelos cilindros para produzir uma carga máxima de até $766 \mathrm{kN} / \mathrm{m}^{2}\left(16.000 \mathrm{lbf} / \mathrm{ft}^{2}\right)$. As cargas aplicadas foram medidas com auxílio da instalação de células de carga. O segundo arranjo experimental com tubos longos emprega 50 cilindros hidráulicos, 5 em cada um dos dez braços. Esses cilindros aplicam pressão em um prato com 3,0x6,0 m de comprimento, localizado na superfície do solo, abaixo da qual encontra-se o tubo enterrado. Uma pressão de $1436 \mathrm{kN} / \mathrm{m}^{2}$ (30.000 lbf/ $\mathrm{ft}^{2}$ ) foi empregada neste caso. As células de carga simularam sobrecargas sobre o sistema enterrado. 
Os deslocamentos diametrais foram medidos com o auxílio de um LVDT instalado em um aparato de três hastes ajustáveis, colocado no interior do tubo, de forma a permitir que o LVDT pudesse mover-se e registrar as variações diametrais do tubo.

Moser et al. (1985) relatam, entre outras coisas, a influência da densidade e do tipo de solo ou material de envolvimento. A Figura 3.3 mostra os resultados obtidos em três testes realizados em areia siltosa, classificada como SM pela Classificação Unificada, em densidades de 90\%, 80\% e 70\% relativas à Energia Normal. A influência da densidade do solo pode ser facilmente visualizada, mostrando a importância da compactação e do estado dos materiais de envolvimento na redução de deslocamentos diametrais dos tubos. É interessante observar a diferença entre os deslocamentos nas direções verticais e horinzontais, principalmente no caso de materiais de envolvimento mais densificados, apesar de ser adotada a igualdade destes deslocamentos para efeitos de cálculos nos projetos estruturais, como foi visto no capítulo 2.

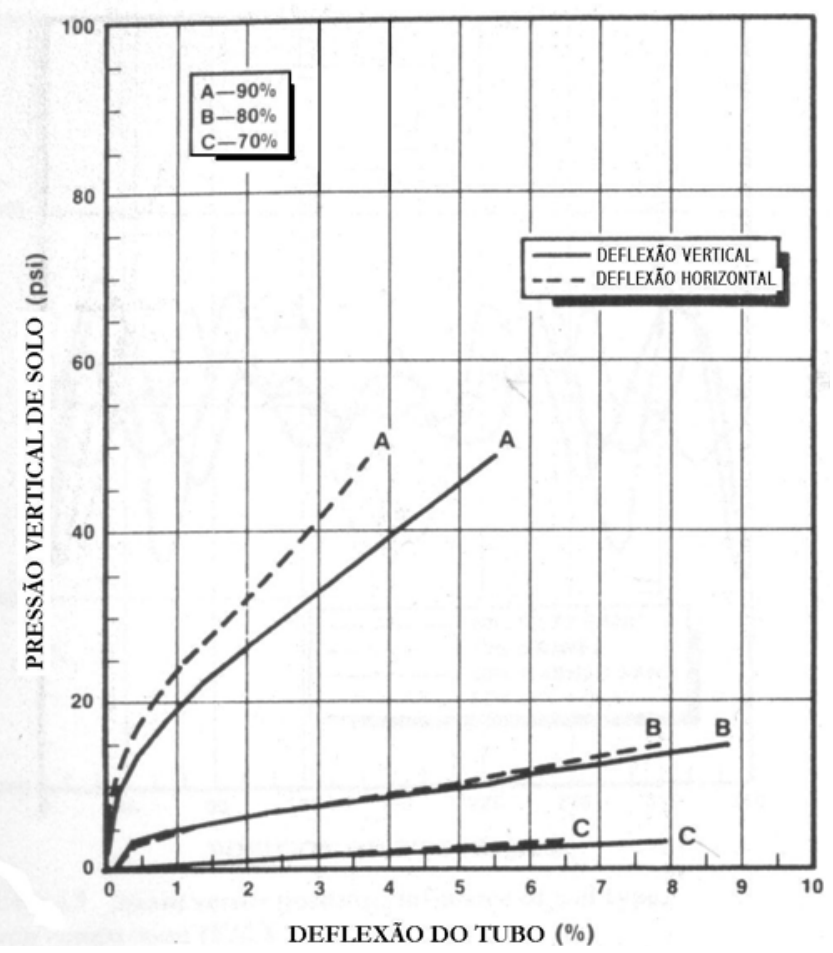

Figura 3.3 - Influência da densidade do solo em testes com tubos com rigidez anular de $69 \mathrm{kN} / \mathrm{m}^{2}$ (10 psi), onde A, B e C são os graus de compactação do material de envolvimento relativo à Energia Normal (Moser et al., 1985) 
A Figura 3.4 mostra o efeito do tipo de solo de envolvimento no comportamento mecânico de tubos com rigidez anular de $69 \mathrm{kN} / \mathrm{m}^{2}$ (10 psi). Para o mesmo grau de compactação, pode-se notar que a areia sem finos oferece melhor desempenho como material de envolvimento que a areia siltosa, proporcionando maior resistência ao deslocamento do tubo. Observa-se que o uso de brita, mesmo em estado pouco densificado, leva a resultados da mesma ordem de grandeza que as areias puras, mais densificadas. A argila exibe os piores resultados de desempenho mecânico do sistema solo-tubo flexível. Estes dados demonstram a importância da seleção dos materiais de envolvimento e a superioridade dos materiais granulares frente àqueles com finos ou argilosos.

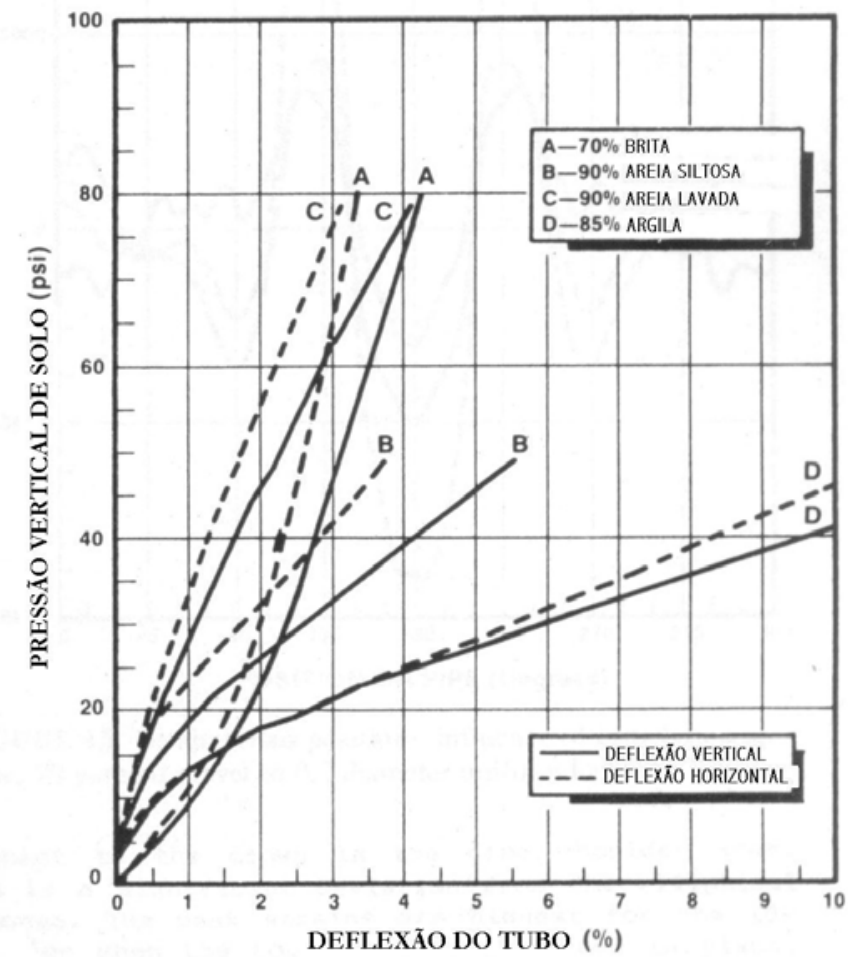

Figura 3.4 - Influência do tipo de solo de envolvimento em testes com tubos com rigidez anular de $69 \mathrm{kN} / \mathrm{m} 2$ (10 psi) (Moser et al., 1985)

Selig e McGrath (1994) estudaram um sistema de drenagem que incorporou aproximadamente $11 \mathrm{~km}$ de tubos de argamassa plástica reforçada com fibra de vidro (RPM) com diâmetros variando entre 500 a 1100 mm. Pouco tempo após a instalação foram constatados deslocamentos verticais diametrais considerados altos nos tubos, 
provocando a ocorrência de fissuras na superfície da via. Em conseqüência destas, formaram-se panelas (buracos) que provocaram a deterioração da rodovia. Inspeções mostraram que mais da metade dos tubos de RPM haviam se deslocado mais de 5\%, limite imposto pelo contrato, com alguns tubos apresentando mais de $20 \%$ de redução do seu diâmetro original, e com numerosas seções de tubo fissuradas ou com rupturas no topo.

Investigações mostraram que as deflexões (deslocamentos verticais dos tubos) e rupturas resultaram principalmente do controle inadequado do nível d'água no solo durante a construção e desatenção com relação à graduação da brita que envolvia o tubo e da areia natural que cobriu a vala. Durante a construção, o sistema de drenagem não conseguiu manter o nível do lençol freático abaixo do fundo da vala, resultando em infiltração de água e carreamento de areia para dentro da vala através das aberturas existentes entre as cortinas de contenção das paredes da vala. Quando as cortinas foram retiradas, a brita que envolvia o tubo perdeu capacidade de suporte e moveu-se, permitindo altas deflexões dos tubos. A migração de finos foi resultado do uso de um material de graduação aberta, com poucos finos, junto a uma areia de graduação uniforme. O elevado nível d'água e a alta permeabilidade da areia criaram uma situação em que ocorreu um fluxo capaz de misturar os materiais adjacentes, contribuindo para a perda gradual da capacidade de suporte do sistema solo-tubo.

Esses problemas podem não ser detectados antecipadamente pelo engenheiro ou pelo empreiteiro. Entretanto, a migração de finos para a camada de brita graduada deveria ter sido identificada durante a fase de projeto e a ineficiência da drenagem identificada e corrigida pelos inspetores durante a construção. Se tivessem sido observadas as deflexões dos tubos ao final da instalação, os problemas poderiam ter sido identificados e corrigidos antes que o sistema entrasse em operação.

Sargand et al. (1995) realizaram um experimento para testar dois tipos diferentes de tubos de PVC, de diferentes diâmetros. O primeiro objetivo era examinar os modos de ruptura dos perfis da parede dos tubos. O segundo propósito era estabelecer parâmetros de projeto, baseados em propriedades mecânicas reais do solo de envolvimento e na flexibilidade do tubo. O terceiro objetivo era desenvolver um critério de projeto e 
procedimentos analíticos para determinar o desempenho do solo e do tubo. O último objetivo era desenvolver ensaios de laboratório para simular o comportamento de campo, visando a garantia da qualidade dos tubos plásticos de parede estruturada.

O primeiro tubo, denominado PVC-1, possuia diâmetro nominal de $475 \mathrm{~mm}$. O projeto estrutural desse tubo constituía-se em uma seção uniforme, sem emenda, com nervuras radiais perpendiculares. O segundo tubo, PVC-2, tinha um diâmetro nominal de 914 $\mathrm{mm}$. O perfil da parede era liso (sem nervuras), consistindo de vigas I interligadas. A tabela 3.1 resume algumas das propriedades básicas dos tubos e os perfis típicos são mostrados na Figura 3.5. Ambos tubos têm sido normalmente usados em sistemas de esgoto (escoamento por gravidade) nos Estados Unidos (Sargand et al., 1995).

Tabela 3.1 - Características dos tubos estudados por Sargand et al. (1995)

\begin{tabular}{lcc}
\hline & PVC-1 & PVC-2 \\
\hline Diâmetro interno médio & $448 \mathrm{~mm}$ & $896 \mathrm{~mm}$ \\
\hline Diâmetro externo médio & $502 \mathrm{~mm}$ & $952 \mathrm{~mm}$ \\
\hline Área da parede & $7,8 \mathrm{~mm}^{2} / \mathrm{mm}$ & $14,4 \mathrm{~mm}^{2} / \mathrm{mm}$ \\
\hline Momento de inércia & $464 \mathrm{~mm}^{4} / \mathrm{mm}$ & $17190 \mathrm{~mm}^{4} / \mathrm{mm}$ \\
\hline Rigidez mínima do tubo & $413,7 \mathrm{kN} / \mathrm{m} / \mathrm{m}$ & $317,17 \mathrm{kN} / \mathrm{m} / \mathrm{m}$ \\
\hline
\end{tabular}

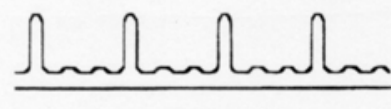

PVC-1

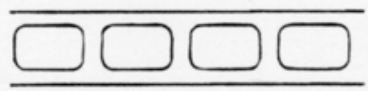

PVC-2

Figura 3.5- Perfis típicos das paredes dos tubos (segundo o eixo longitudinal) utilizados por Sargand et al. (1995)

Nesse estudo de Sargand et al. (1995), os tubos de PVC testados foram instalados no campo de acordo com procedimento padrão adotado pelo Departamento de Transportes de Ohio (DOT-Ohio) e submetidos a incrementos de carga usando um equipamento especial para tal finalidade. Esse equipamento consiste de dois componentes principais - dois cilindros hidráulicos de alta capacidade e uma armação estrutural ancorada em uma camada profunda de rocha. 
Os procedimentos de instalação dos tubos foram basicamente os mesmos. Primeiro escavou-se a vala de aproximadamente $7,6 \mathrm{~m}$ de comprimento e $3,7 \mathrm{~m}$ de largura. A profundidade da vala foi estendida até o topo da camada de rocha, de forma que o tubo não foi apoiado diretamente sobre o solo. Um berço de densidade satisfatória foi formado esparramando-se e compactando-se camadas de pedra calcária britada encontrada nas especificações de materiais para sub-base do Obio DOT n. ${ }^{\circ} 310$. A espessura do berço foi de $508 \mathrm{~mm}$ para o PVC-1 e $915 \mathrm{~mm}$ para o PVC-2. O topo da camada de pedra calcárea britada coincidiu exatamente com a metade do tubo (sentido vertical). O solo de envolvimento, colocado acima da pedra britada, se estendeu até 610 $\mathrm{mm}$ acima da geratriz superior do tubo para o PVC-1 e $305 \mathrm{~mm}$ para o PVC-2. Essa diferença nas condições de instalação foi introduzida para examinar, em termos gerais, a influência da altura de cobrimento no desempenho do tubo e testar alguns dos métodos analíticos existentes.

Após a compactação do material de envolvimento dos tubos e a colocação da plataforma de carregamento, o teste de carga foi iniciado pressurizando-se os dois cilindros hidráulicos. Cada incremento de carga durou quinze minutos, durante os quais foram feitas três leituras, a cada cinco minutos, em todos os sensores simultaneamente.

As ferramentas analíticas aplicadas para analisar os dois tubos de PVC foram a fórmula de Iowa Modificada (apresentada no capítulo 2 anterior) e as soluções elásticas de Burns e Richard ${ }^{7}$ apud Sargand et al (1995). Foi aplicada a teoria das cascas para o tubo e a função de tensão de Mitchell para o solo, considerado um meio elástico.

Durante o preenchimento e a compactação da vala o diâmetro do tubo na direção vertical aumentou em torno de 0,20\% para o PVC-1 e 0,11\% para o PVC-2. Isso indica que o procedimento de reaterro da vala induz a deflexões praticamente desprezíveis. Os tubos não respondem instantaneamente à aplicação de carga, porém, quando a influência do carregamento aparece, a resposta do tubo estabiliza rapidamente. Isso se deve ao uso de um material de envolvimento granular.

\footnotetext{
${ }^{7}$ Burns, J. Q. e Richard, R. M. (1964), Attenuation of Stresses for Buried Cylindres, Proc. Symposium on Soil-Structure Interaction, Engineering Research Laboratory, University of Arizona, pp. 378-392.
} 


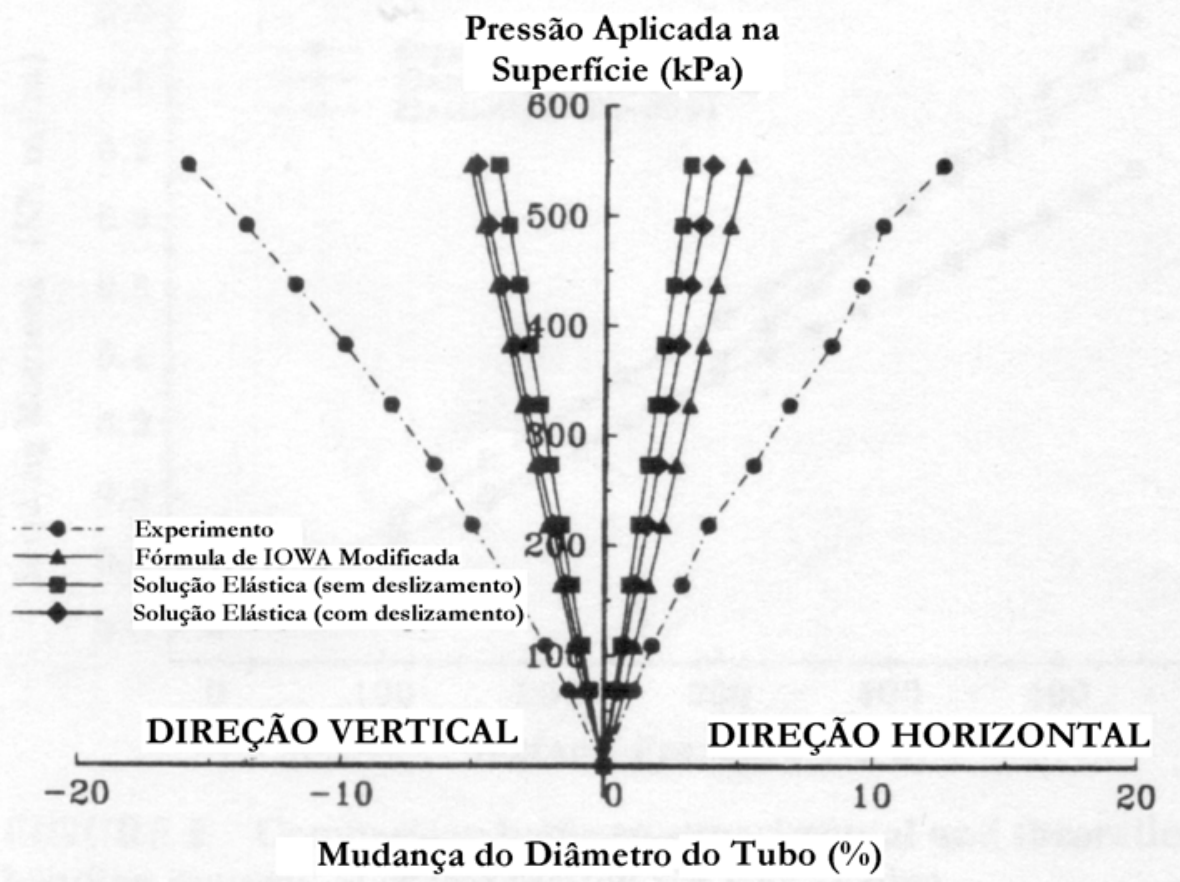

(a)

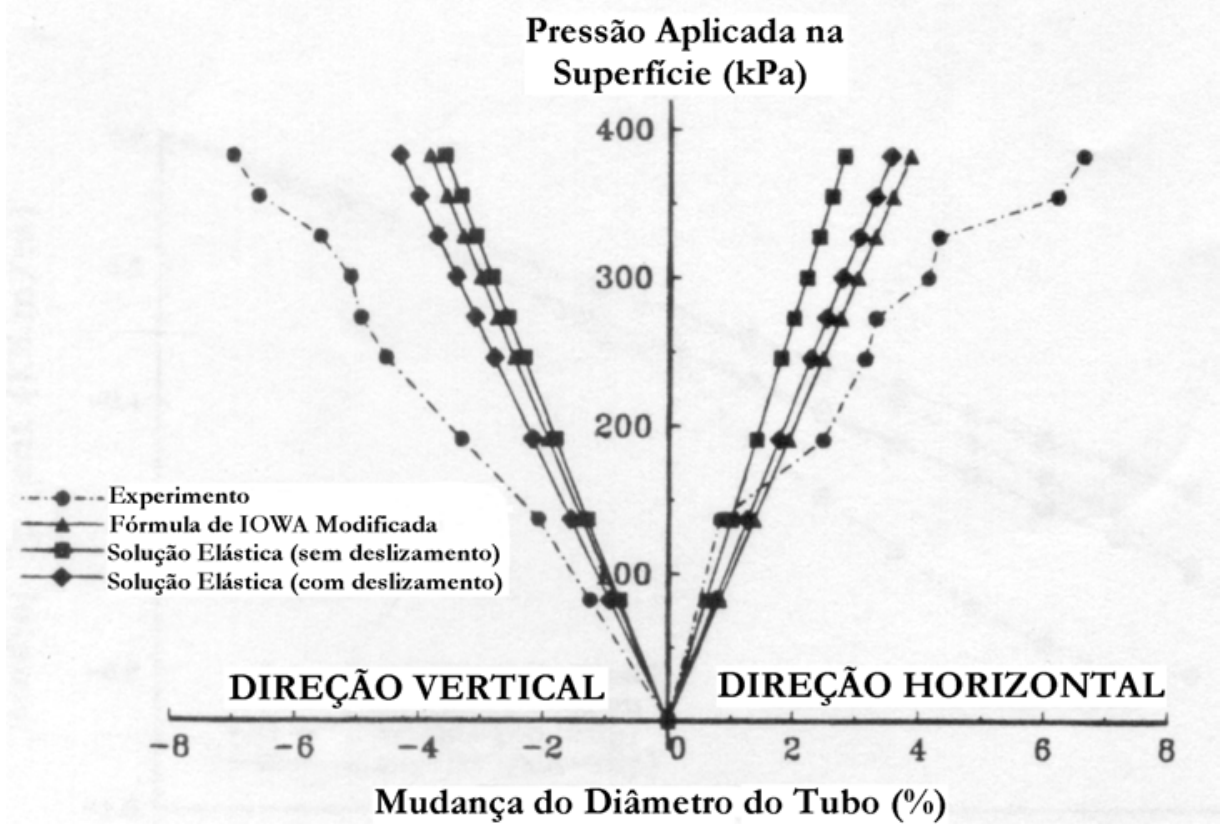

(b)

Figura 3.6 - Deflexões dos tubos de PVC-1 (a) e de PVC-2 (b) durante os testes de campo realizados por Sargand et al (1995) 
As condições de carregamento simuladas nesse estudo refletem, possivelmente, a pior condição de carregamento a que esses tubos possam ser expostos. Os testes de carga demonstraram que ambos poderiam suportar carregamento significativo. Sob a pressão aplicada, o PVC-1 continuou deformando sem mostrar qualquer prejuízo estrutural. Uma reversão de curvatura muito leve foi observada no topo (geratriz superior do tubo) com mudança no diâmetro vertical de 17\%. O PVC-2 deformou menos sob a mesma pressão. Porém, sua capacidade de carga estava limitada pela emenda. As deflexões calculadas através da fórmula de Iowa Modificada foram ligeiramente maiores do que as deflexões obtidas do pela solução elástica de Burns e Richard. Para os dois tubos, as deflexões medidas no experimento foram maiores do que os resultados de ambos os métodos analíticos - Figura 3.6. Este é um resultado alarmante, e conduz a colocar em dúvida os valores de E' que têm sido assumidos para os materiais de envolvimento. Os resultados mostram a importância de retronalisar com base em medidas reais os reais valores de E' para determinados materiais, dependendo do estado de compactação dos mesmos. Segundo Sargand et al (1995) as soluções elásticas são válidas para analisar tubos circulares flexíveis enterrados em solo homogêneo com altura de cobrimento acima da geratriz superior maior do que um diâmetro do tubo.

Moser (1996) realizou um experimento em verdadeira grandeza com tubos de polietileno de alta densidade na Utah State University. Os diâmetros testados foram 750 $\mathrm{mm}, 1900 \mathrm{~mm}$ e $2000 \mathrm{~mm}$. O objetivo do experimento foi determinar as características de desempenho estrutural em função da altura de cobrimento. Os parâmetros observados (variáveis dependentes) foram deflexão e qualquer evidência visual de dano. As variáveis independentes foram o tipo de solo, a densidade do solo (dependente da compactação) e a carga imposta pela altura de solo sobre o tubo (peso próprio).

O solo usado para envolver os tubos foi uma areia siltosa designada como Classe III pela ASTM D2321. Esse solo é classificado como SM de acordo com o Sistema Unificado de Classificação de Solos. Os testes foram executados de novembro de 1994 a outubro de 1995 em tubos Rib-Loc de polietileno de parede estruturada reforçada com perfis de aço. Os testes permitiram uma investigação dos limites de desempenho do tubo quando sujeitos a pressões externas de solo. Os tubos foram ensaiados na Utah 
State University nas mesmas instalações descritas no início deste sub-item. Alguns detalhes dos testes podem ser vistos na Tabela 3.2.

Tabela 3.2 - Características dos testes realizados por Moser (1996)

\begin{tabular}{|c|c|c|c|}
\hline Teste & $\begin{array}{l}\text { Diâmetro do Tubo } \\
(\mathrm{mm})\end{array}$ & $\begin{array}{c}\text { Grau de Compactação } \\
\text { (\% Proctor Normal) }\end{array}$ & Informação Adicional \\
\hline 1 & 750 & $87 \%$ & Classe 15 \\
\hline 2 & 750 & $85 \%$ & Classe 15 com junta \\
\hline 3 & 750 & $75 \%$ & Classe 15 \\
\hline 4 & 1900 & $87 \%$ & Classe 40 \\
\hline 5 & 2000 & $86 \%$ & Classe 40 com junta \\
\hline 6 & 2000 & $91 \%$ & Classe 40 \\
\hline
\end{tabular}

Os tubos enterrados em solos menos compactados claramente deformam mais do que os enterrados em solos mais densos porque solos menos densos são mais compressíveis. Para alcançar um elevado valor de E' o solo de envolvimento do tubo deve ser bem compactado. As variações no valor efetivo de E’ em função do grau de compactação para a areia siltosa usada no experimento é mostrada na Tabela 3.3.

Tabela 3.3 - Variação do valor de E’ em função do grau de compactação (Moser, 1996)

\begin{tabular}{cc}
\hline $\begin{array}{c}\text { Grau de Compactação } \\
(\% \text { Proctor Normal })\end{array}$ & E' Efetivo \\
\hline $75 \%$ & $1034 \mathrm{kN} / \mathrm{m}^{2}(150 \mathrm{psi})$ \\
\hline $85 \%$ & $6205 \mathrm{kN} / \mathrm{m}^{2}(900 \mathrm{psi})$ \\
\hline $90 \%$ & $27579 \mathrm{kN} / \mathrm{m}^{2}(4000 \mathrm{psi})$ \\
\hline
\end{tabular}

Fica claro que pequenas variações no grau de compactação podem causar grandes divergências no valor efetivo de E' (Moser, 1996). Isso é especialmente verdadeiro entre $85 \%$ e $95 \%$ de grau de compactação. Assim um tubo envolto por solo compactado a 85\% da Energia Normal (Proctor Normal) deformará duas vezes mais do que um tubo envolto por solo compactado a $87 \%$ de grau de compactação com relação à mesma energia (Moser, 1996). Dessa forma, pequenos erros na determinação da densidade do 
material de envolvimento podem levar a grandes discrepâncias ao comparar-se os valores obtidos em campo com os valores esperados (teóricos).

Moser (1996) recomenda ainda que o solo de envolvimento do tubo deve ser cuidadosamente compactado a um mínimo de $85 \%$ da densidade máxima obtida no ensaio de compactação normatizado de Energia Normal; acrescenta que os dados indicam que seria preferível atingir sempre um grau de compactação de $90 \%$.

Em 1998, Moser publicou os resultados de um outro experimento realizado nas mesmas instalações na Utah State University. Os testes foram conduzidos em tubos de polietileno de alta densidade (HDPE). Os tubos foram carregados até a ruptura. Esses tubos de HDPE são reforçados por tiras e enrolados helicoidalmente junto com um perfil de aço, para aumentar ainda mais a rigidez do tubo ${ }^{8}$. A tira de aço é muito mais rígida do que o plástivo, dessa forma, na deflexão vertical, a tira de aço absorve a maior parte da carga, provocando menores deslocamentos.

O objetivo do novo teste de Moser foi determinar o desempenho estrutural como função da altura de cobrimento. As variáveis dependentes e independentes e o solo foram os mesmos do experimento publicado em Moser (1996). As cargas são transformadas em valores equivalentes de sobrecarga de solo. A descrição e os resultados são apresentados na Tabela 3.4.

Claramente os tubos tem deflexão maior (sob a mesma carga) em solos com menor grau de compactação, porque solos não compactados ou pouco compactados são mais compressíveis. O solo deve ser granular e fortemente compactado se o tubo estiver a grandes profundidades ou sob ação de cargas de grande magnitude. Entretanto, entre $75 \%$ e $85 \%$ de grau de compactação (Energia Normal) o efeito da densidade não foi claro (Moser, 1998). Outros fatores devem ter influenciado de forma a dificultar uma análise mais simples comparativa.

\footnotetext{
${ }^{8}$ Produto semelhante ao produzido no Brasil pela Tigre Tubos e Conexões SA, designado no mercado por Rib Steel ${ }^{\mathrm{TM}}$.
} 
Moser (1998) ainda afirma que o comportamento do tubo é essencialmente controlado pela tira de aço que o envolve. A falência é muito mais pronunciada em tubos reforçados com a tira de aço do que no caso de tubos corrugados de aço ou HDPE, isto é, o colapso pode ocorrer sem um aumento da carga.

Tabela 3.4 - Resultados dos testes realizados por Moser (1998)

\begin{tabular}{ccccccc}
\cline { 3 - 6 } Teste & & \multicolumn{2}{c}{ Ruptura Local } & \multicolumn{2}{c}{ Ruptura Generalizada } \\
\hline & $\begin{array}{c}\text { Diâmetro } \\
(\mathbf{m m})\end{array}$ & $\begin{array}{c}\text { Grau de } \\
\text { Compactação } \\
\mathbf{( \% )}\end{array}$ & $\begin{array}{c}\text { Cobrimento } \\
(\mathbf{m})\end{array}$ & $\begin{array}{c}\text { Deflexão } \\
\mathbf{( \% )}\end{array}$ & $\begin{array}{c}\text { Cobrimento } \\
(\mathbf{m})\end{array}$ & $\begin{array}{c}\text { Deflexão } \\
\mathbf{( \% )}\end{array}$ \\
\hline H-1 & 1200 & 95 & 10,4 & 2,0 & 21,0 & 6,0 \\
\hline H-2 & 1200 & 75 & 6,7 & 6,5 & 10,4 & 9,0 \\
\hline H-3 & 1200 & 85 & 5,8 & 3,0 & 14,0 & 8,7 \\
\hline H-4 & 1200 & 85 & 10,4 & 5,5 & 15,8 & 9,8 \\
\hline H-5 & 1500 & 94 & 20,0 & 5,3 & 32,0 & 12,2 \\
\hline H-6 & 1500 & 85 & 16,0 & 6,5 & 22,0 & 11,7 \\
\hline A-1 & 1200 & 75 & 8,5 & 10,0 & 10,4 & 13,1 \\
\hline A-2 & 1200 & 85 & 8,8 & 5,0 & 18,0 & 11,5 \\
\hline A-3 & 1200 & 96,5 & 36,6 & 3,5 & 55,0 & 6,3 \\
\hline R-1 & 1900 & 87 & 12,0 & 2,8 & 18,0 & 6,7 \\
\hline R-2 & 2000 & 86 & 12,2 & 3,5 & 15,8 & 5,0 \\
\hline R-3 & 2000 & 91 & 12,2 & 0,9 & 15,9 & 1,4 \\
\hline$*$
\end{tabular}

${ }^{*}$ Espessura da parede dobrada

** Tubulação de polietileno com nervuras de aço

As análises de Zhan e Rajani (1997) mostraram que o uso de materiais de reaterro cimentados em lugar de materiais tradicionais como areia argilosa, resultam em significativa redução de tensão nos sistemas enterrados de PVC, sob a ação das cargas advindas do tráfego.

O material usado por Zhan e Rajani (1997) como material de envolvimento de valas é uma mistura de cimento portland, agregado, cinza volante e água. As propriedades do material podem ser variadas mudando-se a proporção de cada componente. Esse 
material tem muitas vantagens sobre os materiais tradicionais, como a fácil colocação e ausência de problemas de adensamento ou acomodação de material ao longo do tempo, com mínimo controle e nenhum esforço de compactação. Seu módulo de elasticidade típico varia de 80 a $250 \mathrm{MPa}$ (Lasater, $1990^{9}$ apud Zhan e Rajani, 1997). Tendo maior resistência e módulo de elasticidade do que reaterros arenosos, argilosos ou de solos locais.

Todos os experimentos realizados em verdadeira grandeza demonstram a grande importância na seleção do material de envolvimento e da compactação deste. Os resultados são altamente afetados por qualquer alteração no grau de compactação, podendo ser observadas rupturas do sistema caso não sejam atendidos os requisitos mínimos de projeto, conforme foi abordado no capítulo anterior.

${ }^{9}$ Lasater, D. V. (1990), Resilient Performance of controlled Density Fill in Utility Trench Excavations, MS thesis, Dept. of Civ. Engrg., Univ. of Washington, Seattle, Washington. 


\section{EXPERIMENTO}

A parte experimental desta pesquisa consiste em testar o desempenho do tubo plástico flexível de parede estruturada enterrado em vala cujo material de envolvimento consiste em areia, material tipicamente utilizado atualmente no Brasil em obras desta natureza. $\mathrm{O}$ objetivo final do estudo foi a análise do comportamento da areia tendo como base as medidas dos deslocamentos dos tubos frente a solicitações comumente verificadas nas condições brasileiras.

\subsection{Concepção e Descrição do Experimento}

O experimento consiste de quatro valas construídas na Área de Pesquisas e Testes de Pavimentos do Protocolo de Colaboração UFRGS/DAER-RS, em Porto Alegre, Rio Grande do Sul, para fins específicos de pesquisa, financiadas pelo convênio UFRGS/DAER-RS/Tigre. A elaboração da proposta de pesquisa, concepção dos testes, seleção dos materiais e análise de resultados ficarm a cargo da Escola Politécnica da USP em convênio de pesquisa com a Tigre Tubos e Conexões SA. Foi programada a abertura de duas valas rasas, com o tubo próximo a superfície, e duas profundas, onde a influência de cargas de roda são menos significativas. Para cada par de valas com a mesma profundidade, uma teve o material de envolvimento fortemente compactado, enquanto que na outra não houve compactação do material por meio de equipamentos, sendo este apenas depositado dentro da vala.

As valas têm largura de 1,4 metros e 5,0 metros de comprimento, aproximadamente. As profundidades programadas são totais de 1,1 metros e 2,3 metros, imediatamente acima 
da superfície do berço. Os testes foram executados com tubos de $800 \mathrm{~mm}$ de diâmetro, perfil tipo 140 BR2 (descrito no próximo sub-item).

Foram aplicados dois tipos distintos de carregamento, quais sejam:

- Carregamento dinâmico - passagens múltiplas de carga com aumento gradual de um valor mínimo de 3,0 tf a um valor máximo de 6,0 tf para simular o efeito de carga de roda transiente, com velocidade média de cerca de $18 \mathrm{~km} / \mathrm{h}$;

- Carregamento estático - aplicação de carga de mesma magnitude das aplicadas nos ensaios dinâmicos, porém de forma estática, sem movimento.

A magnitude dos carregamentos foi definida entre 3,0 tf e 6,0 tf , limites mínimo e máximo do sistema hidráulico de aplicação de carga do simulador de tráfego. As cargas foram aplicadas de maneira cíclica, em movimento, e após a repetição de algumas solicitações de mesma magnitude, estas sofreram determinados acréscimos até atingir 6 tf. Esta progressão de carregamentos foi realizada para determinação da resposta dos tubos e possibilitar o estudo da linearidade de comportamento tensão-deslocamento. Além disso, este estudo objetivou o conhecimento do comportamento dos tubos frente a carregamento transiente, de forma a proporcionar uma verificação de deflexões que podem ser impostas a estruturas de pavimentos assentes sobre sistemas desta natureza.

Da mesma forma, carregamentos foram aplicados de maneira estática, com duração de alguns minutos cada um, para conhecer o comportamento do tubo quanto à deformação permanente, simulando um acréscimo de carga estática ou de peso próprio.

As medidas realizadas durante o ensaio compreenderam o registro dos deslocamentos diametrais verticais do tubo por meio de equipamento de medida de deslocamento do tipo LVDT (Linear V ariable Differential Transformer).

As variáveis consideradas para análise do comportamento estrutural do sistema são: o tipo de material de envolvimento utilizado, o grau de compactação, a altura de material sobre o plano no qual está contida a geratriz superior do tubo, ou seja, a altura de cobrimento total e o tipo (estático ou dinâmico) e a magnitude do carregamento. A 
carga foi aplicada pelo Simulador de Tráfego instalado na Área de Pesquisas e Testes de Pavimentos UFRGS/DAER-RS.

Os ensaios nos sistemas tubos flexíveis de parede estruturada de PVC - areia proporcionaram:

- A obtenção de valores in situ de deslocamento diametral vertical dos tubos e sua correlação com a natureza e o estado dos materiais de envolvimento, bem como das cargas atuantes;

- A observação do desempenho dos equipamentos recomendados para a compactação do material de envolvimento;

- A observação da praticidade e eficiência dos métodos de controle de compactação do material de envolvimento.

\subsection{Materiais}

\subsubsection{Tubos plásticos flexíveis de parede estruturada em PVC}

São fabricados no Brasil pela Tigre Tubos e Conexões S.A. quatro tipos diferentes de perfis, denominados 112BR, 140BR1, 140BR2 e 168BR2. As características dos perfis relevantes para o projeto estrutural foram fornecidas pelo fabricante nacional e detentor da patente no Brasil, e estão apresentadas na Tabela 4.1 e Figuras 4.1 e 4.2.

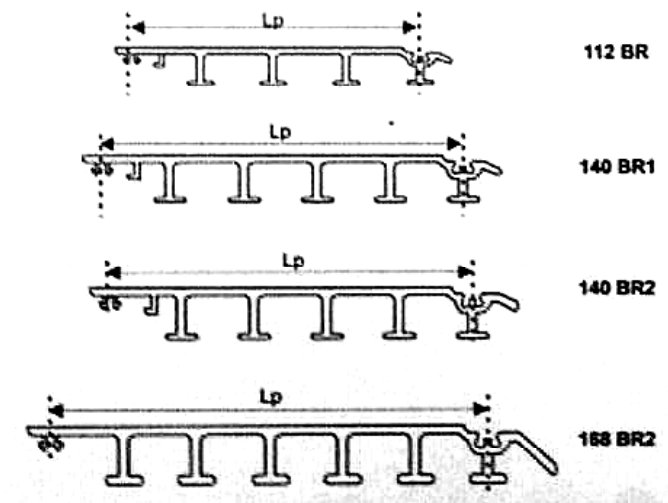

Figura 4.1 - Perfis fabricados no Brasi $1^{10}$

\footnotetext{
10 Tigre Rib Loc: A solução mais ágil e flexível em drenagem pluvial - manual. Tigre S.A. Tubos e Conexões, Joinvile-SC, sem data.
} 


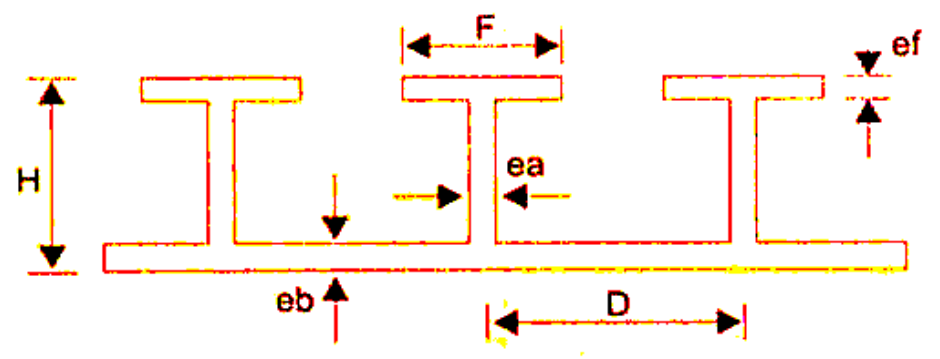

Figura 4.2 - Localização dos componentes do perfil (Tabela 1) ${ }^{9}$

Tabela 4.1 - Principais características geométricas e mecânicas dos perfis ${ }^{9}$

\begin{tabular}{|c|c|c|c|c|c|c|}
\hline \multicolumn{3}{|l|}{ Dimensão } & \multicolumn{4}{|c|}{ Perfil } \\
\hline Posição & & Unidade & 112BR1 & 140BR1 & 140BR2 & 168BR2 \\
\hline Diâmetros & & $\mathrm{mm}$ & 300,400 & 500,600 & 700,800 & 1500 a 3000 \\
\hline Largura do perifl & LP & $\mathrm{mm}$ & 112 & 140 & 140 & 168 \\
\hline Número de Tês & $\mathrm{n}$ & - & 4 & 5 & 5 & 6 \\
\hline Distância entre Tês & $\mathrm{D}$ & $\mathrm{mm}$ & 28 & 28 & 28 & 28 \\
\hline Altura total do perfil & $\mathrm{H}$ & $\mathrm{mm}$ & 13,5 & 17 & 19,5 & 23 \\
\hline Largura da flange & $\mathrm{F}$ & $\mathrm{mm}$ & 8 & 9 & 13 & 13 \\
\hline Espessura da flange & ef & $\mathrm{mm}$ & 1,3 & 1,5 & 2 & 3 \\
\hline Espessura da alma & ea & $\mathrm{mm}$ & 1,4 & 1,6 & 2,1 & 2,8 \\
\hline Espessura da base & $\mathrm{eb}$ & $\mathrm{mm}$ & 1,3 & 1,5 & 2 & 3 \\
\hline Área do perfil & A & $\mathrm{mm}$ & 301,2 & 460,4 & 678 & 1226 \\
\hline $\begin{array}{l}\text { Massa por comprimento de } \\
\text { perfil }\end{array}$ & MP & $\mathrm{g} / \mathrm{m}$ & 444 & 647 & 944 & 1651 \\
\hline Massa por área de perfil & $\mathrm{mp}$ & $\mathrm{kg} / \mathrm{m}$ & 3,96 & 4,62 & 6,74 & 9,83 \\
\hline
\end{tabular}

Foi escolhido um valor mínimo de rigidez anular de $700 \mathrm{~Pa}$ visando principalmente garantir a segurança no manuseio, transporte, assentamento, instalação e compactação do material de envolvimento. Em LTP-PTR-EPUSP/Tigre (1998b) foi realçada a importância do solo de envolvimento como sendo o componente principal para o desempenho mecânico desse tipo de sistema. Assim sendo, poder-se-ia trabalhar com tubos de menor rigidez anular, se não fosse a questão da técnica construtiva. 
A Figura 4.3, apresentada originalmente em LTP-PTR-EPUSP/Tigre (1998b), ilustra a menor importância da rigidez anular de um tubo plástico com parede estruturada no desempenho estrutural do sistema solo-tubo. São apresentadas curvas de deformação diametral hipotéticas em função da carga permanente devida ao peso de solo sobre o tubo, para um tubo de rigidez anular de $1000 \mathrm{~Pa}$ envolto por um solo de módulo de reação E' de 7,0 $\mathrm{MPa}$ ou um outro de 1,4 $\mathrm{MPa}$. Comparativamente, mostra-se a curva hipotética correspondente a um tubo de rigidez anular nula, representando a situação em que não há contribuição da rigidez do tubo para o sistema estrutural solo-tubo.

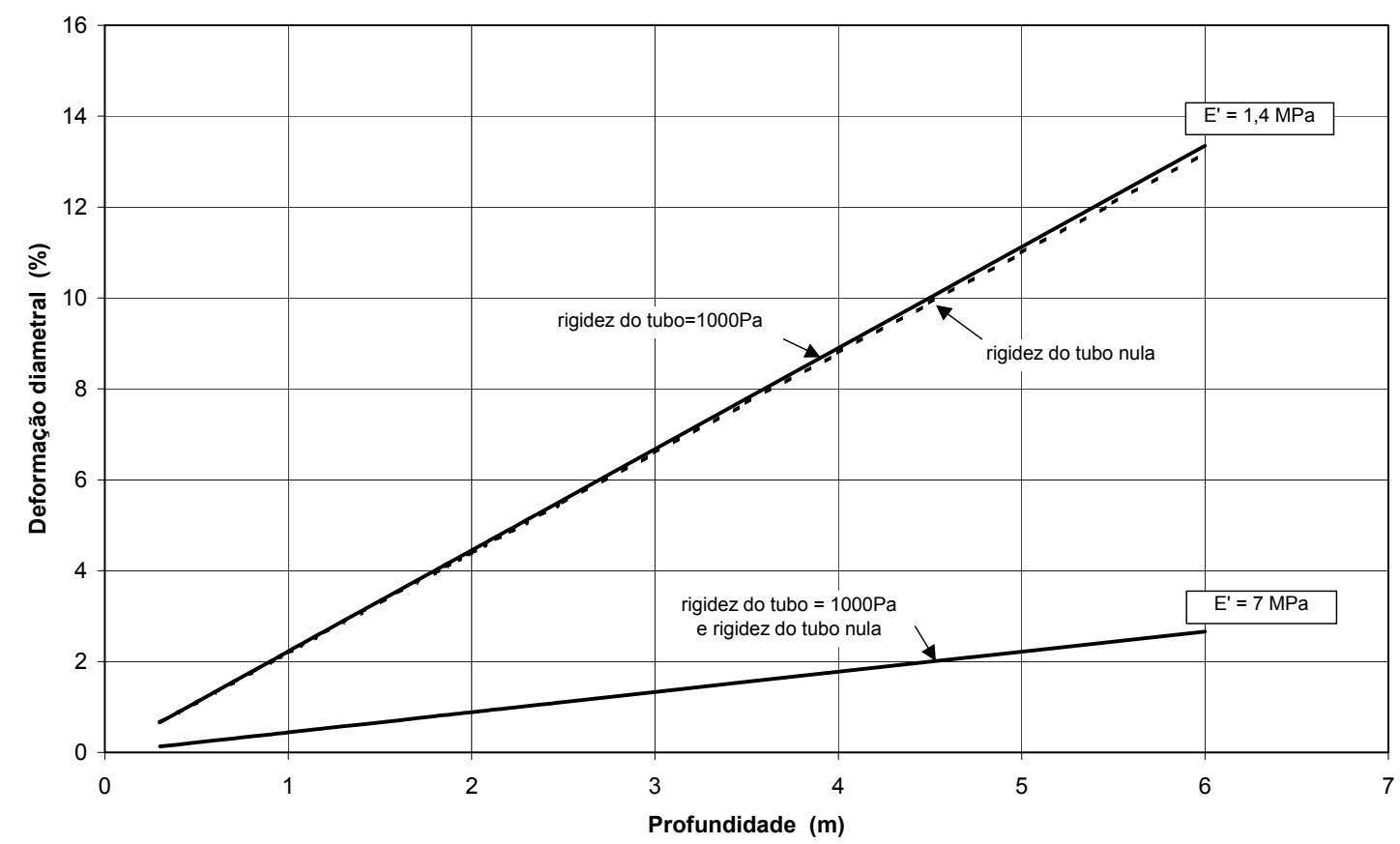

Figura 4.3 - Deformação diametral em função da carga permanente para RA=1000 Pa e RA nula (LTP-PTR-EPUSP/Tigre, 1998b)

\subsubsection{Materiais de Envolvimento}

O material utilizado para envolver os tubos flexíveis nas valas experimentais foi um material granular, fortemente recomendado em países que empregam a técnica dos tubos plásticos de parede estruturada. Trata-se de uma areia mal graduada, procedente do Rio Guaíba. 
Como a areia é um material que se pode obter com relativa facilidade em quase todo o país, optou-se então por realizar o estudo com esse material. Além disso, pretende-se testar até que ponto a graduação desse material influencia no desempenho do sistema solo-tubo. É de conhecimento geral que materiais granulares dependem basicamente do confinamento a que estão submetidos para determinar a sua resistência, assim como do grau de compactação, da graduação, da forma do grão, da textura superficial, de sua resistência, entre outros aspectos.

\subsection{Métodos}

\subsubsection{Métodos de seleção de materiais}

Preferencialmente, devem ser escolhidos materiais granulares, de graduação bem distribuída, com grãos de forma cúbica, resistentes, de textura áspera, com poucos finos (silte e argila) ou nenhuma fração desta natureza. Este critério é tradicionalmente aceito em países em que esta técnica vem sendo empregada.

Inicialmente, objetivava-se comparar o desempenho mecânico dos sistemas solo-tubo com materiais de envolvimento granulares com casos em que se empregasse solos locais lateríticos. No entanto, por atrasos em obras, não foi possível executar a segunda parte do projeto para fins de comparação. No entanto, o ineditismo do assunto no Brasil e a importância do estabelecimento de valores de módulo de reação E’ em sistemas com tubos brasileiros e areias tipicamente encontradas em regiões lacustres e marítimas, são suficientemente valiosos para a tecnologia nacional e para uma pesquisa de uma dissertação de mestrado.

\subsubsection{Métodos de compactação}

O solo pode ser compactado de basicamente de duas formas:

- Com o auxílio de soquete manual; ou

- Com o auxílio de um compactador mecânico de pequeno porte, como sapo mecânico ou placa vibratória. 
Vale lembrar que a compactação, principalmente do material de envolvimento, é determinante para o bom desempenho estrutural do sistema solo-tubo. É importante também que a compactação seja uniforme dos lados do tubo, para não permitir deformações diferenciais ao longo do mesmo.

No experimento na área de testes da UFGRS/DAER-RS foi utilizado um compactador tipo sapo mecânico - Figura 4.4. Tentou-se utilizar o soquete manual, mas este não forneceu a energia necessária para a compactação da areia.

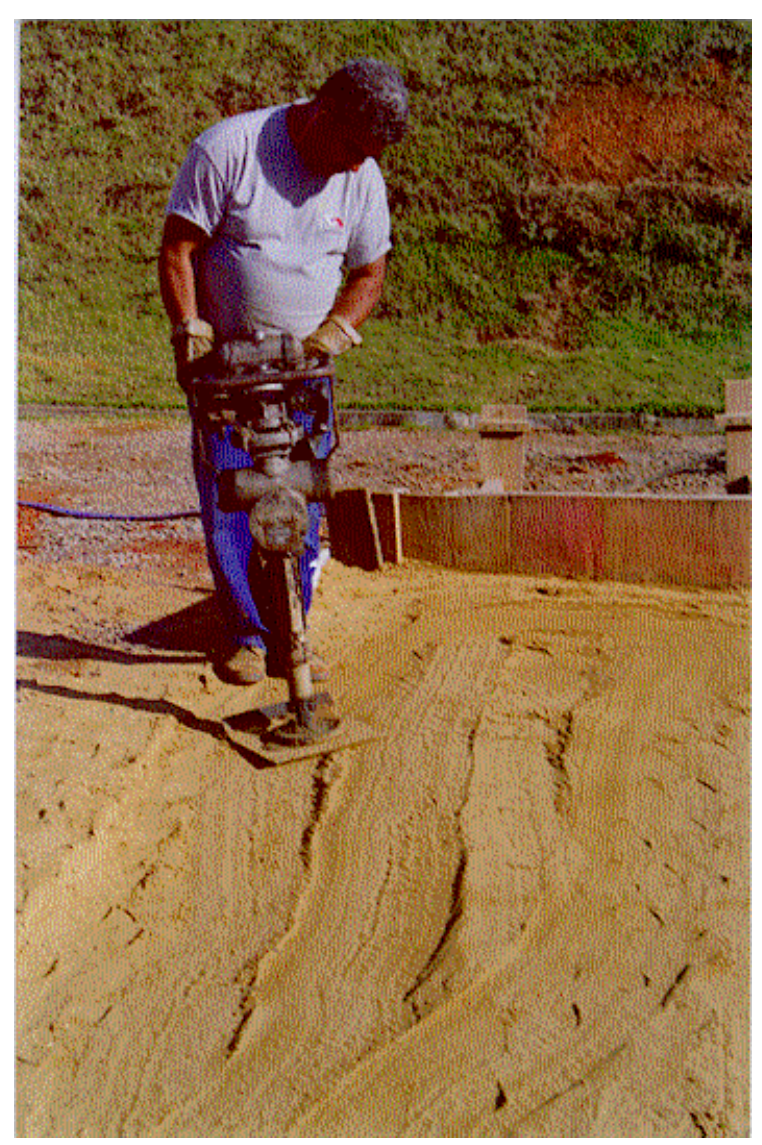

Figura 4.4-Compactador utilizado na área de testes

\subsubsection{Métodos de controle de compactação}

O controle de compactação foi realizado mediante o uso de três equipamentos diferentes: DCP, UFV-II (ambos constituem-se cones de penetração dinâmica) e equipamento de impacto Clegg, que trabalha medindo o requipe de um martelo que cai 
sobre a superfície de uma altura pré-definida. Paralelamente, foram utilizados outros recursos após todos os ensaios para verificação de densidade e grau de compactação. $\mathrm{O}$ objetivo foi de determinar o método de controle de compactação mais adequado para cada tipo de material.

Foi executada uma camada de berço de $20 \mathrm{~cm}$, antes da colocação do tubo, para todas as valas com a areia selecionada para material de envolvimento. Em seguida, nas valas em que o material de envolvimento foi compactado, procedeu-se à colocação do tubo na vala e à compactação de camadas de altura final de aproximadamente $20 \mathrm{~cm}$.

A primeira série de ensaios para o controle da compactação foi executada a partir da segunda camada assentada, sendo que foram utilizados apenas os cones de penetração dinâmica. O controle compactação foi conduzido de maneira semelhante nas camadas seguintes. O Equipamento de Impacto Clegg foi utilizado apenas na última camada.

Na Figura 4.5 é mostrada, de maneira esquemática, a localização das valas-teste e dos pontos em que foi executado o controle de compactação. Os pontos indicados por F1, F2 e F3 correspondem aos pontos em foi feito o ensaio de penetração com Penetrômetro Dinâmico de Cone, no solo de fundação da vala, antes de colocar o material de envolvimento. Os pontos indicados por A1, A2, A3, A4, A5 e A6 são os pontos em que foi realizado o controle de compactação ao longo do preenchimento da vala.

Os pontos A2 e A5 estão localizados na parte central da vala, considerando seu comprimento, mas não atingem o tubo, pois estão na lateral deste, entre o tubo e a parede da vala. Os demais pontos (A1, A3, A4 e A6) distam $80 \mathrm{~cm}$ dos pontos centrais, no mesmo alinhamento. 


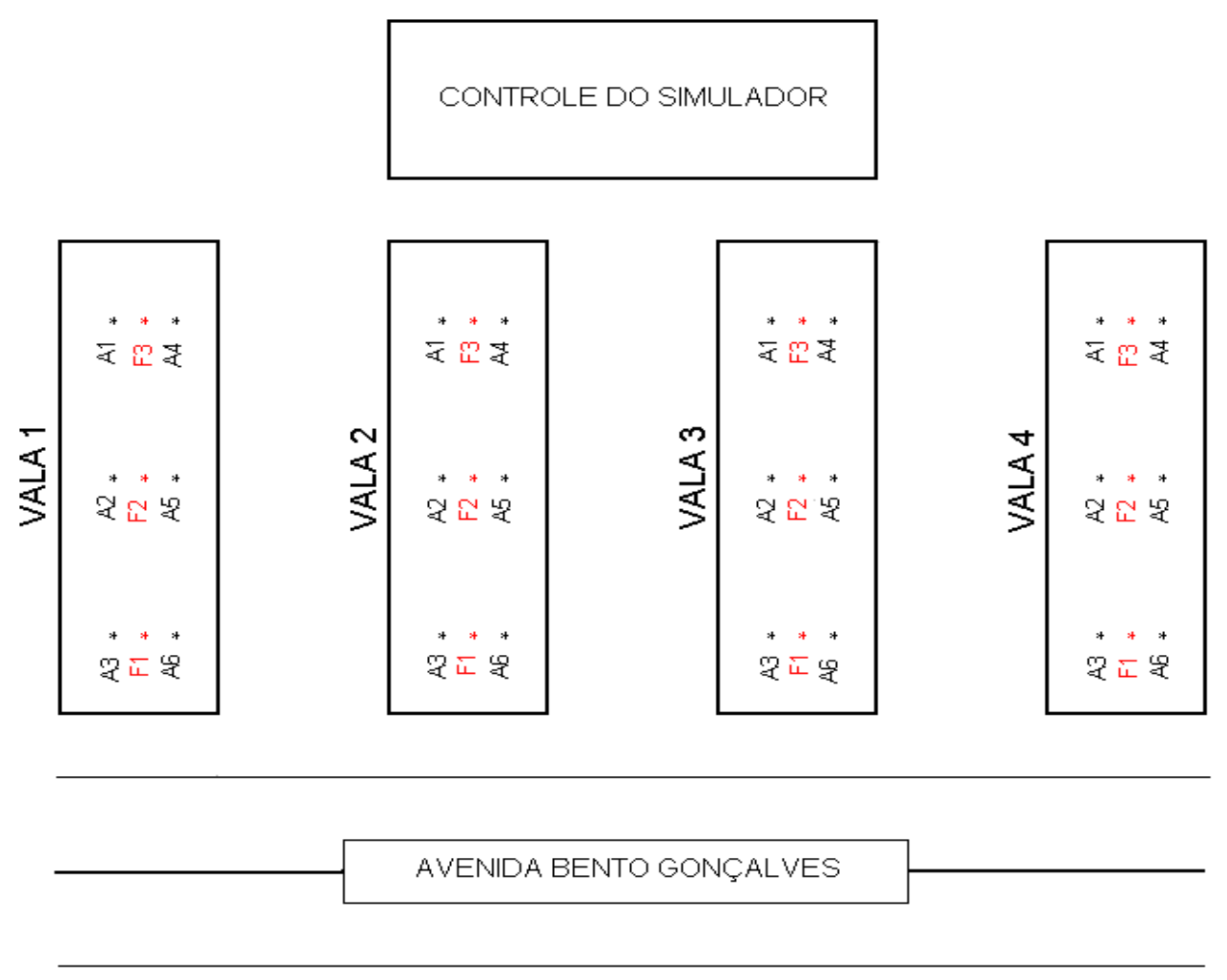

Figura 4.5 - Localização esquemática das valas e dos pontos de controle de compactação

\section{Penetrômetro Dinâmico de Cone}

O Penetrômetro Dinâmico de Cone (Dynamic Cone Penetrometer - DCP, Kleyn, 1975) é um equipamento muito estudado e utilizado por vários países como África do Sul, Israel, Argentina, Austrália e Estados Unidos, para caracterizar a capacidade de suporte do solo em seu estado natural ou em camadas compactadas. Apresenta como vantagens o fato de ser um ensaio rápido, fácil e de baixo custo, além de ser não destrutivo.

Nos países aonde o DCP vem sendo utilizado existem várias correlações de calibração entre o DCP e outros parâmetros do solo, tradicionalmente medidos. Para que se possa utilizar esse equipamento de forma eficaz no Brasil, é necessário que se estabeleçam correlações apropriadas para os solos brasileiros, que possuem características bastante peculiares. No Brasil, o DCP foi e vem sendo utilizado principalmente em pesquisa, destacando-se trabalhos como a pesquisa realizada pelo IPAI para o DER-SP (1977) e o 
trabalho recente de Trichês e Cardoso (1999). A Figura 4.6 traz um desenho esquemático do DCP.

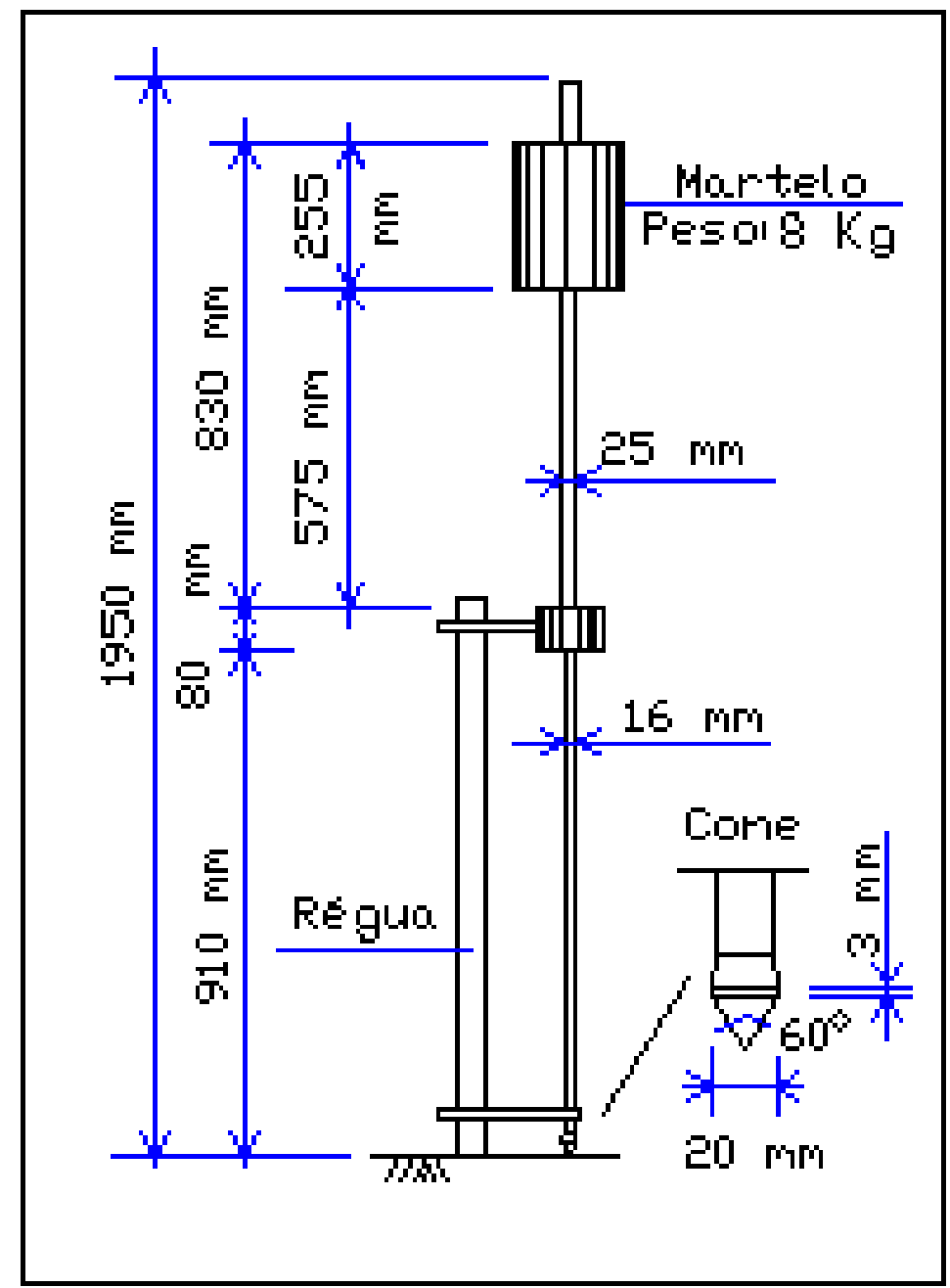

Figura 4.6 - Penetrômetro Dinâmico de Cone (cedido por Trichês e Cardoso)

Esse equipamento permite realizar ensaios de penetração dinâmica em estruturas de pavimentos cujas camadas são principalmente de materiais granulares ou solos. Em linhas gerais, o equipamento é formado por uma barra de aço de $16 \mathrm{~mm}$ de diâmetro, a qual possui um cone de aço com $20 \mathrm{~mm}$ de diâmetro de base e ângulo de $60^{\circ}$ fixado na ponta. O conjunto penetra no solo pelo impacto de um martelo de aço de $8 \mathrm{~kg}$, que cai de uma altura de $575 \mathrm{~mm}$, que desliza por uma barra de aço de $25 \mathrm{~mm}$ de diâmetro.

O DCP é recomendado para solos arenosos, tendo como provável limite de utilização a areia grossa; solos finos com uma pequena quantidade de grãos maiores não 
impossibilitam sua utilização, sendo que os resultados discrepantes devem ser desconsiderados (Röhm, 1984).

O ensaio de penetração dinâmica pode ser realizado de forma expedita, por duas pessoas. Durante o ensaio mede-se a penetração do conjunto no solo com o auxílio de uma régua acoplada ao equipamento e relaciona-se essa medida com o número de golpes necessário para tal deslocamento.

O índice de penetração é obtido através da representação do número de golpes acumulado contra a profundidade penetrada pelo equipamento. A tangente das retas representa o índice de penetração. $O$ índice de penetração é obtido por meio da razão entre a profundidade e o número de golpes necessários para penetrar a respectiva profundidade, e pode ser expresso por:

$$
D C P=\frac{\text { profundidade }}{\text { número } \cdot \text { de } \cdot \text { golpes }}
$$

Onde:

DCP representa o Índice de Penetração.

Pode-se relacionar o índice de penetração com o CBR, sendo que existem várias correlações desse tipo no mundo. Algumas delas serão apresentadas a seguir. Deve-se salientar, entretanto, que muitos dos autores não fazem referência às características do equipamento utilizado (abertura do cone), às condições dos ensaios ou às peculiaridades dos materiais empregados, o que dificulta o uso dessas correlações.

Oliveira (1998) realizou ensaios com o DCP (abertura do cone $-60^{\circ}$ ) em corpos de prova preparados para o ensaio de CBR, sem imersão e com imersão de quatro dias, em cinco teores de umidade de moldagem diferentes. As amostras de solo, num total de dez, foram retiradas de diferentes áreas da região do Vale do Paraíba, sendo representativas dos solos transicionais utilizados no estudo. A relação (4.2) foi obtida pela combinação dos dados obtidos nos corpos de prova imersos e sem imersão.

$$
\log C B R=2,490-1,057 \times \log D C P
$$


Livneh (1989) apresenta uma correlação (4.3) e menciona a comparação com outras correlações existentes na literatura técnica que validaria a correlação estabelecida (Livneh, $1987 \mathrm{a}^{11}$ e $1987 \mathrm{~b}^{12}$ apud Livneh, 1989). O cone usado nos testes tem ângulo de abertura de $30^{\circ}$.

$$
\log C B R=2,20-0,71 \times(\log D C P)^{1,5}
$$

$\mathrm{Na}$ Indonésia, Harison (1987 $7^{13}$ apud Livneh, 1989) estabeleceu uma correlação (4.4) obtida a partir de ensaios de campo e laboratório para solos argilosos, areia e pedrisco graduados, com o emprego de cone com ângulo de abertura da ponteira de $60^{\circ}$.

$$
\log C B R=2,81-1,32 \times \log D C P
$$

Kleyn (1982 $2^{14}$ apud Trichês e Cardoso 1999) realizou ensaios de penetração dinâmica em rodovias da África do Sul e chegou a seguinte correlação (4.5):

$$
\log C B R=2,60-1,26 \times \log D C P
$$

Angelone et. al (1991 ${ }^{15}$ apud Trichês e Cardoso 1999) na Argentina, chegaram a correlação (4.6):

$$
C B R=450(D C P)^{-1,05}
$$

\footnotetext{
${ }^{11}$ Livneh, M., Ishai, I. (1987a), "Pavement and Material Evaluation by a Dynamic Cone Penetrometer", Proc. $6^{\text {th }}$ Int. Conf. On the Structural Design of Asphalt Pavements, Ann-Arbor.

1212 Livneh, M., Ishai, I. (1987b), “The Relationship between In-Situ CBR Values for Subgrades and Pavements in Arid Zones”. Proc. $8^{\text {th }}$ Asian Conf. On Soil Mechanics and Foundations Engineering, Kyoto.

${ }^{13}$ Harison, J. A. (1987), Correlation between California Bearing Ratio and Dinamic Cone Penetrometer Strength Measurement of Soils, Proc. Instn. Civ. Engs. Part 2, 83, Technical Note No 463.

${ }^{14}$ Kleyn, E. and Savage, P. E. (1982) The Application of the Pavement DCP to Determine the Bearing Properties and Performance of Road Pavement, Proc. Int. Symp. on Bearing Capacity of Roads and Airfields, Trondheim.

${ }_{15}$ Angelone, S., Tosticarelli, J. E Martinez, F. (1991), El Penetrometro Dinamico de Cono, su Aplication al Control y Diseño Estructural de Pavimentos, $6^{\circ}$ Congresso Ibero-Latino Americano del Asfalto.
} 
Heyn (1986) realizou seus estudos em rodovias no estado do Paraná e obteve a correlação (4.7) a seguir.

$$
C B R=443,45(D C P)^{-1,30}
$$

Nogami e Villibor (1998) publicaram uma correlação (4.8) do índice de Penetração com o Mini-CBR. A correlação é tanto conservadora, segundo os próprios autores. O cone usado tem ângulo de $30^{\circ}$ e os solos ensaiados são de comportamento laterítico.

$$
\text { Mini }-C B R=360(D C P)^{-1,179}
$$

\section{Penetrômetro Dinâmico Leve UFV-II}

O Penetrômetro Dinâmico Leve, conhecido também como mini-cone, é um equipamento que funciona de maneira semelhante ao Penetrômetro Dinâmico de Cone, só que com dimensões reduzidas. O equipamento foi desenvolvido na Universidade Federal de Viçosa, Minas Gerais, como parte integrante do trabalho de Röhm (1984).

Devido à elevada potência do Penetrômetro Dinâmico de Cone UFV-I, desenvolvido inicialmente por Röhm com base no original mostrado no item anterior, e conseqüente baixa sensibilidade e seletividade. Percebeu-se a necessidade de desenvolver um outro penetrômetro dinâmico, mais leve, denominado UFV-II. A Figura 4.7 traz um desenho esquemático do Penetrômetro Dinâmico Leve UFV-II. 


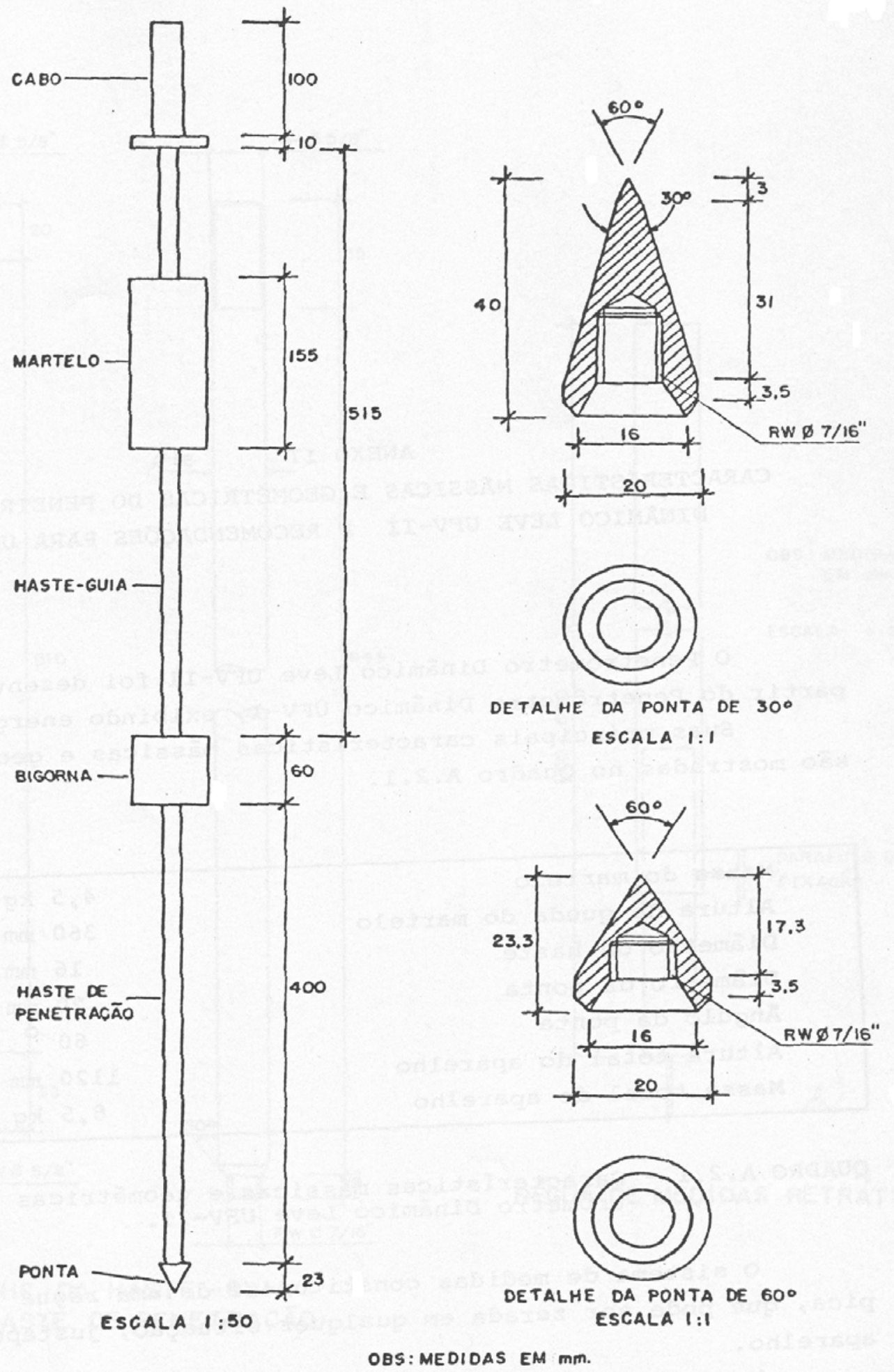

Figura 4.7 - Vista geral do Penetrômetro Dinâmico Leve UFV-II e detalhes das pontas de $30^{\circ}$ e $60^{\circ}$ (Röhm, 1984) 
Ainda segundo Röhm (1984) o Penetrômetro Dinâmico de Cone é capaz de atender às necessidades de simplificação de serviços de controle e reprodutibilidade de ensaios. Tanto o UFV-I como o UFV-II, ambos desenvolvidos na Universidade Federal de Viçosa, são concebidos com a finalidade de efetuar o controle de compactação; no entanto, Röhm recomenda o Penetrômetro Leve UFV-II para os casos específicos de pavimentos de solo arenoso fino.

Röhm (1984) desenvolveu correlações do UFV-II com o CBR e com o Mini-CBR, ensaio comumente aplicado em solos finos, para os quais o cone foi desenvolvido. As correlações deste estudo estão expressas em (4.9) e (4.10).

$$
\begin{gathered}
\log C B R=2,3523( \pm 0,0485)-1,2769( \pm 0,0206) \times \log U F V-I I \\
\operatorname{LogMini}-C B R=2,4738( \pm 0,0865)-2,1662( \pm 0,0367) \times \log U F V-I I
\end{gathered}
$$

Onde:

UFV-II representa o índice de penetração .

\section{Equipamento de Impacto Clegg}

O Equipamento de Impacto Clegg é utilizado para verificar se as camadas compactadas estão dentro das especificações de projeto e para verificar a uniformidade da compactação em grandes áreas. $\mathrm{O}$ equipamento funciona com um acelerômetro na extremidade de um soquete que cai de uma altura padronizada, e que registra em um visor digital um número que se relaciona com a rigidez da camada; este equipamento avalia a "intensidade" no repique ao impacto.

O equipamento, mostrado de maneira esquemática na Figura 4.8, é composto basicamente de três partes:

- Soquete de impacto munido com sensor de tensão;

- Tubo-guia com base alargada e alça para transporte manual;

- Display digital para registro da força de repique medida. 


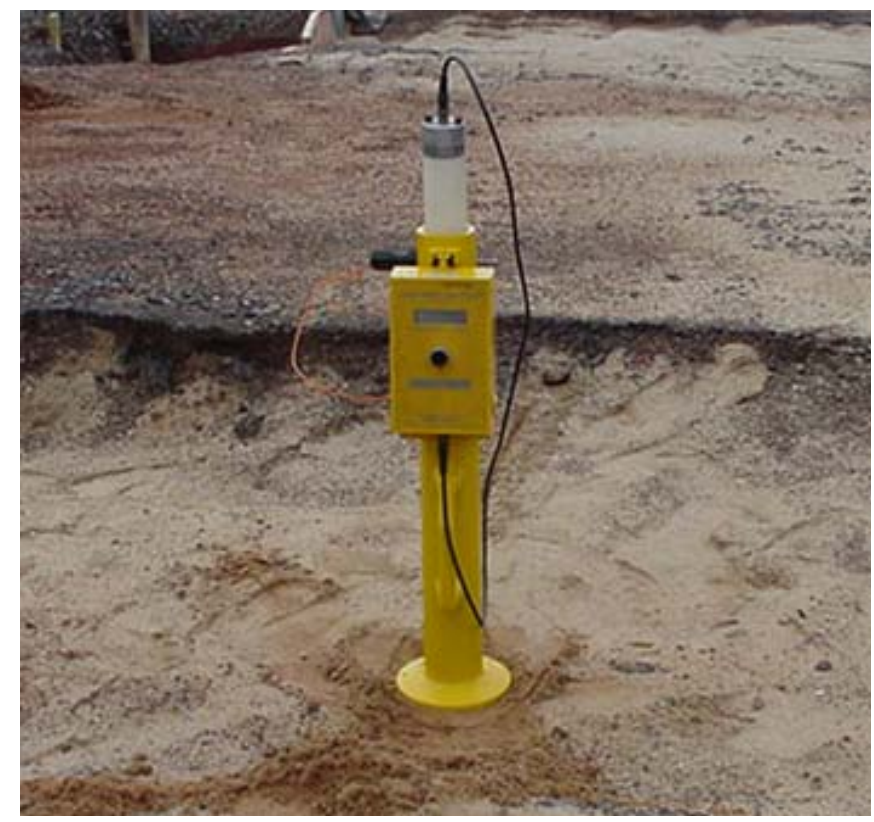

Figura 4.8 - Equipamento de Impacto Clegg (Trevor Deakin Consultants Ltd ${ }^{16}$ )

Quando o soquete cai livremente de uma altura fixa, dentro do tubo-guia, o cilindro bate na superfície, desacelerando a uma taxa determinada pela capacidade de suporte ou pela rigidez do material que sofreu o impacto. Dentro do soquete de impacto, há um acelerômetro que é conectado ao registrador que marca a desaceleração do soquete no impacto. São aplicados golpes consecutivos, todos exatamente no mesmo lugar; a leitura obtida no quarto golpe é o valor de impacto (IV - Impact Value) do material que está sendo testado. O display possui um visor de cristal líquido onde se pode ler o valor de impacto. Quanto maior o grau de compactação da camada, ou seja, quanto mais rígido e resistente for o material, maior será o valor de impacto.

O valor de impacto obtido no quarto golpe pode ser convertido num valor de "CBR equivalente", através da seguinte expressão (4.11) (Clegg, 1983):

$$
C B R_{\text {equivalente }}=0,07\left(I V_{4}\right)^{2}
$$

Os dados foram obtidos de ensaios realizados em um grande número de materiais por uma quantidade de diferentes pesquisadores. Note-se que os valores determinados em campo se correlacionam com o CBR não imerso e sem sobrecarga, simulando as mesmas condições de teste em pista (Clegg, 1983).

\footnotetext{
16 Trevor Deakin Consultants Ltd (1990), Clegg Impact soil Tester. Trowbrigde, Wiltshire, Engeland.
} 
Se qualquer uma das leituras for menor do que o valor de impacto do golpe anterior menos dois ou se a quinta leitura for, além da condição anterior, maior do que a quarta leitura mais dois é um sinal de que as medidas não são confiáveis e o local do teste deve ser desconsiderado. O teste deve ser repetido cerca de $300 \mathrm{~mm}$ afastados do local onde foi realizado o teste anterior. Esses limites são mostrados de maneira mais clara na tabela 4.2.

Tabela 4.2 - Limites válidos para as leituras de valor de impacto

\begin{tabular}{cccc}
\hline \multirow{2}{*}{ Golpe } & Valor de Impacto & \multicolumn{3}{c}{ Limite } \\
\cline { 3 - 4 } & & Inferior & Superior \\
\hline 1 & $\mathrm{~A}$ & - & - \\
\hline 2 & $\mathrm{~B}$ & $\mathrm{~A}-2$ & - \\
\hline 3 & $\mathrm{C}$ & $\mathrm{B}-2$ & - \\
\hline 4 (Valor Crítico) & $\mathrm{D}$ & $\mathrm{C}-2$ & - \\
\hline 5 & $\mathrm{E}$ & $\mathrm{D}-2$ & $\mathrm{D}+2$ \\
\hline
\end{tabular}

Normalmente, para bons materiais, adequadamente compactados, obtêm-se leituras consistentes. Leituras inconsistentes geralmente indicam problemas e requerem investigação mais apurada.

\subsection{Construção e Instrumentação das Valas-Teste}

A Figura 4.9 mostra uma vista geral das quatro valas abertas na Área de pesquisas e Testes de pavimentos UFRGS/DAER-RS. 


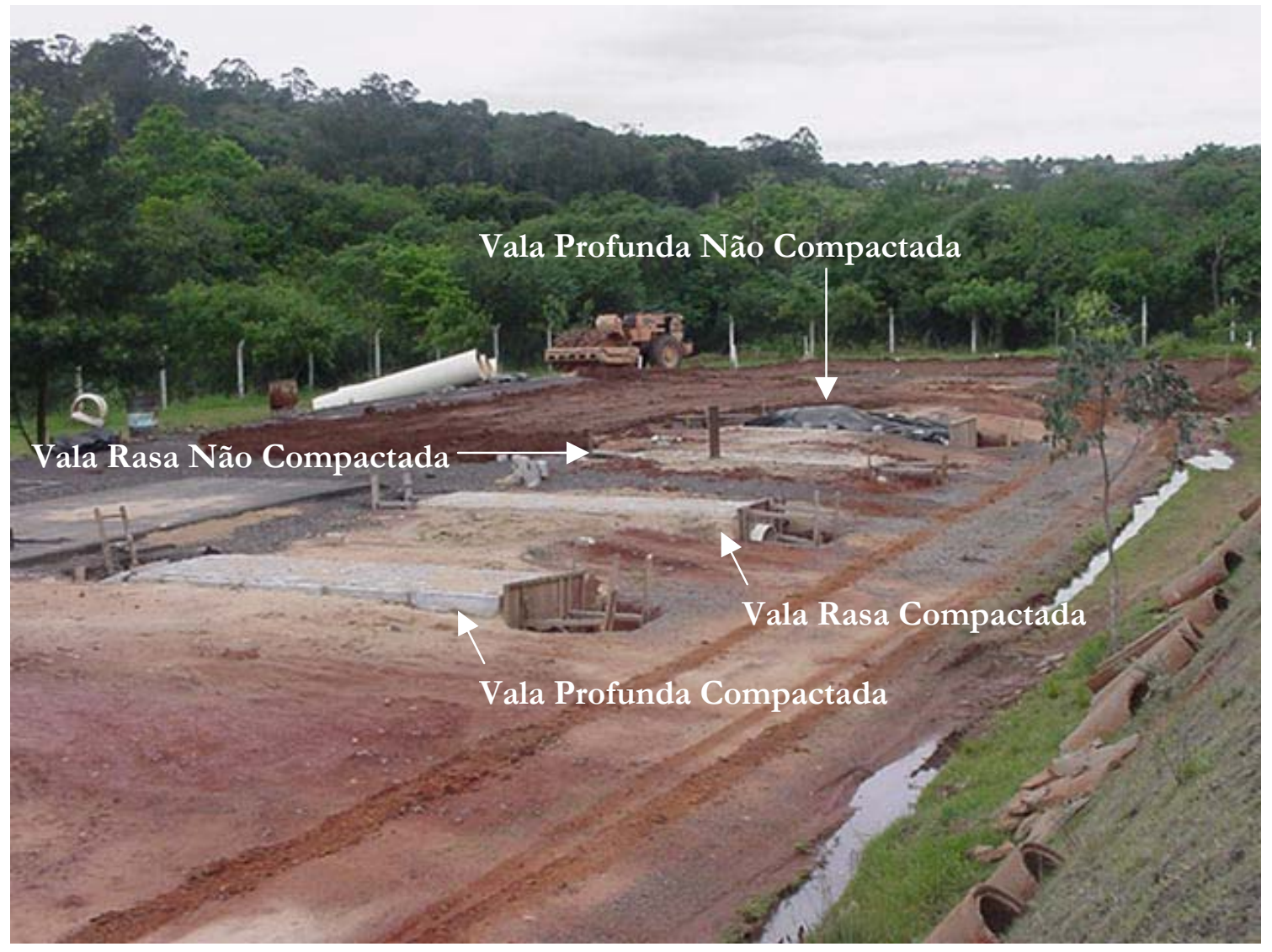

Figura 4.9 - Vista geral das valas-teste

\subsubsection{Processo de Instalação do Tubo na Vala e Compactação dos Materiais de Envolvimento e Reaterro}

Com o objetivo de garantir as especificações e recomendações de projeto estrutural são apresentadas a seguir algumas observações sobre a instalação de tubos plásticos com parede estruturada dentro da vala.

A Figura 4.10 apresenta esquematicamente, de forma simplificada, as etapas do processo de instalação do tubo na vala, com comentários visando o bom desempenho estrutural do sistema solo-tubo (LTP-PTR-EPUSP/Tigre, 1998b). 


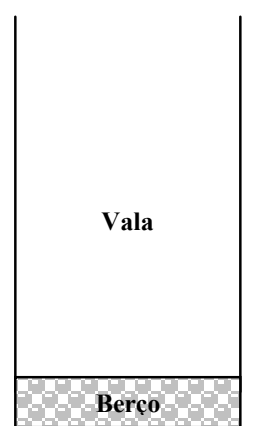

Tubo
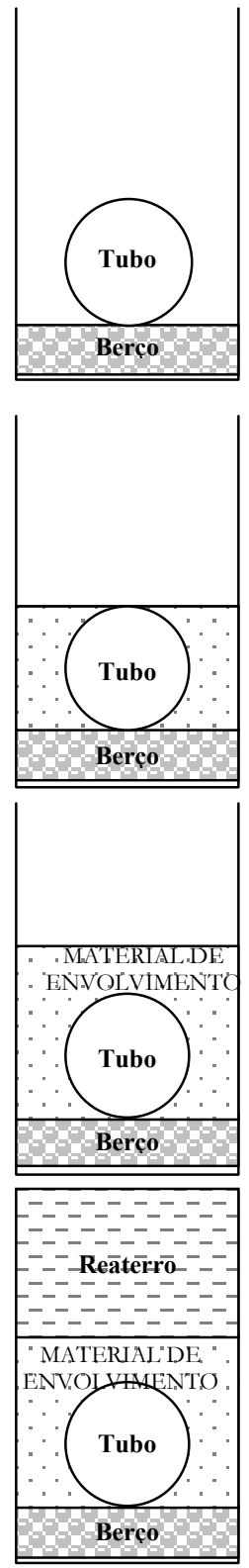

O berço deve ser constituído de material essencialmente granular, compactado com grau de compactação de no mínimo $90 \%$ da Energia Normal, resultando em camada de espessura entre 0,10 e 0,20 metros.
O assentamento do tubo deve ser centralizado dentro da vala. Todo o processo de instalação, incluindo juntas e emendas, deve ser realizado conforme as especificações do fabricante.

O material de envolvimento, essencial para o bom desempenho do sistema solo-tubo, deve ser cuidadosamente compactado. A compactação deve ser realizada em camadas de 0,10 a 0,20 metro de espessura, proporcionando uma leve deformação diametral vertical negativa (deslocamento para cima), de modo a reduzir as deformações diametrais verticais positivas de serviço.

Sobre o tubo é necessário haver uma camada de material de envolvimento de espessura entre 0,10 e 0,20 metros. Toda a compactação até este momento só pode ser feita com soquete manual ou sapo mecânico.

A camada de reaterro sobre o material de envolvimento deve ser compactada com soquete manual ou sapo mecânico até que haja pelo menos 0,30 metro de cobrimento sobre o tubo. A partir dessa espessura, pode-se utilizar outro tipo de equipamento de compactação.

Figura 4.10 - Algumas observações sobre a instalação do tubo na vala pertinentes ao projeto estrutural (LTP-PTR-EPUSP/Tigre, 1998) 
Dificuldades foram encontradas no que concerne à compactação e ao controle da compactação do material de envolvimento dos tubos nas valas. Durante a compactação é extremamente difícil manter o tubo na cota estabelecida em projeto. Ao compactar-se o material de envolvimento nas laterais, o tubo é "empurrado" para cima. Decorre que a altura de cobrimento nestes casos resulta menor que aquela projetada e, em conseqüência, podem ocorrer deformações indesejadas.

Além disso, chuvas intensas durante o período de construção das valas-teste ocasionaram a "fuga" da areia que envolvia o tubo por entre as pequenas frestas existentes entre os painéis de contenção nas extremidades (Figura 4.11 (a) e (b)) e as paredes das valas e entre os painéis de contenção e os tubos. Criaram-se bolsões vazios, que formam zonas frágeis. Por este motivo o grau de compactação da areia passou ser heterogêneo e prejudicou o desempenho estrutural do sistema solo-tubo. Para amenizar esse dano, as valas foram cobertas para evitar o fluxo de água da chuva por entre a camada de areia compactada. Entretanto, essa cobertura ocorreu somente depois que o problema foi constatado, o que acarretou certos danos ao primeiro teste.

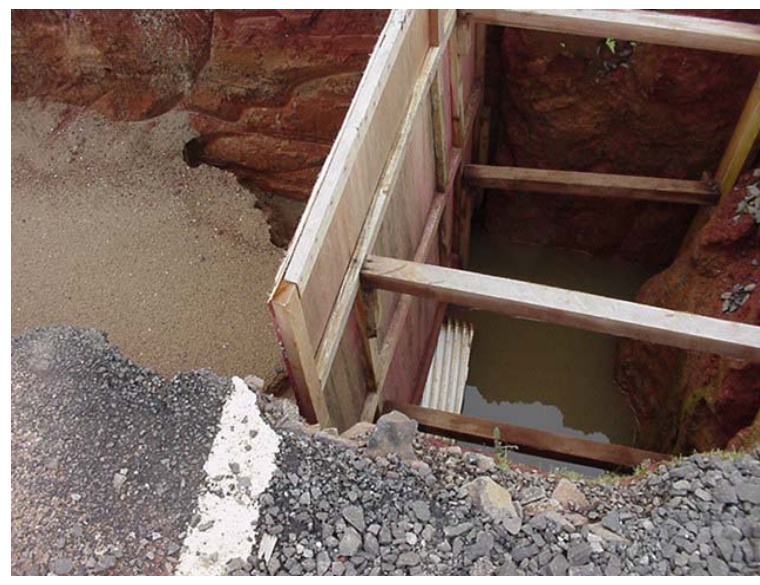

(a)

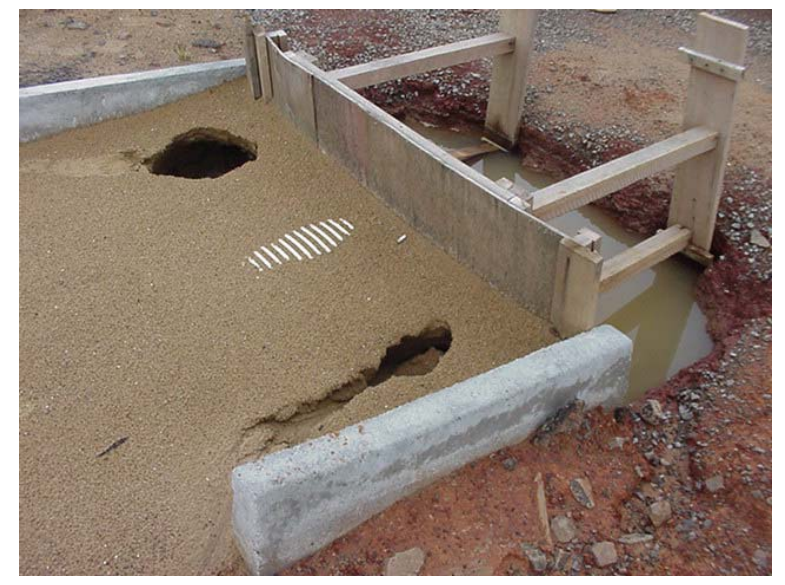

(b)

Figura 4.11 - Falhas no preenchimento das valas provocadas pela chuva

Esses danos puderam ter sua influência praticamente desconsiderada, uma vez que os testes de carga foram realizados nas regiões centrais das valas e os vazios dentro da camada compactada concentraram-se nos extremos, perto dos painéis de contenção. 


\subsubsection{Instalação dos LVDT's}

Após o revestimento das valas foram instalados os instrumentos para medir o deslocamento vertical do tubo, do tipo LVDT (Linear V ariable Differential Transformer), da marca KYOWA, modelo DLT-50 AS, com curso de $\pm 50 \mathrm{~mm}$.

Esses instrumentos são muito delicados e requerem extremo cuidado e precisão em sua instalação para que não sejam danificados e para garantir uma boa confiabilidade nas medidas registradas.

Os sensores foram instalados no centro dos tubos, de maneira que ficassem alinhados com o diâmetro vertical do tubo. As Figuras 4.12 (a) e (b), e 4.13 mostram detalhes da fixação dos sensores dentro dos tubos. Para garantir a verticalidade dos sensores foram usados níveis de bolha.

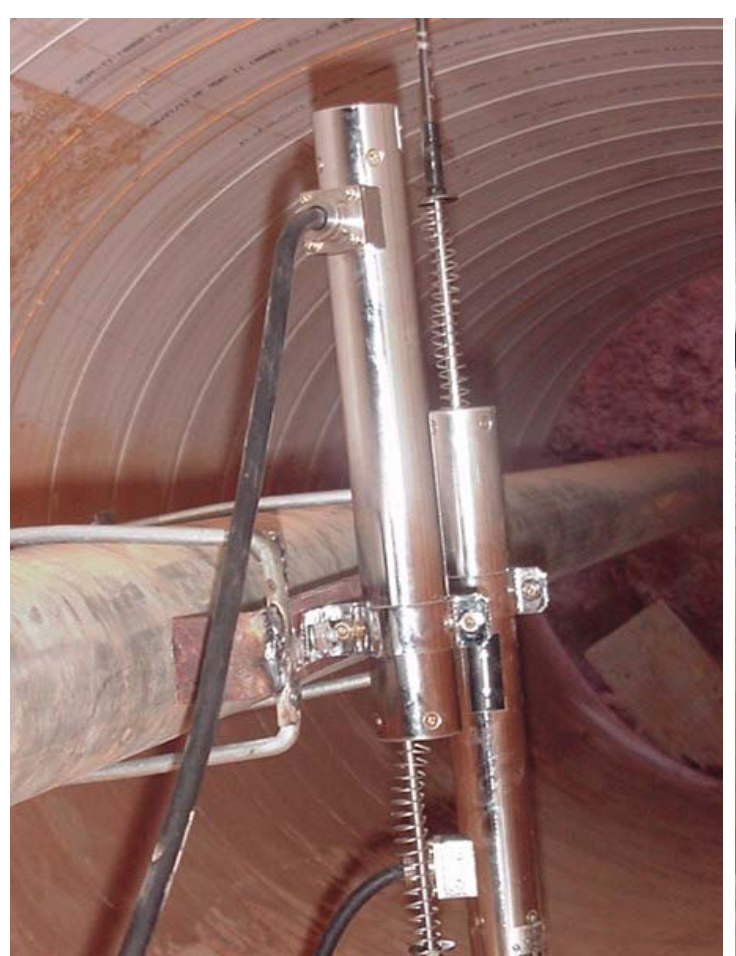

(a)

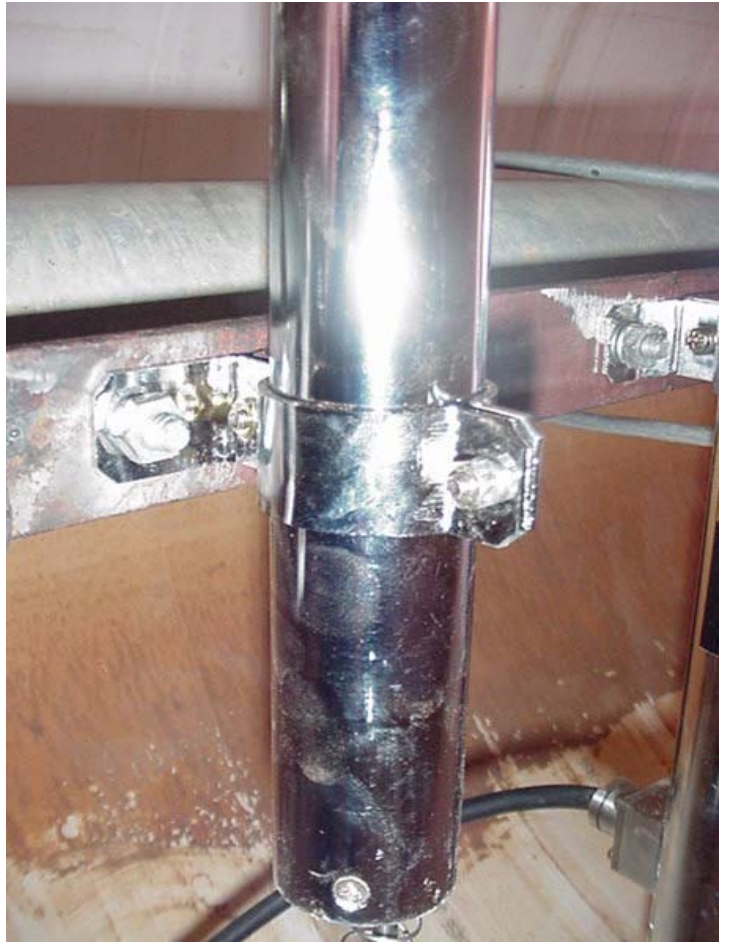

(b)

Figura 4.12 - Detalhes da fixação dos sensores tipo LVDT dentro dos tubos 


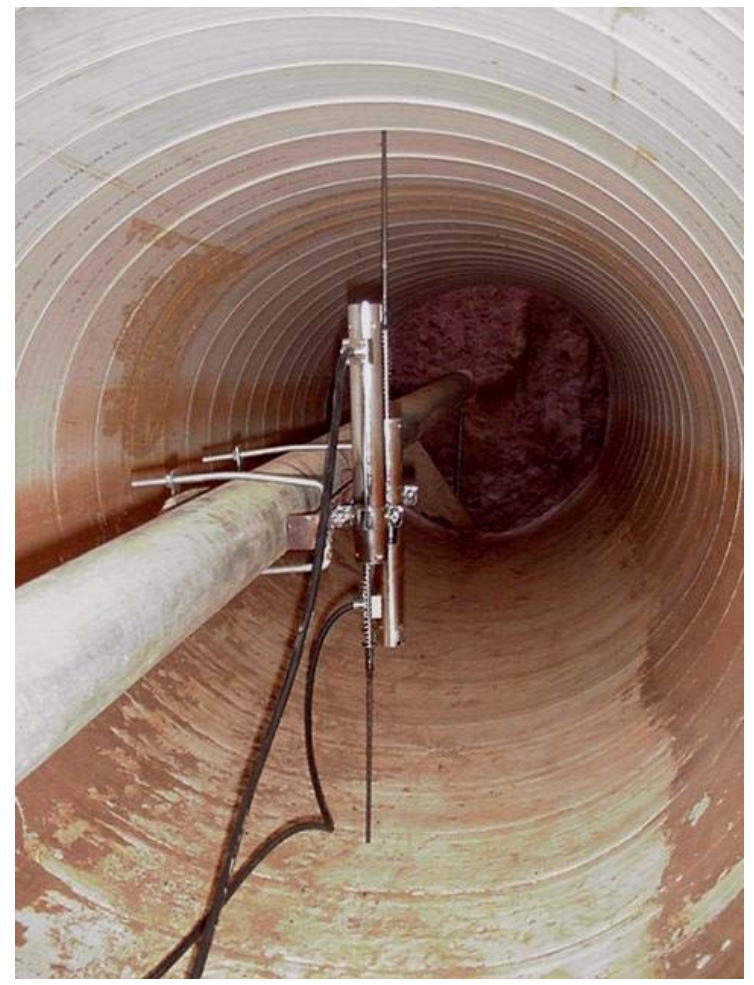

Figura 4.13 - Vista geral das instalações internas de um tubo preparado para a execução do ensaio e registro dos deslocamentos

Os sensores foram calibrados e as curvas de calibração de cada sensor são apresentadas no ANEXO I.

\subsubsection{Sistema de Aquisição de Dados}

O sistema de aquisição de dados utilizado faz parte de uma outra pesquisa em andamento na Área de Pesquisas e Testes de Pavimentos (Gonçalves et al., 2000), onde foram instrumentadas seções-teste de pavimentos. Em virtude da aplicação de grande número de carregamentos dinâmicos nas referidas seções-teste, o sistema tem elevada capacidade de aquisição de dados; esta característica do sistema auxiliou a aquisição e armazenamento de dados para a pesquisa de sistemas solo-tubo, uma vez que nesta era necessário o registro de vários dados devido aos carregamentos cíclicos e aos estáticos.

As características da fonte de alimentação utilizada são: saída simétrica de 0 a 30 volts ajustáveis; saída independente de 5 volts; corrente máxima de saída de 2 A; estabilidade e baixo nível de ruído. A configuração do sistema de aquisição de dados é composta por 
uma placa amplificadora e uma conversora A/D (analógico para digital). A placa amplificadora é da marca ComputerBoards (tipo CIO-SSH16); possui 4 canais de leitura (padrão) expansível até 16 canais (foram utilizados dois canais); tempo de aquisição de 4uS; taxa máxima de aquisição de $250 \mathrm{KHz}$; amplificação de 1x, 10x, 100x, 200x, 300x, 500x, 600x, 700x, 800x e precisão de 0,01\% \pm 1 bit (Gonçalves et al., 2000).

Vários programas computacionais foram usados na aquisição de dados, dentre eles Microsoft Windows 98, Microsoft Excel e Microsoft Word. O programa de controle foi desenvolvido em um software comercial chamado HP-VEE, desenvolvido pela Hewlett Packard, que está disponível para aquisição de dados e controle de processos. Suas características são: programação visual, utilização de sub-rotinas pré-programadas e interface com outros aplicativos. Para esta pesquisa foi desenvolvido apenas um software, capaz de armazenar os dados provenientes tanto do ensaio dinâmico, quanto do ensaio estático. 


\section{ENSAIOS REALIZADOS E}

RESULTADOS

Neste capítulo são apresentados todos os resultados dos ensaios realizados, tanto de caracterização dos materiais, do controle de compactação, como dos deslocamentos registrados sob ação de carga.

\subsection{Ensaios de Laboratório}

A granulometria foi determinada por peneiramento no Laboratório de Mecânica dos Solos da Escola Politécnica da USP (LMS-USP), segundo procedimento de ensaio preconizado na NBR 7181 e está representada na Figura 5.1.

Trata-se de uma areia fina a média mal graduada, com elevada presença de material entre as peneiras de $\mathrm{n}^{\circ} 40$ e $\mathrm{n}^{\circ}$ 100, chegando a mais de $70 \%$ em peso nesta fração correspondente à areia fina, o que acentua a inclinação da curva nesta região do gráfico. Possui cerca de $25 \%$ de fração areia média e apenas $5 \%$ de areia grossa. Não contém finos (silte e argila).

Com base na curva granulométrica calculou-se o coeficiente de não uniformidade, sendo $\mathrm{CNU}=2,10$ e o coeficiente de curvatura $\mathrm{CC}=0,86$. Uma areia é considerada bem graduada no caso em que o CNU seja superior a 6 e que o CC esteja entre 1 e 3 ; areias com CNU inferior a 2 são denominadas uniformes. A areia utilizada para o experimento é considerada mal graduada, praticamente uniforme. 


\section{Curva Granulométrica}

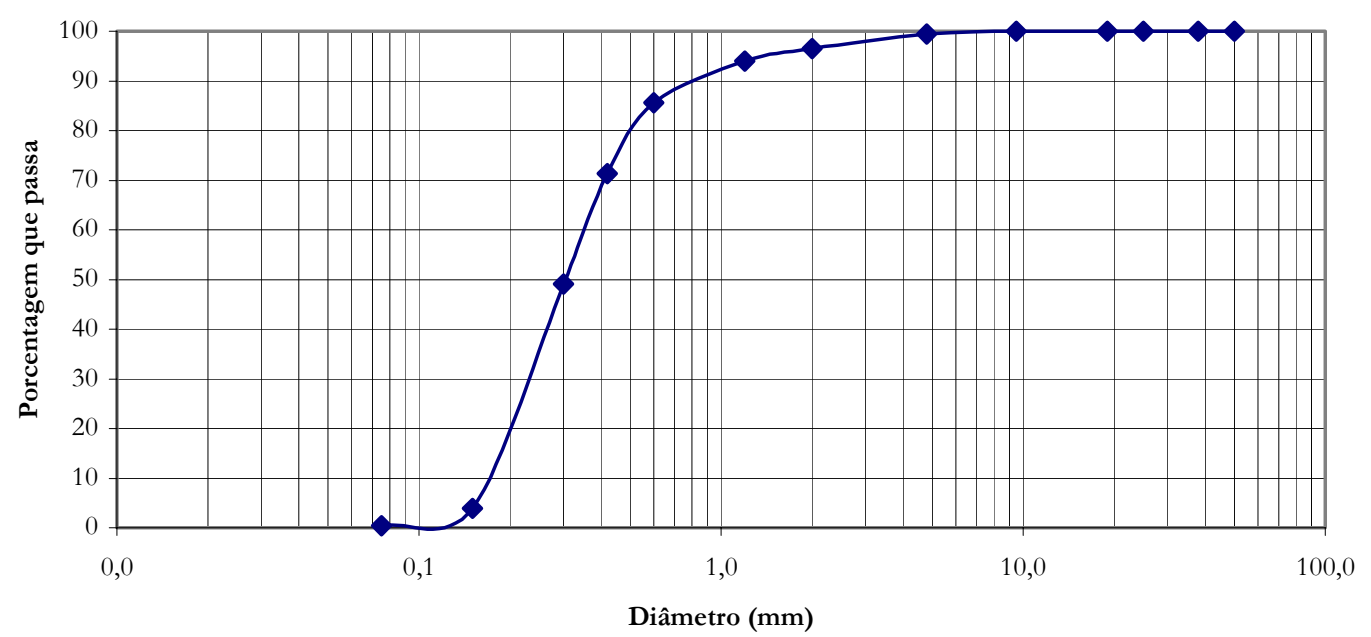

Figura 5.1 - Curva granulométrica da areia

Com os dados obtidos da curva granulométrica e sabendo-se que se trata de material não-plástico, pode-se classificar a areia usada como material de envolvimento dos tubos. Trata-se de material classificado como SP pela Classificação Unificada, onde S indica areia e P mal graduada; e A3 no Sistema Rodoviário de Classificação, indicando também areia sem finos ou sem coesão.

A determinação do índice de vazios máximo e mínimo, e da densidade real dos grãos foi também realizada no LMS-USP. Os índices de vazio máximo e mínimo são, respectivamente, 0,85 e 0,51. A densidade real dos grãos da areia utilizada é de 2,66 $\mathrm{g} / \mathrm{cm}^{3}$.

Foi realizado ensaio de compactação na Energia Normal em cinco teores de umidade diferentes - Figura 5.2. O peso específico aparente seco máximo encontrado foi de 16,6 $\mathrm{kN} / \mathrm{m}^{3}$ para um teor de umidade de aproximadamente $7,4 \%$. Foi realizado ensaio de CBR na areia em condição de umidade e peso específico aparente seco próximos do estado correspondente ao ótimo e ao máximo, respectivamente. O resultado encontrado foi de CBR de apenas 2,7\%, para um peso específico aparente seco, $\gamma_{\mathrm{d}}$, de $16,1 \mathrm{kN} / \mathrm{m}^{3}$ 
e umidade de 7,0\%. Nesta condição, o grau de compactação, correspondente à relação em porcentagem entre o peso específico seco obtido no ensaio e o peso específico seco máximo, é de 97\%.

CURVA DE COMPACTAÇÃO - ENERGIA NORMAL

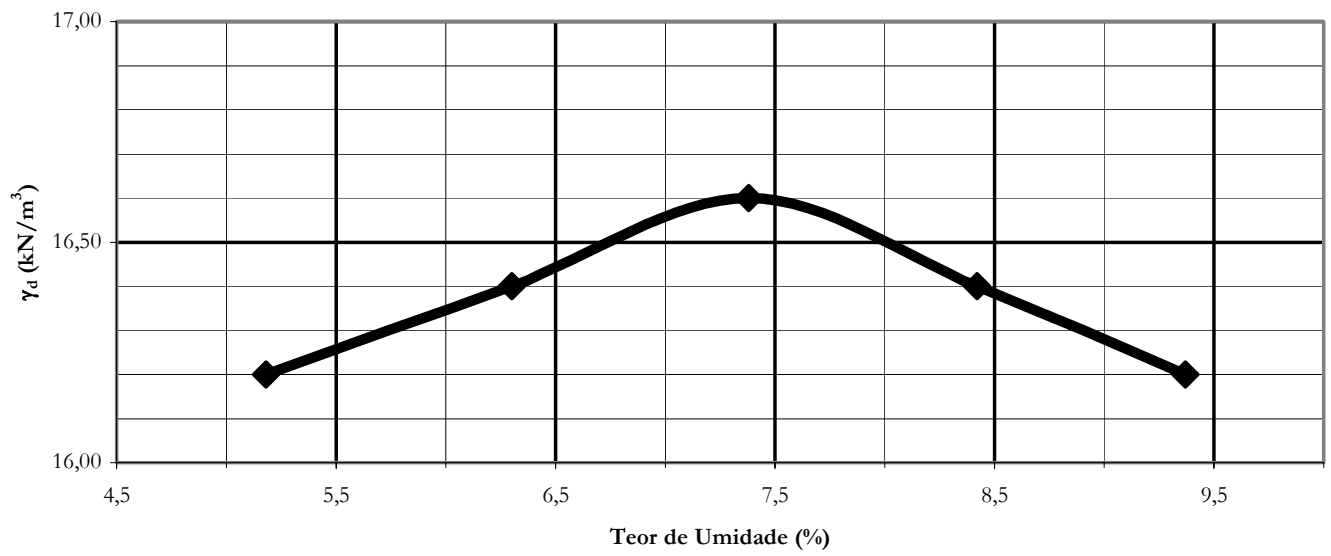

Figura 5.2 - Curva de compactação da areia

Ensaios de CBR também foram realizados para diferentes compacidades relativas CR, sendo este índice correspondente à relação entre a diferença do índice de vazios máximo com aquele obtido com o material no ensaio e a diferença entre os índice de vazios máximo e mínimo. O grau de compactação de 97\% obtido no ensaio do CBR corresponde a uma compacidade relativa CR de 65\%. Os resultados encontrados de CBR em função da CR são mostrados na Figura 5.3. 


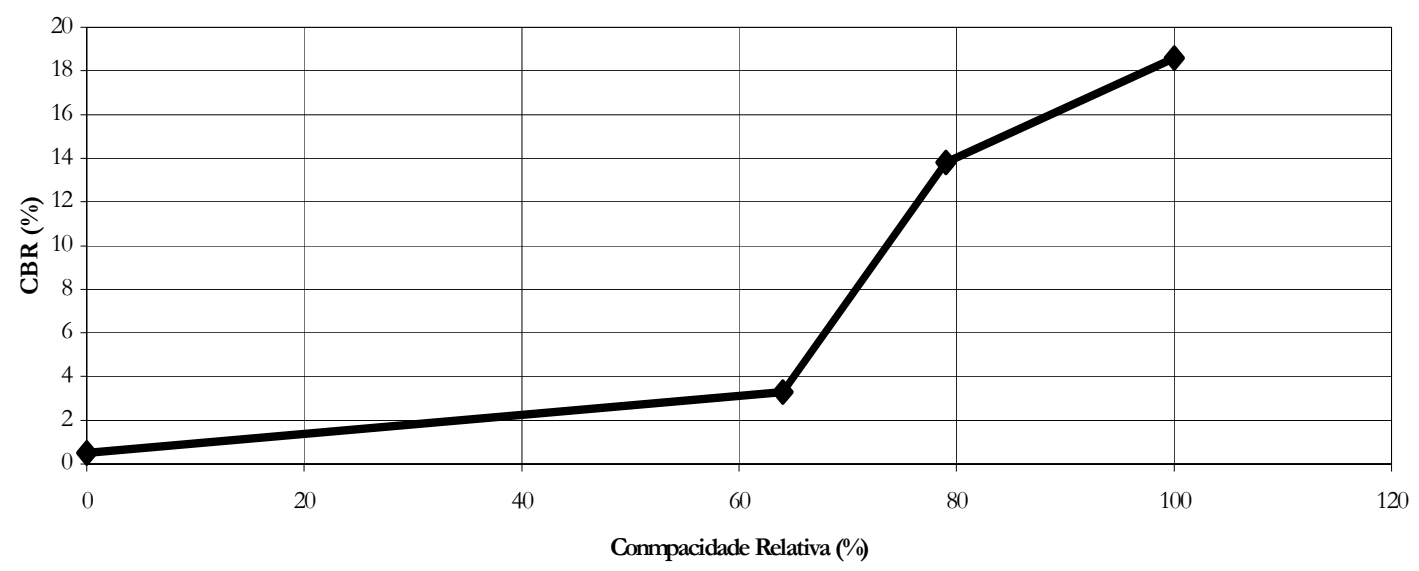

Figura 5.3 - Variação do valor de CBR com a compacidade relativa

Pelo gráfico da Figura 5.3 pode-se perceber que o valor de CBR só passa a aumentar significativamente depois de atingir compacidade relativa superior a $60 \%$. As areias podem ser consideradas no estado compacto, quando o CR está acima de 0,66, corroborando os resultados experimentais obtidos. Isto demonstra a dificuldade de se trabalhar com materiais desta natureza e obter elevados valores de CBR e de Módulo de Reação E'. Deve-se, no entanto, considerar que o CBR de laboratório pode não corresponder à resistência que se pode obter na prática em areias sem coesão. A própria especificidade do ensaio e a forma com que é feita a penetração do pistão na areia levam a baixos resultados de CBR de areias finas e uniformes, dado o pequeno confinamento com que a areia trabalha superficialmente.

\subsection{Ensaio de Campo - Controle de Compactação}

\subsubsection{Cones de Penetração Dinâmica}

A seguir são apresentadas fotos (Figura 5.4 (a) e (b), e 5.5 (a) e (b)) que ilustram a realização dos ensaios de controle de compactação nas valas-teste com o Cone de Penetração Dinâmica (DCP) e com o cone tipo UFV-II, respectivamente. 


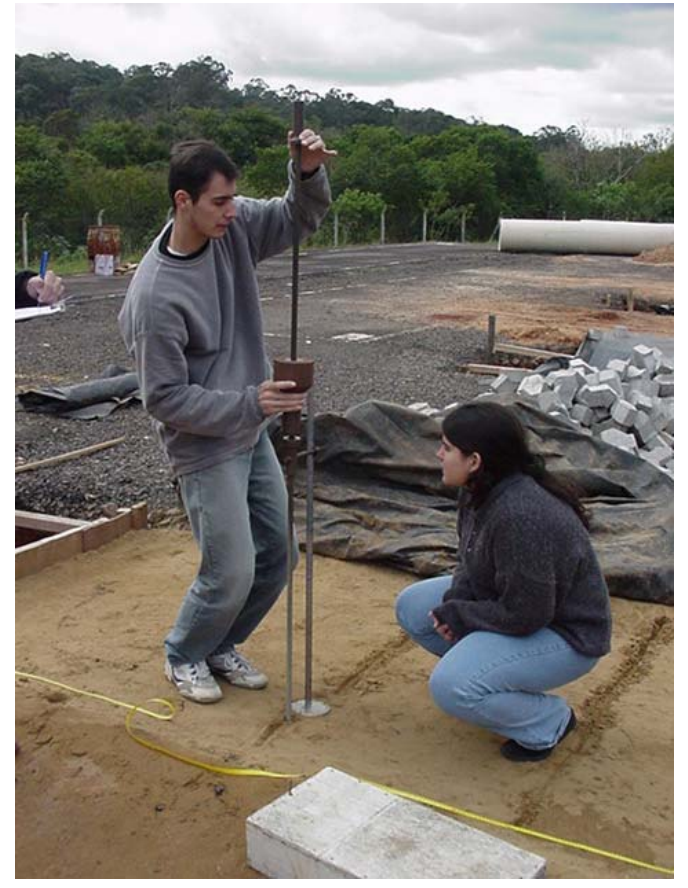

(a)

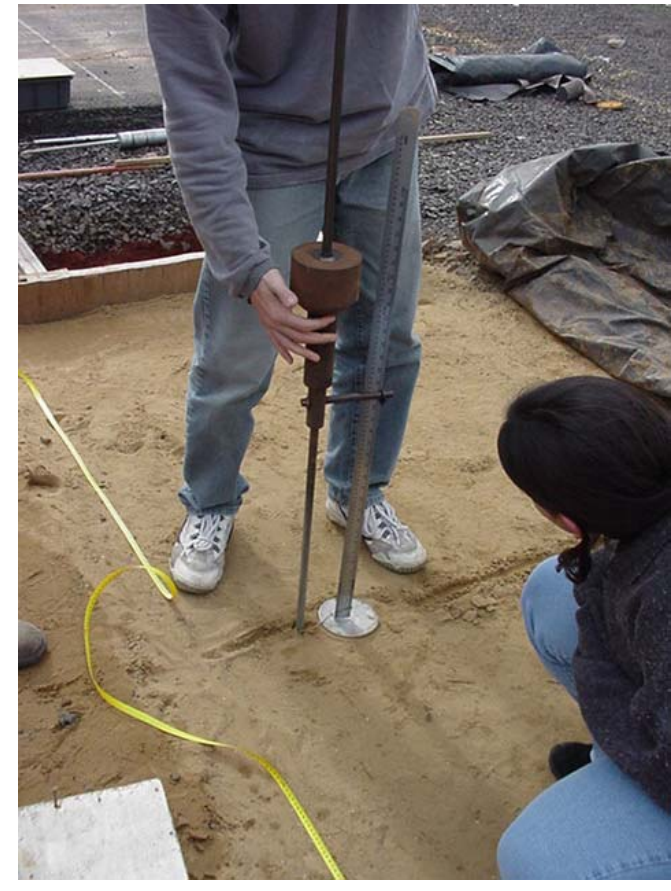

(b)

Figura 5.4 - Ensaio com o DCP para controle de compactação das valas-teste na Área de Pesquisas e Testes de Pavimentos UFRGS/DAER-RS

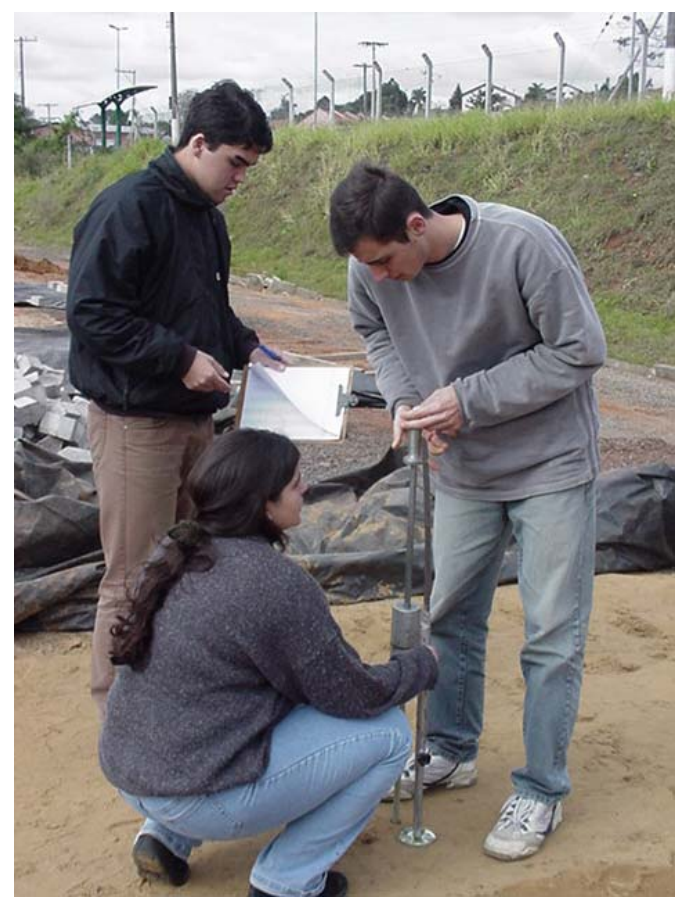

(a)

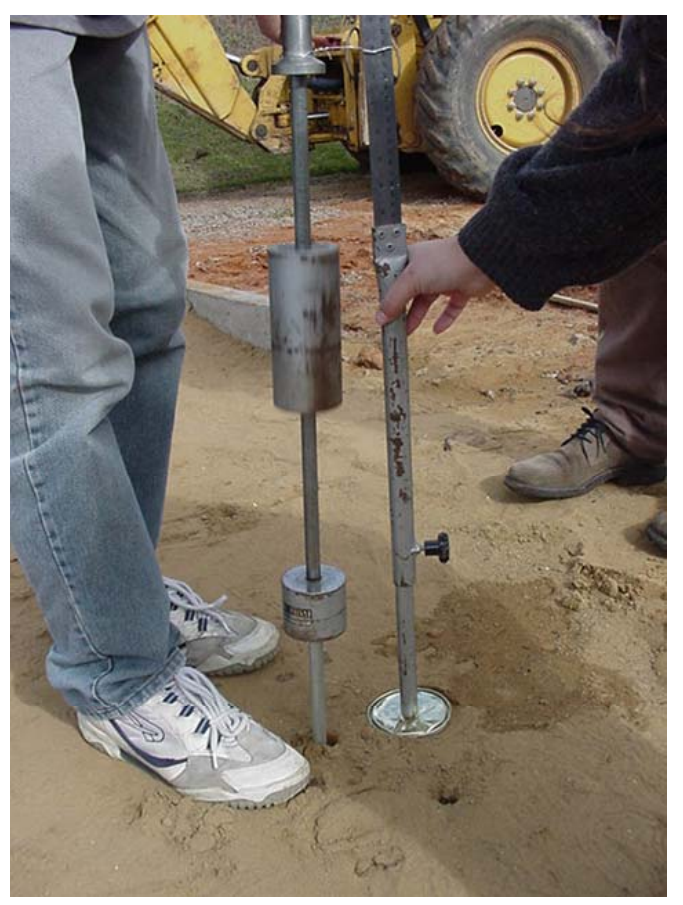

(b)

Figura 5.5 - Ensaio com o UFV-II para controle de compactação das valas-teste na Área de Pesquisas e Testes de Pavimentos UFRGS/DAER-RS 
Um dos principais objetivos da compactação é o aumento de resistência do material de envolvimento e a homogeneidade das tensões em torno do tubo frente às solicitações. Dessa forma, os resultados foram agrupados por camadas.

Os gráficos das Figuras 5.6 a 5.9 mostram os resultados dos ensaios de penetração dinâmica realizados com DCP no material de fundação das valas-teste, correspondente ao berço compactado e ao material natural do fundo da vala, constituído por solo residual de granito.

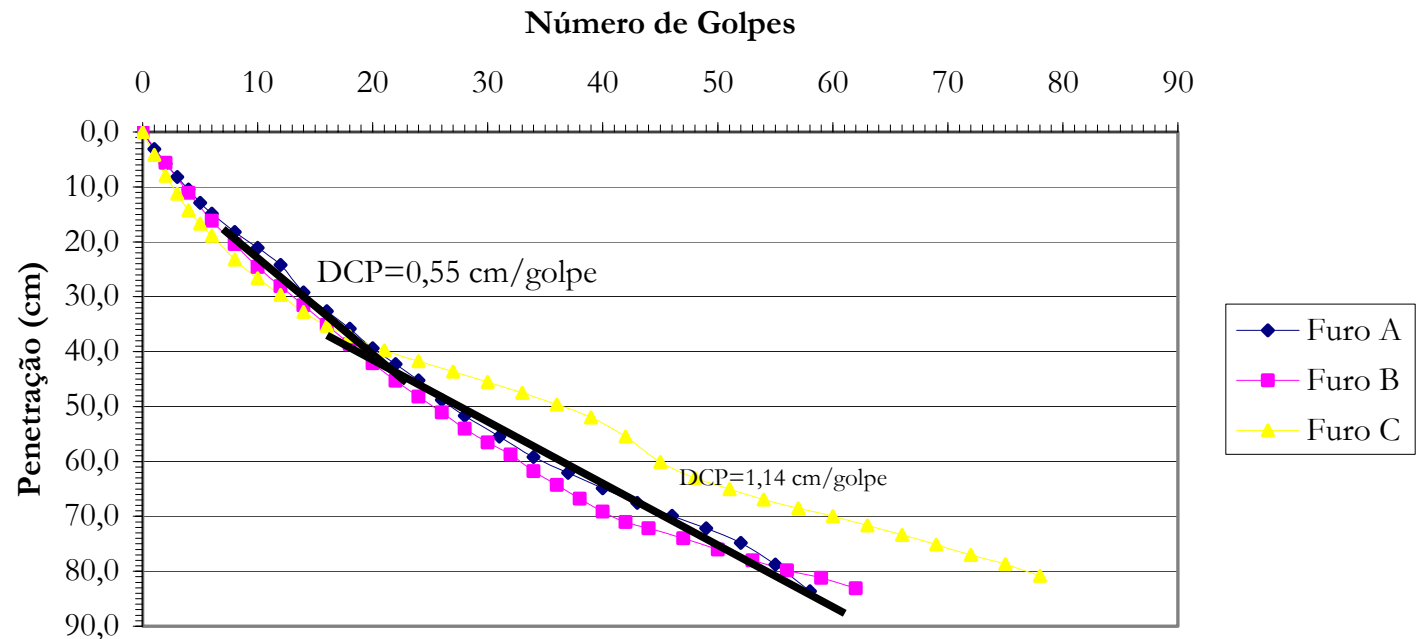

Figura 5.6 - Resultados dos ensaios de penetração dinâmica com DCP no solo de fundação da vala profunda compactada 


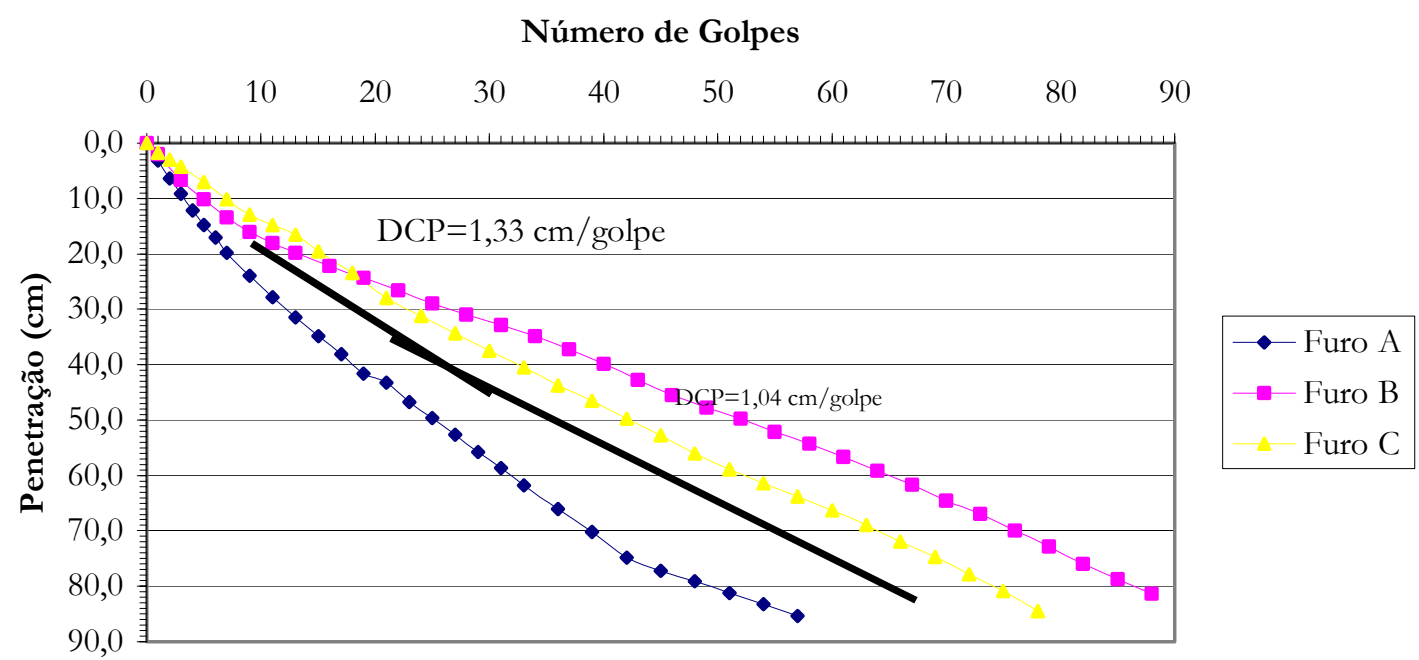

Figura 5.7 - Resultados dos ensaios de penetração dinâmica com DCP no solo de fundação da vala rasa compactada

\section{Número de Golpes}

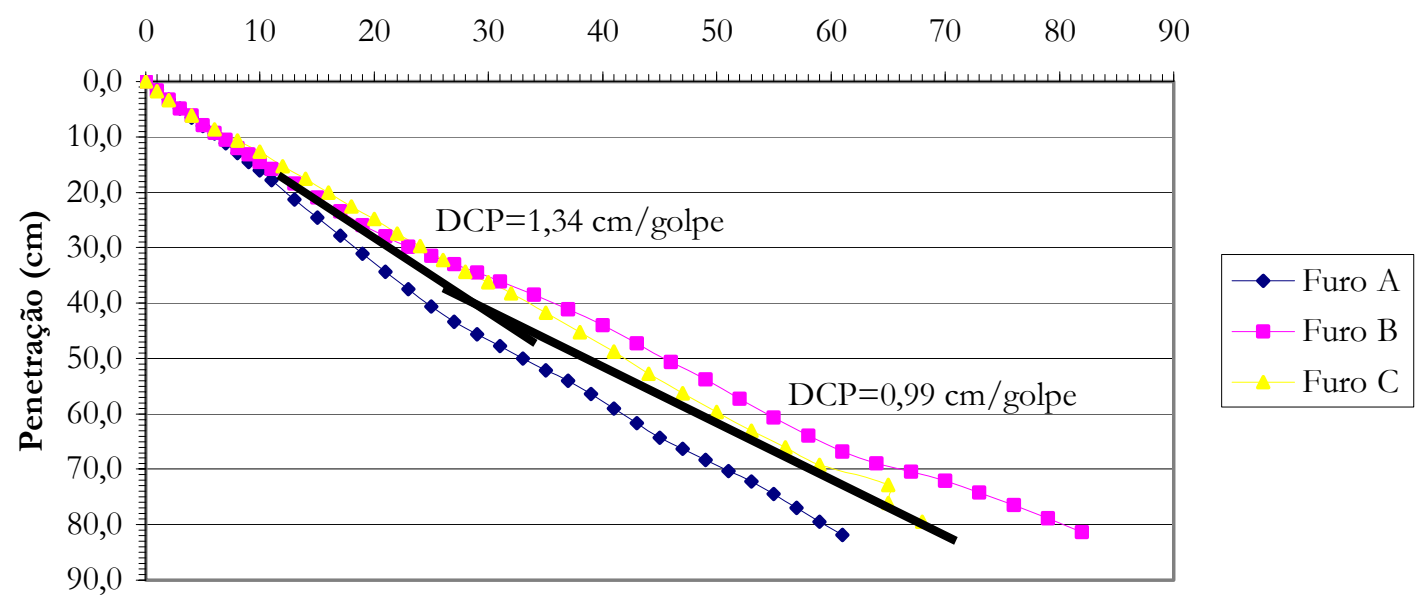

Figura 5.8 - Resultados dos ensaios de penetração dinâmica com DCP no solo de fundação da vala rasa não compactada 


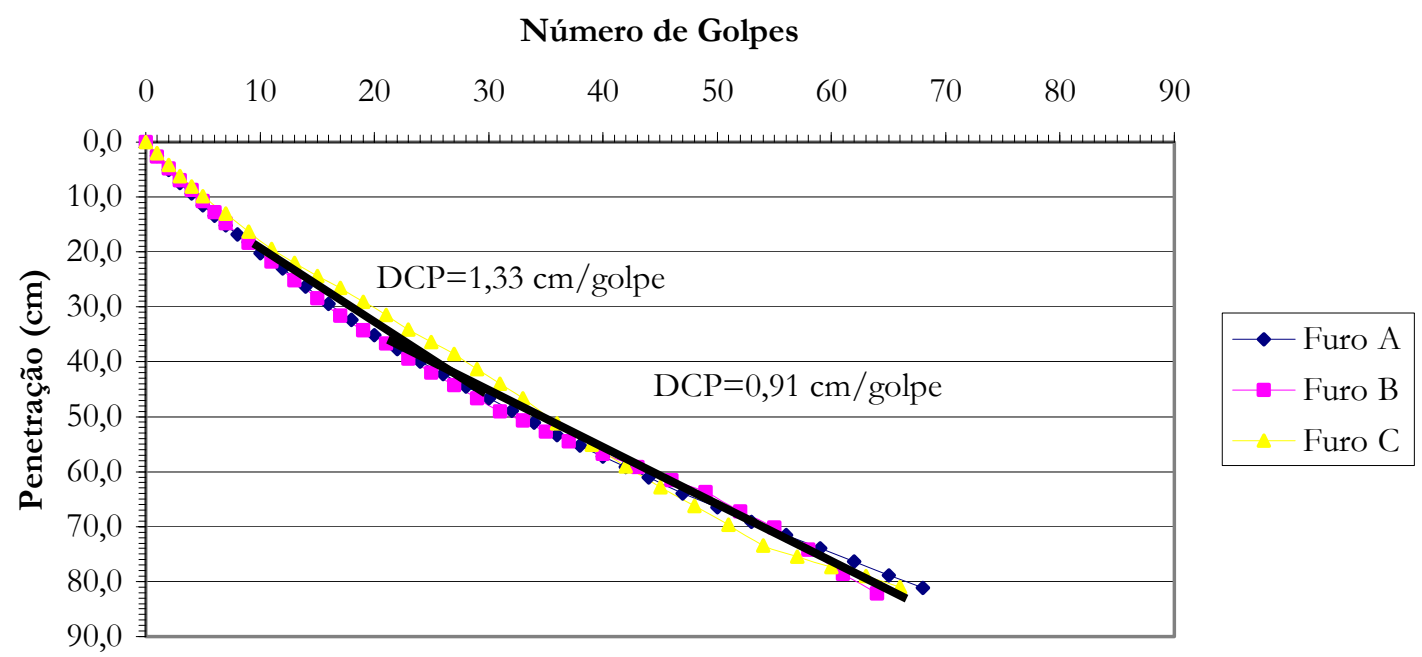

Figura 5.9 - Resultados dos ensaios de penetração dinâmica com DCP no solo de fundação da vala profunda não compactada

Pode-se observar que as curvas apresentam sempre dois trechos distintos entre a parte mais superficial e a mais profunda, sendo que esta última está mais densa que a superior. Isto demonstra que o solo de fundação é bastante resistente no estado natural e que a compactação do material que estava solto na superfície foi insuficiente para oferecer ao solo as mesmas condições de estado que este apresentava antes da abertura da vala, de seu revolvimento e de sua compactação.

Para cada camada de areia compactada na vala foi traçado um gráfico com as curvas número de golpes $v s$. penetração obtidas para os seis pontos em que foi realizado o ensaio e então determinados dois valores de índice de penetração, um para a parte inicial da curva (primeiros $20 \mathrm{~cm}$ a $30 \mathrm{~cm}$ ) e outro para o restante da curva.

Os resultados obtidos na superfície (última camada compactada) de cada vala compactada estão mostrados nas figuras 5.10 a 5.13. A exceção ocorre para os resultados do controle de compactação com o UFV-II na Vala Profunda Compactada em que os resultados apresentados na Figura 5.11 são os da sexta camada compactada, última camada ensaiada, pois o equipamento quebrou nesse estágio da obra. 
Todos os resultados de controle de compactação obtidos em cada vala compactada, sejam na profunda como na rasa, podem ser vistos nos ANEXOS II, III, IV e V. Os resultados com o DCP estão nos ANEXOS II e III, e com o UFV-II nos ANEXOS IV e V.

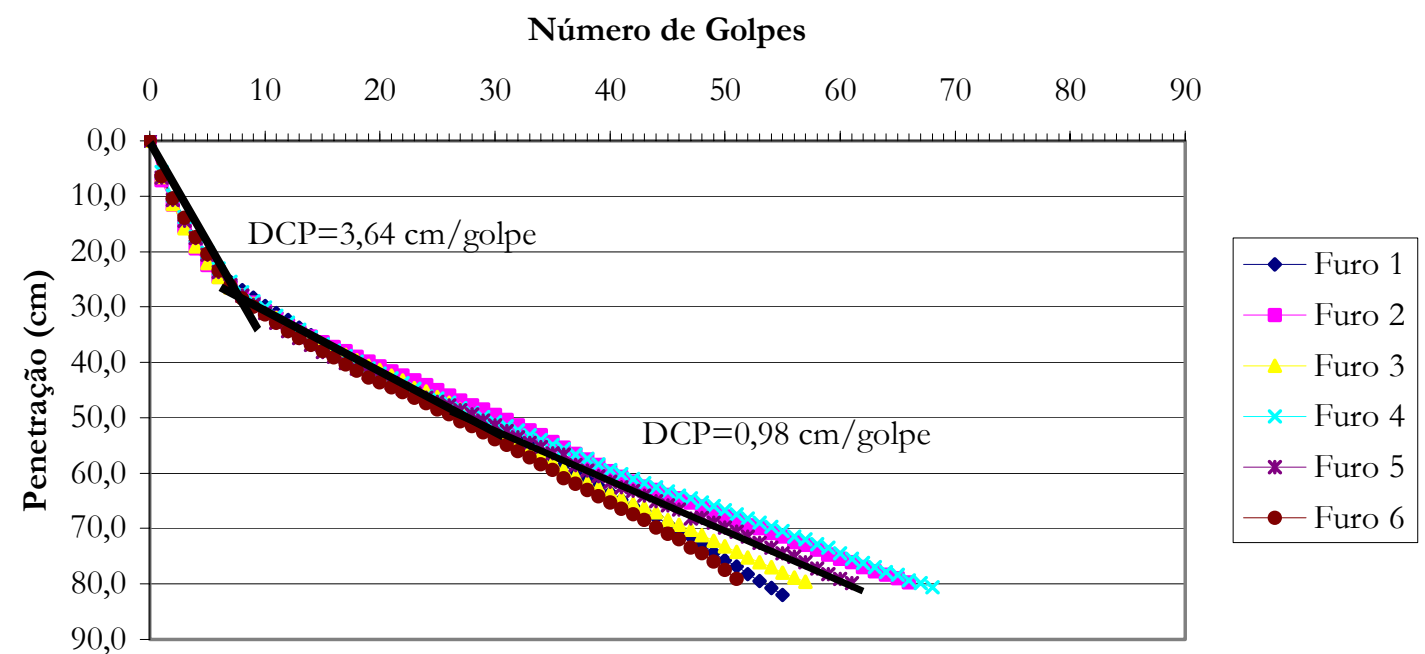

Figura 5.10 - Resultados de controle de compactação com DCP na superfície da Vala Profunda Compactada antes da simulação de tráfego

Número de golpes

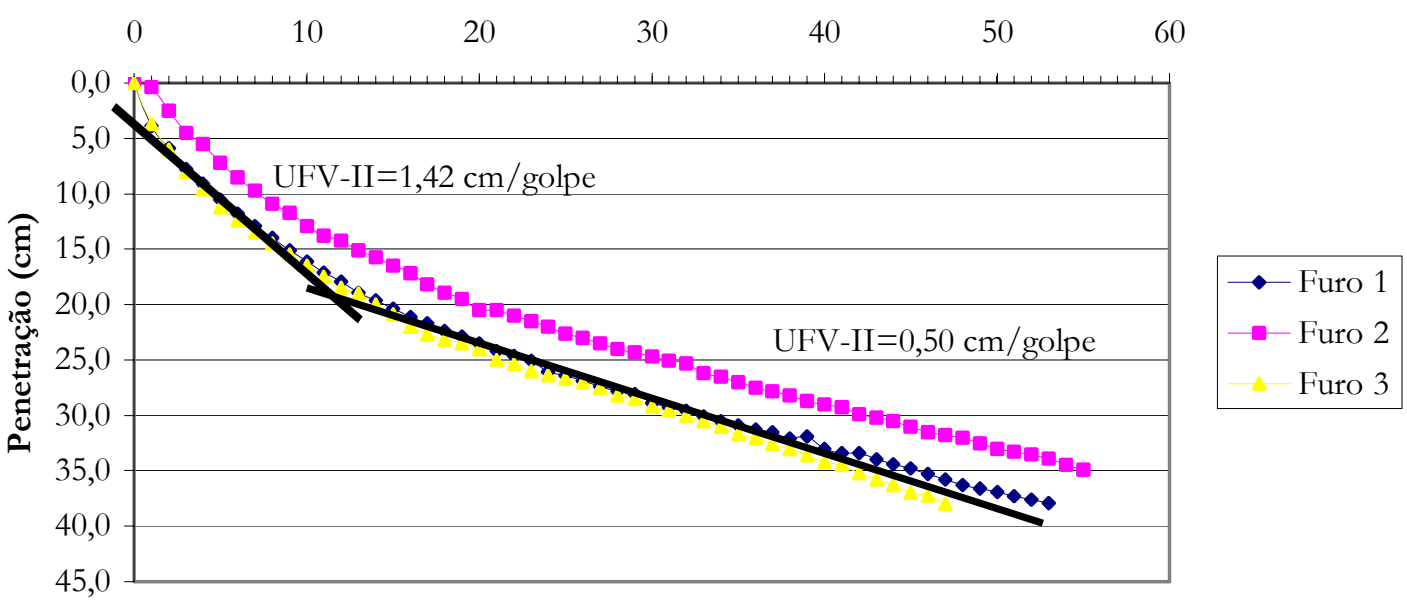

Figura 5.11 - Resultados de controle de compactação com UFV-II na sexta camada da Vala Profunda Compactada antes da simulação de tráfego 


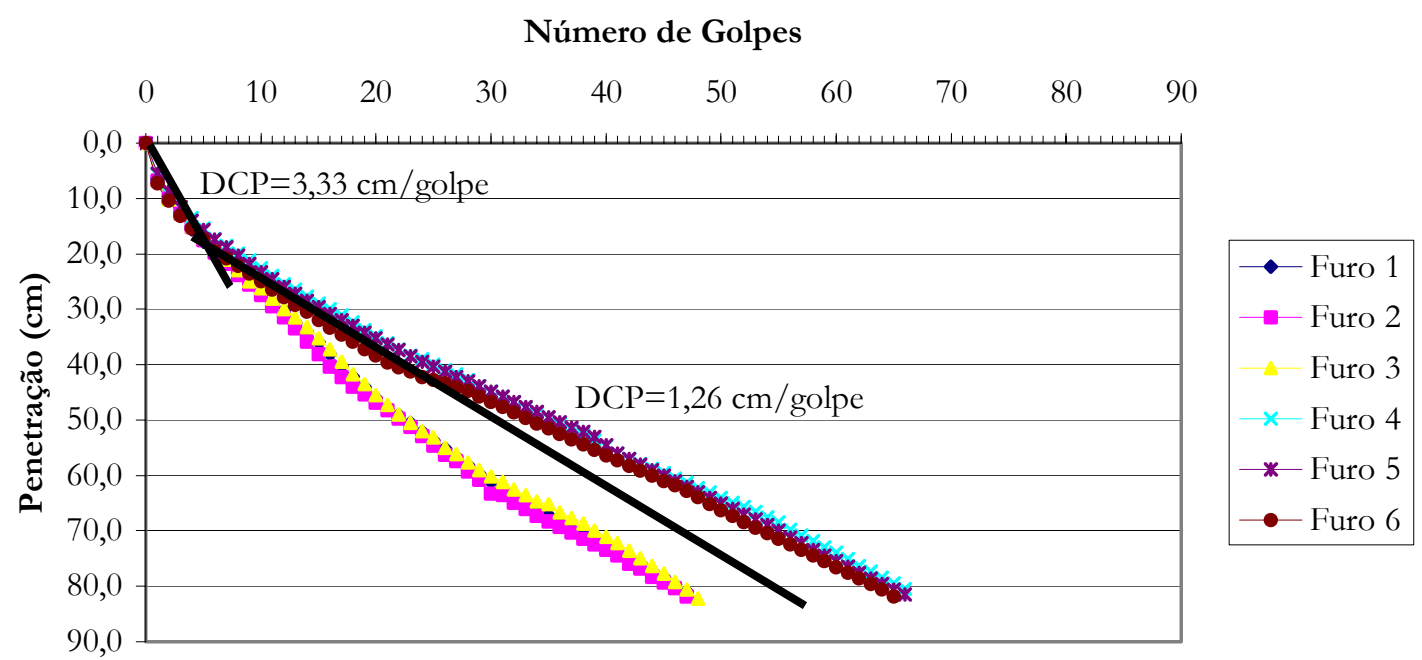

Figura 5.12 - Resultados de controle de compactação com DCP na superfície da Vala Rasa Compactada antes da simulação de tráfego

Número de golpes

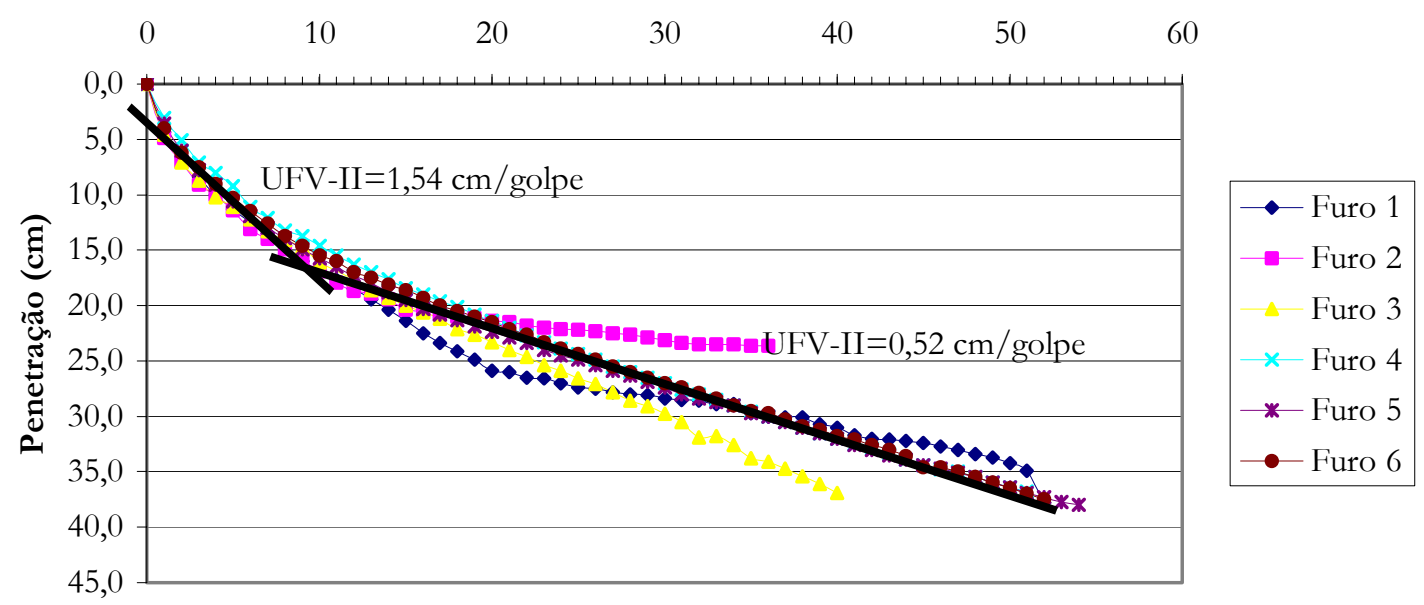

Figura 5.13 - Resultados de controle de compactação com UFV-II na superfície da Vala Rasa Compactada antes da simulação de tráfego

Os primeiros 20 a $30 \mathrm{~cm}$ de penetração do DCP, quando do controle de compactação de areias, podem ser em alguns casos desconsiderados. No entanto, nesse estudo, tornase útil essa informação uma vez que as inclinações das retas ajustadas às curvas obtidas nos seis locais de controle de cada vala, mostradas nas Figuras 5.10 e 5.12, repetem-se para praticamente todas as camadas superficiais e apresentam valores de índice de 
penetração (equação 4.1, apresentada no Capítulo 4) na ordem de 3,3 a 3,6 cm/golpe. Para as camadas subjacentes, o índice de penetração DCP passa a ser praticamente o mesmo para toda a profundidade ensaiada abaixo dos 30 primeiros $\mathrm{cm}$, com valores na faixa de $0,9 \mathrm{~cm} /$ golpe a 1,5 cm/golpe. É interessante observar a grande diferença que há entre os valores de DCP na camada superficial e no material abaixo dos primeiros 30 $\mathrm{cm}$. A areia confinada apresenta-se cerca de 3 vezes mais resistente que aquela presente nos primeiros 20 a $30 \mathrm{~cm}$, tanto nos ensaios com o DCP como com o UFV-II.

Observa-se que na Vala Profunda Compactada, nas camadas abaixo dos primeiros 20 a $30 \mathrm{~cm}$, o estado da areia parece ser mais homogêneo, mostrado pelas inclinações relativamente próximas de todas as curvas de controle. Não se sabe se o serviço de compactação foi mais homogêneo no caso da Vala Profunda Compactada, porém espera-se que a ausência do tubo nas camadas controladas dessa vala auxiliou os serviços de compactação. Deve-se lembrar que na situação retratada nas Figuras 5.10 e 5.11, a geratriz superior do tubo se encontra a cerca de 1,0 a 1,5 metros da superfície, conforme foi descrito anteriormente no capítulo4, item 4.1. Já no caso da Vala Rasa Compactada, a presença do tubo cerca de 20 a $30 \mathrm{~cm}$ abaixo da superfície causou uma perturbação nos serviços de densificação e conseqüente heterogeneidade de estado do material.

Na superfície, embora possa ter sido realizada uma intensa compactação desta camada, a areia mantém-se sob baixo confinamento e, em consequência, a resistência ao cisalhamento pode ser baixa. A compactação da camada superior acaba por densificar as camadas subjacentes, porém o pequeno confinamento continua sendo um dos fatores preponderantes para a baixa resistência nos primeiros 20 a $30 \mathrm{~cm}$ de uma areia malgraduada.

Para as valas não compactadas, tentou-se realizar o ensaio com o DCP antes da simulação de tráfego. No entanto, o peso próprio do cone era suficiente para fazer penetrar todo o comprimento da haste, mostrando que a areia estava bastante fofa.

A simulação de tráfego sobre as valas só pode ser realizada algum tempo depois que as mesmas foram revestidas, período no qual registrou-se a ocorrência de chuvas intensas. 
Foram realizados ensaios de controle de compactação na superfície das valas, após a simulação de tráfego para verificar a interferência das chuvas e do próprio ensaio. Os resultados obtidos na superfície das valas, após chuvas e simulação (e remoção dos blocos de concreto) são mostrados nas Figuras 5.14 a 5.21 .

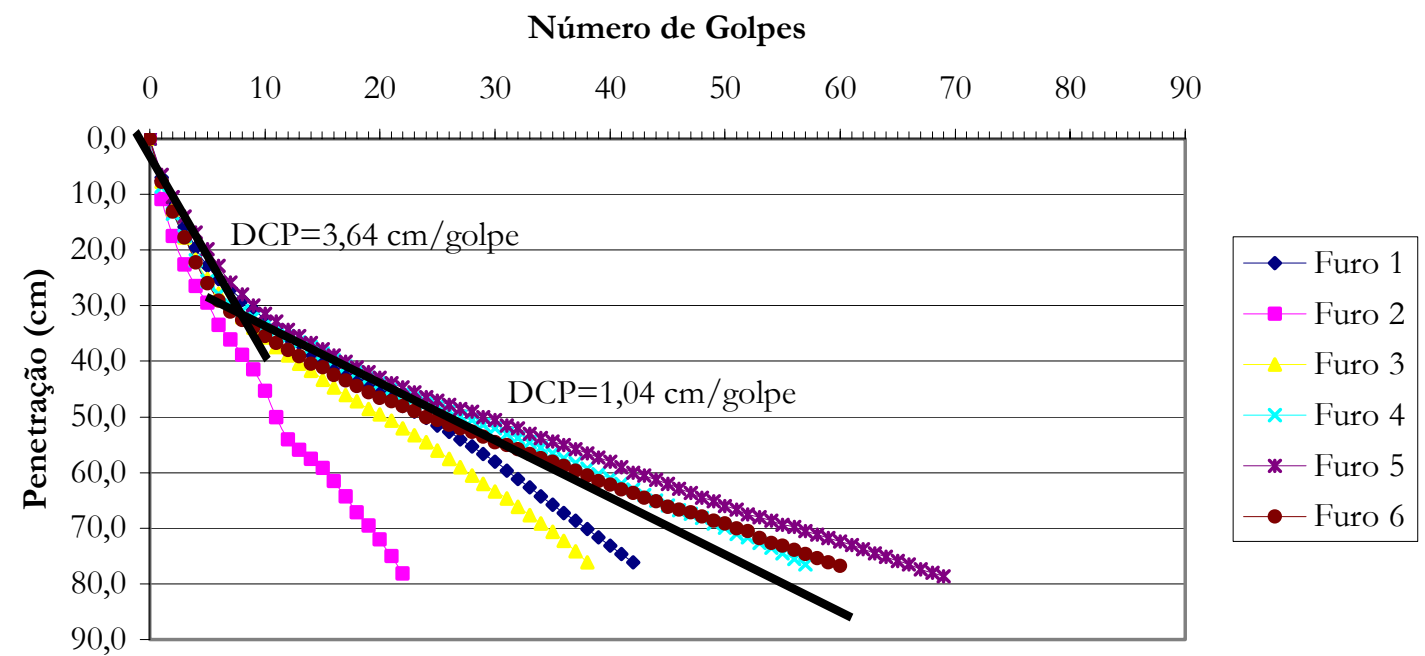

Figura 5.14 - Resultados de controle de compactação com DCP na Vala Profunda Compactada após a simulação de tráfego

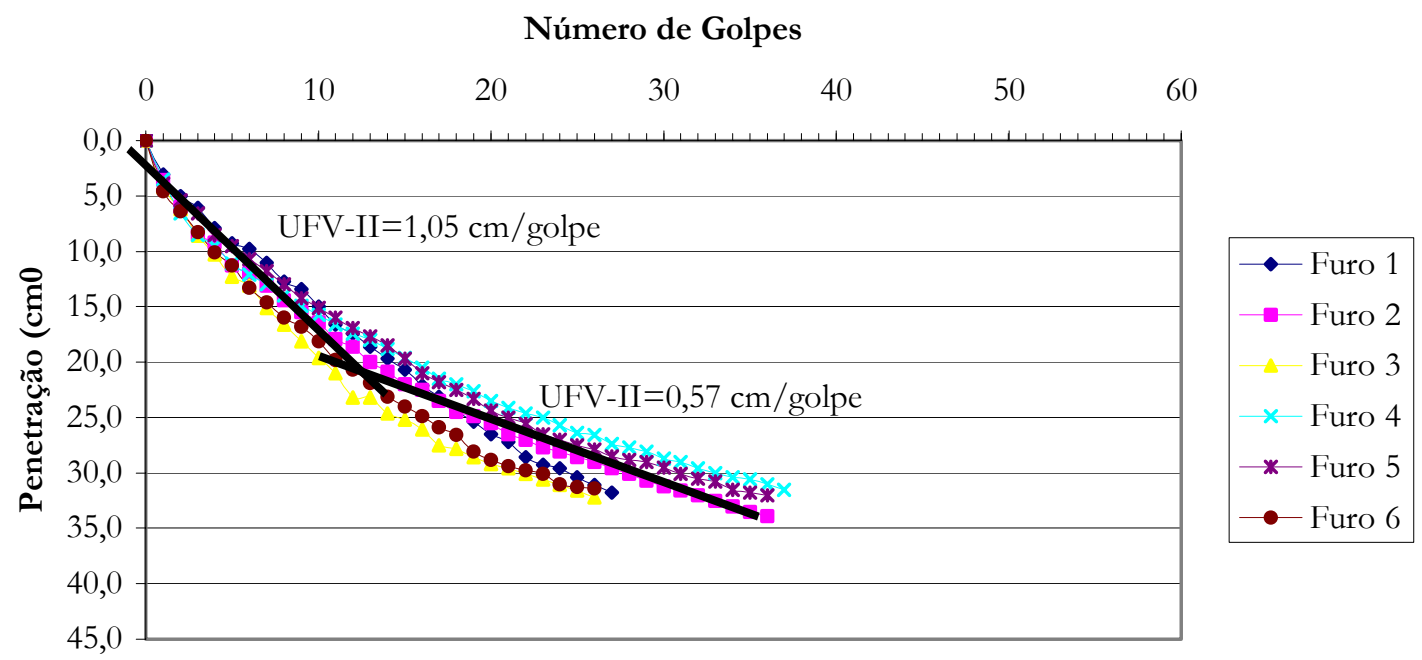

Figura 5.15 - Resultados de controle de compactação com UFV-II na Vala Profunda Compactada após a simulação de tráfego 
Número de Golpes

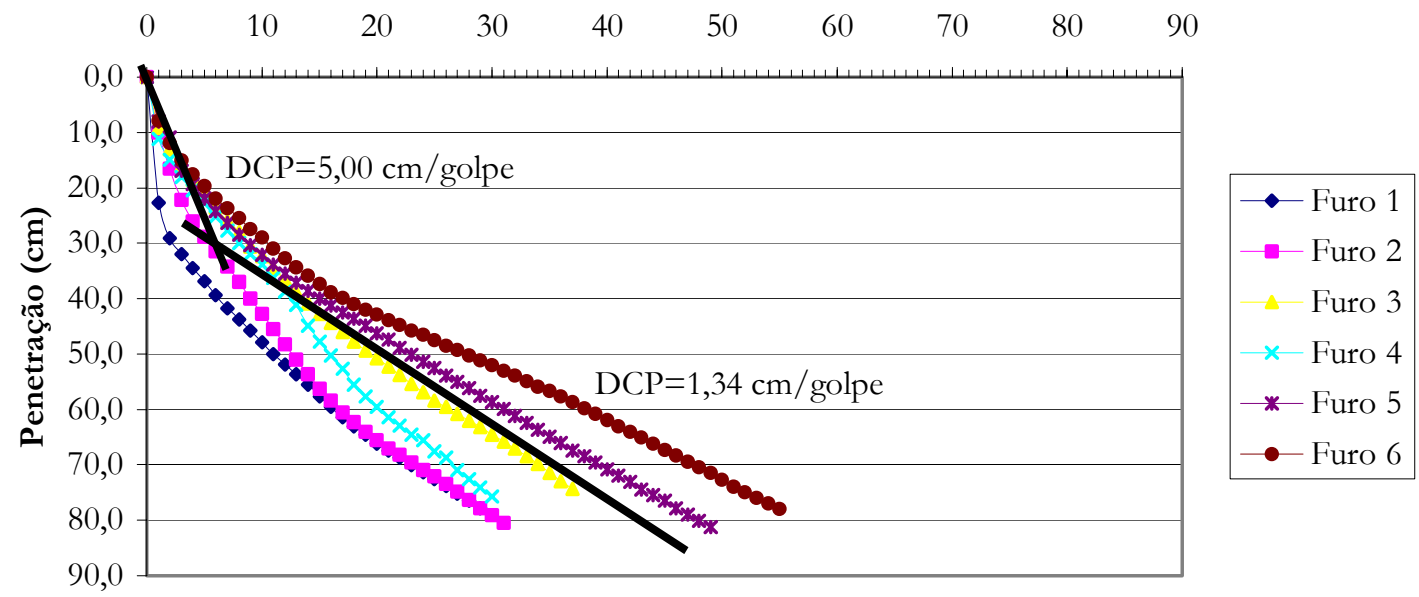

Figura 5.16 - Resultados de controle de compactação com DCP na Vala Rasa Compactada após a simulação de tráfego

Número de Golpes

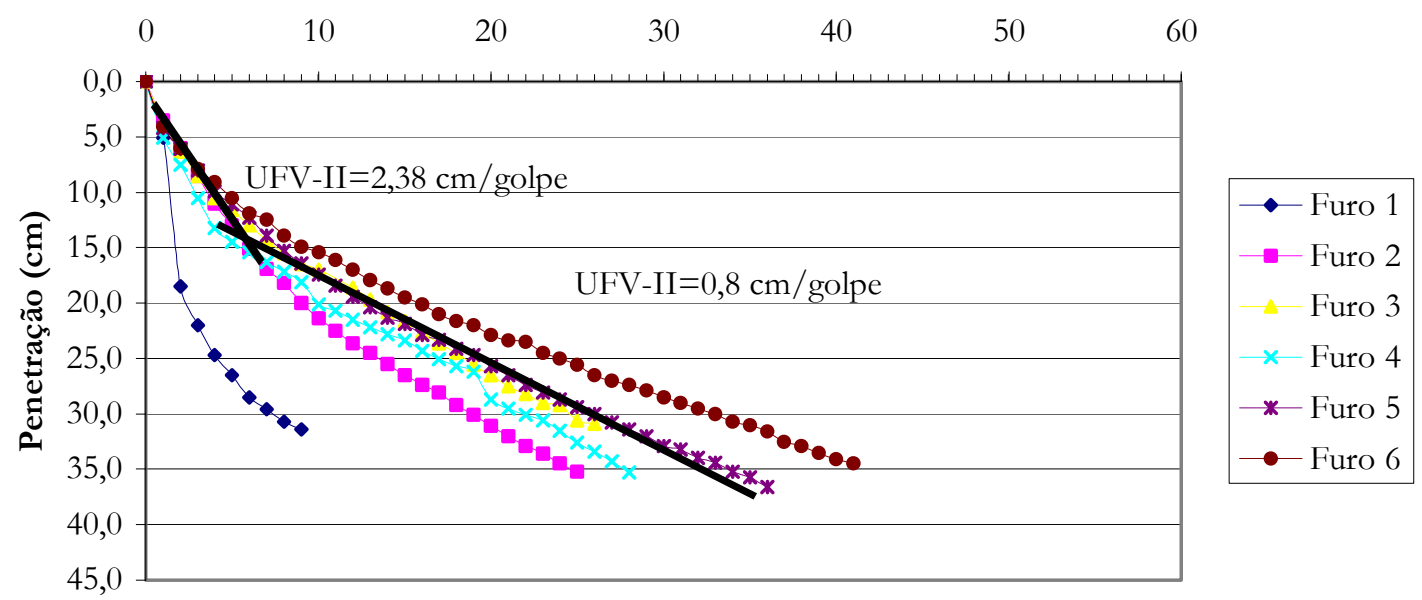

Figura 5.17 - Resultados de controle de compactação com UFV-II na Vala Rasa Compactada após a simulação de tráfego

Constata-se que houve um acréscimo do índice de penetração DCP e do UFV-II na vala Rasa Compactada. Houve uma certa perda de resistência, com grande variação de valores de índice de penetração dependendo do ponto ensaiado. A presença do tubo muito próximo à superfície, o problema de confinamento próximo à superfície e a simulação provocando carregamento em movimento em um único sentido levaram a 
acentuar a heterogeneidade do sistema. Já no caso da Vala Profunda Compactada, os valores de índice de penetração praticamente mantiveram-se como inicialmente, demonstrando maior estabilidade do sistema à infiltração d'água e ao carregamento transiente do que nos casos onde os tubos estão muito próximos à superfície.

Para areias bem compactadas, deve-se lembrar que a areia pode aumentar de volume ao sofrer cisalhamento, tornando-a menos compacta. No entanto, nos testes executados em campo não se pode afirmar que tal fenômeno tenha ocorrido; é provável que os outros fatores levantados sejam mais preponderantes para explicarem os resultados obtidos.

Nas valas onde o material de envolvimento não foi compactado, foi possível encontrar um valor, ainda que elevado, de índice de penetração após as chuvas e a simulação de carga. Os resultados estão nas Figuras 5.18 a 5.21. Tal fato comprova o aumento de densidade do material, pois antes do ensaio de aplicação de carga apenas o peso próprio do cone era suficiente para que a haste inteira penetrasse na areia.

Número de Golpes

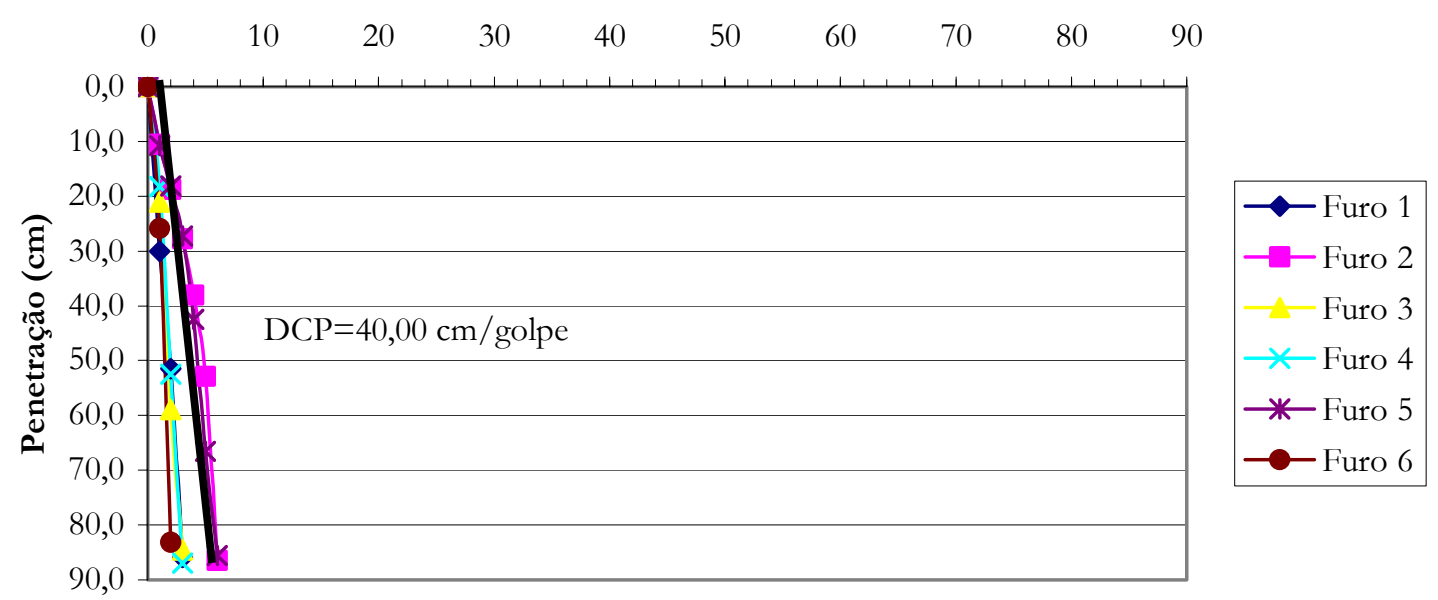

Figura 5.18 - Resultados de controle de compactação com DCP na Vala Rasa Não Compactada após a simulação de tráfego 
Número de Golpes

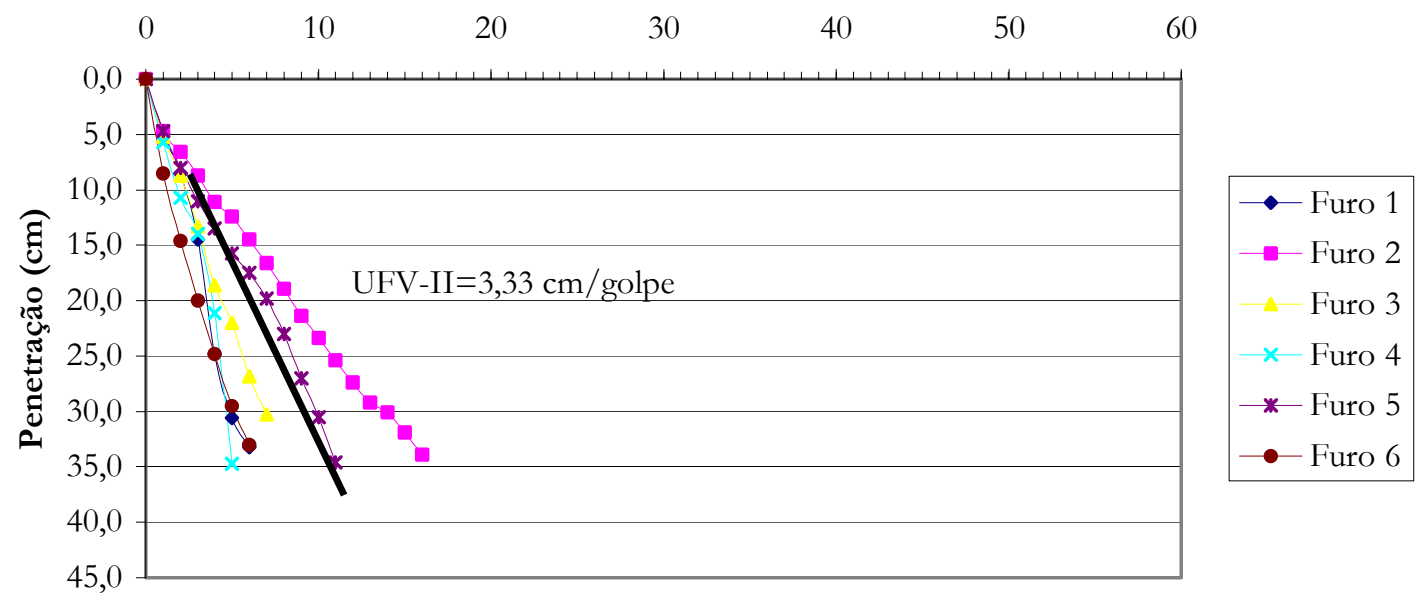

Figura 5.19 - Resultados de controle de compactação com UFV-II na Vala Rasa Não Compactada após a simulação de tráfego

Número de Golpes

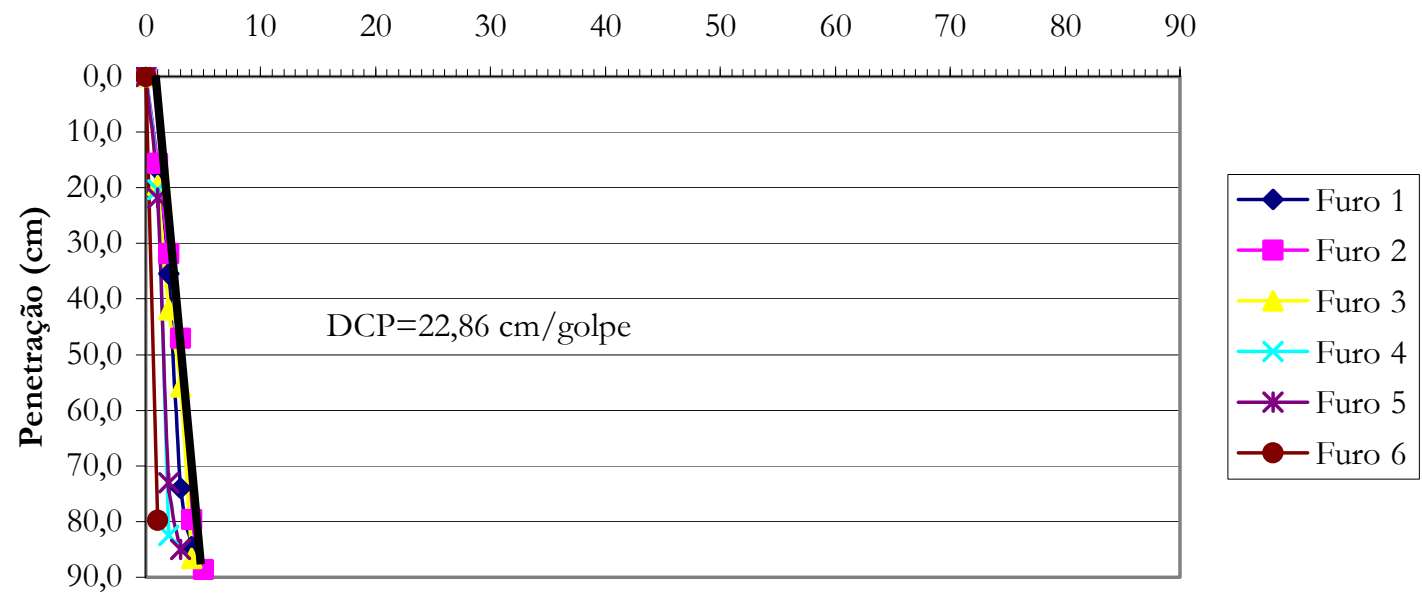

Figura 5.20 - Resultados de controle de compactação com DCP na Vala Profunda Não Compactada após a simulação de tráfego 
Número de Golpes

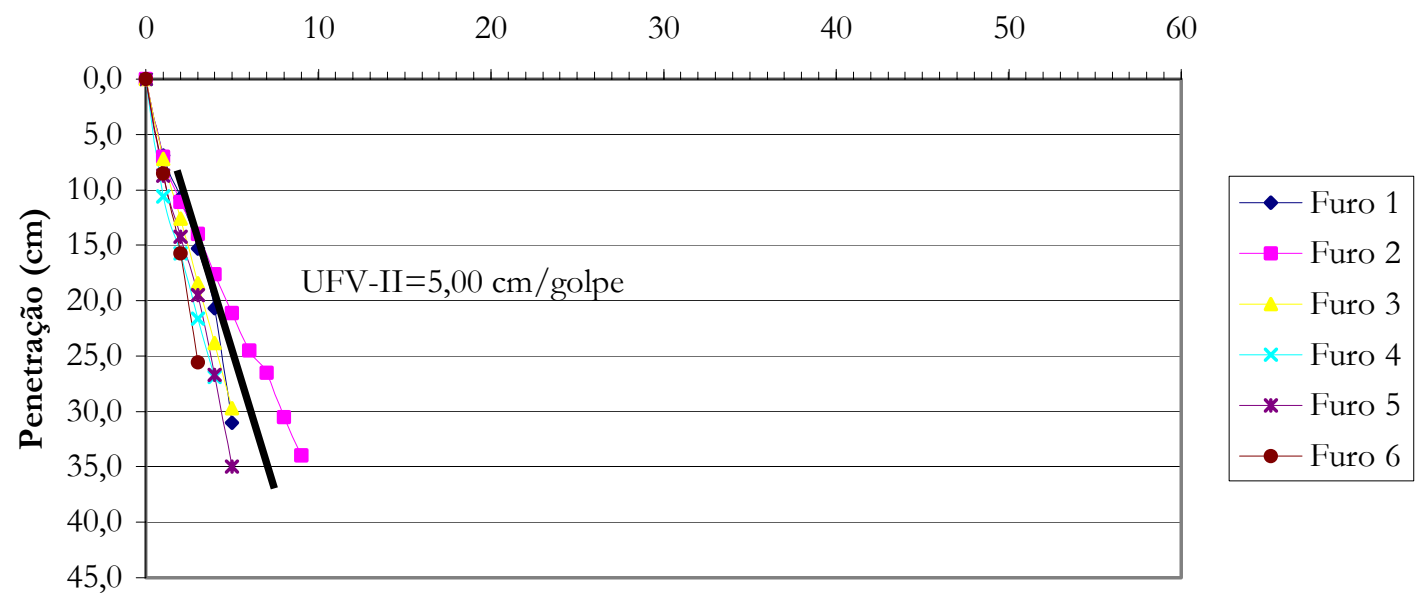

Figura 5.21 - Resultados de controle de compactação com UFV-II na Vala Profunda Não Compactada após a simulação de tráfego

Nota-se que a areia pode facilmente ganhar resistência quando o confinamento ou grau de compactação é muito baixo. No entanto, comparando-se valores de DCP obtidos deve-se realçar que a areia apenas depositada (provavelmente em estado fofo) é ainda cerca de 6 a 10 vezes menos resistente que aquela que foi densificada com equipamentos de compactação.

Pode-se observar também que para o UFV-II foram obtidas curvas de Penetração vs. Número de Golpes não tão uniformes quanto às obtidas nos ensaios com o DCP. No entanto, dois fatos não podem ser esquecidos. Primeiro, o equipamento avalia somente a camada mais superficial do material, região onde se sabe que a areia não fica confinada. Segundo, o UFV-II foi desenvolvido como uma alternativa ao DCP na análise de materiais não convencionais, mais especificamente solo arenoso fino laterítico, portanto este talvez não seja o equipamento mais adequado para o controle de compactação da areia. 


\subsubsection{Equipamento de Impacto Clegg}

A Figura 5.22 (a) e (b) mostra o uso do equipamento de impacto Clegg no controle de compactação na superfície das valas-teste na Área de Pesquisas e Testes de Pavimentos UFRGS/DAER-RS.

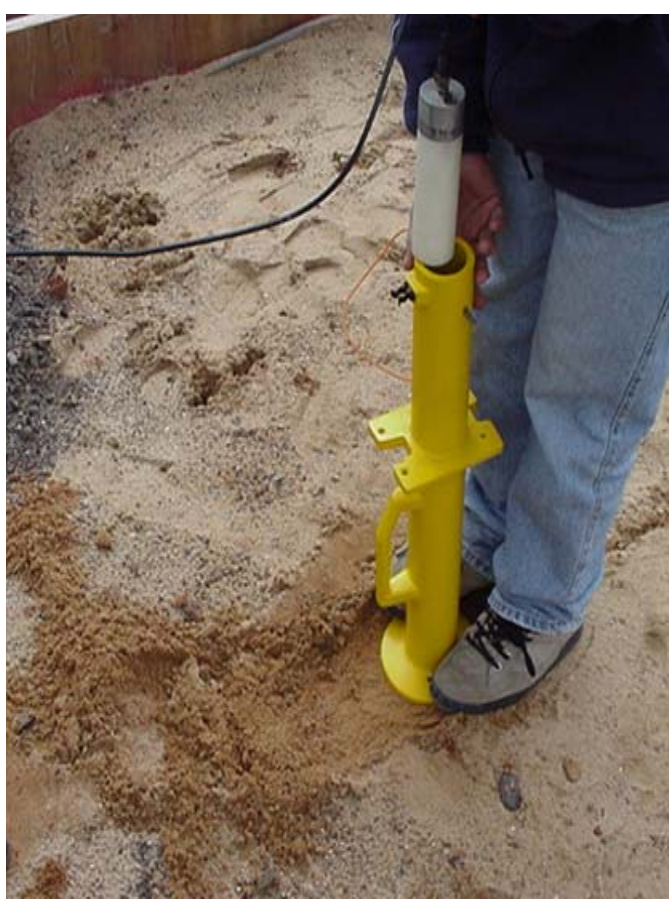

(a)

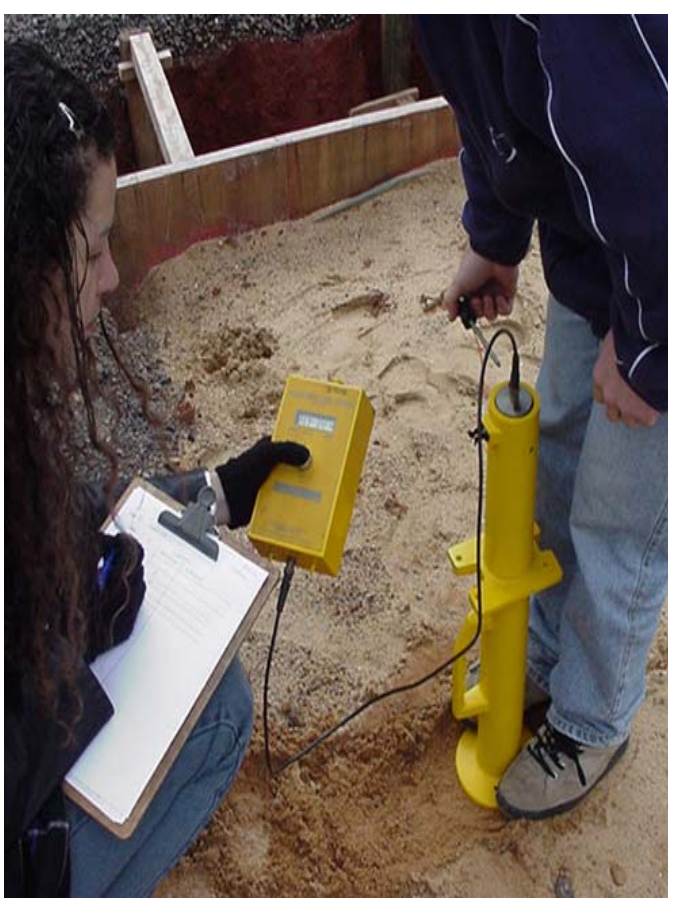

(b)

Figura 5.22 - Ensaio com o Equipamento de Impacto Clegg para controle de compactação das valas-teste na Área de Pesquisas e Testes de Pavimentos

\section{UFRGS/DAER-RS}

Os ensaios com o Equipamento de Impacto Clegg foram realizados apenas na superfície das valas compactadas. As tentativas de obter resultados na superfície das valas não compactadas antes da simulação foram frustradas. Entretanto, após a realização da simulação de carga pôde-se obter alguns resultados consistentes nas valas onde o material de envolvimento não foi compactado, devido à densificação promovida pelo assentamento dos blocos de concreto usados no revestimento e pelo próprio ensaio. Além disso, as chuvas devem ter influenciado no estado do material, como já foi dito anteriormente. 
Na Tabela 5.1 são apresentados os valores de CBR obtidos pela correlação de Clegg (1983) em cada ponto de ensaio.

Tabela 5.1 - Resultados de CBR obtidos através da correlação de Clegg (1983)

\begin{tabular}{ccccccc}
\hline \multirow{2}{*}{ Pontos } & \multicolumn{2}{c}{ Antes da Simulação } & \multicolumn{5}{c}{ Depois da Simulação } \\
\cline { 2 - 7 } & PC & RC & PC & RC & RNC & PNC \\
\hline 1 & 34 & 106 & 25 & 20 & 16 & - \\
\hline 2 & 44 & 59 & 16 & - & 25 & 81 \\
\hline 3 & 47 & - & 18 & 40 & 51 & 34 \\
\hline 4 & 59 & - & 18 & 7 & - & - \\
\hline 5 & 51 & 86 & 18 & - & 28 & 23 \\
\hline 6 & - & 142 & 25 & 12 & 40 & - \\
\hline Média & 47 & 98 & 20 & 20 & 32 & 46 \\
\hline PC: & $\begin{array}{l}\text { Profunda Compactada } \\
\text { RC: }\end{array}$ & & & & \\
RNC: & $\begin{array}{l}\text { Rasa Compactada } \\
\text { PNCa Compactada }\end{array}$ & & & & \\
Profunda Não Compactada & & & & & \\
\hline
\end{tabular}

Os resultados de CBR obtidos pela correlação de Clegg (1983) mostram uma grande dispersão. Para a Valas Profundda Compactada antes da aplicação de carga pode-se observar valores de aproximadamente $34 \%$ até $59 \%$. Na Vala Rasa Compactada os valores atingiram $59 \%$ até $142 \%$ ! Ainda que a compactação não estivesse homogênea, uma variação dessa magnitude torna esses resultados pouco confiáveis. Deve-se realçar que o DCP não mostrou variação de tal monta que o Clegg exibiu. No caso da Vala Profunda Compactada, o DCP praticamente não variou nos seis pontos de controle.

Ao contrário das valas não compactadas, nas valas em que a areia foi compactada observa-se uma redução dos Valores de Impacto e, conseqüentemente, dos valores de CBR obtidos. Esses resultados são semelhantes aos obtidos com os cones de penetração dinâmica, porém com diferenças mais pronunciadas. Não há, no entanto, uma razão muito clara da grande disparidade de valores de CBR encontrados em materiais compactados e não compactados após a simulação. A calibração de equipamentos desta natureza é tarefa obrigatória para seu uso. Os valores encontrados não permitem 
emprego de forma simples, seja em projeto, como para rejeição ou aceitação em controle de obras.

\subsection{Simulação de Campo}

\subsubsection{Instalaçções e Carregamentos Empregados}

O Simulador de Tráfego UFRGS/DAER-RS foi desenvolvido para uso em estudos e pesquisas rodoviárias. O simulador de tráfego tem aproximadamente 15 metros de comprimento, 2,5 metros de largura e 4,3 metros de altura; o curso de aplicação de carga sobre o pavimento é de 8 metros; o curso de aceleração e desaceleração é de 3 metros; a carga aplicada sobre o pavimento é regulável de 0 a $65 \mathrm{kN}$; seu princípio de aplicação de carga é hidráulico, com aplicação de carga linear, unidirecional, não tracionada; seu sistema de rodado pode ser simples ou duplo, articulado e regulável; sua velocidade de deslocamento é regulável de até $20 \mathrm{~km} / \mathrm{h}$; seu princípio de acionamento geral é elétrico (Ceratti e Oliveira, 1993).

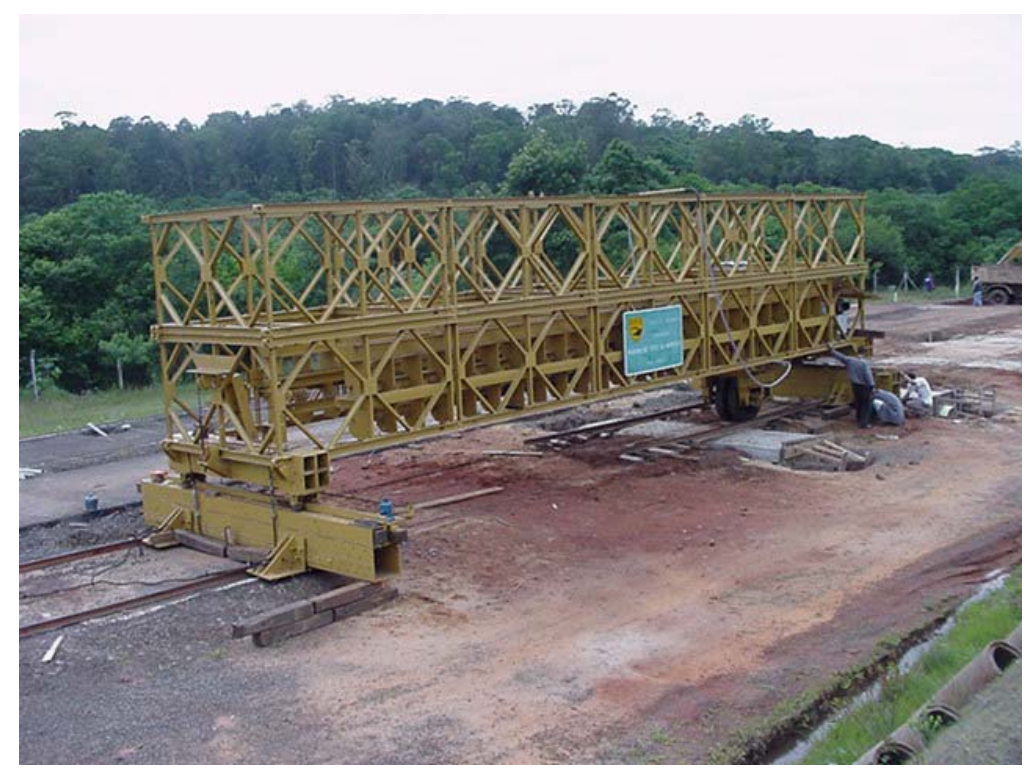

Figura 5.23 - Simulador de Tráfego UFRGS/DAER-RS

Para cada vala foram feitas solicitações dinâmicas e estáticas, sendo que a carga aplicada variou de um valor mínimo de 3,0 tf a um valor máximo de 6,0 tf, conforme já apresentado no Capítulo 4. Os ensaios realizados em primeiro lugar foram os ensaios 
dinâmicos, pois estes possivelmente causariam menor deformação permanente no sistema solo-tubo do que os ensaios estáticos.

A seqüência de ensaio em cada vala começou com três passagens da carga mínima estabelecida para a vala ensaiada, seguiram-se três aplicações estáticas de carga de mesma magnitude durante cinco minutos, sendo que o intervalo entre cada aplicação de carga estática era o suficiente para estabilizar a leitura do sensor, ou seja, para que o tubo recuperasse o deslocamento não permanente. A seguir aumentou-se a carga aplicada pelo simulador de tráfego e seguiu-se a mesma seqüência anterior até atingir-se a carga máxima aplicada.

Os valores das cargas aplicadas em cada vala são mostrados na Tabela 5.2, devendo-se salientar que para cada nível de carregamento, sem exceção, foram realizadas tanto solicitações dinâmicas como estáticas, como descrito anteriormente.

Tabela 5.2 - Cargas aplicadas em cada vala

\begin{tabular}{lc}
\hline \multicolumn{1}{c}{ Vala } & Carga Aplicada (tf) \\
\hline Profunda Compactada & 3,$0 ; 4,5$ e 6,0 \\
\hline Rasa Compactada & 3,$0 ; 4,0 ; 5,0$ e 6,0 \\
\hline Rasa Não Compactada & 3,$0 ; 4,0$ e 5,0 \\
\hline Profunda Não Compactada & 3,$0 ; 4,5$ e 6,0 \\
\hline
\end{tabular}

\subsubsection{Deslocamentos Medidos}

Os resultados obtidos de deslocamentos dos tubos devido à solicitação de carga pelo simulador são apresentados nas Figuras 5.24 a 5.26 para a Vala Profunda Compactada, nas Figuras 5.27 a 5.30 para a Vala Rasa Compactada, nas Figuras 5.31 a 5.33 para a Vala Rasa Não Compactada, e nas Figuras 5.34 a 5.36 para a Vala Profunda Não Compactada.

Os resultados de ensaios estão agrupados por carga: para o ensaio com carga de 3,0 toneladas, por exemplo, o gráfico mostra os resultados das três aplicações de carga dinâmica e das três aplicações de carga estática. 


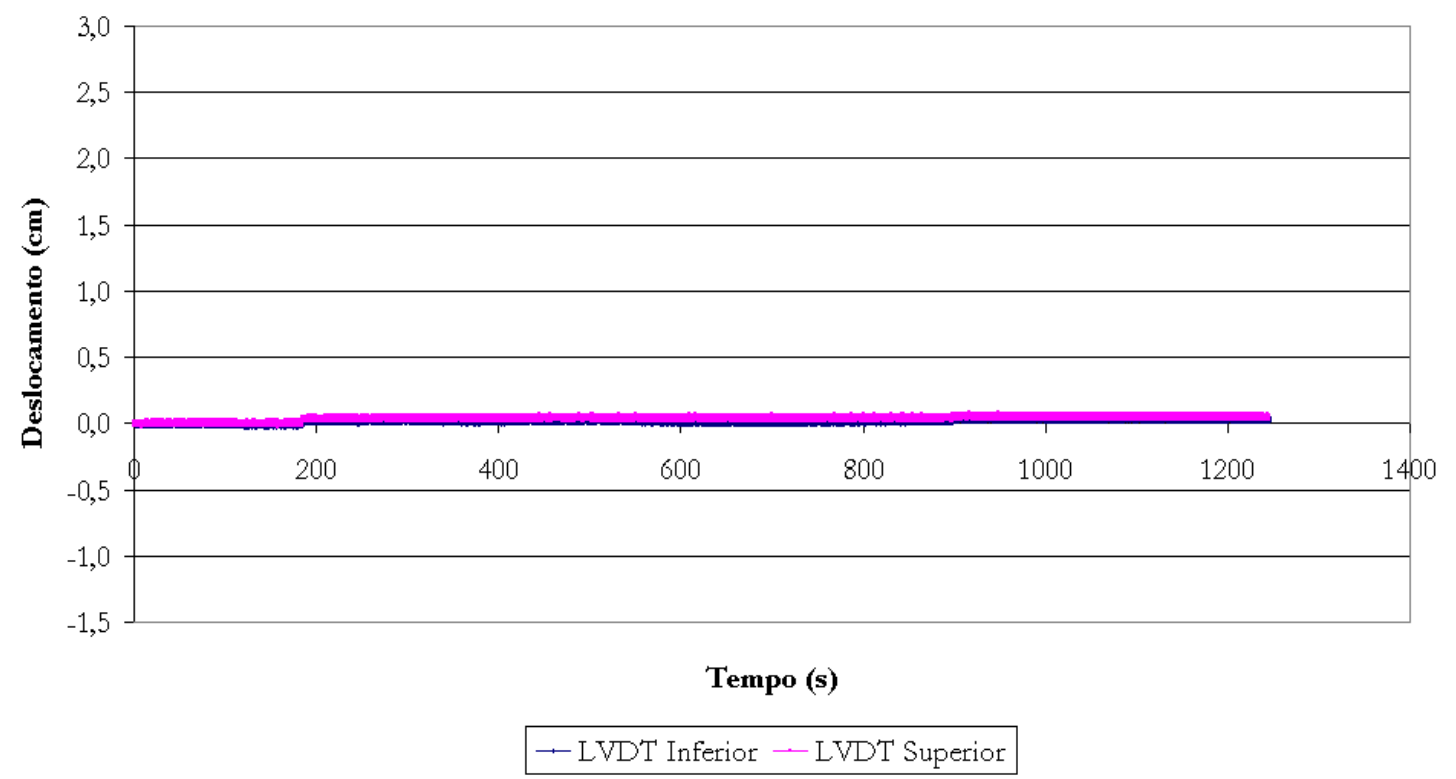

Figura 5.24 - Resultados de deslocamento com carga de 3,0 tf para na Vala Profunda Compactada

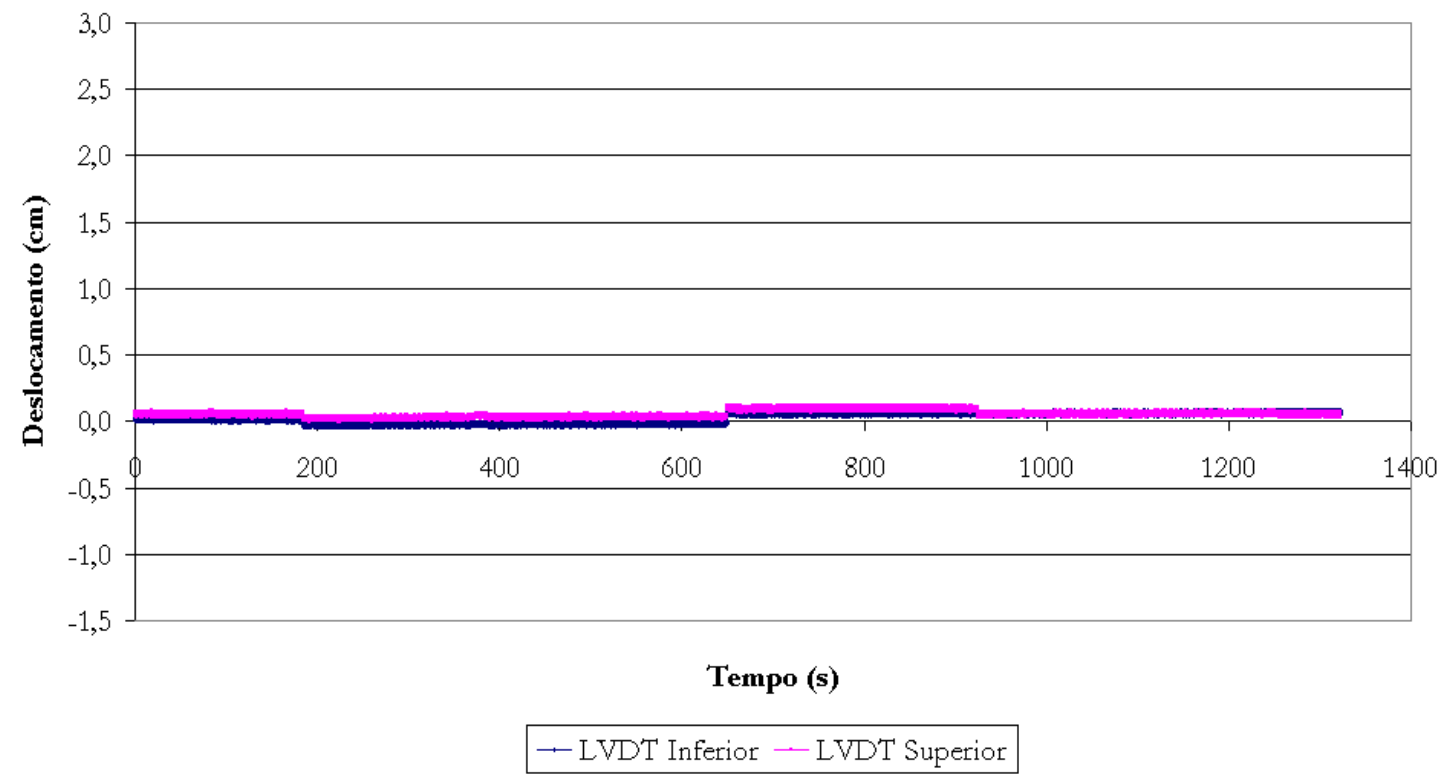

Figura 5.25 - Resultados de deslocamento com carga de 4,5 tf para na Vala Profunda Compactada 


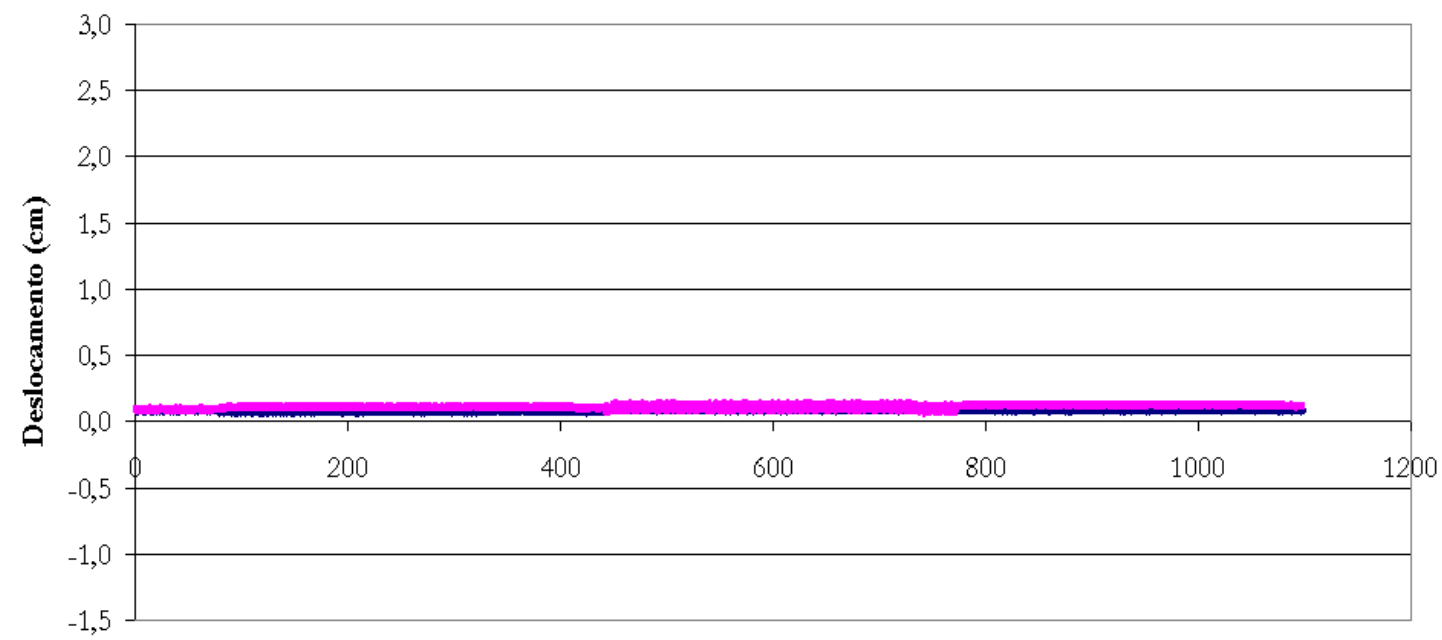

Tempo (s)

- LVDT Inferior - LVDT Superior

Figura 5.26 - Resultados de deslocamento com carga de 6,0 tf para na Vala Profunda Compactada

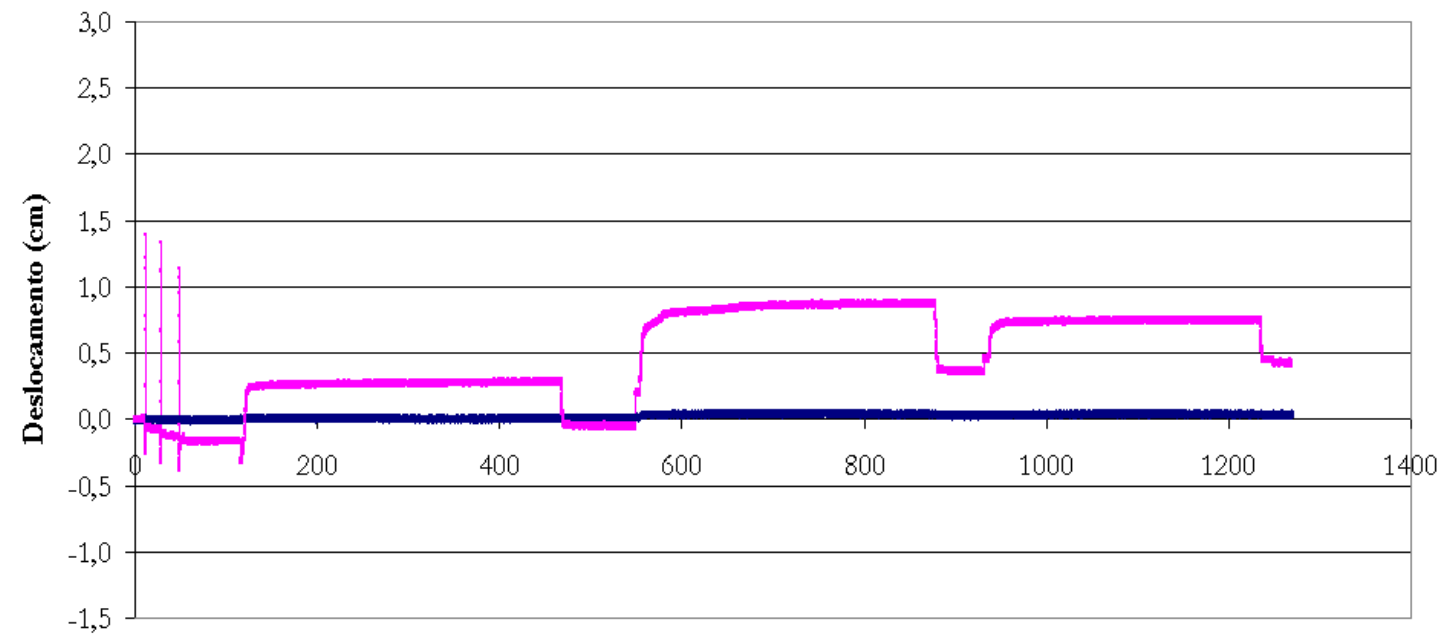

Tempo (s)

- LVDT Inferior - LVDT Superior

Figura 5.27 - Resultados de deslocamento com carga de 3,0 tf para na Vala Rasa

Compactada 


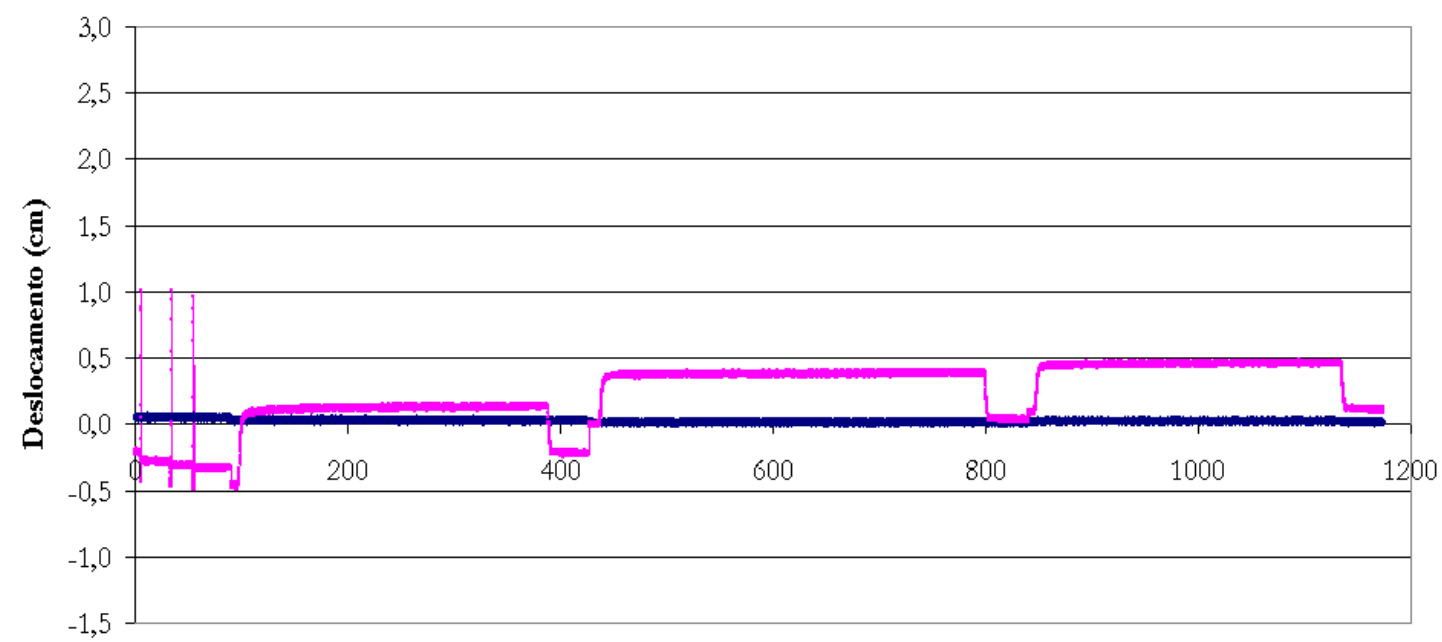

Tempo (s)

- LVDT Inferior - LVDT Superior

Figura 5.28 - Resultados de deslocamento com carga de 4,0 tf para na Vala Rasa Compactada

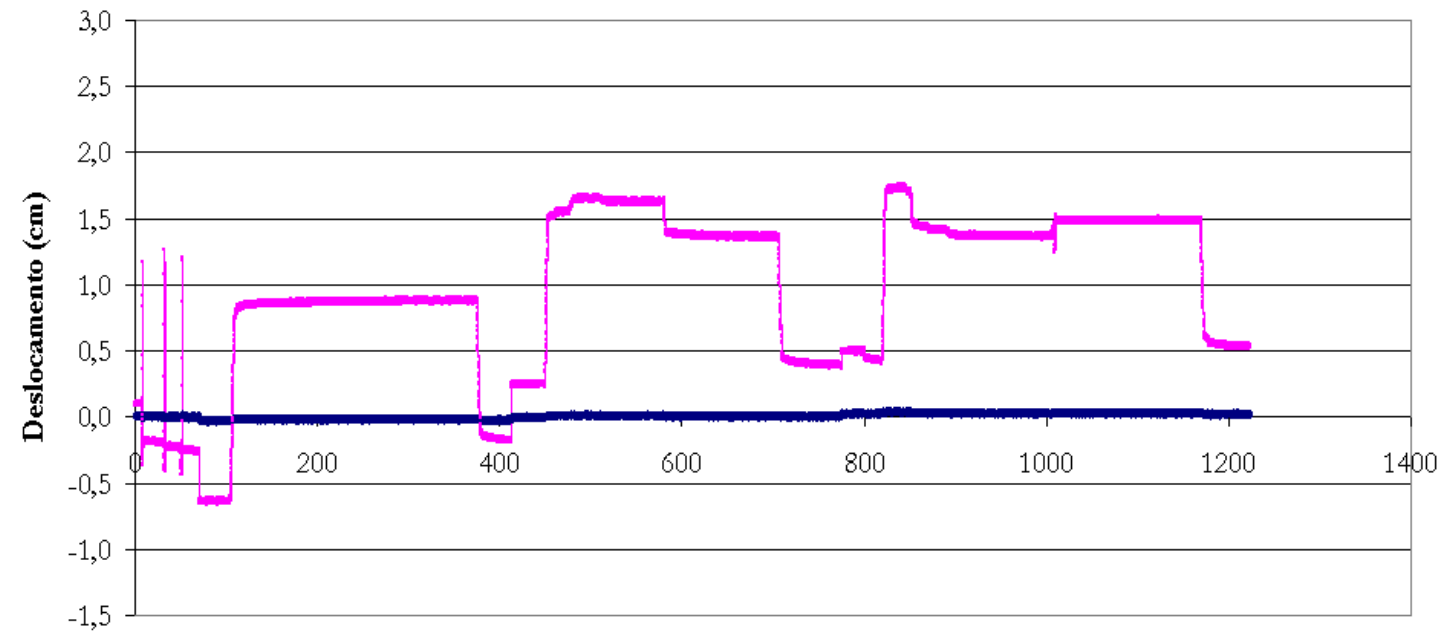

Tempo (s)

$\rightarrow$ LVDT Inferior - LVDT Superior

Figura 5.29 - Resultados de deslocamento com carga de 5,0 tf para na Vala Rasa Compactada 


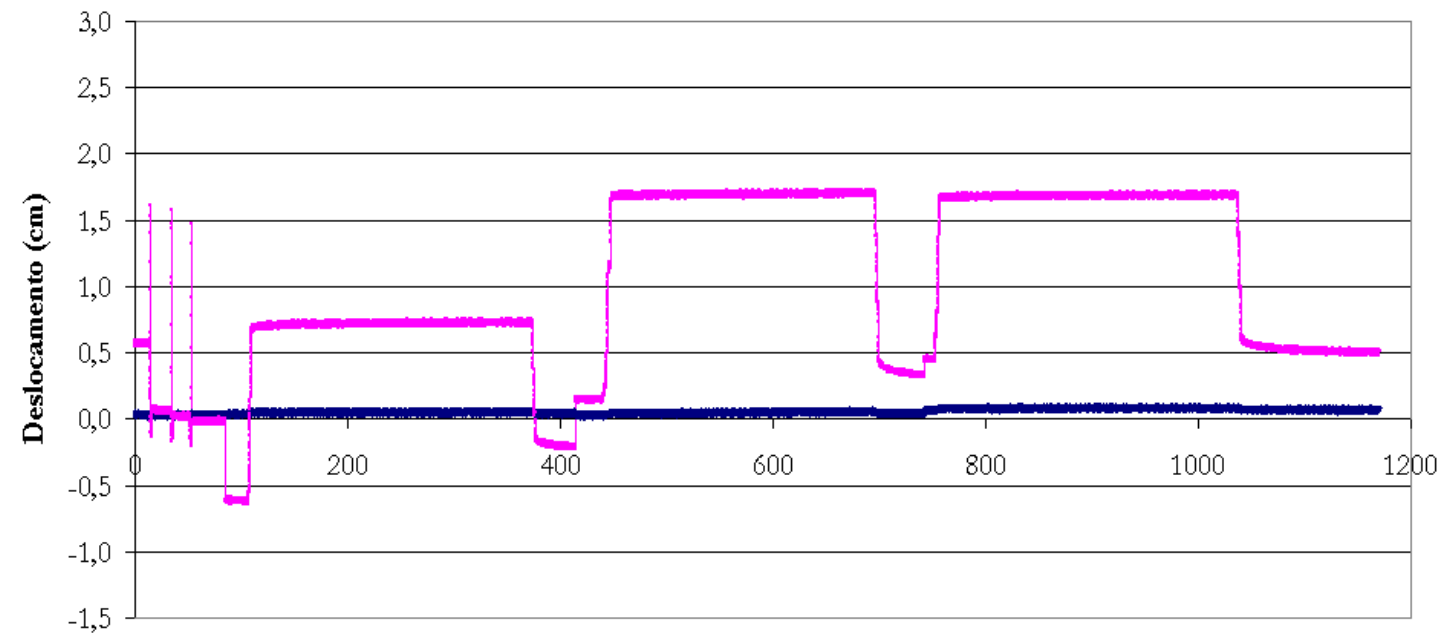

Tempo (s)

- LVDT Inferior - LVDT Superior

Figura 5.30 - Resultados de deslocamento com carga de 6,0 tf para na Vala Rasa Compactada

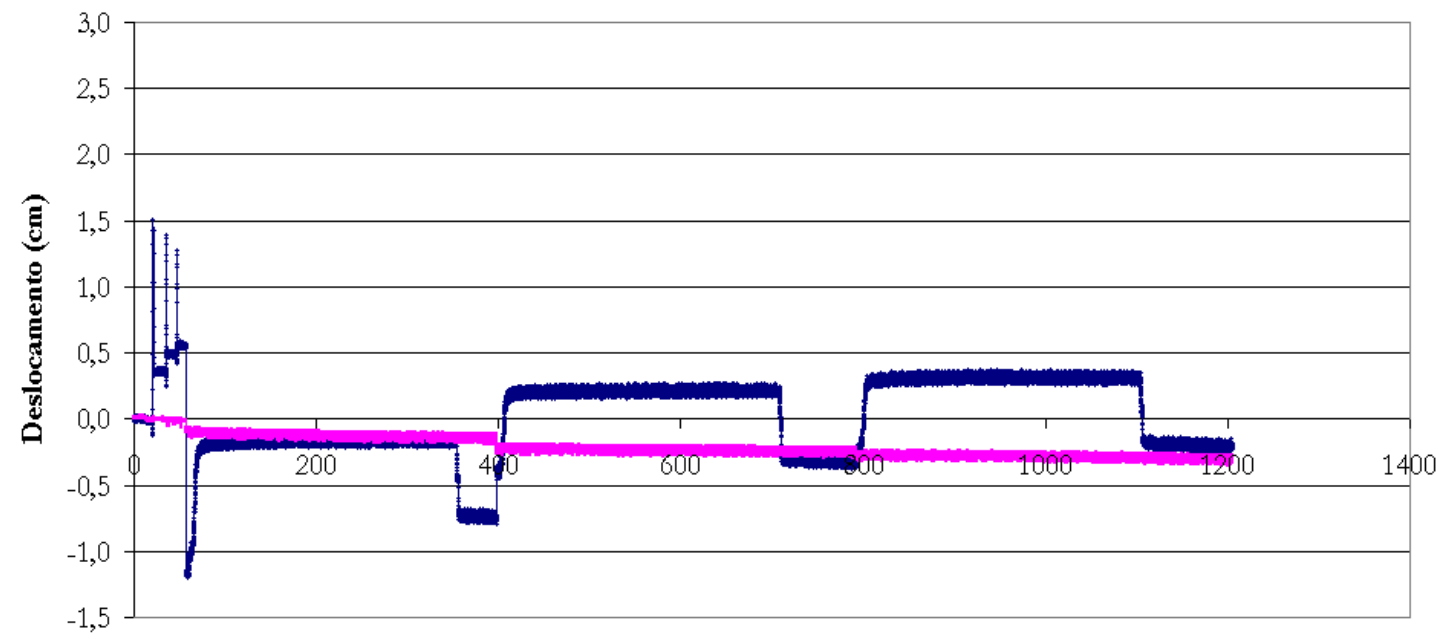

Tempo (s)

LVDT Superior - LVDT Inferior

Figura 5.31 - Resultados de deslocamento com carga de 3,0 tf para na Vala Rasa Não Compactada 


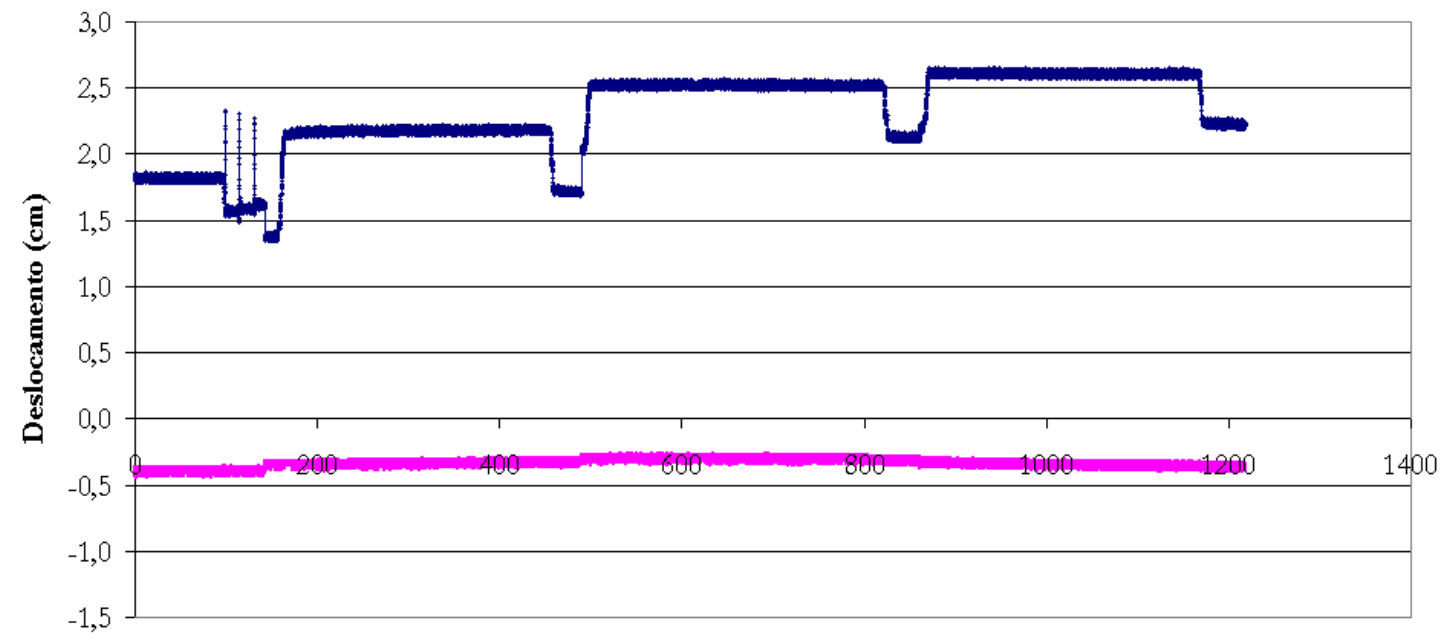

Tempo (s)

$\rightarrow$ LVDT Superior - LVDT Inferior

Figura 5.32 - Resultados de deslocamento com carga de 4,0 tf para na Vala Rasa Não Compactada

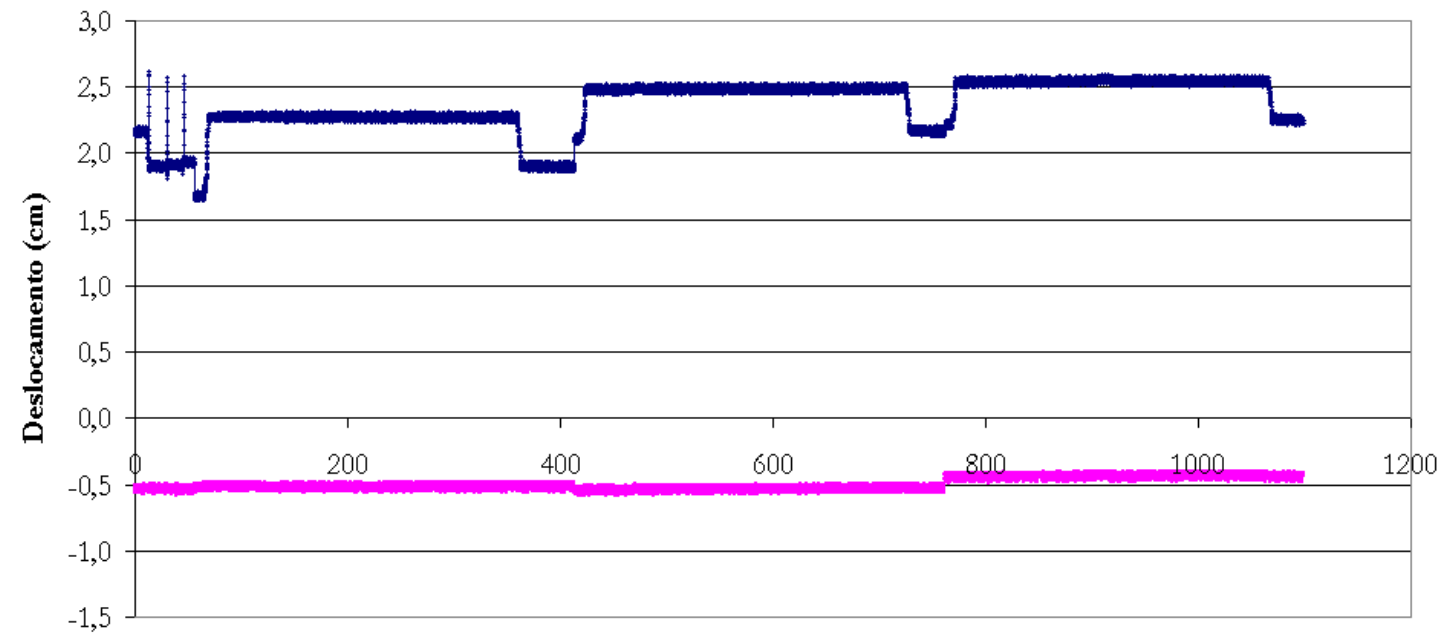

Tempo (s)

- LVDT Superior - - LVDT Inferior

Figura 5.33 - Resultados de deslocamento com carga de 5,0 tf para na Vala Rasa Não Compactada 


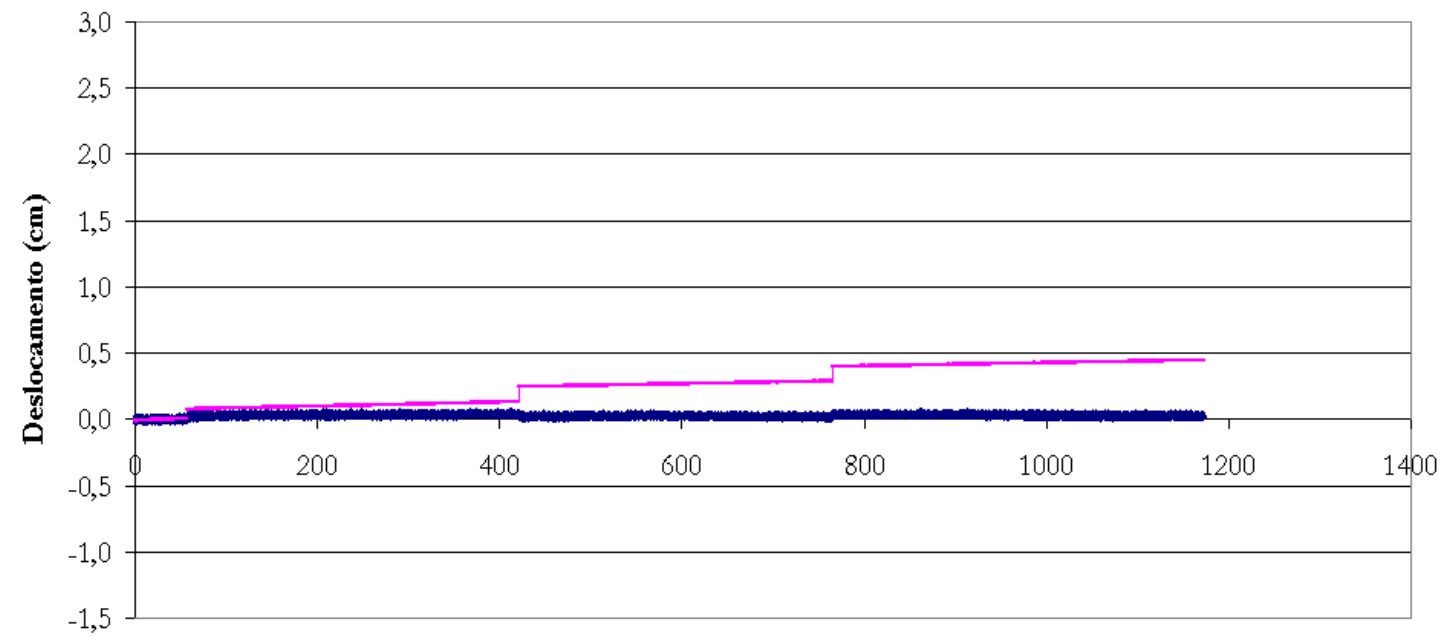

Tempo (s)

$\rightarrow$ LVDT Inferior - LVDT Superior

Figura 5.34 - Resultados de deslocamento com carga de 3,0 tf para na Vala Profunda Não Compactada

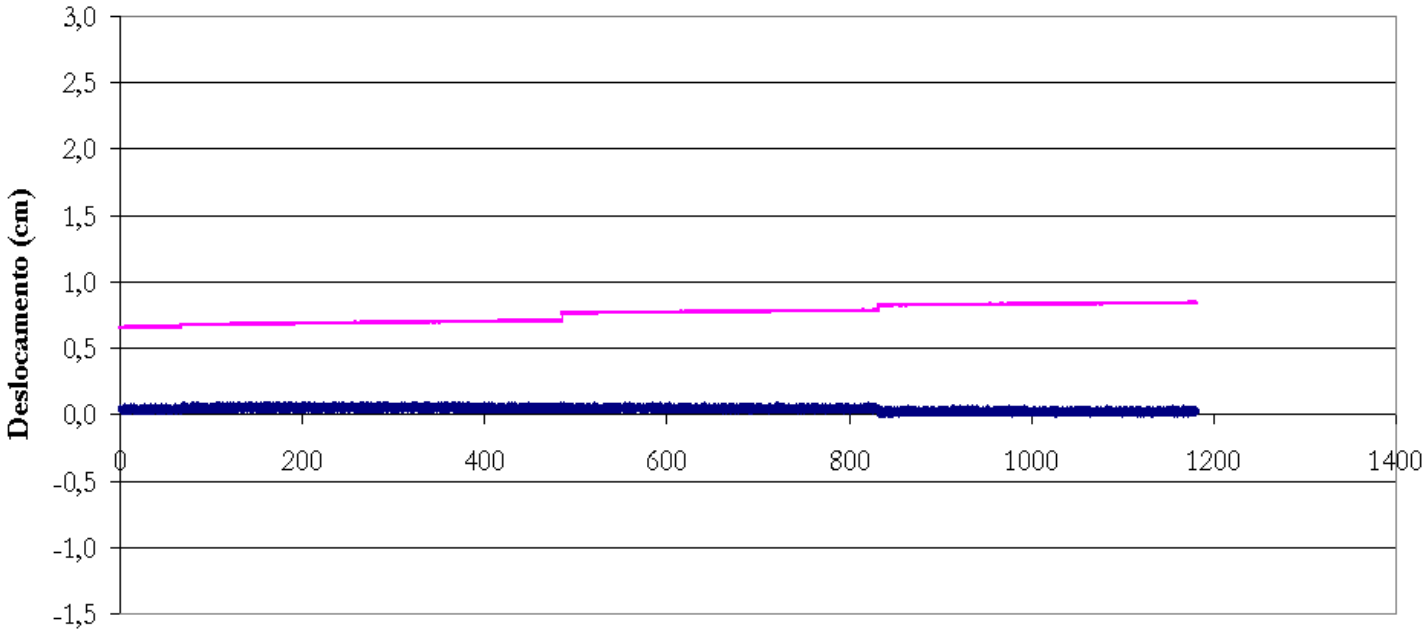

Tempo (s)

- LVDT Inferior - - LVDT Superior

Figura 5.35 - Resultados de deslocamento com carga de 4,5 tf para na Vala Profunda Não Compactada 


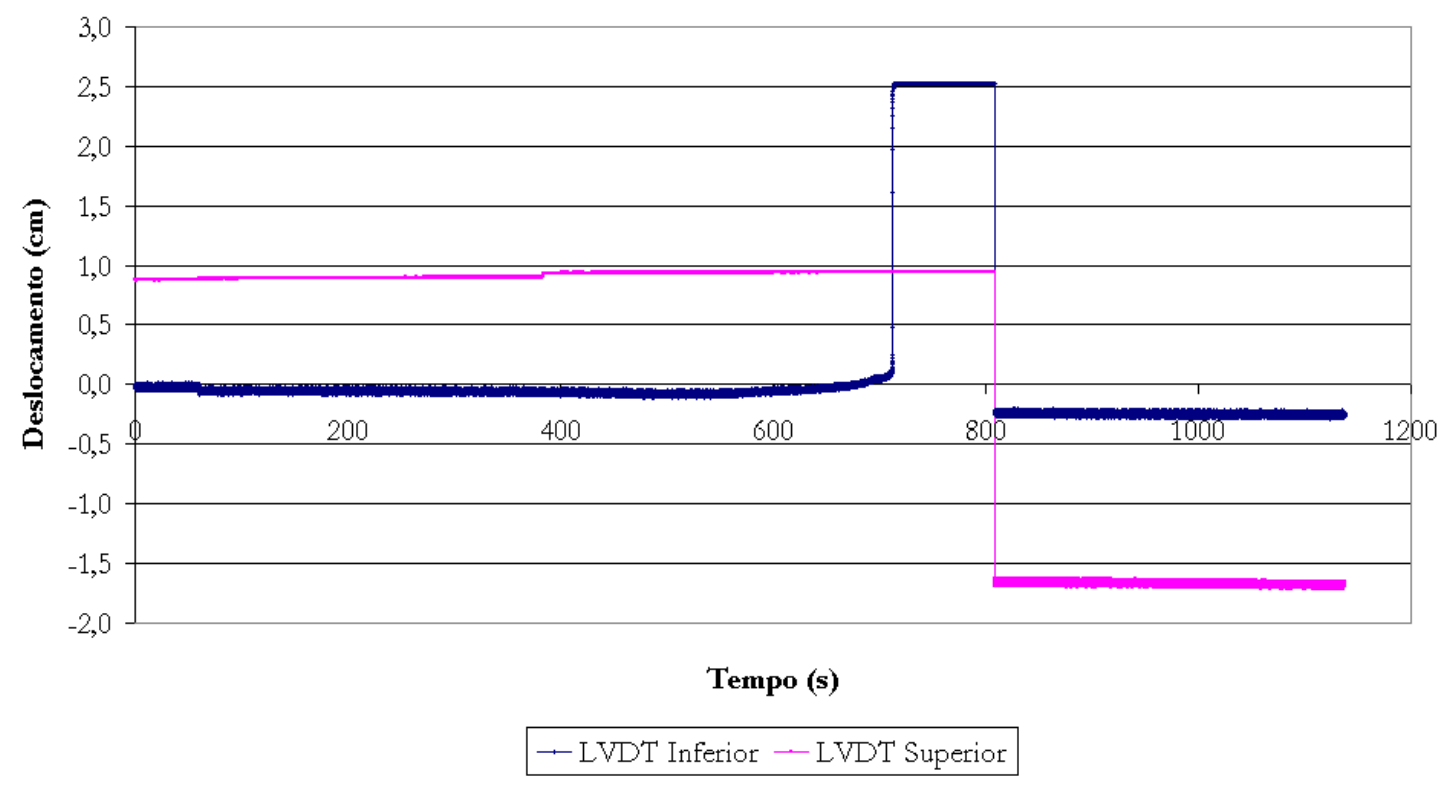

Figura 5.36 - Resultados de deslocamento com carga de 6,0 tf para na Vala Profunda Não Compactada

\subsubsection{Discussão sobre Registros e Dificuldades do Experimento}

Na Vala Profunda Compactada foram registradas leituras de deslocamento dos tubos praticamente nulas - Figuras 5.24 a 5.26. As pouco significativas variações nas respostas de deslocamento registradas pelos sensores, da ordem de décimos de milímetro, podem ter sido causadas por deslocamento relativo do LVDT em relação à parede do tubo, já que os mesmos não foram fixados ao tubo e têm hastes bastante esbeltas. Tal fato pode ter influenciado as leituras nas demais valas da mesma forma.

A dificuldade de posicionar o rodado do simulador de tráfego exatamente em cima do sensor de medida de deslocamento (LVDT) localizado para registrar a variação do diâmetro vertical do tubo influenciou as leituras registradas. Nas valas rasas, a carga de roda levou inicialmente a um deslocamento contrário, de aumento do diâmetro na vertical, com extensão do tubo nesta direção. O cobrimento nessas valas era muito pouco espesso, cerca de 20 a $30 \mathrm{~cm}$, e conseqüentemente qualquer deslocamento que fizesse com que o ponto de aplicação de carga não estivesse exatamente em cima do sensor causaria extensão e não compressão do tubo. A compressão na areia situada ao 
lado da geratriz superior do tubo pressiona o tubo ocasionando uma extensão positiva de seu diâmetro na direção vertical.

A mesma dificuldade explica possivelmente a constatação em alguns casos de deslocamentos de redução de diâmetro dos tubos, maiores nos ensaios dinâmicos em relação aos ensaios estáticos, realizados com carga de mesma magnitude. No caso de carga dinâmica, o LVDT mede os deslocamentos de forma contínua, registrando o máximo sem problemas. No entanto, no caso estático, a carga foi posicionada podendo não estar exatamente centrada com o LVDT, registrando um valor algumas vezes inferior ao máximo real, e inferior ao deslocamento registrado no caso dinâmico.

Caso fosse colocada uma placa rígida sobre a superfície da vala e fosse aplicasse a carga, esta representaria uma altura adicional de solo sobre o tubo. A placa distribuiria melhor a carga e, provavelmente, ocorreria sempre compressão do tubo, no sentido vertical.

Os resultados de deslocamento podem ser vistos em maiores detalhes nos ANEXOS VI a IX.

\subsection{Avaliação das Valas após a Aplicação de Carga}

\subsubsection{Procedimentos e Medidas Realizadas após a Simulação de Carga}

Algum tempo após a simulação de tráfego sobre as valas-teste procedeu-se à retirada do material de envolvimento e dos tubos de dentro das valas. Durante esse processo foram realizados os seguintes ensaios de controle e medições complementares:

1. Medida do diâmetro interno do tubo, na vertical, ao longo de todo perfil, com trena eletrônica. Esse procedimento foi realizado para as quatro valas;

2. Medida da deformação permanente na trilha de roda com auxílio de treliça ou régua para as quatro valas experimentais;

3. Controle de densidade "in situ"

3.1. Para as valas rasas adotou-se o seguinte procedimento: 
- Retirada dos blocos pré-moldados de concreto utilizados como revestimento;

- Remoção em alguns pontos (três de cada lado do tubo - entre tubo e parede da vala) de um pouco da areia, cerca de 20 centímetros, cavando um orifício de cerca de vinte a trinta centímetros de diâmetro. Após escavação do orifício, foi realizado o cravamento de cilindro nos próximos quinze centímetros para a determinação da densidade e compacidade de campo. A escavação inicial foi executada para não perder o efeito do confinamento;

- Remoção de toda a areia sobre o tubo até atingir a geratriz superior;

- Medida do diâmetro vertical do tubo interno, segundo o procedimento do item 1 anterior;

- Realização de novo ensaio de cravação do cilindro, de acordo com o procedimento apresentado acima;

- Remoção de toda a areia;

- Medida da profundidade total da vala (superfície até topo do berço).

3.2. Para as valas profundas adotou-se o seguinte procedimento:

- Remoção dos blocos pré-moldados de concreto utilizados como revestimento;

- Realização de ensaio de cravação do cilindro, de acordo com o procedimento do item 3.1;

- Remoção da areia na profundidade de cerca de 1 metro e nova verificação de densidade segundo o procedimento já apresentado;

- Remoção da areia sobre o tubo até atingir a geratriz superior do mesmo;

a Medida do diâmetro interno do tubo, segundo o procedimento do item 1;

- Realização de ensaio de cravação do cilindro, de acordo com o procedimento já apresentado;

- Remoção de toda a areia;

- Medida da profundidade total da vala (superfície até topo do berço).

\subsubsection{Afundamentos em Trilhas de Rodas}

O afundamento em trilha de roda medido para cada vala consta da Tabela 5.3. 
Tabela 5.3 - Afundamento em trilha de roda medido após o ensaio

\begin{tabular}{lc}
\hline \multicolumn{1}{c}{ Vala } & Profundidade nas trilhas de roda \\
\hline Profunda Compactada & $1,0 \mathrm{~cm}$ \\
\hline Rasa Compactada & $4,5 \mathrm{~cm}$ \\
\hline Rasa Não Compactada & $4,6 \mathrm{~cm}$ \\
\hline Profunda Não Compactada & $5,0 \mathrm{~cm}$ \\
\hline
\end{tabular}

$\mathrm{Na}$ Figura 5.37 podem ser vistas fotos das superfícies das valas após a realização dos ensaios com o simulador de tráfego.

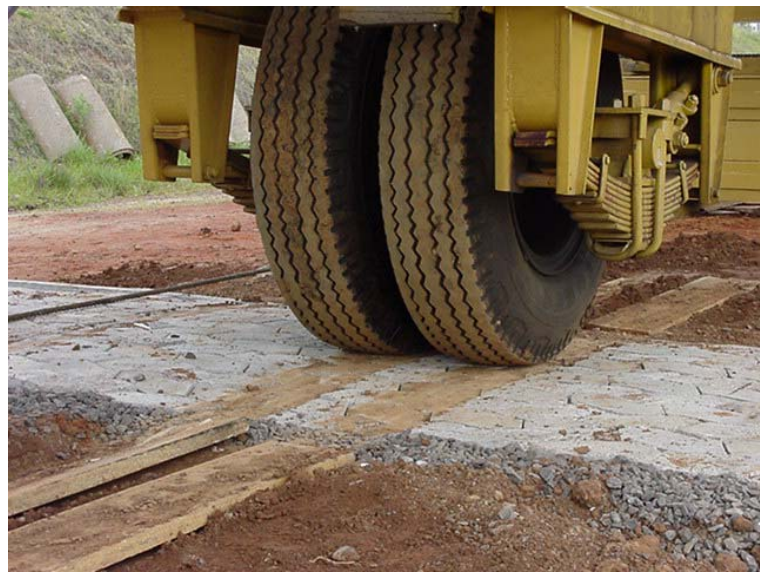

(a)

Vala Profunda Compactada

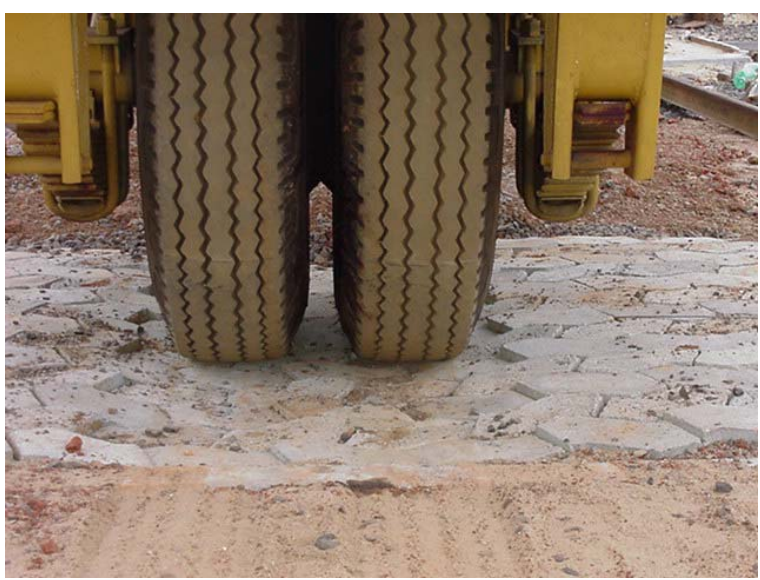

(c)

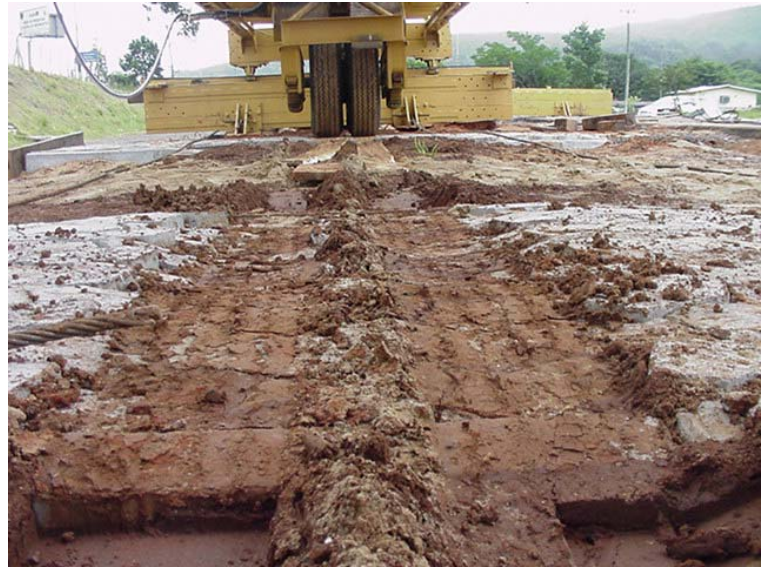

(b)

Vala Rasa Compactada

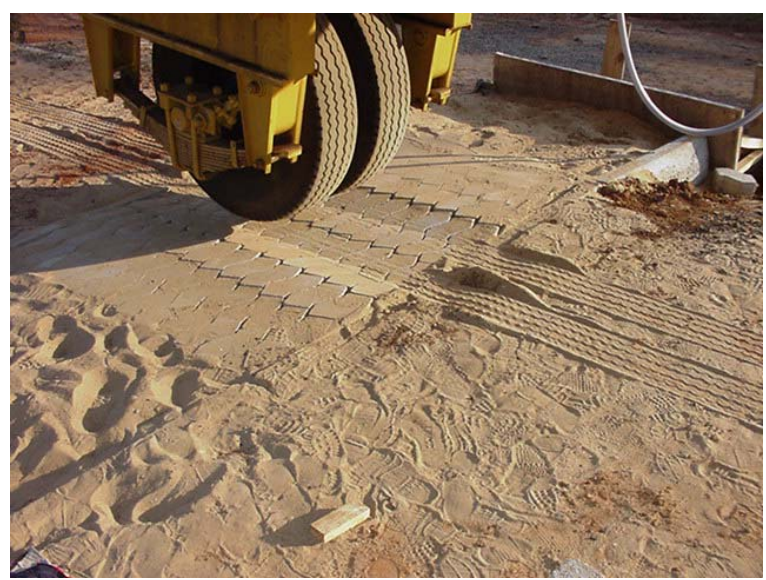

(d)

Vala Rasa Não Compactada

Vala Profunda Não Compactada

Figura 5.37 - Superfície das valas-teste após a simulação de tráfego 
Constata-se a importância da compactação da areia e de seu confinamento para reduzir problemas em trilhas de rodas. Os resultados da vala profunda não compactada mostram que a falta de compactação leva ao comprometimento do sistema como um todo.

Os testes nas valas rasas demonstram que mesmo compactada, uma areia mal graduada não oferece resistência suficiente para o tipo de solicitação realizada. As deformações permanentes são de tal magnitude que inviabilizam a seleção deste tipo de areia em sistemas onde o tubo está muito próximo à superfície.

\subsubsection{Medidas realizadas no interior dos tubos}

Os resultados de medida do diâmetro interno dos tubos são apresentados nas Figuras 5.38 a 5.41 .

Foram realizadas três medidas de diâmetro interno nos tubos: uma quando a vala estava totalmente preenchida e revestida por blocos de concreto antes do ensaio, designada na legenda das figuras por "Antes do Ensaio"; outra medida nas mesmas condições, mas após o ensaio de aplicação de carga, denominada "Depoois do Ensaio"; e outra quando da retirada do material, com o material de envolvimento no nível da geratriz superior do tubo, identificada por "Diâmetro Inicial". As últimas medidas, com a areia no nível da geratriz superior do tubo, foram utilizadas como diâmetro inicial do tubo, e usadas na Fórmula de Iowa Modificada para cálculo de valores de Módulo de Reação do Solo E' (item 6.2). 


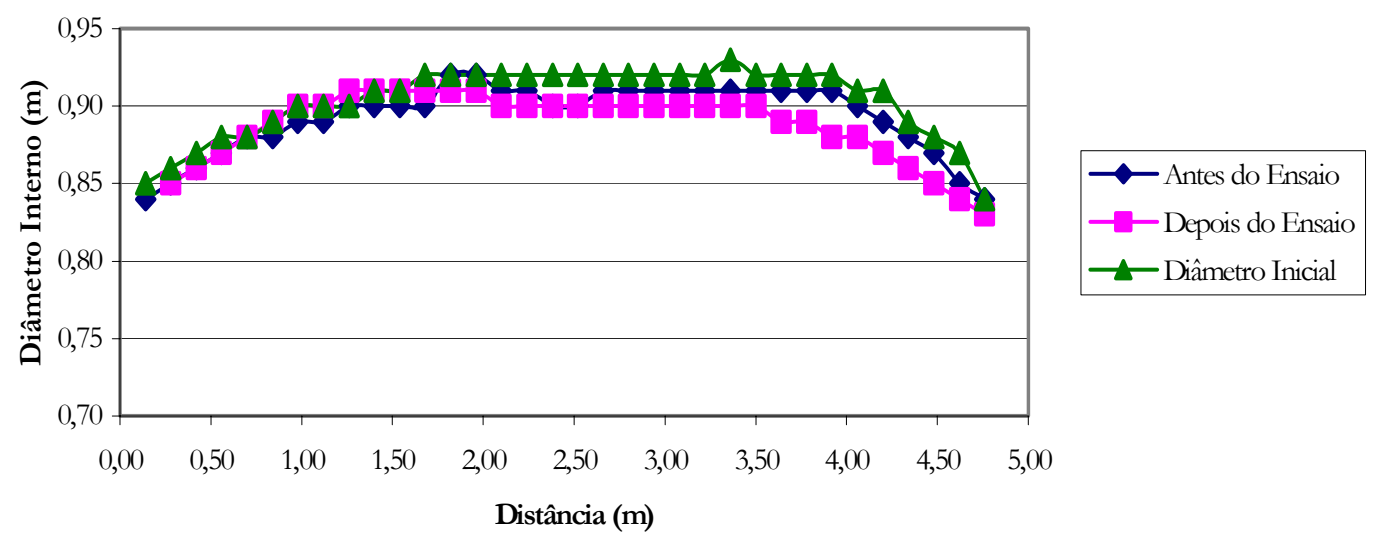

Figura 5.38 - Evolução do diâmetro interno do tubo na Vala Profunda Compactada

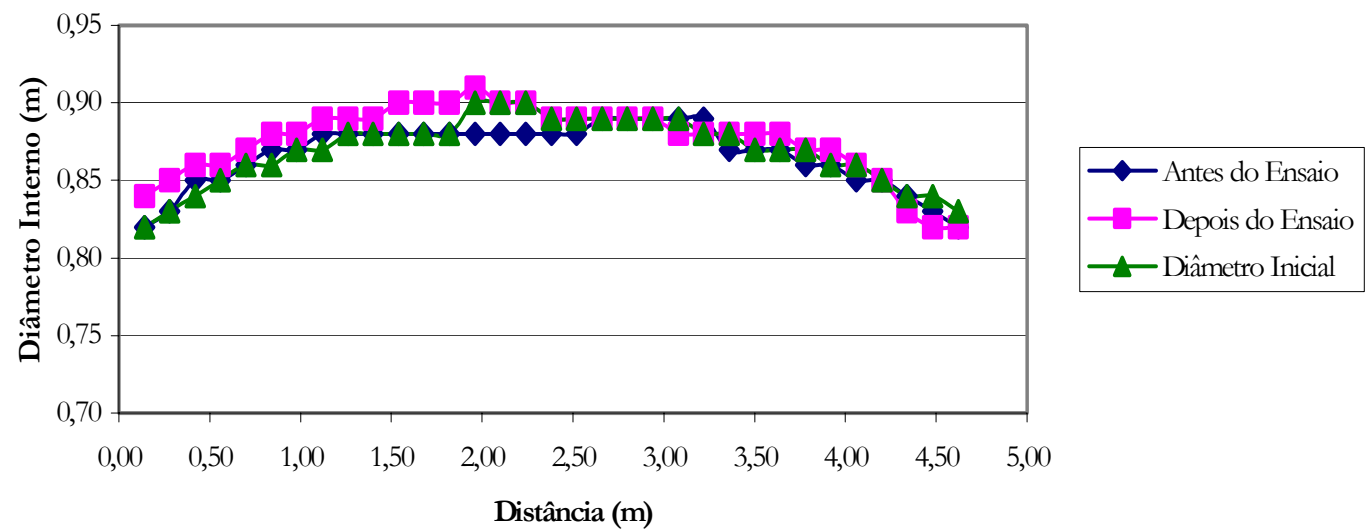

Figura 5.39 - Evolução do diâmetro interno do tubo na Vala Rasa Compactada

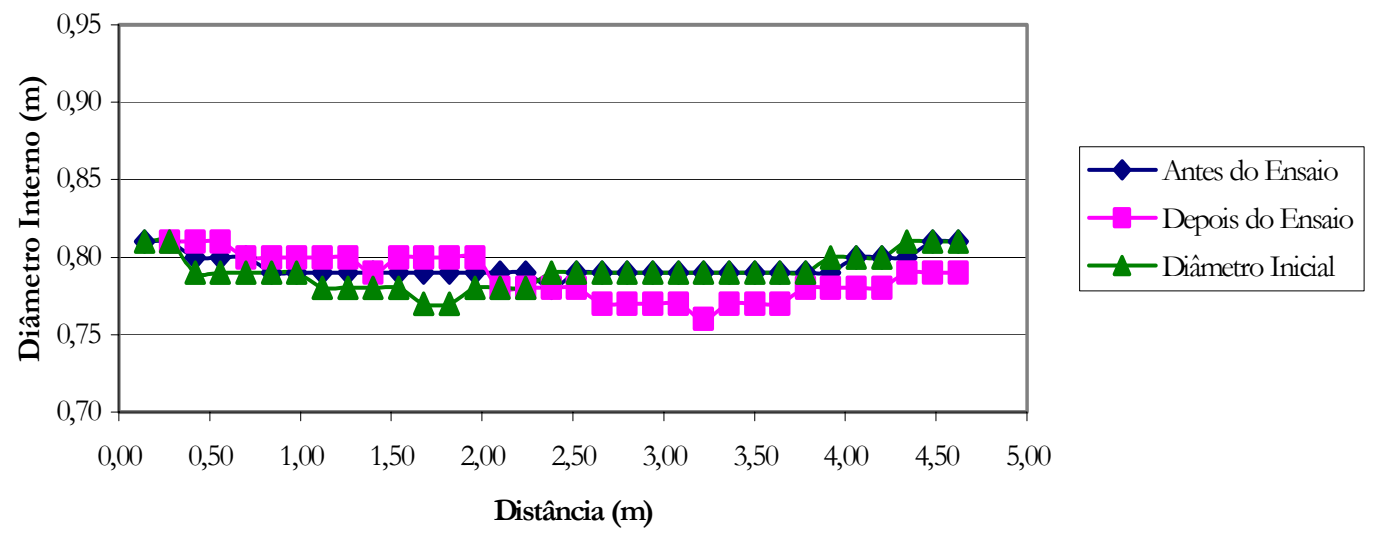

Figura 5.40 - Evolução do diâmetro interno do tubo na Vala Rasa Não Compactada 


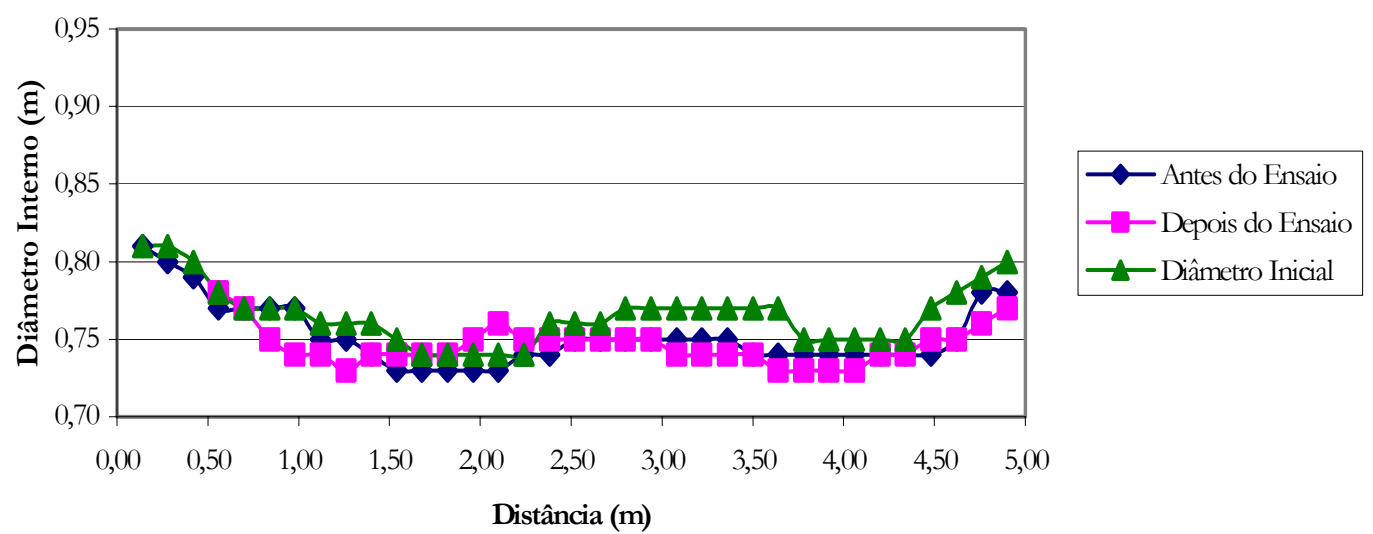

Figura 5.41 - Evolução do diâmetro interno do tubo na Vala Profunda Não Compactada

Pode-se observar curvaturas opostas nos tubos quando consideradas as valas compactadas contras as valas não compactadas. $\mathrm{O}$ aumento do diâmetro interno, em relação ao inicial, para as valas compactadas dá-se em função da compactação do material de envolvimento nas laterais do tubo, não ocorrendo mudança dessa situação durante a aplicação de carga.

\subsubsection{Controle de Compactação da Areia Após a Simulação de Carga}

O controle de densidade foi realizado pela cravação de cilindro segundo o método de ensaio DAER/RS-EL 302/99. Apesar deste método ser indicado para solos finos e coesivos, isentos de pedregulhos, foi escolhido por permitir a manutenção do confinamento da areia, o que não seria possível com a utilização do método do frasco de areia.

De forma sucinta, o procedimento de controle constitui-se em:

- o cilindro é cravado no solo, com a superfície da camada regularizada e plana, pela queda livre do soquete de cravação, tomando-se o cuidado de manter o conjunto na posição vertical;

- o processo de cravação do cilindro deve ser contínuo, sendo interrompido somente quando a sua borda superior estiver $1 \mathrm{~cm}$ abaixo da superfície do terreno; 
口 após a remoção do soquete, escava-se o solo a redor do cilindro, mantendoo na posição original, sendo retirado e posteriormente nivelado com o auxílio de régua biselada;

a pesa-se o cilindro com o solo $\left(\mathrm{P}_{\text {cilindro+solo }}\right)$;

- após a pesagem é retirada uma porção de solo da parte central do cilindro para determinação do teor de umidade.

Pesando-se somente o cilindro $\left(\mathrm{P}_{\text {cilindro }}\right)$ e subtraindo-o do peso do cilindro com solo obtém-se o peso do solo úmido contido no cilindro. A obtenção do valor da massa específica aparente seca do solo pode ser calculada após a determinação da umidade.

Os resultados dos ensaios feitos em campo podem ser vistos na Tabela 5.4. Cada valor apresentado representa a média dos valores obtidos nas seis determinações feitas em cada profundidade.

Tabela 5.4 - Grau de compactação da areia em diversas profundidades

\begin{tabular}{lcccc}
\hline \multirow{2}{*}{ Local do ensaio } & \multicolumn{4}{c}{ Grau de Compactação } \\
\cline { 2 - 5 } & $\begin{array}{c}\text { Profunda } \\
\text { Compactada }\end{array}$ & $\begin{array}{c}\text { Rasa } \\
\text { Compactada }\end{array}$ & $\begin{array}{c}\text { Rasa Não } \\
\text { Compactada }\end{array}$ & $\begin{array}{c}\text { Profunda Não } \\
\text { Compactada }\end{array}$ \\
\hline Superfície & $92,6 \%$ & $99,8 \%$ & $89,7 \%$ & $89,0 \%$ \\
\hline 1 m da superfície & $99,0 \%$ & - & - & $88,5 \%$ \\
\hline Geratriz superior & $98,6 \%$ & $95,6 \%$ & $86,2 \%$ & $86,5 \%$ \\
\hline
\end{tabular}




\section{ANÁlise dos RESUltados}

Neste capítulo são apresentadas análises dos resultados, englobando os ensaios de controle de compactação e dos deslocamentos dos tubos, tanto sob carregamento permanente como sob carga de roda, de modo a obter os Módulos de Reação E' da areia em diferentes estados por retroanálise da fórmula de Iowa Modificada.

\subsection{Controle de Compactação}

\subsubsection{Compactação do Berço}

Pelos resultados de campo no controle do solo de fundação, observou-se que o solo local é bastante resistente no estado natural e que a compactação do material que estava solto na superfície devido à escavação para constituir o berço foi insuficiente para oferecer ao solo as mesmas condições de estado que este apresentava antes da abertura da vala. Pelas correlações apresentadas no capítulo 4 entre CBR e o valor de DCP, observa-se que pelas expressões 4.2, 4.4, 4.5 e 4.7 que o material natural da vala apresenta CBR da ordem de 20 a 30\%; valor da mesma ordem de grandeza foi encontrado para a expressão 4.8 de Nogami e Villibor (1998) relacionando o DCP com o mini-CBR. Já para o material superficial compactado do berço, observa-se uma queda importante de resistência com relação ao mesmo no estado natural, apresentando valores de CBR da ordem de 10 a 20\%. A correlação de Livneh (1989) - expressão 4.3 mostra CBR da ordem de 50\% para o material no estado natural e um valor de cerca de 15\% no estado compactado, mostrando uma queda considerável de resistência neste 
caso. Para a expressão 4.6 de Angeloni et al. (1991) observa-se um valor de CBR de 40\% no estado natural e cerca de 25 a 30\% no estado compactado. Apesar dos valores nem sempre serem próximos dependendo da correlação utilizada, observa-se que todas realçam a queda de resistência após compactação, demonstrando a ineficácia de equipamentos leves de compactação como o sapo mecânico. Deve-se levar em consideração em projetos de sistemas solo-tubo que as condições de serviço dentro de valas são difíceis e não se atingem facilmente graus de compactação como em camadas superficiais de grande área de exposição, compactadas com equipamentos de grande porte.

\subsubsection{Variação da Resistência das Areias Dependendo do Estado}

Pelos resultados experimentais obtidos em laboratório observou-se que a resistência, avaliada através do CBR, aumenta significativamente depois da areia atingir compacidade relativa superior a 60\%; abaixo desta compacidade a resistência é insignificante para o nível de esforços que normalmente ocorrem em sistemas solo-tubo enterrados. Portanto, para areias mal-graduadas, pode-se dizer que a falta ou deficiência de densificação torna este material imprestável do ponto de vista desta aplicação.

A Figura 6.1 ilustra a relação entre o grau de compactação e a compacidade relativa obtidas em campo para as quatro valas ensaidas. Observe-se que o grau de compactação deve ser próximo a 100\% para que se tenha uma compacidade relativa acima de $66 \%$, própria de areias compactas. Valores abaixo deste mostram uma queda importante na compacidade relativa e, portanto, na resistência. Observe-se que para valores de grau de compactação abaixo de $90 \%$ da Energia Nomal, a compacidade relativa é desprezível, demonstrando o estado fofo destas. 


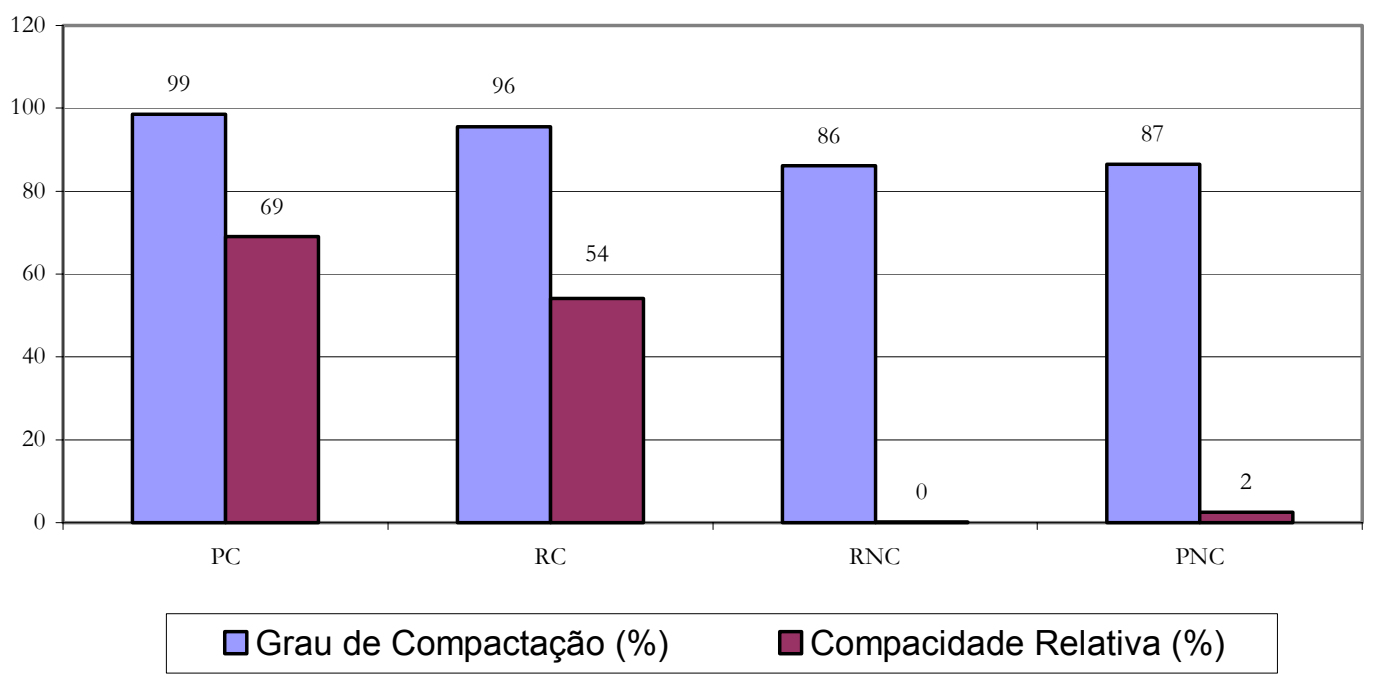

Figura 6.1 - Comparação entre grau de compactação e compacidade relativa

PC: Profunda Compactada

RC: $\quad$ Rasa Compactada

RNC: Rasa Não Compactada

PNC: Profunda Não Compactada

Tendo em vista a possível distorção de resultados em laboratório de CBR, dadas as especificidades do próprio ensaio, analisaram-se os resultados em campo para verificar a variação de resistência com o estado da areia. O controle pelo DCP e pelo UFV-II demonstrou que há uma grande diferença entre a resistência da camada mais superficial com espessura de cerca de 20 a $30 \mathrm{~cm}$, com relação àquelas inferiores. A areia confinada apresenta-se cerca de 3 vezes mais resistente que aquela presente nos primeiros 20 a 30 $\mathrm{cm}$. Observa-se ainda que na vala rasa, a presença do tubo cerca de 20 a $30 \mathrm{~cm}$ abaixo da superfície causou uma perturbação nos serviços de densificação e conseqüente heterogeneidade de estado do material, apresentando maior variação de valores de DCP com relação ao encontrado nas valas profundas. A compactação da camada superior acaba por densificar as camadas subjacentes, porém o pequeno confinamento continua sendo um dos fatores preponderantes para a baixa resistência nos primeiros 20 a $30 \mathrm{~cm}$ de uma areia mal-graduada.

Para a avaliação da variação da resistência de areias mal-graduadas dependendo do estado de tensões a que está submetida, traçou-se um gráfico, apresentado na Figura 6.2, confrontando o DCP de uma determinada camada dependendo da posição em relação à 
superfície livre em que ela se encontra. Para a construção do gráfico anotou-se o valor do índice de penetração (DCP) quando a camada era a mais superficial, ou seja, a camada mais recentemente compactada. Este valor foi localizado no gráfico da Figura 6.2 com a cota zero em relação à superfície. Em seguida, após compactação de uma outra camada sobre a de controle, realizou-se o ensaio com o cone em ponto próximo ao ensaiado anteriormente. Para a representação na Figura 6.2, tomou-se o valor de DCP do segundo trecho da curva Penetração vs. Número de Golpes, relativo à segunda camada ou camada de controle, associando o DCP à profundidade em relação à superfície do topo da camada de controle. Repetiu-se este processo até que o topo da camada de controle estivesse a $60 \mathrm{~cm}$ da superfície livre, uma vez que o comprimento da haste do DCP é de $80 \mathrm{~cm}$.

Ao observar o gráfico de Índice de Penetração DCP vs. Profundidade em Relação à Superfície Livre pode-se constatar um aumento do confinamento a partir dos primeiros 20 a $30 \mathrm{~cm}$ de profundidade. Isto demonstra que tanto o confinamento como o efeito benéfico da compactação das camadas superiores atua abaixo de 20 ou $30 \mathrm{~cm}$ de profundidade. Portanto, tubos plásticos flexíveis enterrados muito próximos à superfície livre contam com pequeno confinamento e pequena resistência de areias em sua camada próxima à superfície, tornando este arranjo indesejado do ponto de vista mecânico do sistema solo-tubo.

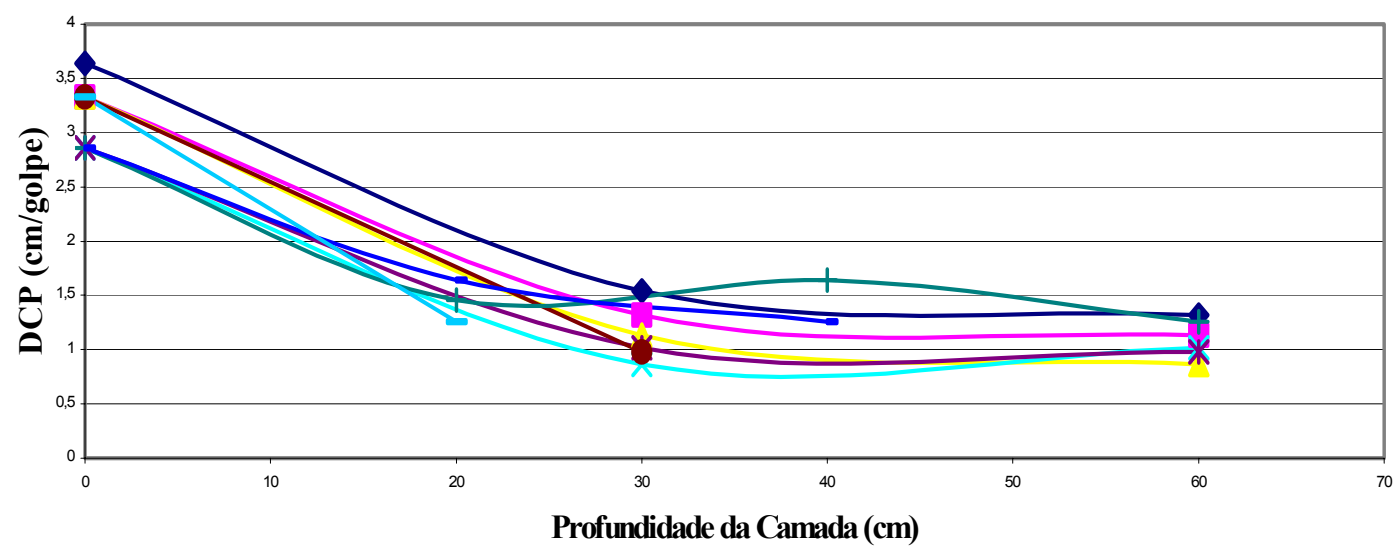

Figura 6.2 - Influência da posição de uma determinada camada com relação à superfície na resistência medida por meio do DCP 
Na Figura 6.3 é apresentado um gráfico que mostra a evolução do índice de penetração UFV-II obtido nos ensaios realizados com o cone tipo Universidade de Viçosa, elaborado de maneira análoga ao gráfico da Figura 6.2. Não se dispõe de tantos dados quanto no caso do DCP porque o UFV-II penetra no solo apenas $0,4 \mathrm{~m}$. Dessa forma, o UFV-II penetra apenas duas camadas, a mais superficial e aquela imediatamente abaixo. Da mesma maneira, pode-se observar a importância do confinamento abaixo de 20 a $30 \mathrm{~cm}$ de profundidade. Infelizmente o cone de Viçosa não pode demonstrar que abaixo desta profundidade os valores se estabilizariam.

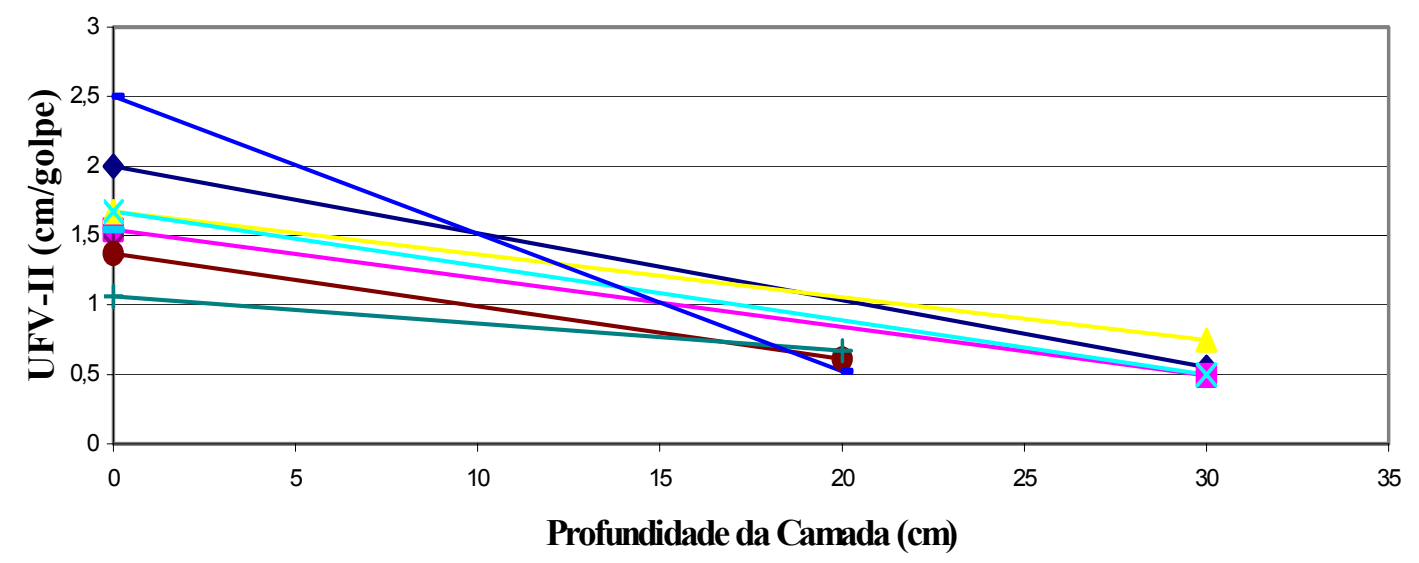

Figura 6.3 - Influência da posição de uma determinada camada com relação à superfície na resistência medida por meio do UFV-II

A Figura 6.4 mostra os valores de CBR e Mini-CBR obtidos a partir de correlações de vários autores, mostradas no item 4.3.3.1, utilizando os valores de DCP apontados pelos resultados obtidos no experimento. Tais valores são estimativos dos valores de CBR possíveis. 


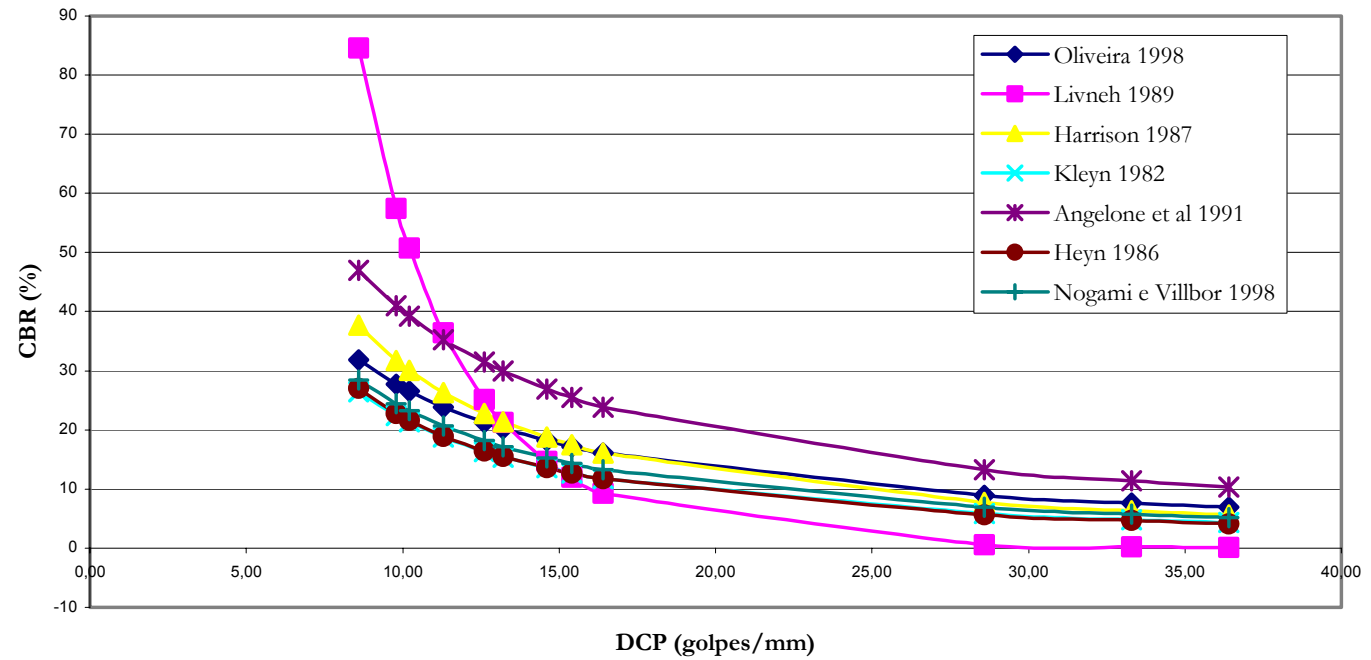

Figura 6.4 - Valores de CBR (\%) e Mini-CBR (\%) obtidos de correlações com DCP $(\mathrm{mm} /$ golpe) de vários autores

Na Tabela 6.1 são apresentados os valores de CBR e Mini-CBR obtidos pela correlação com o índice de penetração do UFV-II desenvolvida por Röhm (1984). Os valores da coluna UFV-II representam o índice de penetração, em mm/golpe, obtidos nos ensaios realizados com esse equipamento, seja na camada mais superficial, como naquela abaixo desta.

Tabela 6.1 - Valores de CBR e Mini-CBR obtidos da correlação com o UFV-II estabelecida por Röhm (1984)

\begin{tabular}{lccc}
\hline \multicolumn{1}{c}{ VALA } & UFV-II & CBR & Mini-CBR \\
\hline Profunda Compactada & 12,66 & 6,81 & 2,38 \\
\cline { 2 - 4 } & 5,88 & 19,21 & 8,94 \\
\hline Rasa Compactada & 12,05 & 7,28 & 2,60 \\
\cline { 2 - 4 } & 7,41 & 14,05 & 6,00 \\
\hline Rasa Não Compactada & 32,26 & 1,92 & 0,48 \\
\hline Profunda Não Compactada & 50,00 & 1,06 & 0,22 \\
\hline
\end{tabular}

A seguir são apresentadas tabelas comparando os resultados de CBR obtidos por várias correlações pra os três equipamentos usados para controlar a compactação das valas- 
teste. Nos valores de CBR para o ensaio de DCP o valor indicado representa a média dos valores obtidos pelas correlações apresentadas anteriormente (Figura 6.3), exceto Livneh (1989) por estar muito distante de todas as outras.

Tabela 6.2 - Valores de CBR antes da simulação de tráfego para as camadas abaixo de $30 \mathrm{~cm}$ da superfície livre

\begin{tabular}{lcccc} 
& \multicolumn{2}{c}{ CBR } & \multicolumn{2}{c}{ Mini-CBR } \\
\cline { 2 - 5 } & PC & RC & PC & RC \\
\hline DCP & 29 (média) & 22 (média) & 24 & 18 \\
\hline UFV-II & - & 25 & - & 13 \\
\hline
\end{tabular}

PC: $\quad$ Profunda Compactada

RC: $\quad$ Rasa Compactada

RNC: Rasa Não Compactada

PNC: Profunda Não Compactada

Tabela 6.3 - Valores de CBR antes da simulação de tráfego para a camada Superficial de 20 a $30 \mathrm{~cm}$ de espessura

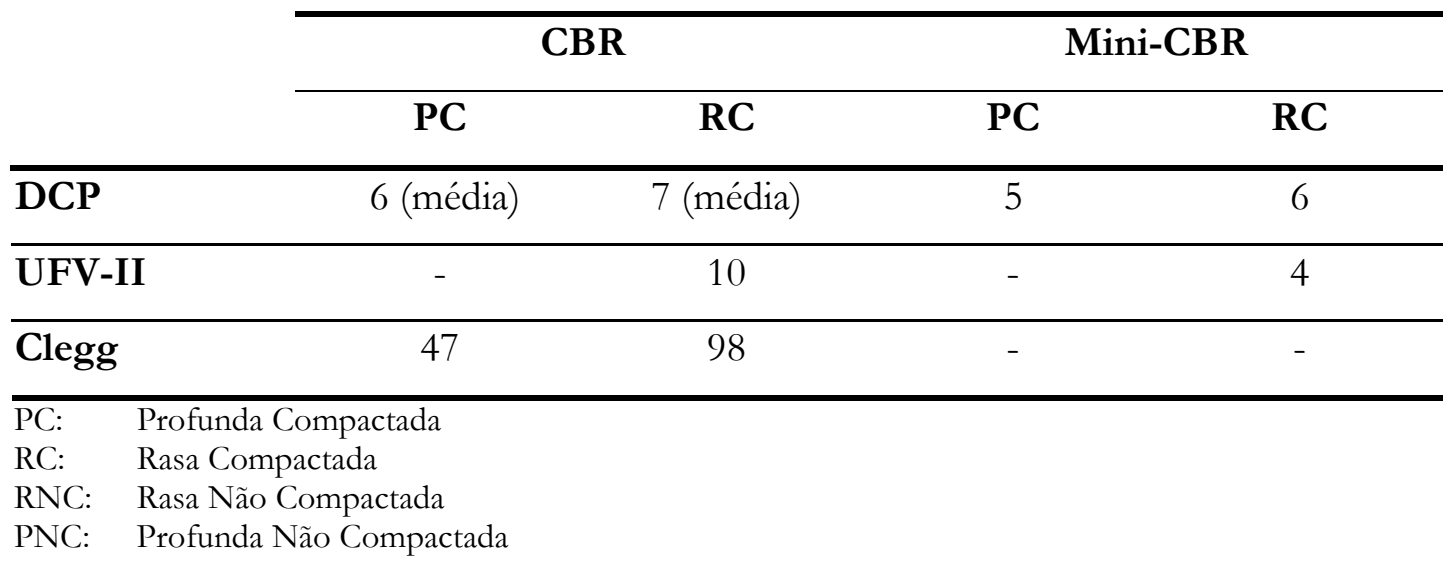

Observa-se que os valores de CBR para as camadas mais profundas de areia malgraduada e bem compactada giram em torno de 20 a 30\% para ambos equipamentos de cone. Para a camada superficial, estes valores de CBR decaem para faixas entre 5 e $10 \%$. Os valores obtidos pela correlação com o Clegg são incompatíveis com os obtidos pelos ensaios penetrométricos. Pode ser um problema relativo à calibração deste equipamento. 
Ponto de destaque é que nas valas com areia apenas depositada, o peso próprio do cone foi suficiente para fazer penetrar todo o comprimento da haste do equipamento, mostrando que a areia estava bastante fofa e em estado inadequado para os propósitos de sistema estrutural solo-tubo flexível.

A tabela 6.4 traz valores de CBR obtidos pelas correlações com os três equipamentos empregados no controle após simulação de carga, para as camadas abaixo de 20 a $30 \mathrm{~cm}$ da superfície livre. Os valores de CBR se mantêm na ordem de 20 a $30 \%$ no caso da areia compactada. Já no caso da areia não compactada, após carregamento, houve um aumento de compacidade, permitindo uma avaliação com os cones, porém o CBR é ainda insignificante, com valores abaixo de $2 \%$. Embora no caso de areia compactada o valor de $\mathrm{CBR}$ obtido pelo Clegg esteja próximo àqueles obtidos por meio dos equipamentos de cone, no caso da areia não compactada, o valor foi novamente incongruente, tornando seu uso impróprio, a não ser que uma nova calibração do equipamento seja feita.

Tabela 6.4 - Valores de CBR após da simulação de tráfego

\begin{tabular}{lcccccccc} 
& \multicolumn{4}{c}{ CBR } & \multicolumn{5}{c}{ Mini-CBR } \\
\cline { 2 - 10 } & PC & RC & RNC & PNC & PC & RC & RNC & PNC \\
\hline DCP & $\begin{array}{c}27 \\
\text { (média) })\end{array}$ & $\begin{array}{c}20 \\
\text { (média) }\end{array}$ & $\begin{array}{c}0,4 \\
\text { (média) }\end{array}$ & $\begin{array}{c}0,8 \\
\text { (média) }\end{array}$ & 23 & 17 & 0,3 & 0,6 \\
\hline UFV-II & 19 & 14 & 2 & 1 & 9 & 6 & 0,5 & 0,2 \\
\hline Clegg & 20 & 20 & 32 & 46 & - & - & - & - \\
\hline PC: & $\begin{array}{l}\text { Profunda Compactada } \\
\text { RC: }\end{array}$ & & & & & & \\
RNC: & $\begin{array}{l}\text { Rasa Compactada Não Compactada } \\
\text { PNC: }\end{array}$ & & & & & & \\
Profunda Não Compactada & & & & & &
\end{tabular}

Todas as avaliações indicam que o cone sul-africano DCP é um tipo de ensaio que pode ser empregado para o controle de compactação em sistemas de tubos plásticos flexíveis enterrados. Os resultados demonstram que a resistência de uma areia mal-graduada é bastante susceptível ao estado de tensões e ao grau de compactação ou à compacidade relativa. É um material que requer um cuidado especial nos procedimentos de 
compactação e no projeto de sistemas solo-tubo flexível devido a esta variação importante das propriedades de resistência.

\subsection{Módulo de Reação E’}

Para analisar o módulo de reação E', utilizaram-se os resultados de deslocamento obtidos em campo, aplicando-os na Fórmula de Iowa Modificada (item 3.2.1). O valor de rigidez anular do tubo adotado nos cálculos foi de $0,7 \mathrm{kN} / \mathrm{m}^{2}$, conforme recomendação do fabricante.

\subsubsection{Carregamentos e Deslocamentos Considerados}

O carregamento permanente ou peso morto $p$ que chega na geratriz superior do tubo foi calculado pela tensão aplicada pelo peso próprio de material sobre a geratriz (solo de envolvimento + solo de reaterro + pavimento). A sobrecarga $q$ foi calculada por três métodos: Boussinesq, Love e Hall.

Os deslocamentos utilizados foram o deslocamento vertical diametral do tubo frente ao carregamento permanente e, no caso de deslocamentos devido à sobrecarga, tomou-se a primeira leitura do ensaio dinâmico (primeiro executado). A partir daí, o sistema se movimentou tanto que não foi possível identificar o que foi registrado, problema agravado pela não fixação do sensor, já mencionada anteriormente. Da mesma forma, os carregamentos ditos estáticos não foram devidamente aplicados na geratriz superior do tubo, como já comentado o capítulo 5.

Os valores de E' foram calculados de três maneiras distintas: com o deslocamento permanente e a carga permanente ( $p$ ), com o deslocamento recuperável e a carga móvel (q) e com ambas deformações e cargas somadas $(p+q)$. Pode-se, assim, analisar melhor a influência de cada carregamento sobre o comportamento estrutural do sistema solotubo.

Os valores resultantes do cálculo com a carga permanente e o deslocamento permanente constam da primeira linha na Tabela 6.5 , designada por "Deformação/ $p$ ", os resultados 
dos cálculos com o deslocamento recuperável e a carga móvel estão sob a designação "Deflexão/q" e os resultados restantes são identificados por "Total/ $(p+q)$ ". Os resultados podem ser vistos na Tabela 6.5 a seguir.

Tabela 6.5 - Deslocamentos e valores de Módulo de Reação (E') obtidos com o carregamento permanente e a sobrecarga do ensaio dinâmico com 3,0 tf

\begin{tabular}{|c|c|c|c|c|c|}
\hline & \\
\hline & & PC & RC & RNC & PNC \\
\hline Deformação/p & & 3,15 & 1,34 & - & 2,35 \\
\hline \multirow{3}{*}{ Deflexão/q } & Boussinesq & - & 17,37 & 10,49 & - \\
\hline & Love & - & 15,15 & 9,54 & - \\
\hline & Hall & - & 4,41 & 5,24 & - \\
\hline \multirow{3}{*}{ Total $/(p+q)$} & Boussinesq & 3,85 & 13,01 & 20,95 & 2,74 \\
\hline & Love & 3,81 & 11,43 & 19,18 & 2,72 \\
\hline & Hall & 5,1 & 3,58 & 11,27 & 3,42 \\
\hline
\end{tabular}

PC: $\quad$ Profunda Compactada

RC: $\quad$ Rasa Compactada

RNC: Rasa Não Compactada

PNC: Profunda Não Compactada

\subsubsection{Interpretação dos Resultados da Retroanálise}

De acordo com a Tabela 3.4, constante no capítulo 3 e publicada em Moser (1990), materiais classificados como SP atingem valores que vão de 1,4 MPa, para materiais sem compactação, a $14 \mathrm{MPa}$, para materiais com grau de compactação acima de 90\% da Energia Normal.

Os deslocamentos permanentes foram calculados por diferença entre o diâmetro medido quando as valas-teste ficaram prontas (com toda a carga permanente aplicada) e o diâmetro medido quando a areia foi retirada até o nível da geratriz superior do tubo. $\mathrm{O}$ melhor procedimento, no entanto, seria medir o diâmetro à medida que as camadas fossem compactadas. O procedimento adotado leva a erros, pois o material de envolvimento foi retirado alguns meses após a compactação das valas e o tubo provavelmente acumulou deformação permanente que não cedeu quando da retirada de material sobre a geratriz do tubo. Portanto, o valor calculado é contra a segurança, e o módulo de reação E' real deve ser provavelmente menor que o calculado e constante na tabela. 
Observe-se que na vala rasa compactada, devido à sua geometria, com o tubo muito próximo à superfície, e a areia mal-graduada sob baixo confinamento, o E' é pouco superior a $1 \mathrm{MPa}$.

O valor de E' para a vala profunda não compactada é intermediário entre o valor obtido na vala rasa e na vala profunda compactadas. Esperava-se realmente que o valor fosse inferior ao da vala profunda, com a mesma geometria, porém compactada. Devido aos erros da forma que se optou pela medida, após os ensaios de simulação, acredita-se o valor calculado de 2,35 $\mathrm{MPa}$ seja superior ao real.

Assim, observa-se que sob estas condições de ensaio e de leitura de deslocamentos permanentes, o valor de E' da areia mal-graduada varia na faixa de 1 a $3 \mathrm{MPa}$. Os valores demonstram que a areia mal-graduada não pode ser empregada com baixo recobrimento sobre o tubo, mesmo com a compactação da areia. A areia quando compactada e confinada apresenta-se ainda assim pouco resistente. Deve-se realçar que os valores reais podem ser menores que os calculados e um fator de segurança deve ser tomado para projetos nesta situação.

Observa-se na Tabela 6.5 que os valores de E' calculados por Boussinesq e Love nas valas rasas são altos em relação aos calculados por Hall. Nessas valas o ponto de aplicação da carga está muito próximo do ponto onde se calculou a tensão (geratriz superior). Nessa região, próxima do ponto de aplicação da carga, o cálculo por Boussinesq fornece valores de tensão elevados devido ao tipo de solução da Teoria da Elasticidade e das condições de contorno assumidas. Se a tensão calculada é maior do que a tensão verdadeiramente aplicada, e o deslocamento que ocorre é relativo à tensão aplicada, e não ao carregamento hipoteticamente calculado por Boussinesq, o valor de E’ resultará maior do que realmente é, ou seja, o sistema parecerá mais resistente do que é na realidade. Portanto, serão desprezados estes valores. Observa-se que nas valas profundas a geratriz do tubo encontra-se mais distante do ponto de aplicação de carga e a tensão calculada pode ser mais próxima da realidade.

Observa-se que nos casos da areia ser compactada, o tubo não se desloca na parte inferior, estando estável. O mesmo não ocorre nas valas com material não compactado. 
Nestes casos, a geratriz inferior do tubo se movimenta para baixo, penetrando no berço. Fato interessante ocorreu na vala profunda não compactada, onde com carga elevada estática de 6tf: o tubo subiu, a geratriz inferior deslocou-se para cima, e a areia desceu, ocupando o lugar do tubo, demonstrando uma instabilidade do sistema frente às solicitações elevadas do tráfego. Este comportamento mostra a inadequação total de uso de areia mal densificada.

Os valores de E' encontrados para a Vala Rasa Não Compactada são bastante distantes dos outros. Nessa vala a areia não estava confinada e acredita-se que durante a aplicação de carga todo o sistema, incluindo o LVDT, tenha movimentado-se demasiadamente. Dessa forma, não é possível identificar que deslocamentos o sensor estava registrando, inclusive na primeira aplicação de carga, por isso a coluna em que aparecem esses resultados está destacada. O que pode ser observado, apesar de se desprezarem os valores, é a tendência de tornar o tubo na forma oval verticalmente, com afundamento da geratriz inferior e aumento de diâmetro registrado inicialmente na geratriz superior. Após esta constatação houve uma redução novamente de diâmetro. Não se sabe a longo prazo o que poderia ter ocorrido se a carga tivesse sido aplicada por muito tempo.

Na Vala Profunda Não Compactada, apesar de se ter calculado um valor de E' de cerca de $2 \mathrm{MPa}$ pelo carregamento permanente, e não se ter registrado leitura de deslocamento no ensaio dinâmico (cíclico de curta duração), deve-se observar que há registro de deslocamento durante a sobrecarga tipo estática, com valores da ordem de 1,5 a $2 \mathrm{~mm}$. Estes valores de deslocamentos são excessivos para pavimentos, levando um revestimento asfáltico ou de concreto de cimento Portland ao colapso rapidamente. Este dado mostra a inviabilidade de uso deste tipo de material de envolvimento sem compactação, caso haja passagem de carga.

$\mathrm{Na}$ Vala Rasa Compactada, os deslocamentos registrados na sobrecarga estática e na cíclica mostram que a magnitude da deflexão é impeditiva para qualquer tipo de pavimento, estando na ordem de centímetros. Portanto, apesar de compactada a areia, a geometria é inviável para tais sistemas solo-tubo. 
Nas valas profundas compactadas não foram obtidas leituras de deslocamentos, isto é, a tensão resultante na geratriz superior do tubo não foi suficiente para causar deslocamentos no tubo. Foi visto anteriormente (Figura 3.10) que a partir de 1,4 m, aproximadamente, a maior parte da tensão sobre o tubo deve-se à carga permanente. Portanto, somente neste caso, pode-se admitir o uso de areia mal-graduada, sendo que esta deve estar obrigatoriamente compactada.

Os resultados de deformação permanente nas trilhas de roda demonstram a impossibilidade de emprego de areias mal-graduadas em valas rasas, quando o sistema será sujeito a carga de roda. Em valas profundas, recomenda-se sempre a densificação da areia pois os deslocamentos permanentes do tubo devido ao peso próprio e ao tráfego levam também à formação de trilhas de roda significativas na superfície dos pavimentos, levando estes ao colapso.

A trilha de roda observada no caso da vala profunda compactada não é desprezível, mas deve ser considerada como aceitável, pois os blocos podem ter se movimentado um pouco devido ao assentamento sem compactação. Outra possibilidade que deve ser explorada é a substituição da areia mal-graduada como material de reaterro por solo coesivo e estável (não expansivo). Esta substituição traria possivelmente melhorias no sentido de reduzir os deslocamentos sofridos pela areia que está muito próxima da solicitação de carga. 


\section{CoNCLusões E Sugestões}

Observou-se que o DCP apresenta resultados mais consistentes do que o UFV-II, para a aplicação específica de controle de compactação da areia estudada em sistemas solotubo plástico flexível. O fato pode ser explicado através da indicação de uso de cada equipamento. O DCP foi desenvolvido para materiais granulares, enquanto que o UFVII tem sua aplicação indicada para solos arenosos finos lateríticos.

As correlações entre índice de penetração e CBR para o DCP foram determinadas por diferentes autores em condições muito diversas e, em alguns casos, muito específicas. Nota-se que à exceção de Livneh (1989), todas as outras correlações seguem a mesma tendência, não mostrando valores significativamente distintos. Já as correlações entre índice de penetração e CBR para o UFV-II foram determinadas por um único pesquisador e não foram comparadas com correlações de outros autores.

As correlações entre índice de penetração e Mini-CBR para ambos cones de penetração dinâmica podem ser comparadas entre si, uma vez que os ensaios foram realizados nos mesmos locais. Embora os equipamentos sejam diferentes, busca-se o mesmo parâmetro de resistência. Entretanto, ao observar-se os valores obtidos, deve-se considerar que os equipamentos têm penetração bastante distinta. No caso da areia esse fato é relevante pois o confinamento tem grande influência na sua resistência. Os valores mais baixos observados para a correlação com o UFV-II foram obtidos a partir de índices de penetração determinados em curvas de ensaios que refletiam apenas as camadas mais superficiais, onde o confinamento é menor e, portanto, a capacidade de suporte é menor. 
Para o Equipamento de Impacto Clegg não foram obtidos resultados consistentes na correlação com CBR, o que dificulta sua utilização no controle de compactação da areia. O equipamento é indicado para o controle de compactação de grandes áreas de material granular; a área reduzida em que foram procedidos os testes e a graduação da areia podem ter afetado o desempenho do equipamento. Outro fator a ser considerado é uma possível descalibração do equipamento.

Os testes com carga móvel mostraram que o tubo tem comportamento elasto-plástico, atingindo deslocamentos recuperáveis de até aproximadamente $2 \%$ nos experimentos realizados. Estes deslocamentos recuperáveis são negligenciados no projeto de sistemas solo-tubo, e não se encontrou na literatura citação sobre este problema. O projeto é sempre voltado para os deslocamentos verticais permanentes dos tubos, sujeitos a carga permanente. Deslocamentos recuperáveis, conhecidos na engenharia rodoviária como deflexões, com a magnitude verificada nos experimentos desta pesquisa, não afetam o comportamento mecânico do tubo, não tendo sido observado qualquer sinal de ruptura deste; entretanto, quando o tubo é utilizado em sistemas de drenagem viária, esses deslocamentos recuperáveis certamente causam a ruptura precoce do pavimento assente sobre o sistema solo-tubo, pois os revestimentos asfálticos ou de concreto rompem com poucas passagens de veículo sob tais condições de deslocamentos recuperáveis.

Com relação à profundidade de assentamento dos tubos, estes não devem estar muito próximos da superfície, seja com a areia densificada ou não, para evitar danos ao tubo e, principalmente, ao pavimento. Observou-se pelos experimentos a inviabilidade de uso de tubos plásticos flexíveis envolvidos por areia mal-graduada com baixo recobrimento. Estes sistemas rasos somente serão possíveis quando não houver em hipótese nenhuma solicitação de tráfego ou sobrecargas. Calcula-se que seja possível a utilização de areia mal-graduada como material de envolvimento com recobrimentos superiores a pelo menos 1 metro, com a areia muito bem compactada, assegurando compacidade relativa acima de $65 \%$, para ser caracterizado o estado compacto.

Fica demonstrado que o grau de compactação tem influência na resistência do sistema solo-tubo, pois a Vala Profunda Compactada apresenta valores de E' maiores do que a Vala Profunda Não Compactada. A magnitude de deslocamentos verificados na Vala 
Profunda Não Compactada mostra igualmente a incompatibilidade desta solução com sistemas enterrados sob pavimentos sujeitos ao tráfego de veículos. Os pavimentos sofrem deslocamentos, principalmente permanentes que o levam à ruptura precoce.

O único arranjo que se demonstrou possível foi aquele onde a areia encontra-se altamente densificada (grau de compactação próximo a 100\% da Energia Normal) e o tubo encontra-se em profundidade tal que as cargas de roda causam uma pequena tensão sobre a geratriz superior. Neste tipo de geometria da vala e estado da areia malgraduada, este material trabalha com módulo de reação E' de 2 a $3 \mathrm{MPa}$. Caso E' seja de $2 \mathrm{MPa}$, é possível trabalhar com a areia mal-graduada como material de envolvimento com até cerca de 4 metros de recobrimento máximo sobre o tubo, e no caso de E' ser 3 $\mathrm{MPa}$, pode-se chegar até cerca de 6 metros de recobrimento máximo sobre a geratriz superior do tubo.

Sugestões para estudo futuros:

Seria interessante determinar para as aplicações nacionais valores típicos de E' de solos tropicais, principalmente dos lateríticos, presentes nas camadas do horizonte superficial em quase a totalidade do território brasileiro. Esses valores só podem ser determinados por ensaios em campo, devendo ser buscado um ensaio laboratorial que possa servir para inferir os resultados de campo. Adicionalmente, deve-se desenvolver modelos utilizando o Método dos Elementos Finitos como ferramenta para interpretação dos experimentos visando determinar o módulo de reação E' e o módulo de elasticidade do material de envolvimento.

Em novos experimentos em verdadeira grandeza seria interessante testar profundidades de assentamento intermediárias, próximas a altura em que a carga permanente e a móvel tenham influência semelhante no deslocamento do tubo.

Uma questão ainda a ser estudada é o efeito nos sistemas solo-tubo plástico flexível da repetição dos deslocamentos recuperáveis a longo prazo. 


\section{REFERÊNCIAS BIBLIOGRÁFICAS}

ALFERINK, F. J. M. Some Experience with 30 Years Old Buried (uPVC) Pipes From the Viewpoint of Stress and Strain. In: George S. Buczala and Michael J. Cassady Editors. Buried Plastic Pipe Technology. Philadelphia: American Society for Testing and Material STP 1093, 1990. p. 233-244.

AMERICAN SOCIETY FOR TESTING AND MATERIALS. ASTM D3034: Specification for Type PSM Poly (Vinyl Chloride) (PVC) Sewer Pipe and Filttings. Easton, 1983.

ASSOCIAÇÃO BRASILEIRA DE NORMAS TÉCNICAS. NBR 7181: Solo - Análise Granulométrica. Rio de Janeiro, 1984.

ASSOCIAÇÃO BRASILEIRA DE NORMAS TÉCNICAS. NBR 9053: Tubos de PVC - Determinação da classe de rigidez. Rio de Janeiro, 1997.

BAUER, D. E. 15 Year Old Polyvinyl Chloride (PVC) Sewer Pipe; a Durability and Performance Review. In: George S. Buczala and Michael J. Cassady Editors. Buried Plastic Pipe Technology. Philadelphia: American Society for Testing and Material STP 1093, 1990. p. 391-401.

CERATTI, J. A. \& OLIVEIRA, J. A. Equipamento Simulador de Tráfego Desenvolvido pelo DAER/RS e UFRGS. In: Reunião Anual de Pavimentação, 27, 1993, Teresina. Anais... Teresina: ABPv, 1993. v. 1, p. 379-393.

CHAMBERS, R. E., HEGER, F. J. and McGRATH, T.J. Plastic Pipe for Subsurface Drainage of Transportation Facilities. National Cooperative Highway Research Program Report, Washington D.C., n. 225, 153 p., 1980.

CHAPMAN, P. G. Field Experience, Performance Testing and Design of Very Flexible Thermoplastic Pipe Systems. In: George S. Buczala and Michael J. Cassady Editors. 
Buried Plastic Pipe Technology. Philadelphia: American Society for Testing and Material STP 1093, 1990. p. 171-184.

CLEGG, B., Application of an Impact Test to Field Evaluation of marginal Base Course Materials. Transportation Research Record, Washington D.C, n. 898, p. 174$181,1983$.

DEPARTAMENTO AUTÔNOMO DE ESTRRADAS DE RODAGEM. DAER/RS - EL 302/99: Determinação da Densidade de Campo dos Solos. Porto Alegre, 1999.

DUNCAN, J. M. \& JEYAPALAN, J. K. Deflection of Flexible Culverts due to Backfill Compaction. Transportation Research Record, Washington D.C, n. 878, p. 10-17, 1982.

ESCOLA DE ENGENHARIA DE SÃO CARLOS. Departamento de Estradas de Rodagem-SP/Instituto de Pesquisas e Aperfeiçoamento Industrial, Convênio $\mathbf{n}^{\mathbf{o}}$ 44, São Carlos, 1977. (Relatório 09, vol. 2).

ESCOLA POLITÉCNICA DA UNIVERSIDADE DE SÃO PAULO. Departamento de Engenharia de Transportes. Convênio LTP-PTR-EPUSP/TIGRE, São Paulo, 1998. (Relatório Final - Caderno 4)

GONÇALVES, F. P., CERATTI, J. A. P. e SOMACAL, L. Investigação do Desempenho de Misturas Asfálticas Convencionais e Modificadas com Polímeros: Proposição de Um Estudo Envolvendo Ensaios Acelerados de Pavimentos com Um Simulador Linear de Tráfego. In: Simpósio Internacional de Manutenção e Restauração de Pavimentos e Controle Tecnológico, 1, 2000, São Paulo. Anais... São Paulo: Universidade Presbiteriana Mackenzie, 2000. p. 248-272.

HEYN, A. Aplicações do Penetrômetro Dinâmico de Ponta de Cone na Avaliação de Estruturas de Pavimentos. In: Reunião de Pavimentação, 21, 1986, Salvador. Anais... Salvador: ABPv, v. 2., 1986. p. 139-149. 
HOWARD, A. K. Modulus of Soil Reaction Values for Buried Flexible Pipes, American Society if Civil Engineering - Journal of the Geotechnical Division, New York, v. 103, n. GT1, p.33-43, 1977.

HOWARD, A. K. Field Test Deflections of Reinforced Plastic Mortar Pipe. Transportation Research Record, Washington D.C, n. 518, p. 39-48, 1974.

HOWARD, A. K. Load-Deflection Field Test of 27-Inch (675-mm) PVC (Polyvinyl Chloride) Pipe. In: George S. Buczala and Michael J. Cassady Editors. Buried Plastic Pipe Technology. Philadelphia: American Society for Testing and Material STP 1093, 1990. p. 125-140.

INTERNATIONAL ORGANIZATION FOR STANDARDIZATION. ISO 9969: Thermoplastics pipes - Determination of ring stiffness. Genebra, 1994.

JANSON, L-E. Plastics pipes - how long can they last?. Estocolmo: Kontrollrådet för Plasttrör, 1996. (Report no 4).

KAY, J. N. Minimum Acceptable Soil Cover Heights for Ribbed, Spirally-Wound PVC Drainage and Sewer Pipe Installed in a Trench and Subject to Severe Vehicle Loading. Adelaide: The university of Adelaide - Department of Civil Engineering, 1984. (Report on Preliminary Tests).

KLEYN, E. G. The Use of the Dinamic Cone Penetrometer (DCP). Pretória: Transvaal Roads Department, 1975.

KURAOKA, S., RAJANI, B., ZHAN, C. Pipe-Soil Interaction Analysis of Field Tests of Buried PVC Pipe. American Society if Civil Engineering - Journal of Infrastructure Systems, New York, v. 2, n. 4, p.162-170, 1996.

LIVNEH, M. In-situ CBR Testing by Indirect Methods. In: International Conference on Soil Mechanics and Foundation Engineering, 2, 1989, Rio de Janeiro. Proc... Rio de Janeiro: Publications Committee of XII ICSMFE, 1989. v. 1. p. 267-270. 
MONGE, O. R., Diseño Estructural: Sistemas Rib-Loc, Tuberías Perfiladas de PVC Enterradas, San José: Durman Esquivel S. A., 1996.

MOSER, A. P. Buried Pipe Design. 1. ed. New York: McGraw-Hill, 1990. 219 p.

MOSER, A. P. Structural Performance of Buried Profile-Wall High-Density Polyethylene Pipe and Influence of Pipe Wall Geometry. Transportation Research Record, Washington D.C., n. 1008, p. 109-116, 1985.

MOSER, A. P. The Structural Performance of Buried Rib-Loc Pipe (Polyethylene whit External Steel Rib). Logan: Utah State University, 1996.

MOSER, A. P., BISHOP, R. R., SHUPE, O. K. \& BAIR, D. R. Deflection nad Strains in Buried FRP Pipes Subjected to Various Installation Conditions. Transportation Research Record, Washington D.C., n. 1431, p. 22-26, 1994.

NOGAMI, J. S. \& VILLIBOR, D. F. Considerações Geotécnicas Sobre o Bom Desempenho de Pavimentos Envolvendo Solos Lateríticos. In: Congresso Brasileiro de Mecânica dos Solos e Engenharia Geotécnica, 11, 1998, Brasília. Anais... Brasília: ABMS, 1998. v. 1. p. 615-622.

PARMELEE, R. A. \& COROTIS, R. B. Analytical and Experimental Evaluation of Modulus of Soil Reaction. Transportation Research Record, Washington D.C., n. 518, p. 29-38, 1974.

RÖHM, S. A. Considerações sobre Penetrômetros Dinâmicos Leves Aplicados na Construção e Avaliação de Pavimentos de Baixo Custo. 1984. 109 p. Dissertação de Mestrado - Escola de Engenharia de São Carlos, Universidade de São Paulo, São Paulo.

SARGAND, S. M.; HAZEN, G. A.; LIU, X.; MASADA, T. e HURD J. O. Strutural Performance of Buried Polyvinyl Chloride Pipes Under Large Distributed Load. Transportation Research Record, Washington D.C., n. 1514, p. 59-67, 1995. 
SELIG, E. T. \& McGRATH, T. J. Pipe Failure Caused by Improper Groundwater Control. Transportation Research Record, Washington D.C., n. 1431, p. 22-26, 1994.

SPANGLER, M. G. Stress Distribution in Soil. In: Soil Engineering, 1. ed. Scranton: International Textbook Co., 1951. cap. 17, p 251-264.

SPANGLER, M. G. Thickness of Flexible Pavements. In: Soil Engineering, 1. ed. Scranton: International Textbook Co., 1951. cap. 16, p 227-250.

TRICHÊS, G. e CARDOSO, A.B. Avaliação da Capacidade de Aterros e Subleito de rodovias Utilizando o Penetrômetro Dinâmico de Cone e a Viga Benkelman. In: Congresso de Pesquisa e Ensino em Transportes, 13, 1999, São Carlos. Anais... São Carlos: ANPET, 1999. v. 1, p. 406-416.

WATKINS, R. K. \& SPANGLER, M. G. Some Characteristics of the Modulus of Passive Resistance of Soil: A Study in Similitude. Proc... Washington D.C.: Highway Research Record, 1958. v. 37, p. 576-583.

WATKINS, R. K. (1966), Structural Design of Buried Circular Conduits. Highway Research Record, Washington D.C., n. 145, 1966.

WATKINS, R. K. Plastic Pipes Under High Landfills. In: George S. Buczala and Michael J. Cassady Editors. Buried Plastic Pipe Technology. Philadelphia: American Society for Testing and Material STP 1093, 1990. p. 379-392.

ZAIDKER, W. Projetos Estruturais de Tubos Enterrados. 1. ed. São Paulo: Pini, 1983. $106 \mathrm{p}$.

ZHAN, C. \& RAJANI, B. Load Transfer Analyses of Buried Pipe in Different Backfills. Journal of Transportation Engineering, New York, v. 123, n. 6, p. 447-453, 1997. 


\section{ANEXO I}

Curvas de Calibração dos Sensores de Medida de Deslocamento LVDT's 


\section{LVDT 7x0510001}

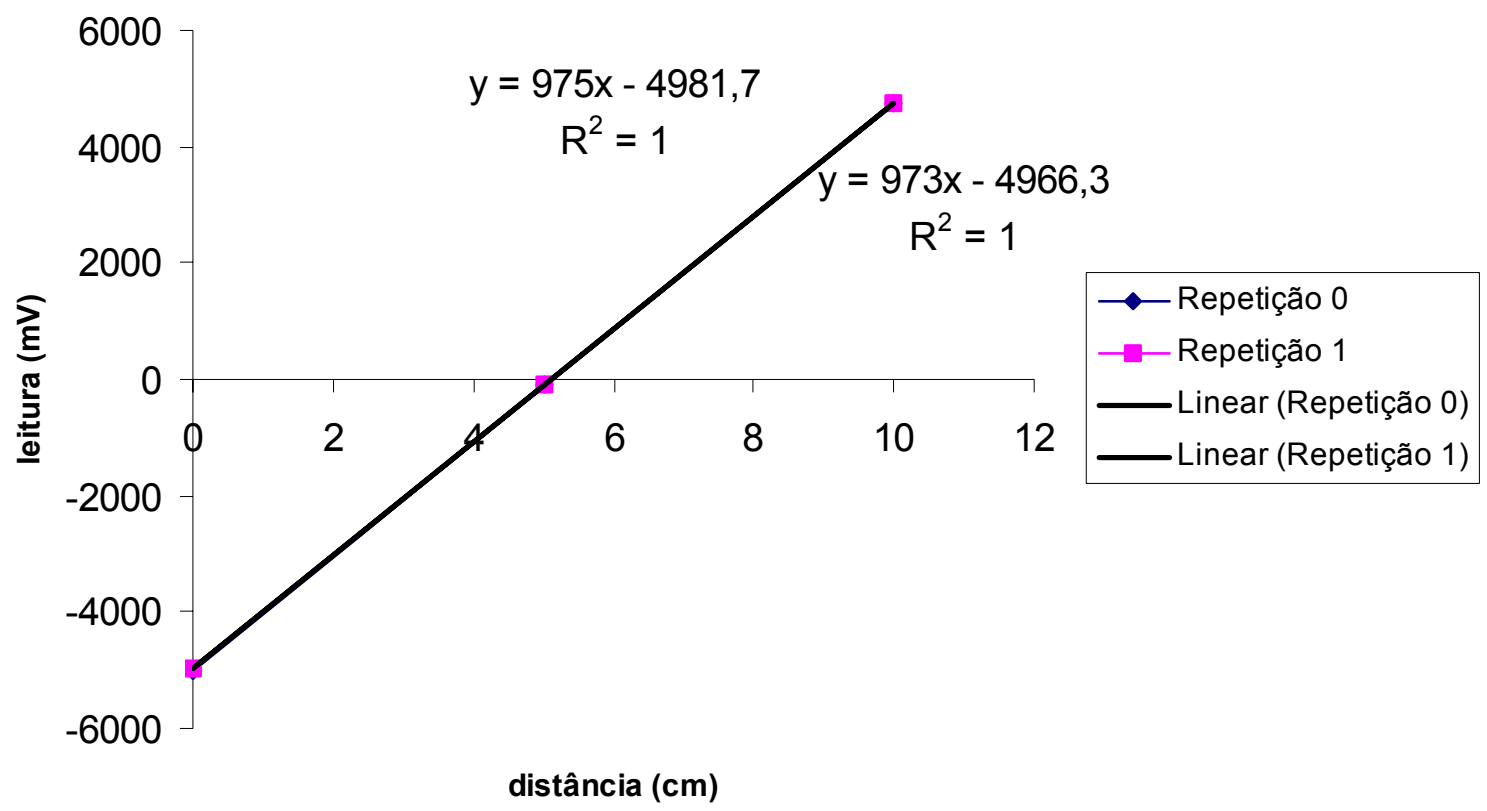

LVDT 7X0510002

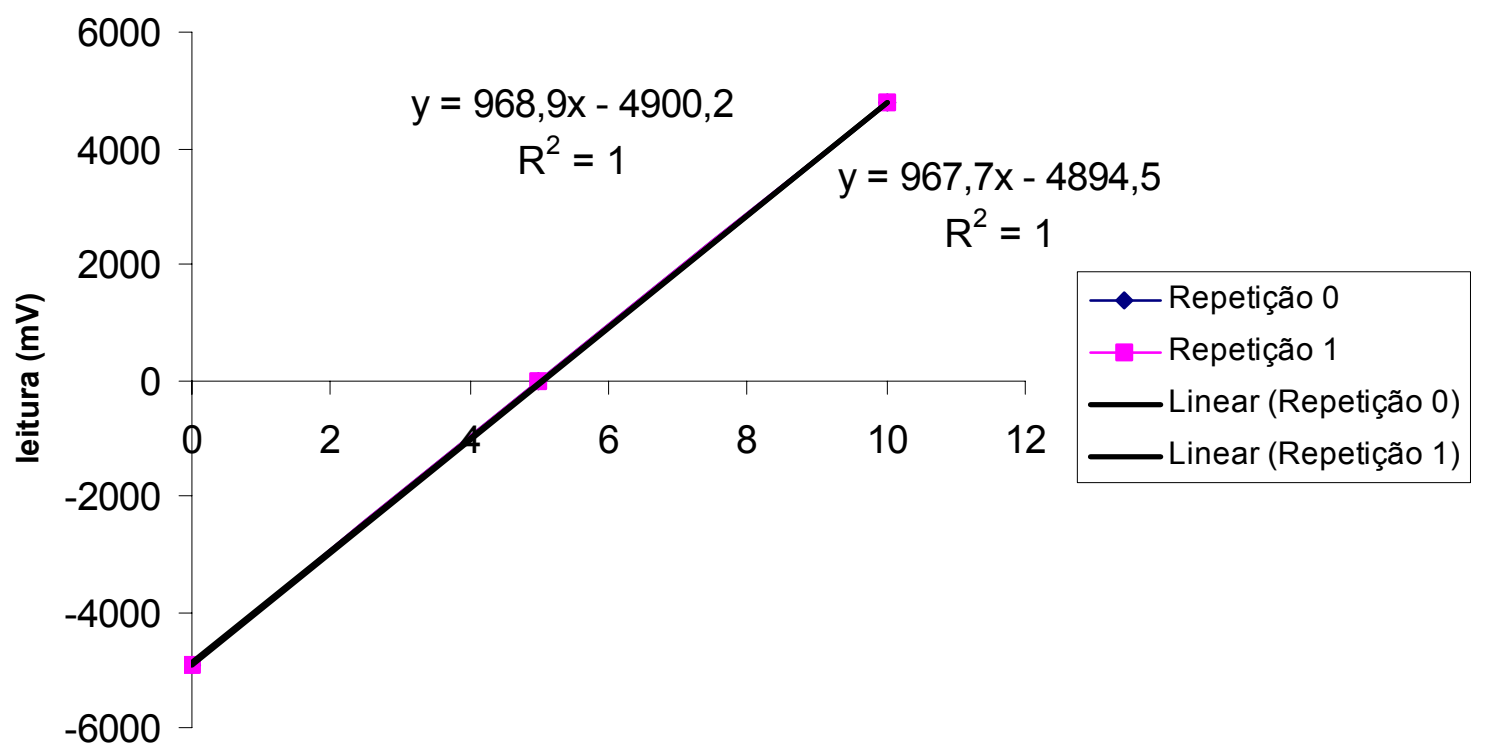

distância (cm) 


\begin{abstract}
ANEXO II
Curvas de Controle de Compactação com o Uso do DCP na Vala Profunda Compactada
\end{abstract}


Vala Profunda Compactada - $2^{\mathrm{a}}$ Camada

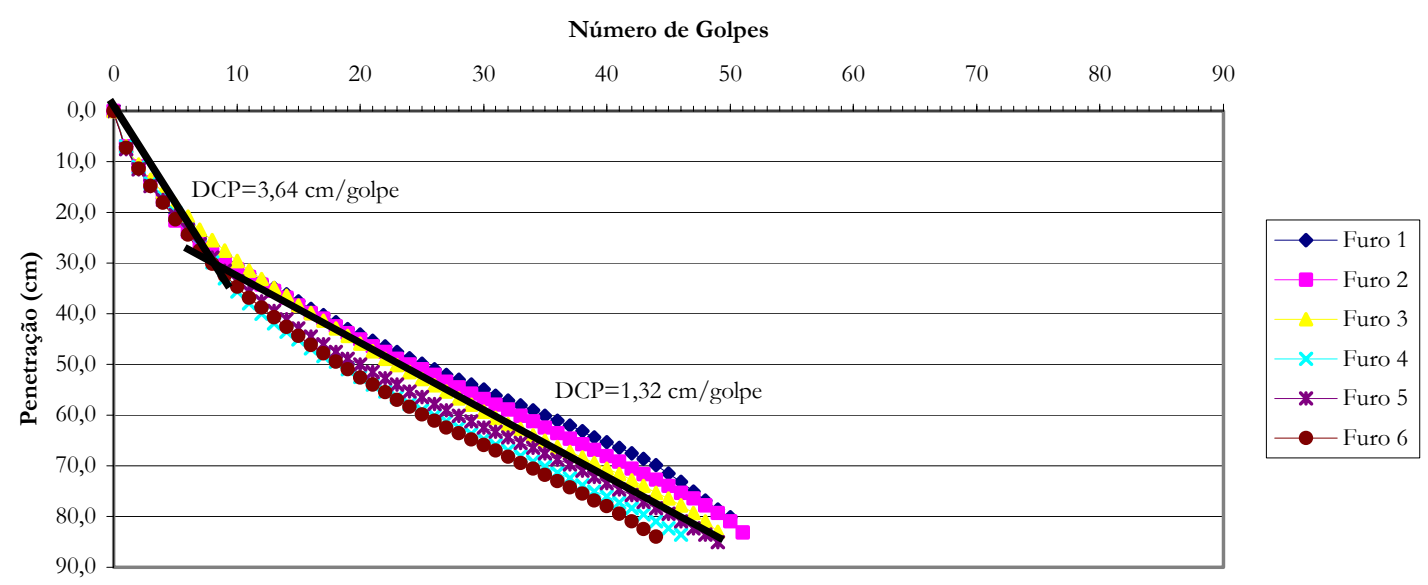

Vala Profunda Compactada - $3^{\mathrm{a}}$ Camada

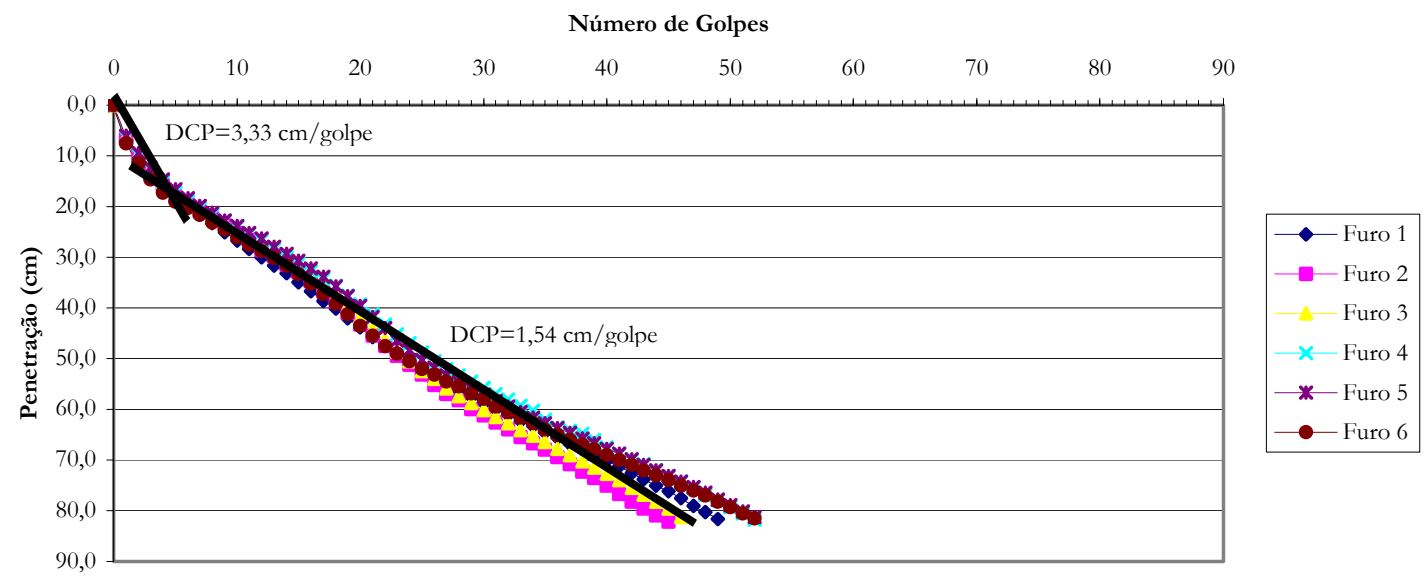


Vala Profunda Compactada - $4^{\mathrm{a}}$ Camada

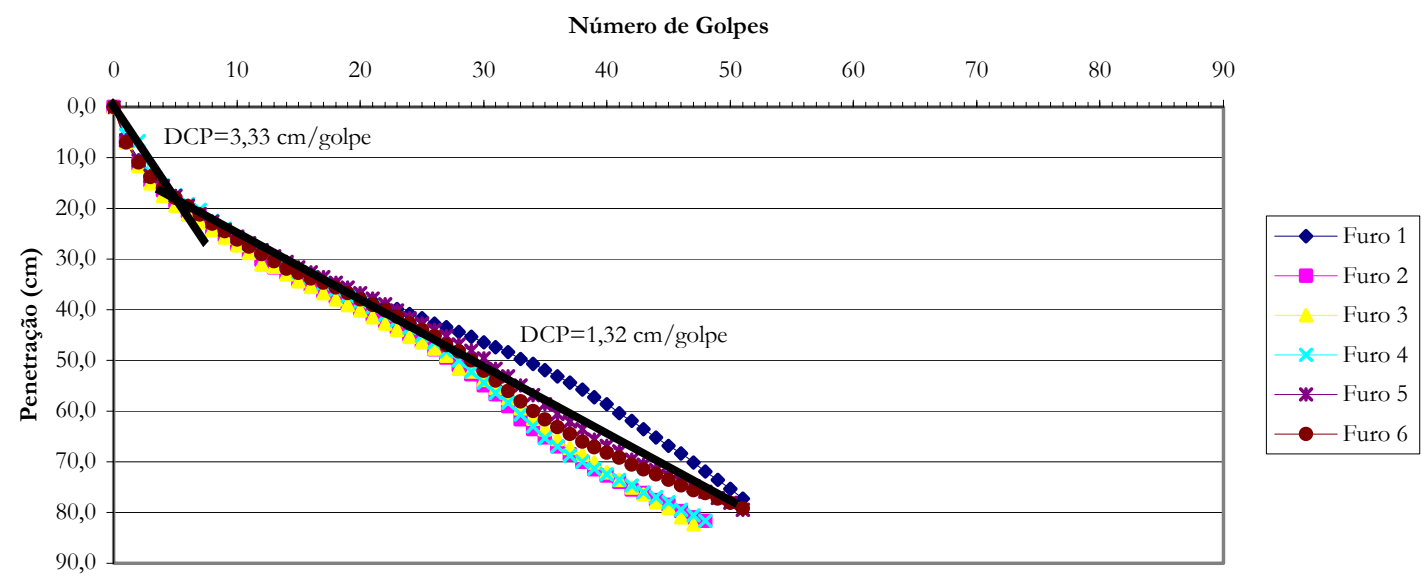

Vala Profunda Compactada - $5^{\mathrm{a}}$ Camada

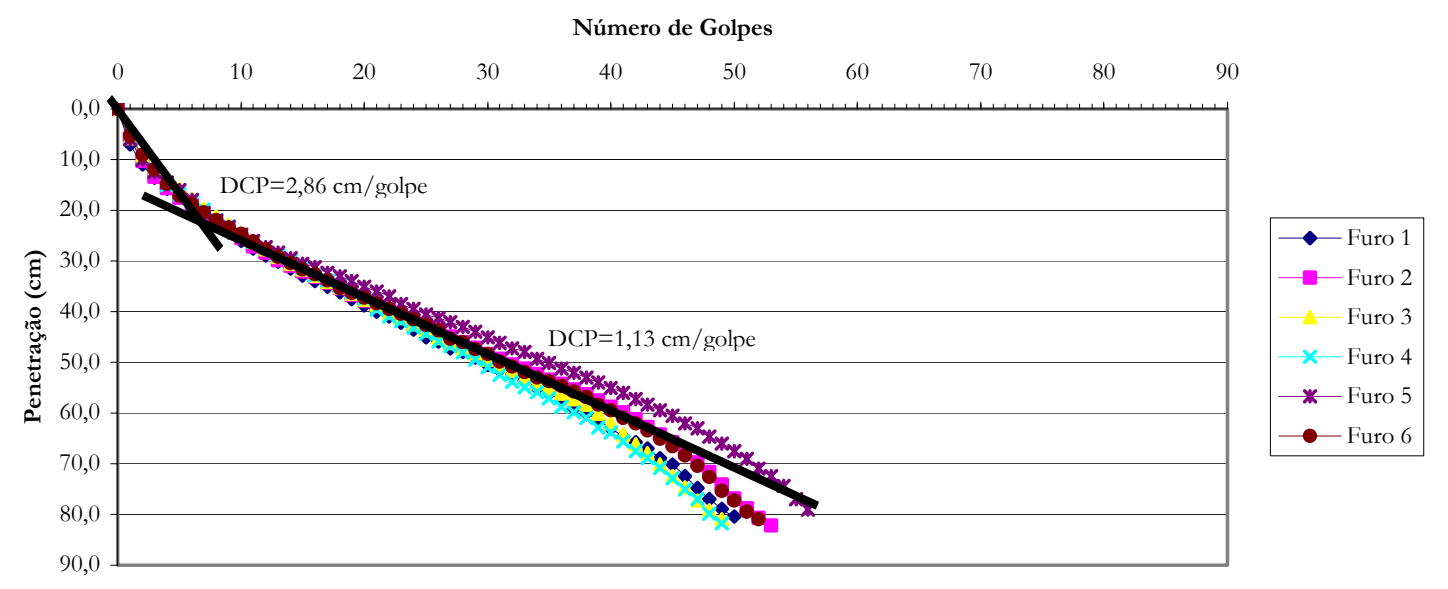


Vala Profunda Compactada - $6^{a}$ Camada

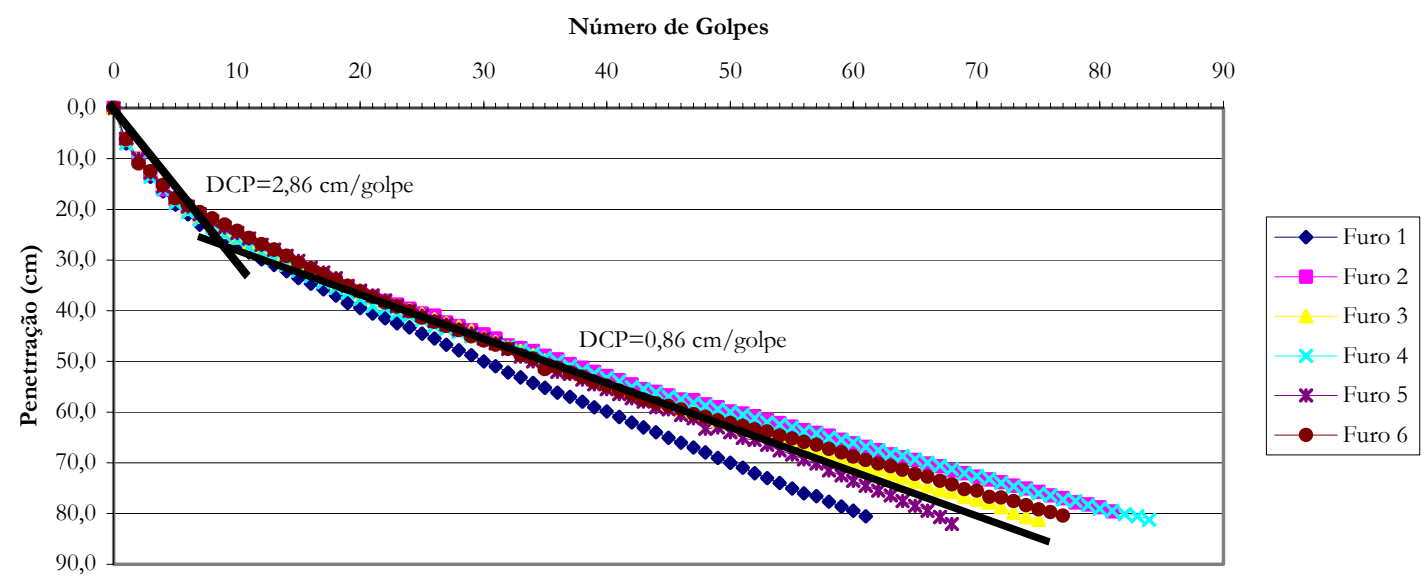

Vala Profunda Compactada - $7^{a}$ Camada

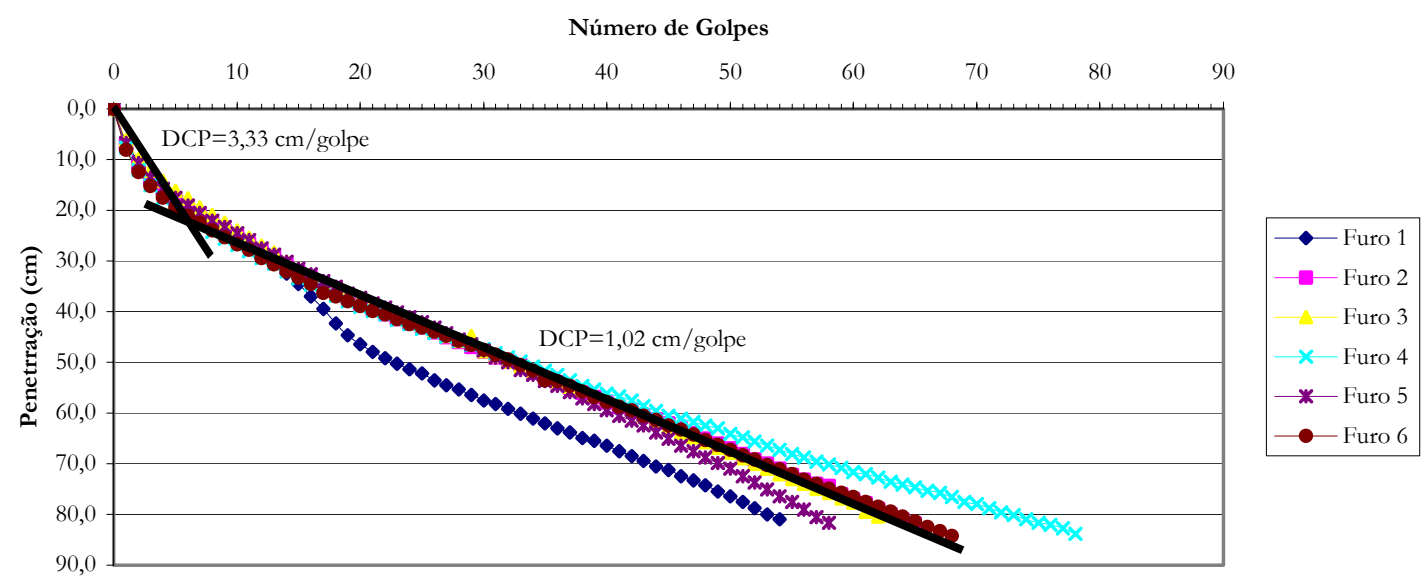


ANEXO III

Curvas de Controle de Compactação com o Uso do DCP na Vala Rasa Compactada 
Vala Rasa Compactada - $2^{a}$ Camada

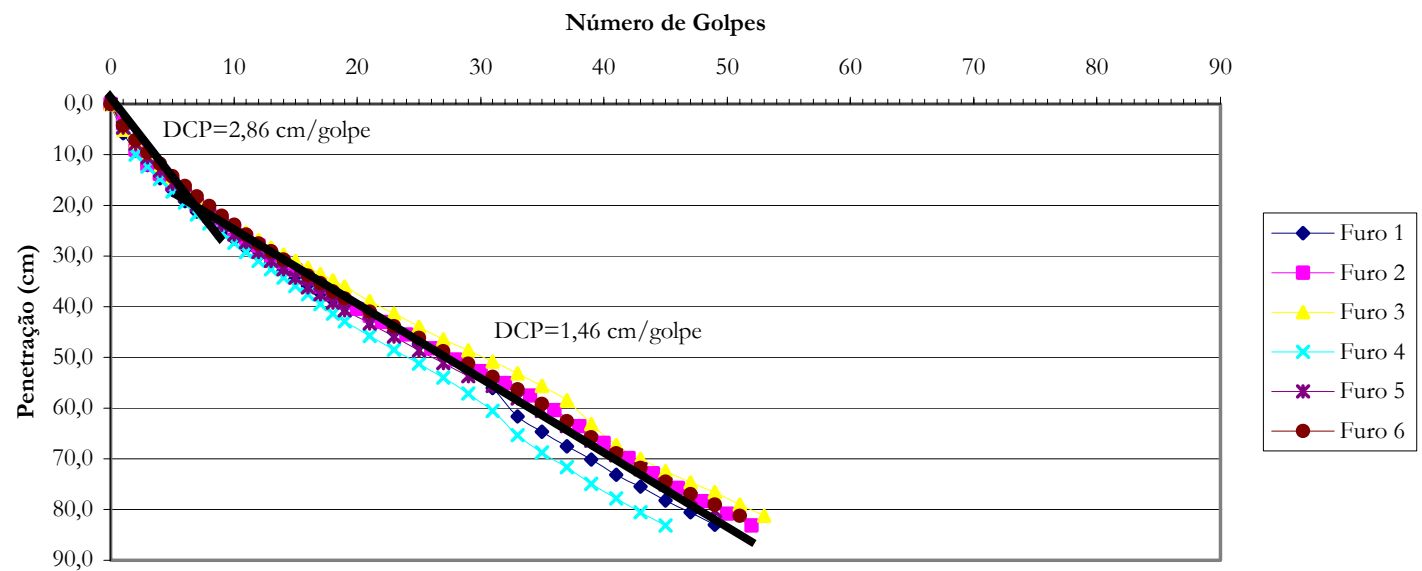

Vala Rasa Compactada - $3^{a}$ Camada

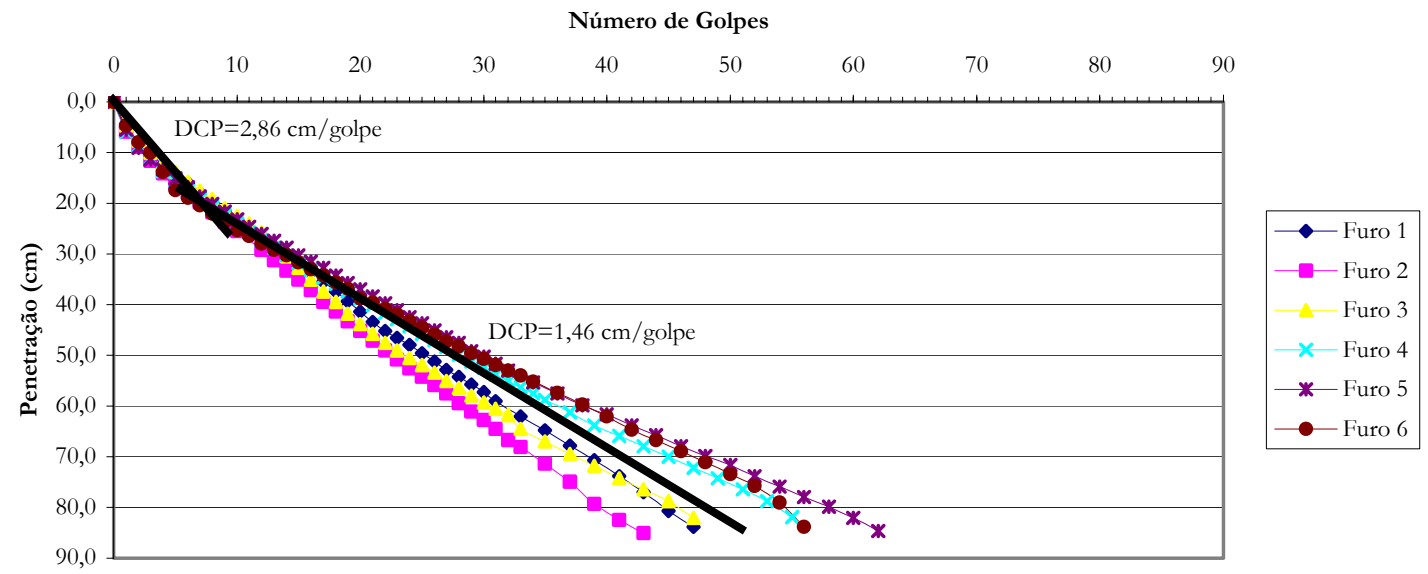


134

Vala Rasa Compactada - $4^{a}$ Camada

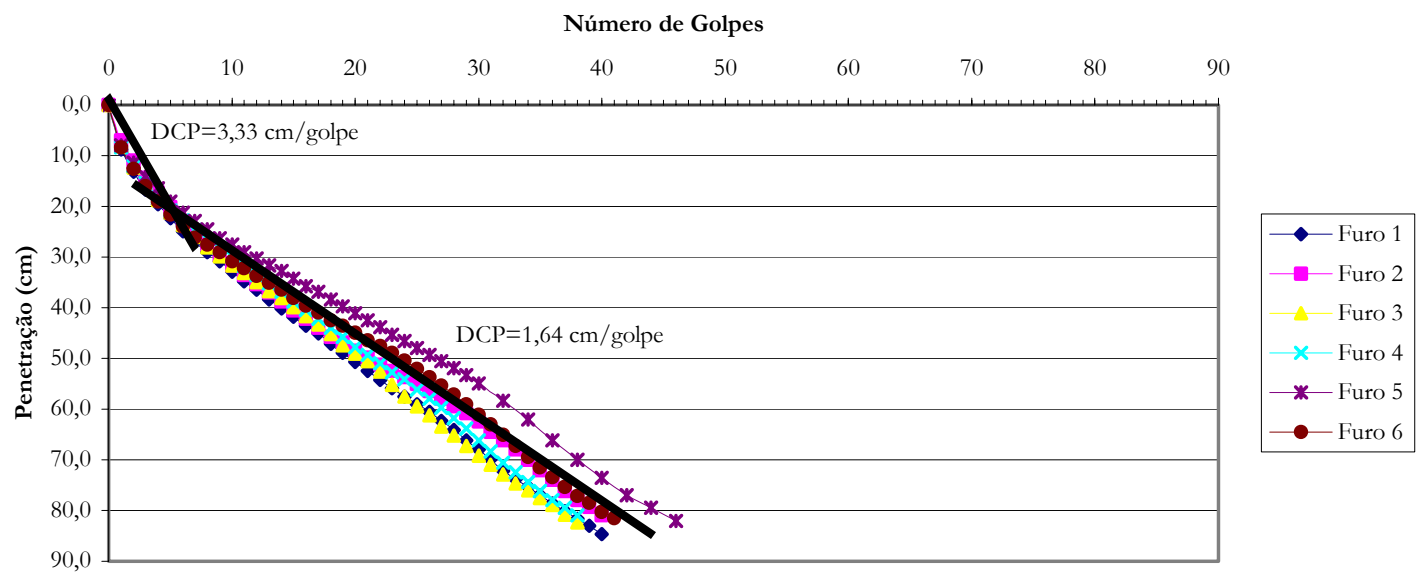




\section{ANEXO IV \\ Curvas de Controle de Compactação com o Uso do UFV-II na Vala Profunda Compactada}


Vala Profunda Compactada - $2^{a}$ Camada

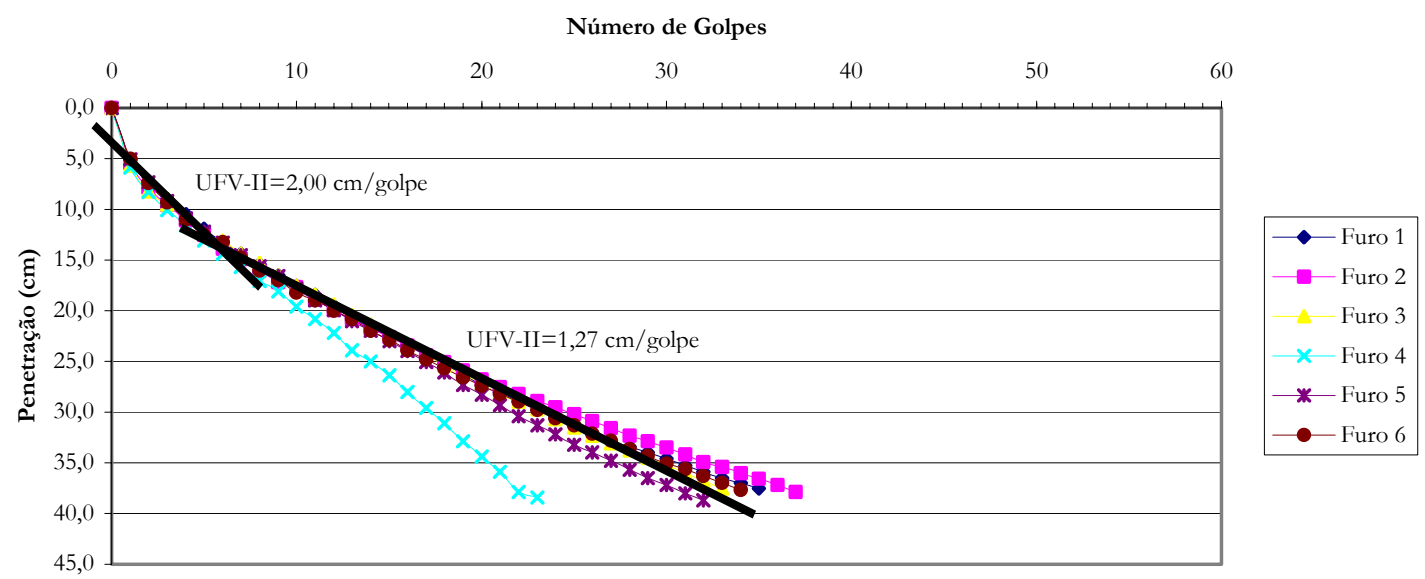

Vala Profunda Compactada $-3^{\text {a }}$ Camada

Número de Golpes

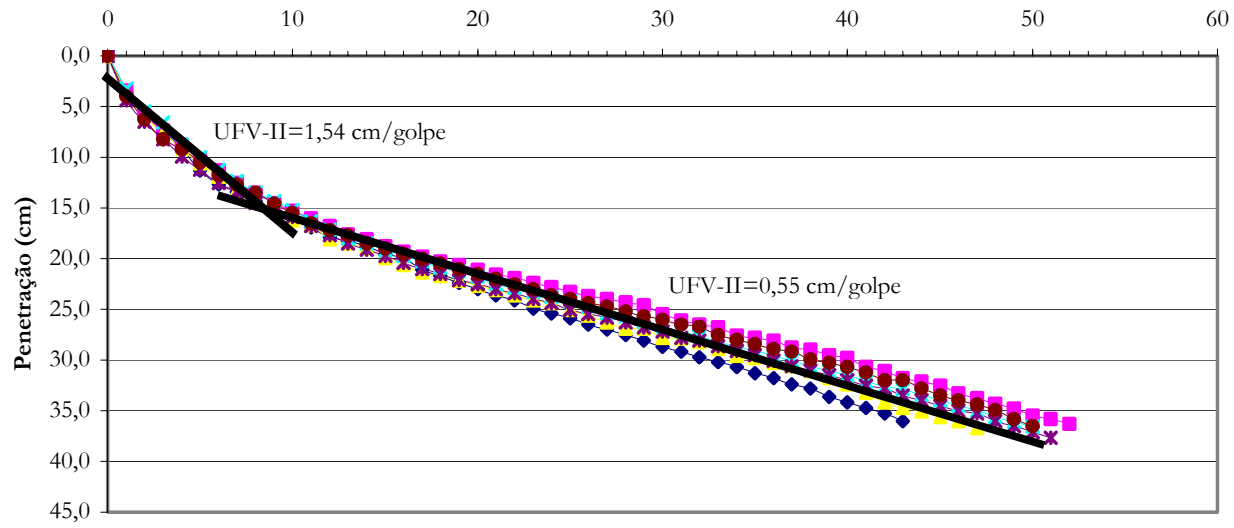


Vala Profunda Compactada $-4^{a}$ Camada

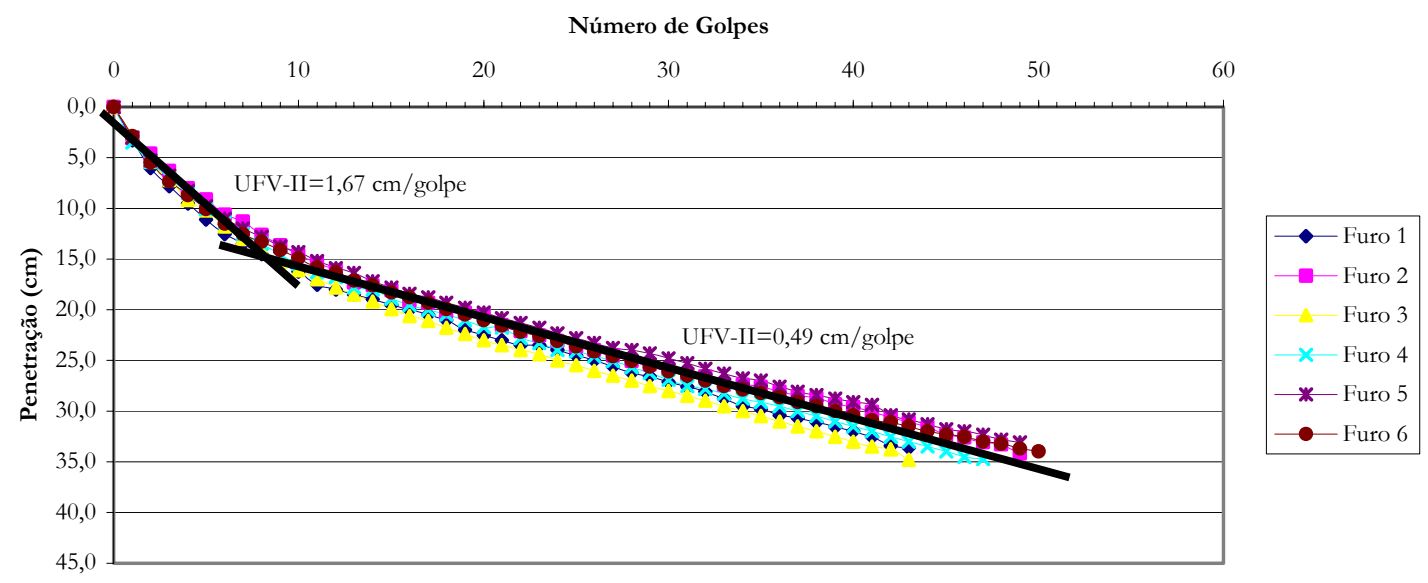

Vala Profunda Compactada - $6^{a}$ Camada

Número de golpes

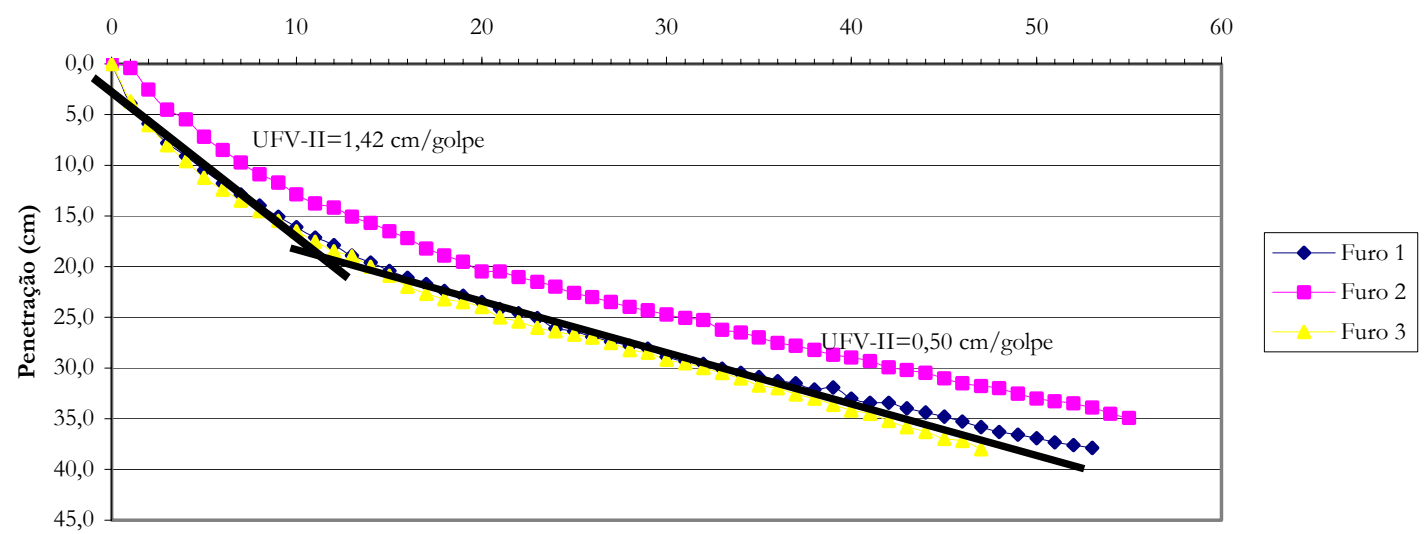




\section{ANEXO V \\ Curvas de Controle de Compactação com o Uso do UFV-II na Vala Rasa Compactada}


Vala Rasa Compactada - $2^{a}$ Camada

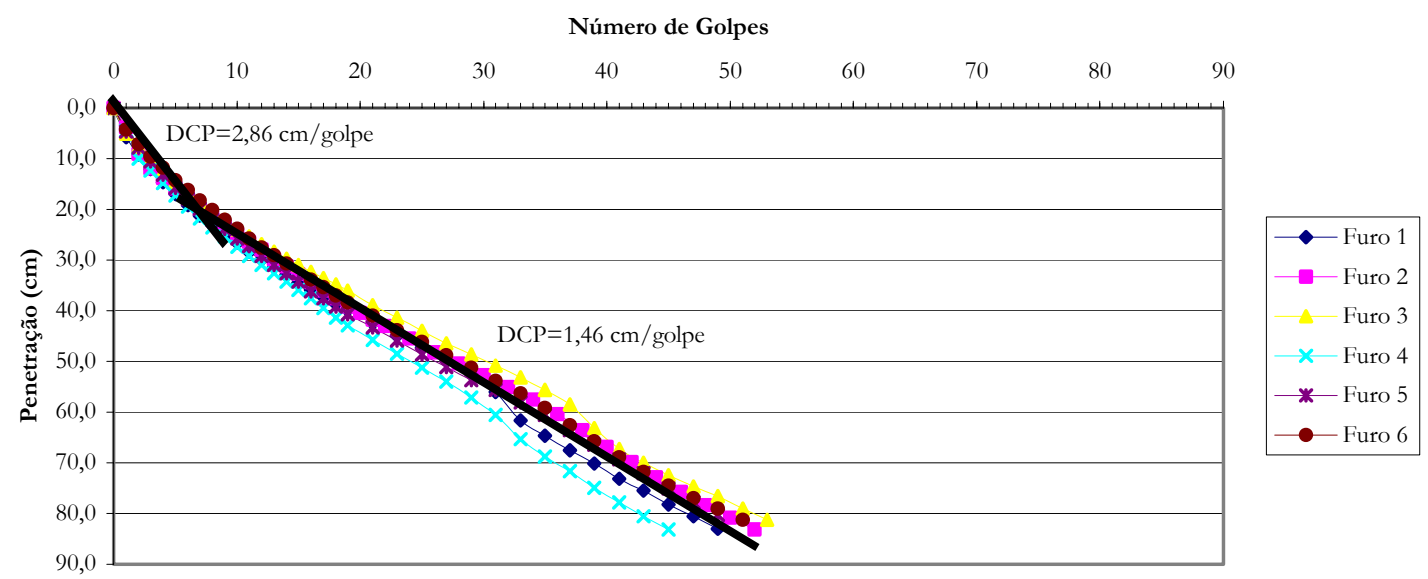

Vala Rasa Compactada - $3^{\text {a Camada }}$

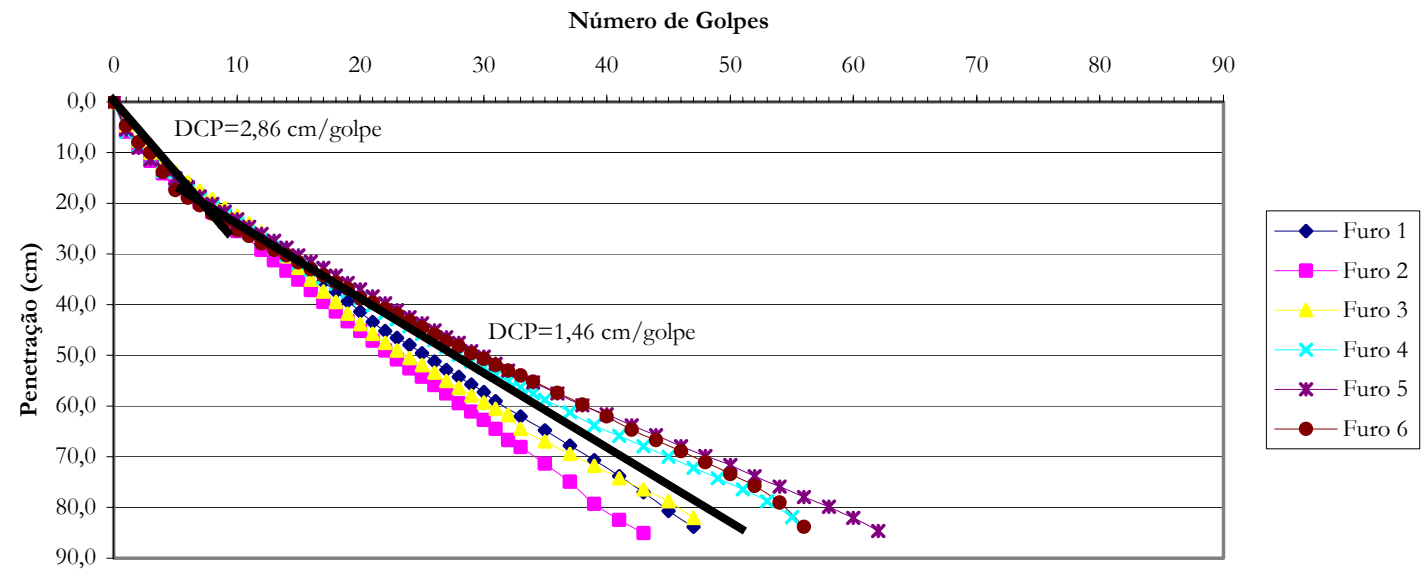


Vala Rasa Compactada - $4^{\mathrm{a}}$ Camada

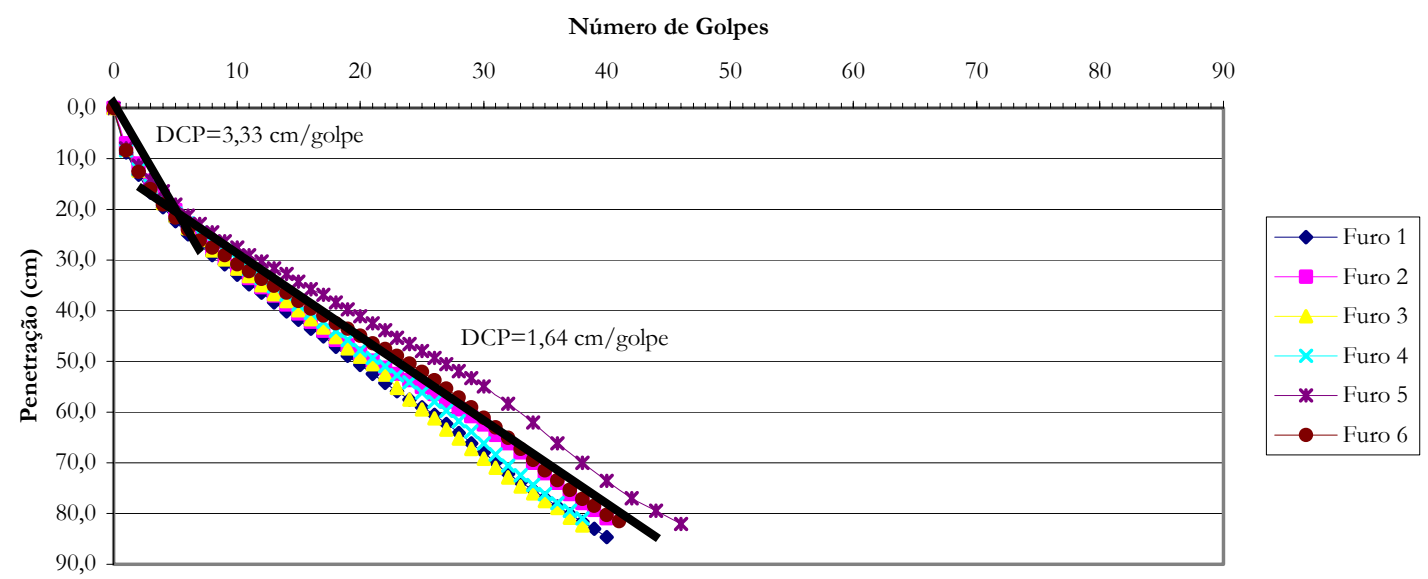

Vala Rasa Compactada - $5^{\text {a }}$ Camada

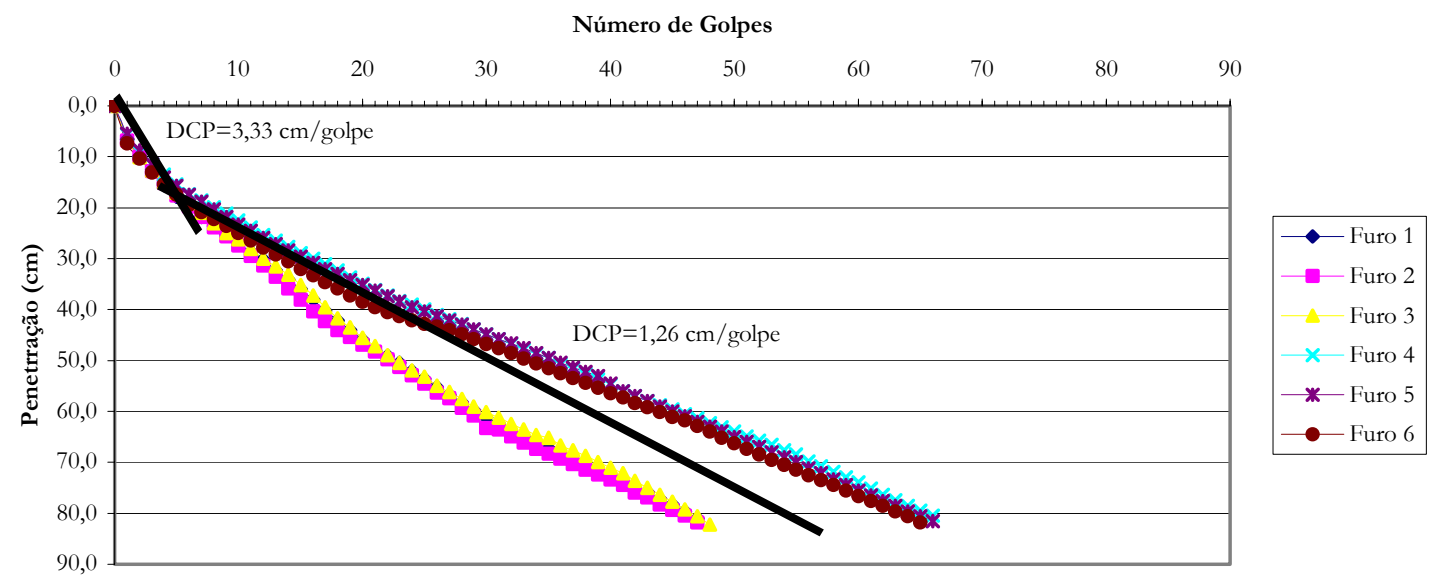




\section{ANEXO VI}

Resultados de Deslocamento da Vala Profunda Compactada 
Vala Profunda Compactada - 3,0 ton - Dinâmico

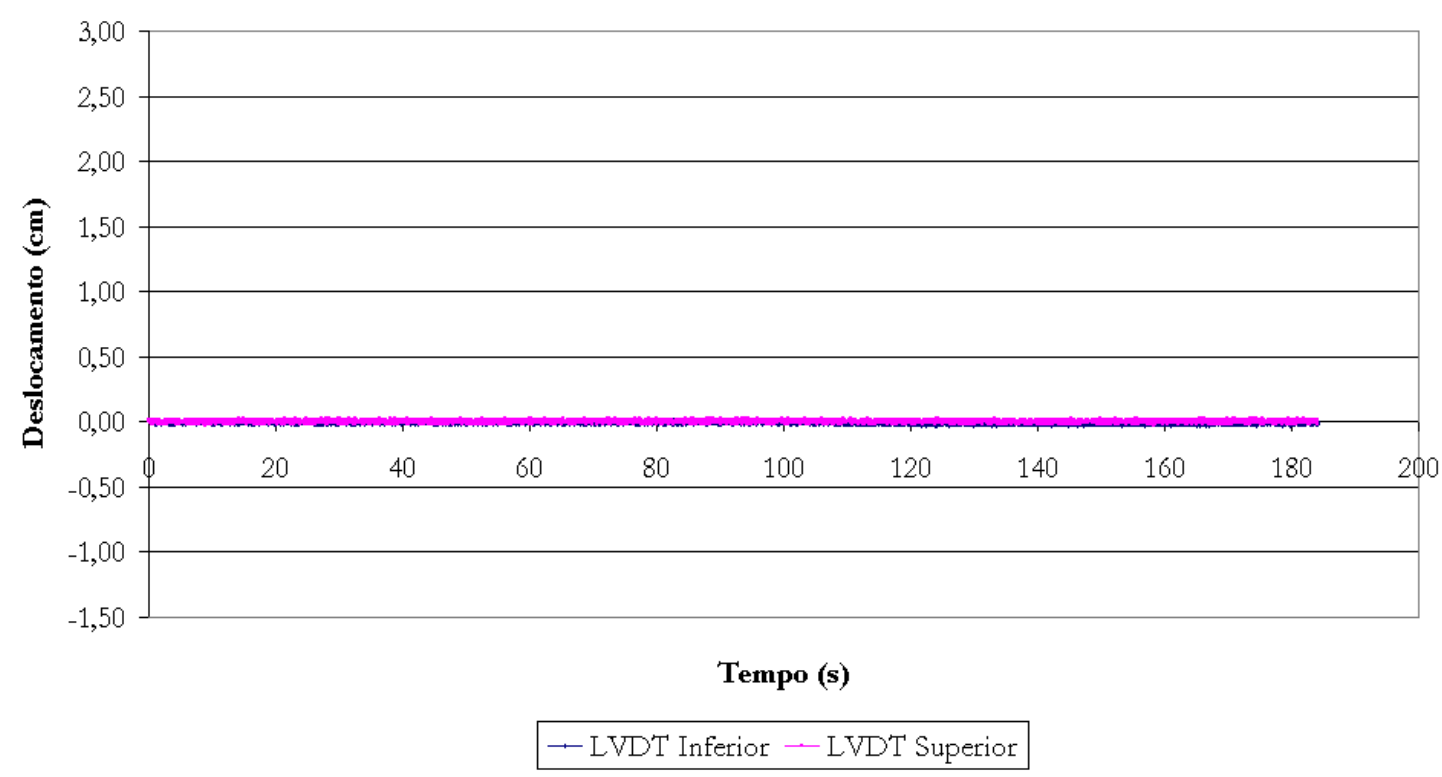

Vala Profunda Compactada - 3,0 ton - Estático 1

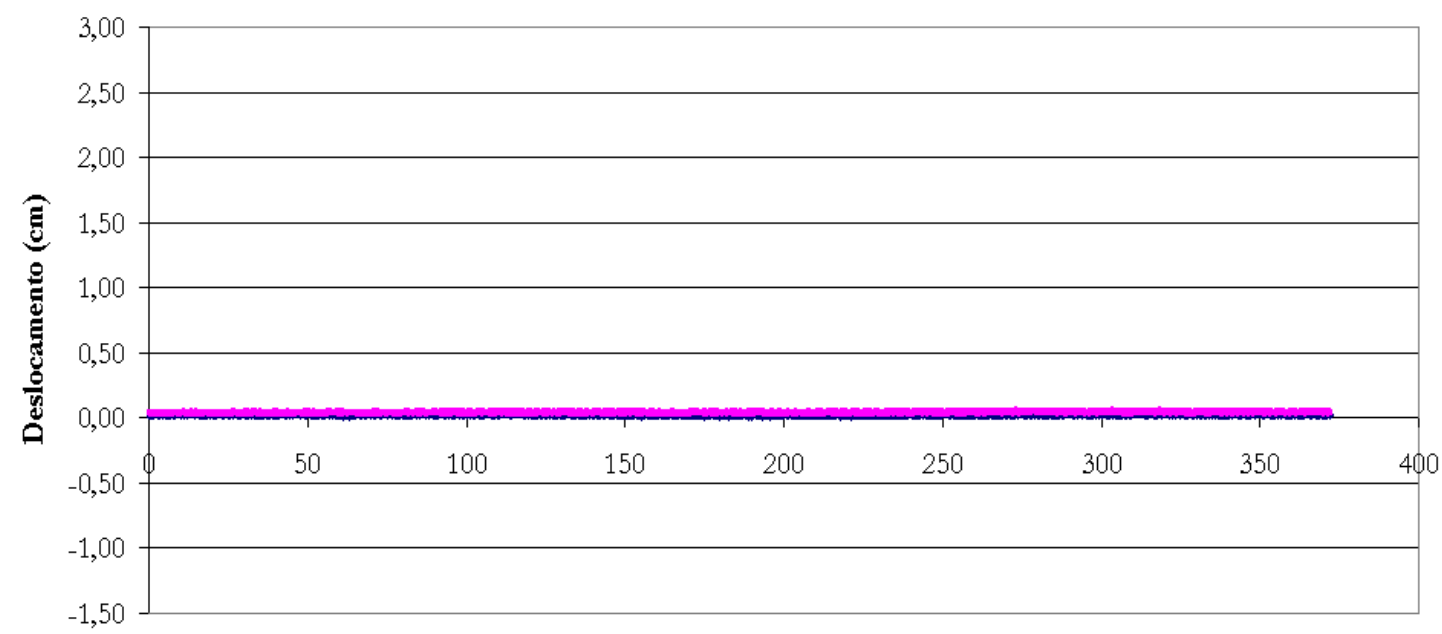

Tempo (s)

- LVDT Inferior - LVDT Superior 
Vala Profunda Compactada - 3,0 ton - Estático 2

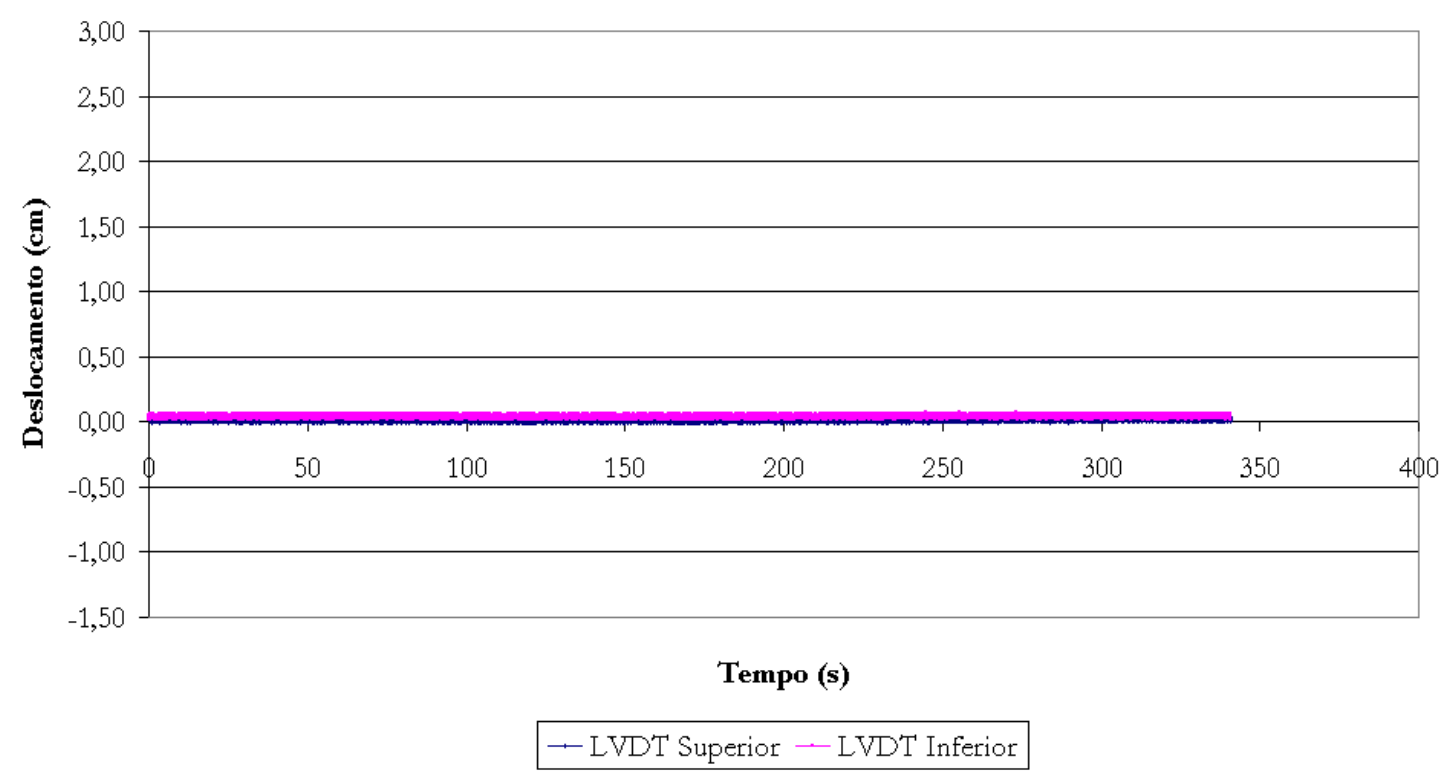

Vala Profunda Compactada - 3,0 ton - Estático 3

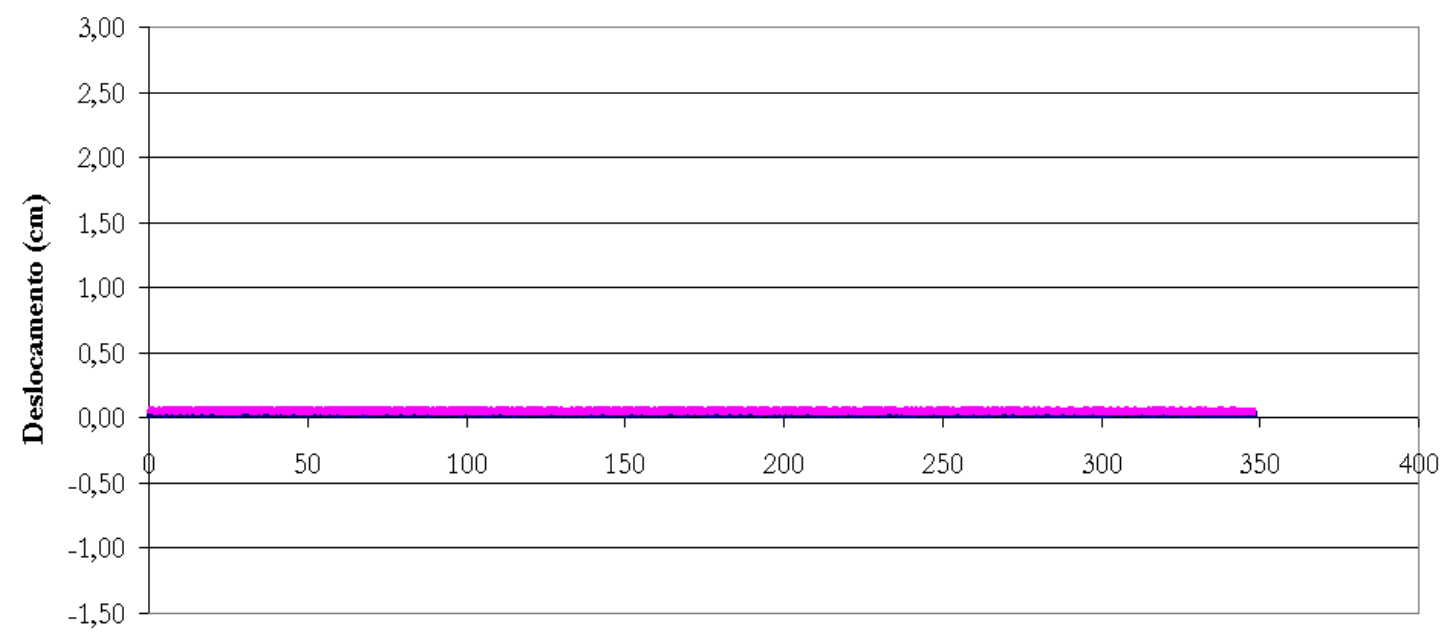

Tempo (s)

- LVDT Inferior - - LVDT Superior 
Vala Profunda Compactada - 4,5 ton - Dinâmico

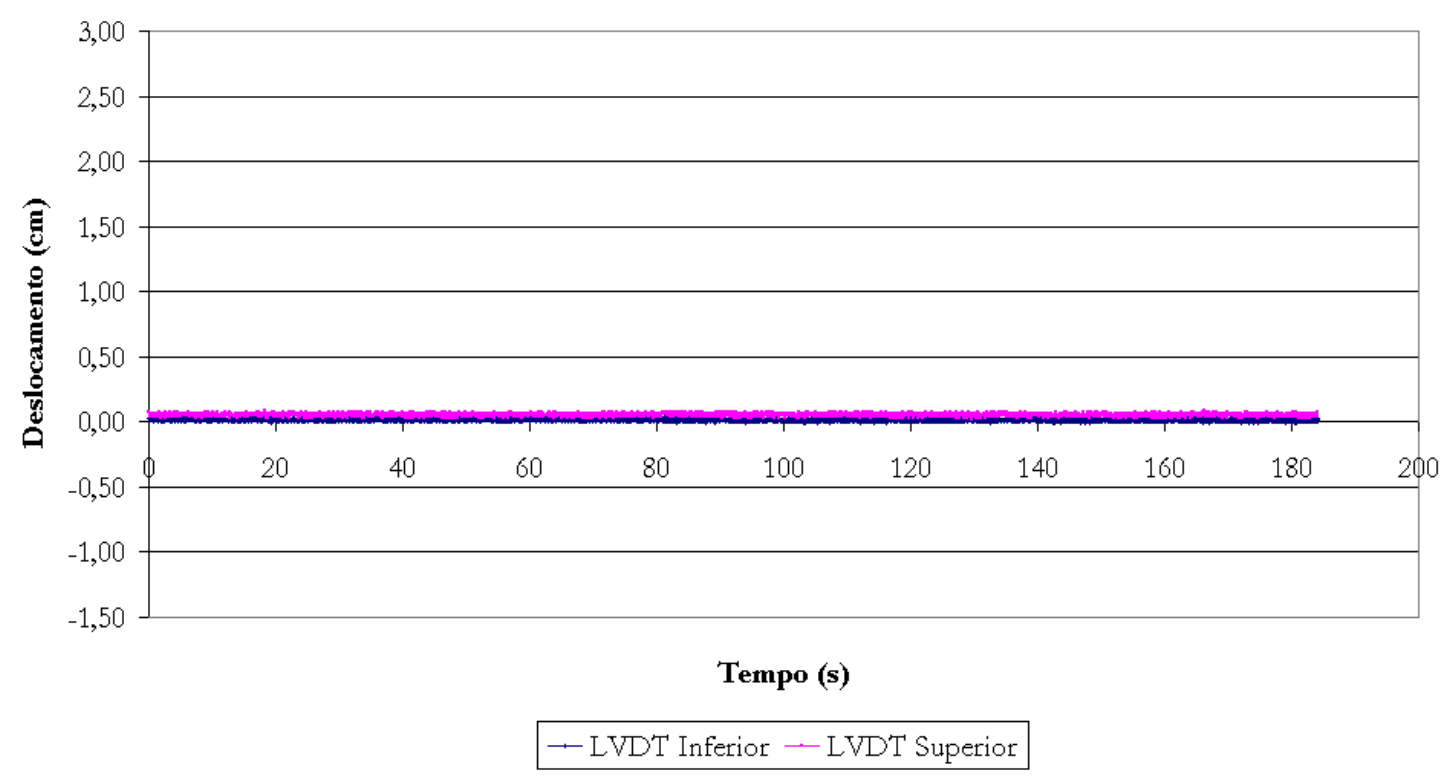

Vala Profunda Compactada - 4,5 ton - Estático 1

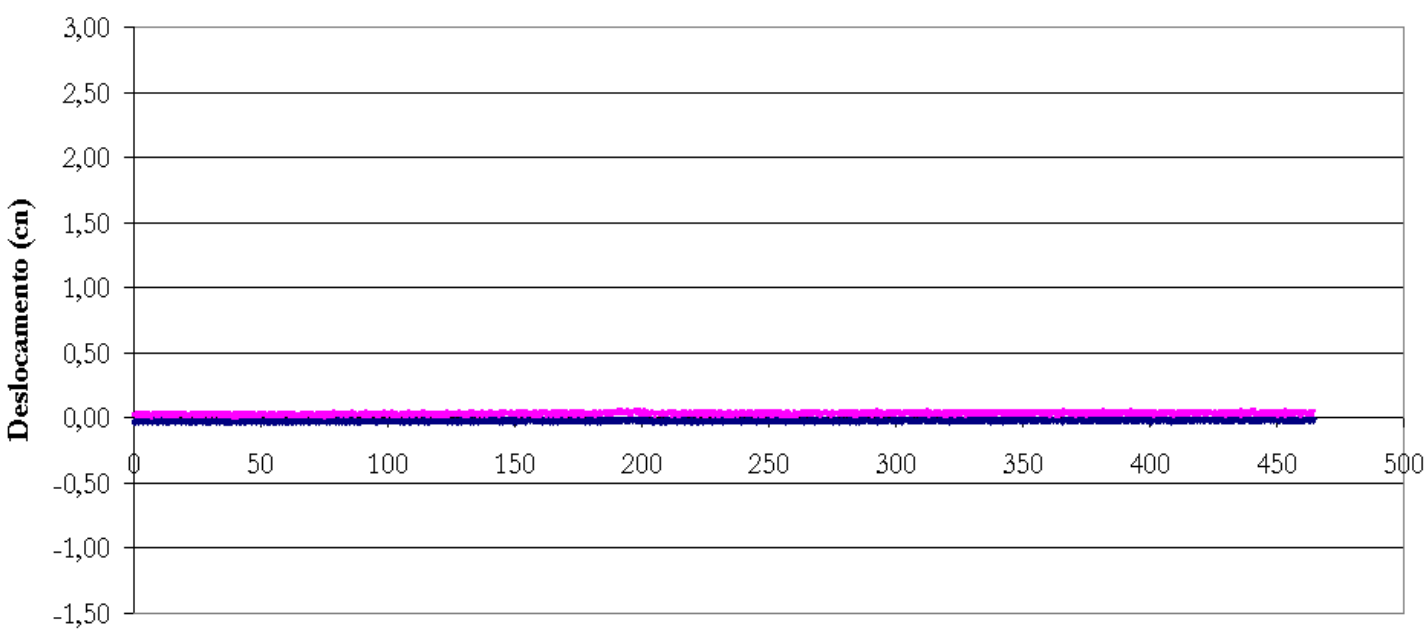

Tempo (s)

- LVDT Inferior - - LVDT Superior 
Vala Profunda Compactada - 4,5 ton - Estático 2

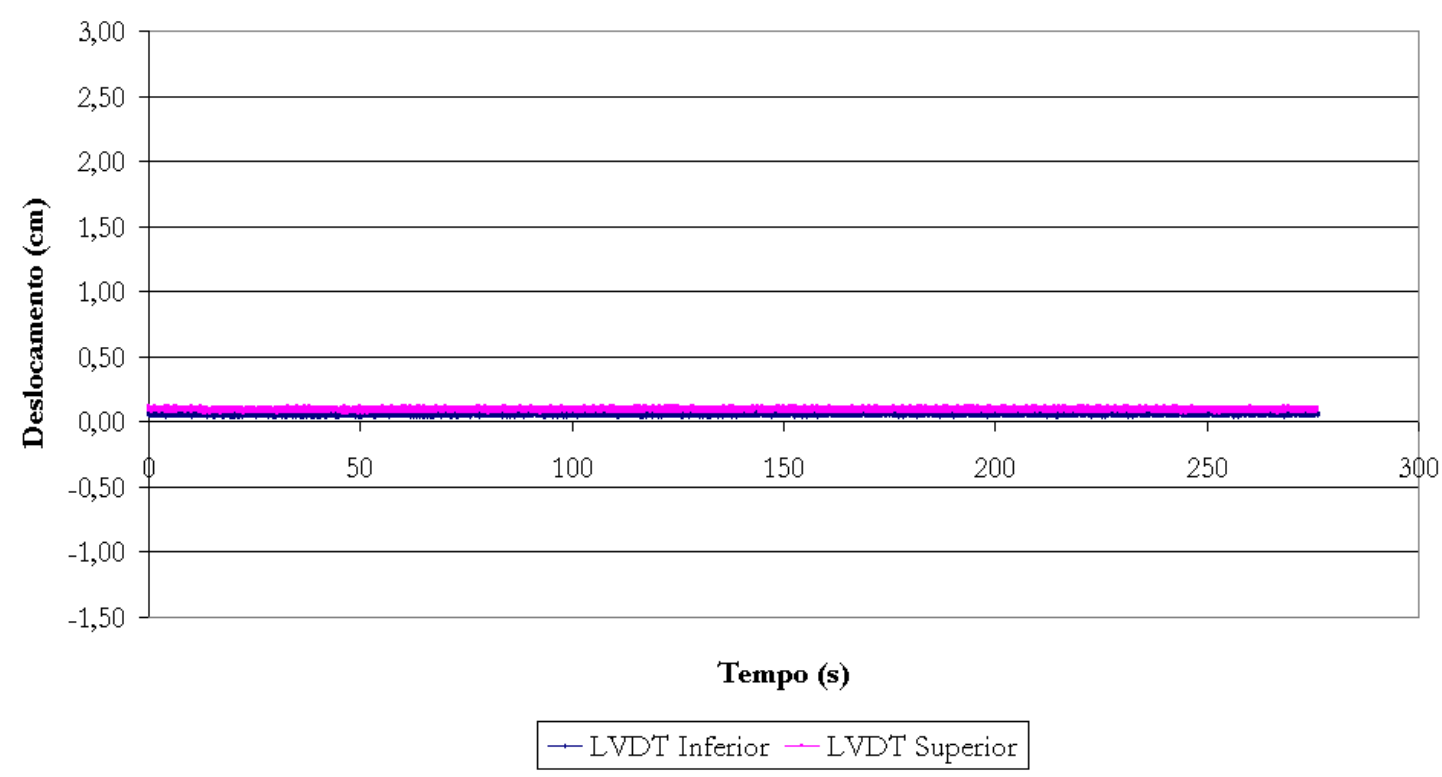

Vala Profunda Compactada - 4,5 ton - Estático 3

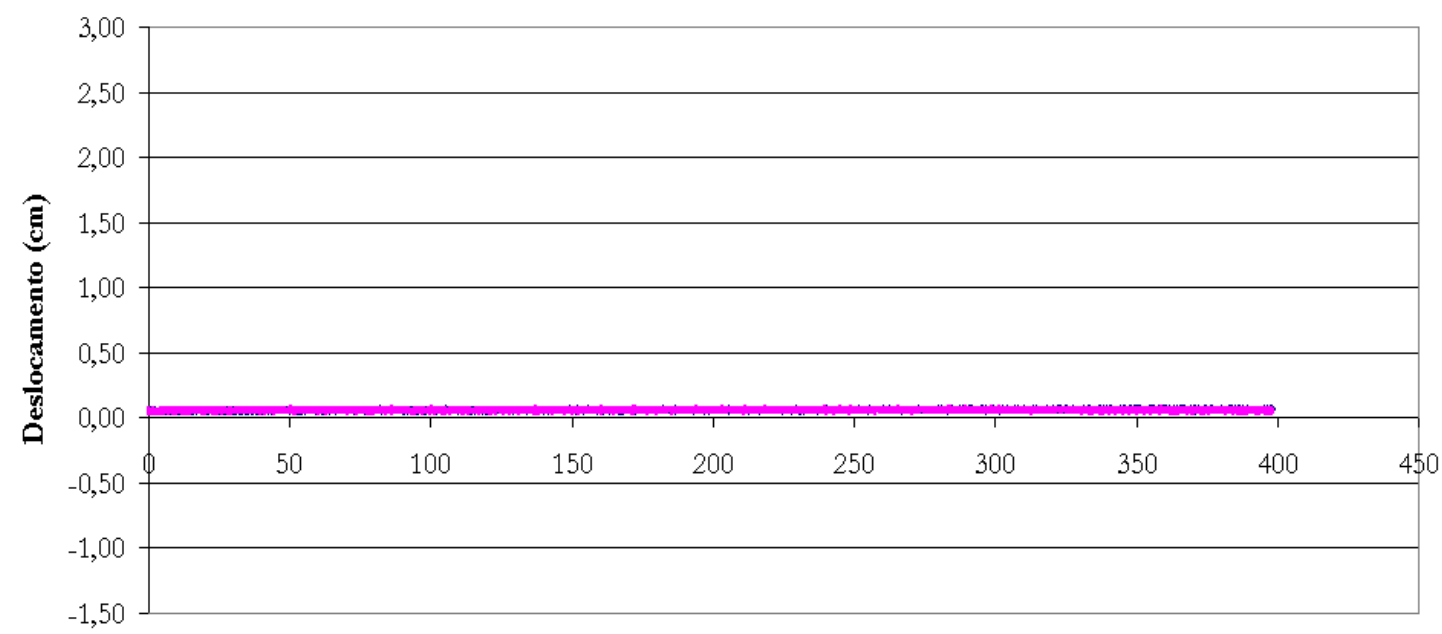

Tempo (s)

$\rightarrow$ LVDT Inferior - LVDT Superior 
Vala Profunda Compactada - 6,0 ton - Dinâmico

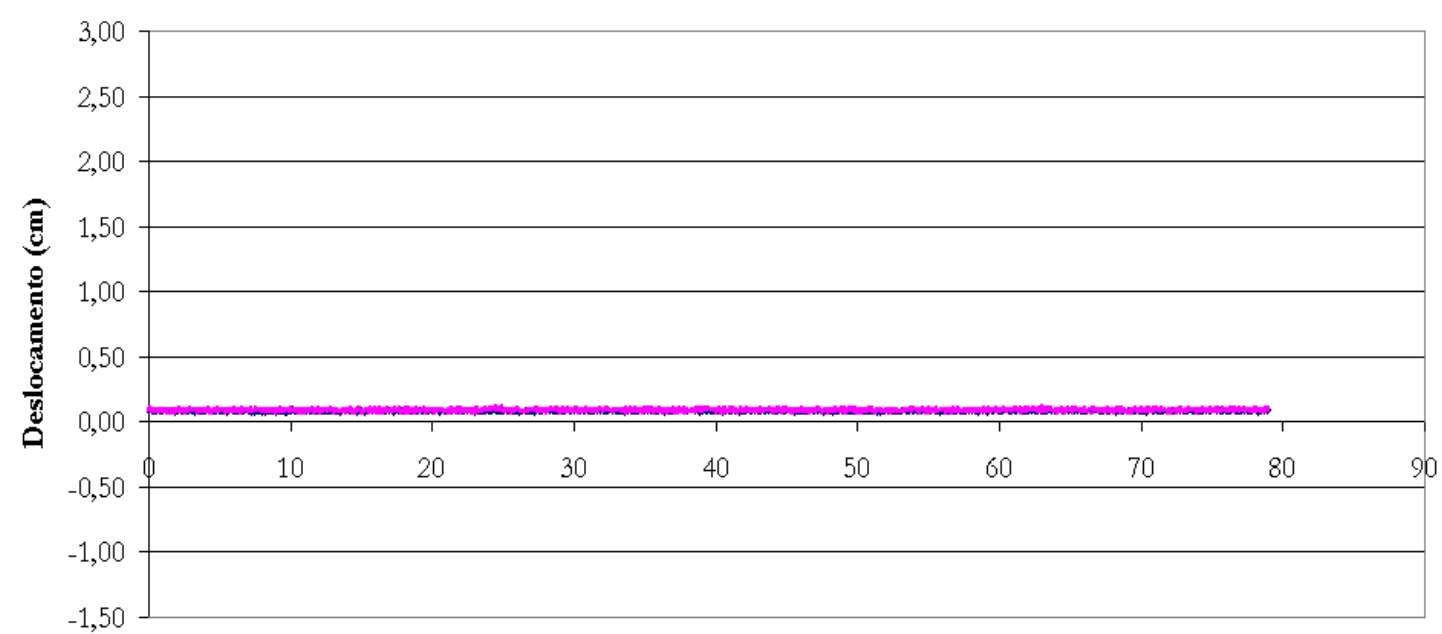

Tempo (s)

- LVDT Inferior - LVDT Superior

Vala Profunda Compactada - 6,0 ton - Estático 1

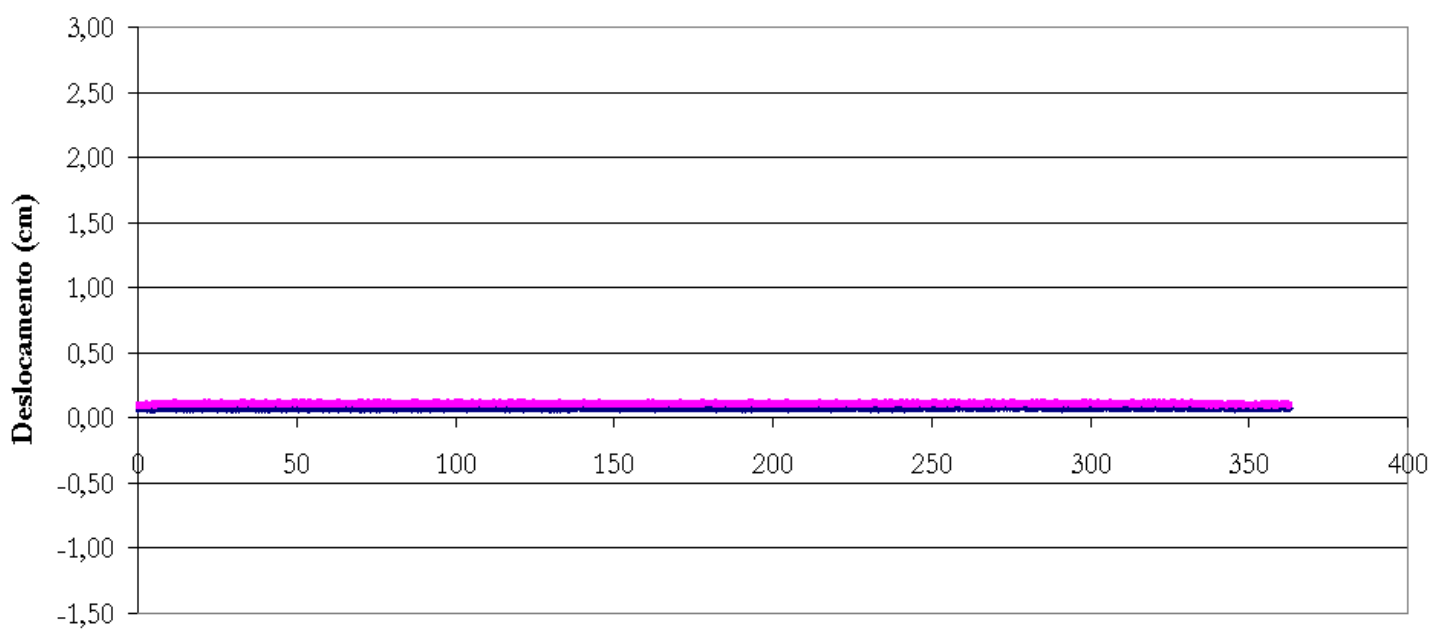

Tempo (s)

- LVDT Inferior - - LVDT Superior 
Vala Profunda Compactada - 6,0 ton - Estático 2

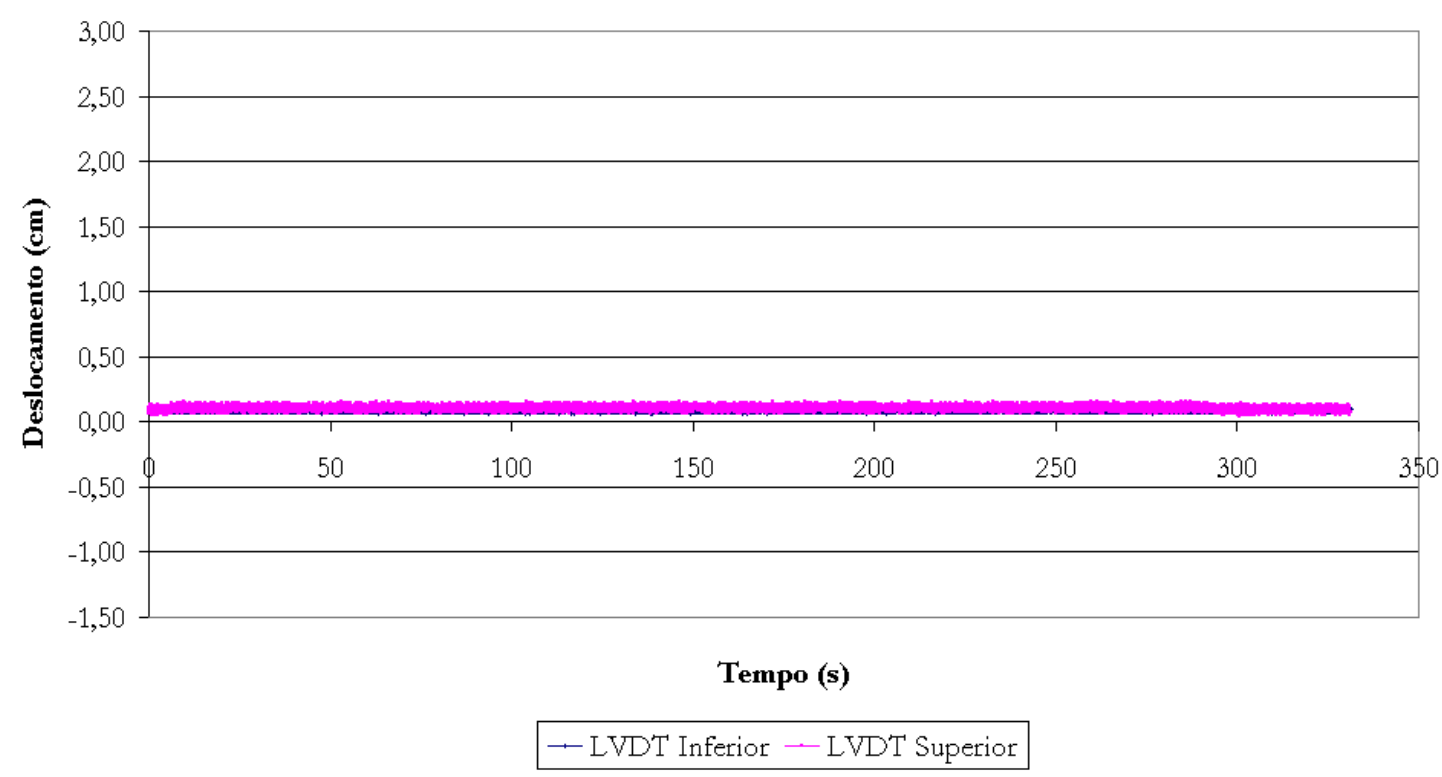

Vala Profunda Compactada - 6,0 ton - Estático 3

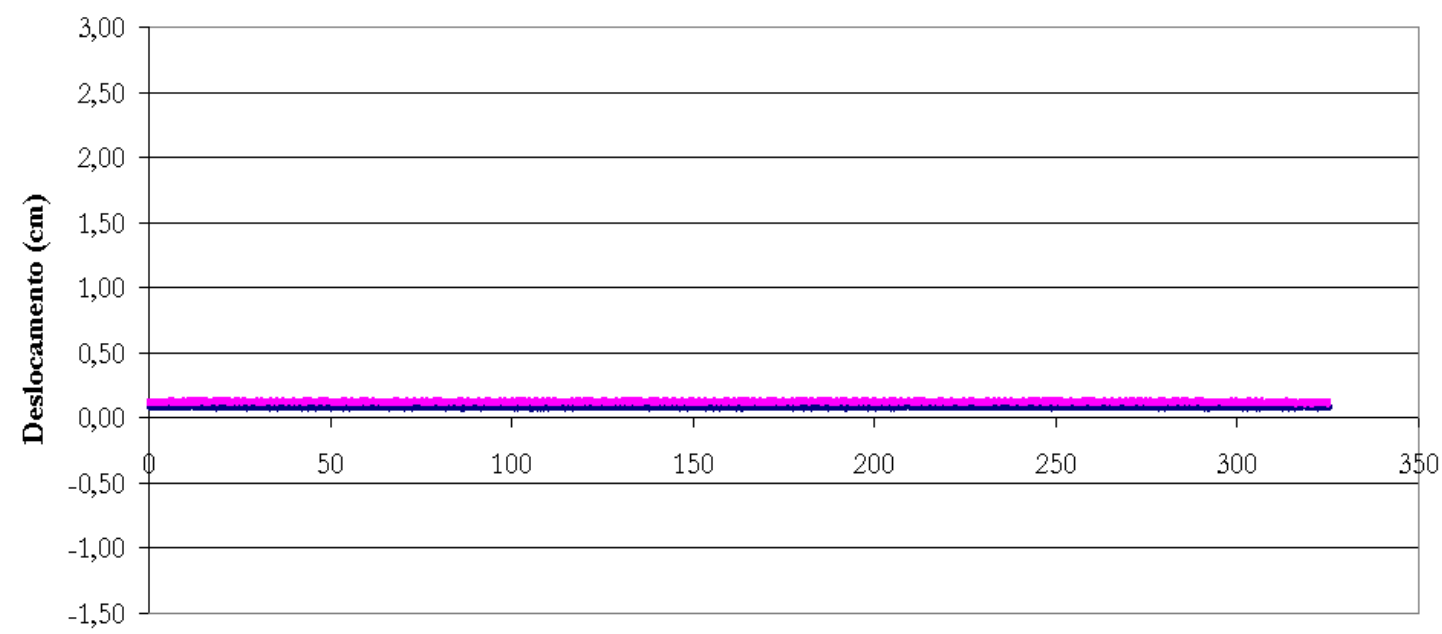

Tempo (s) 
ANEXO VII

Resultados de Deslocamento da Vala Rasa Compactada 
Vala Rasa Compactada - 3,0 ton - Dinâmico

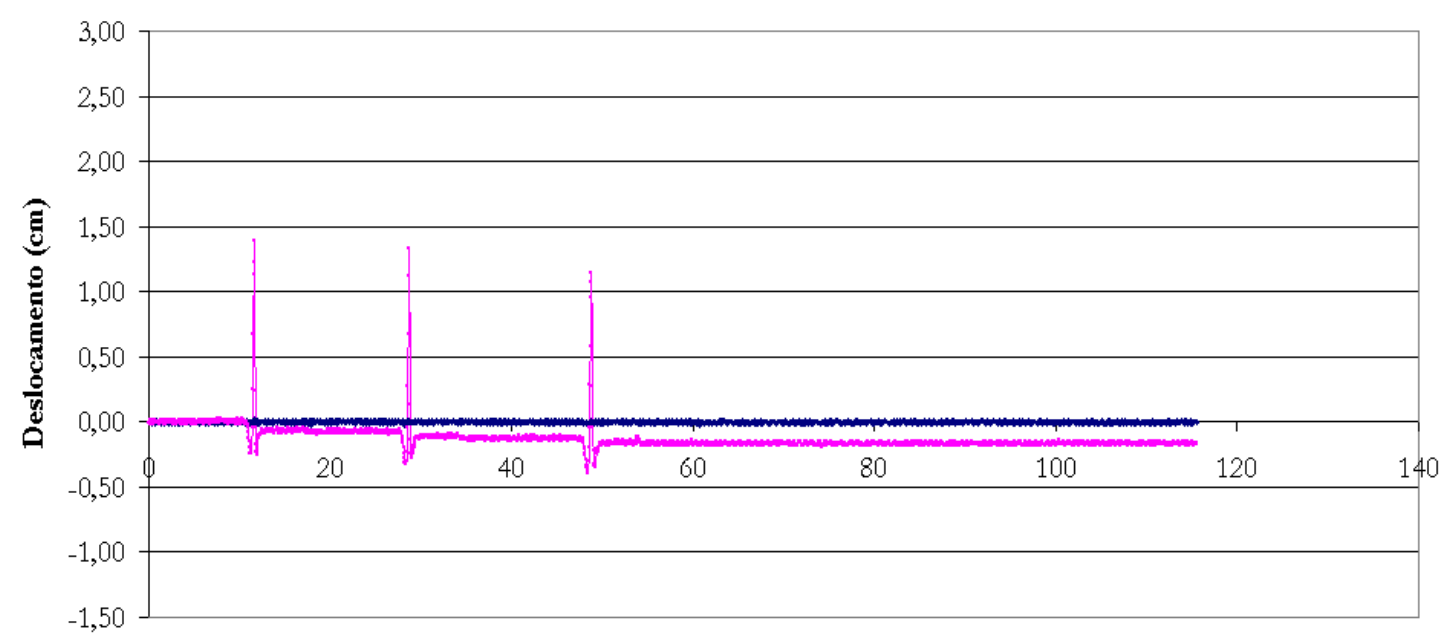

Tempo (s)

$\rightarrow$ LVDT Inferior - - LVDT Superior

Vala Rasa Compactada - 3,0 ton - Estático 1

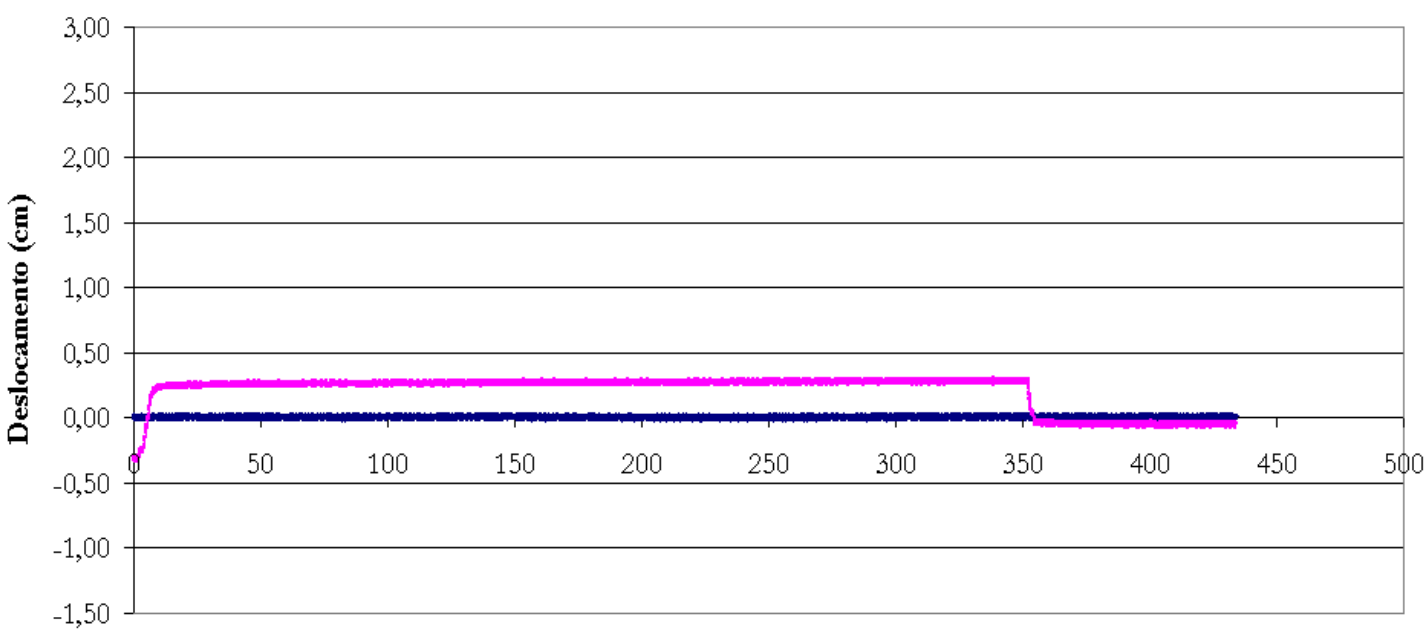

Tempo (s)

$\rightarrow$ LVDT Inferior - LVDT Superior 
Vala Rasa Compactada - 3,0 ton - Estático 2

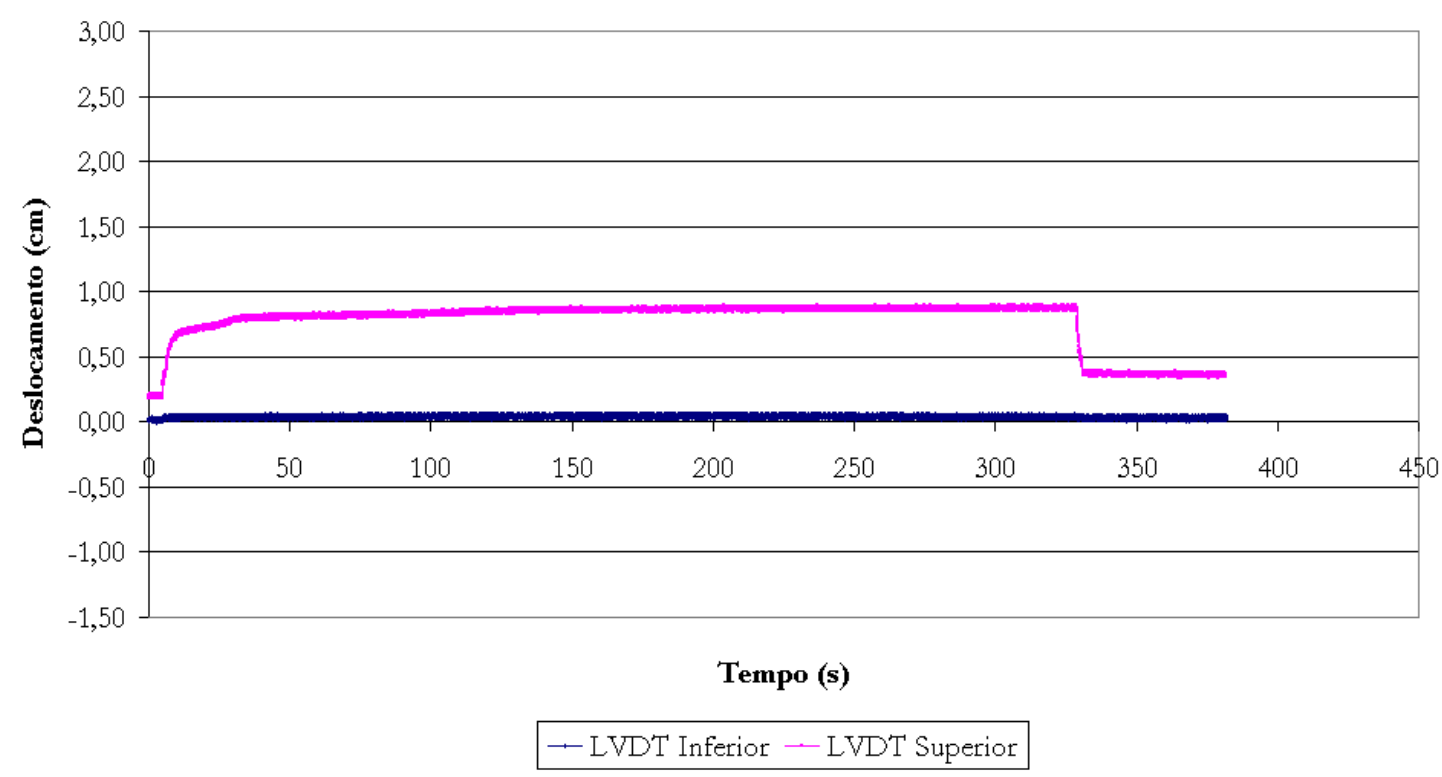

Vala Rasa Compactada - 3,0 ton - Estático 3

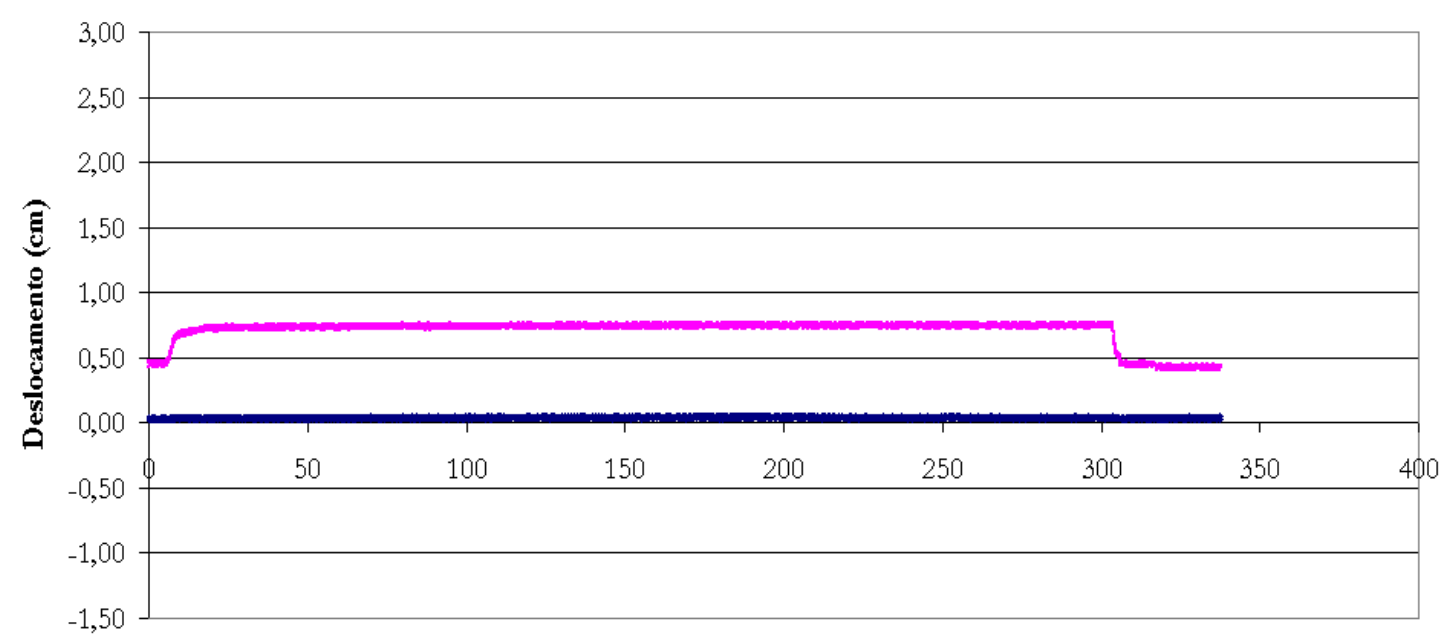

Tempo (s)

$\rightarrow$ LVDT Inferior - LVDT Supeior 
Vala Rasa Compactada - 4,0 ton - Dinâmico

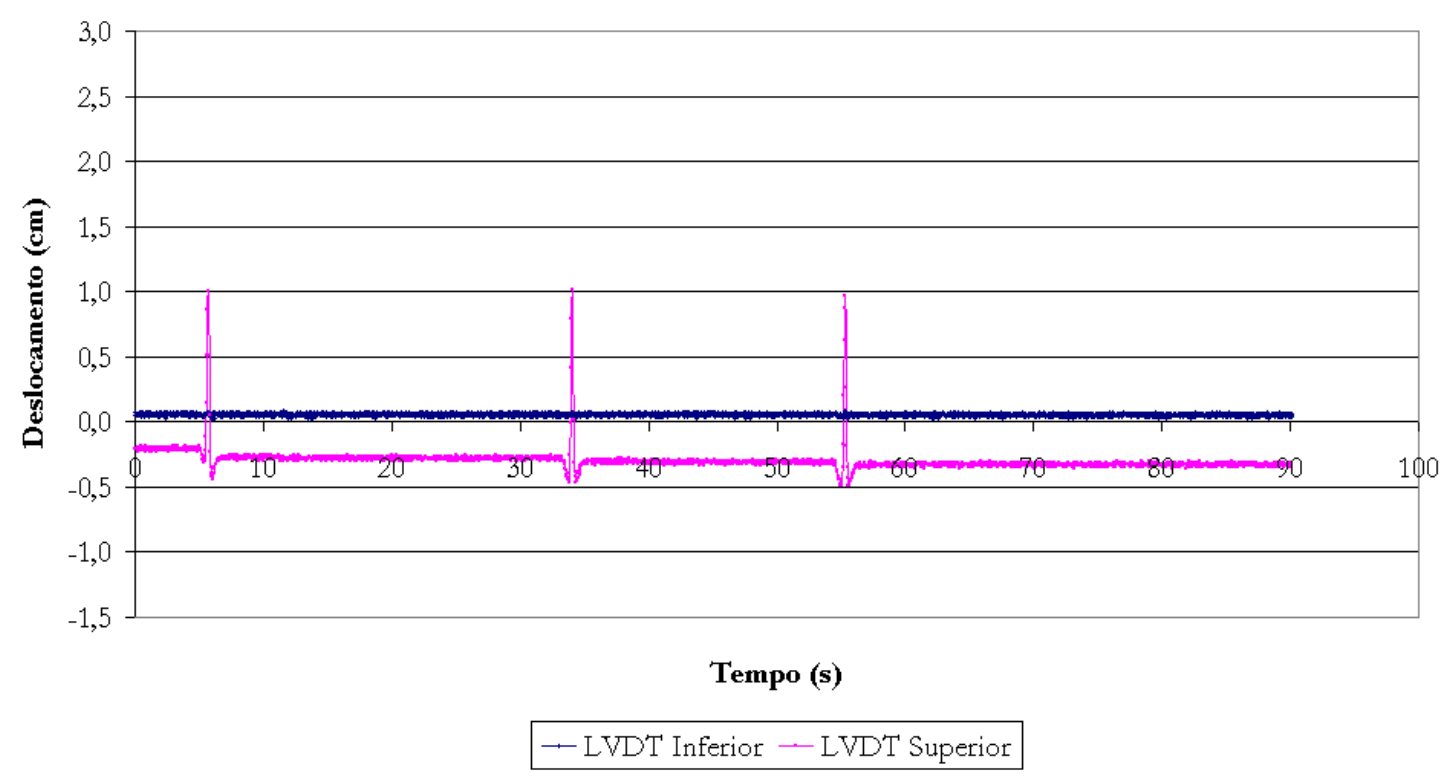

Vala Rasa Compactada - 4,0 ton - Estático 1

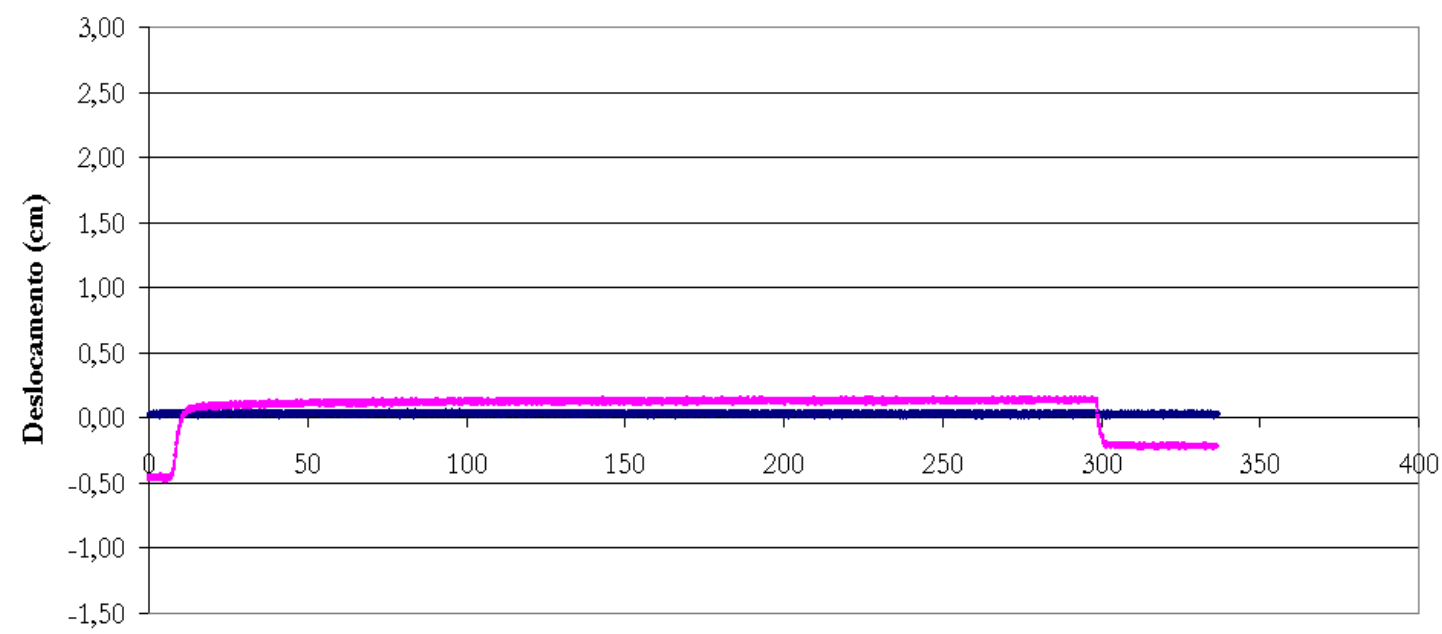

Tempo (s)

- LVDT Inferior - - LVDT Superior 
Vala Rasa Compactada - 4,0 ton - Estático 2

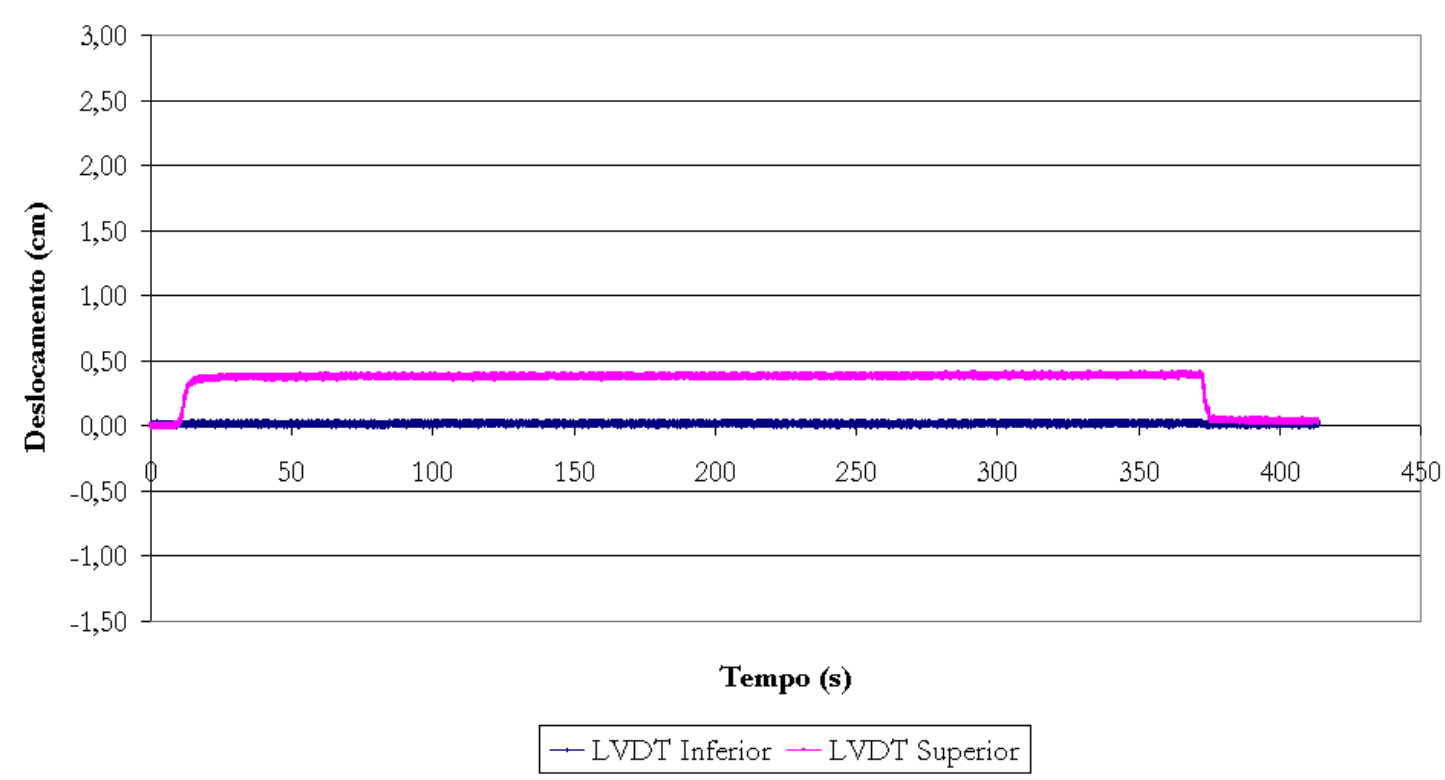

Vala Rasa Compactada - 4,0 ton - Estático 3

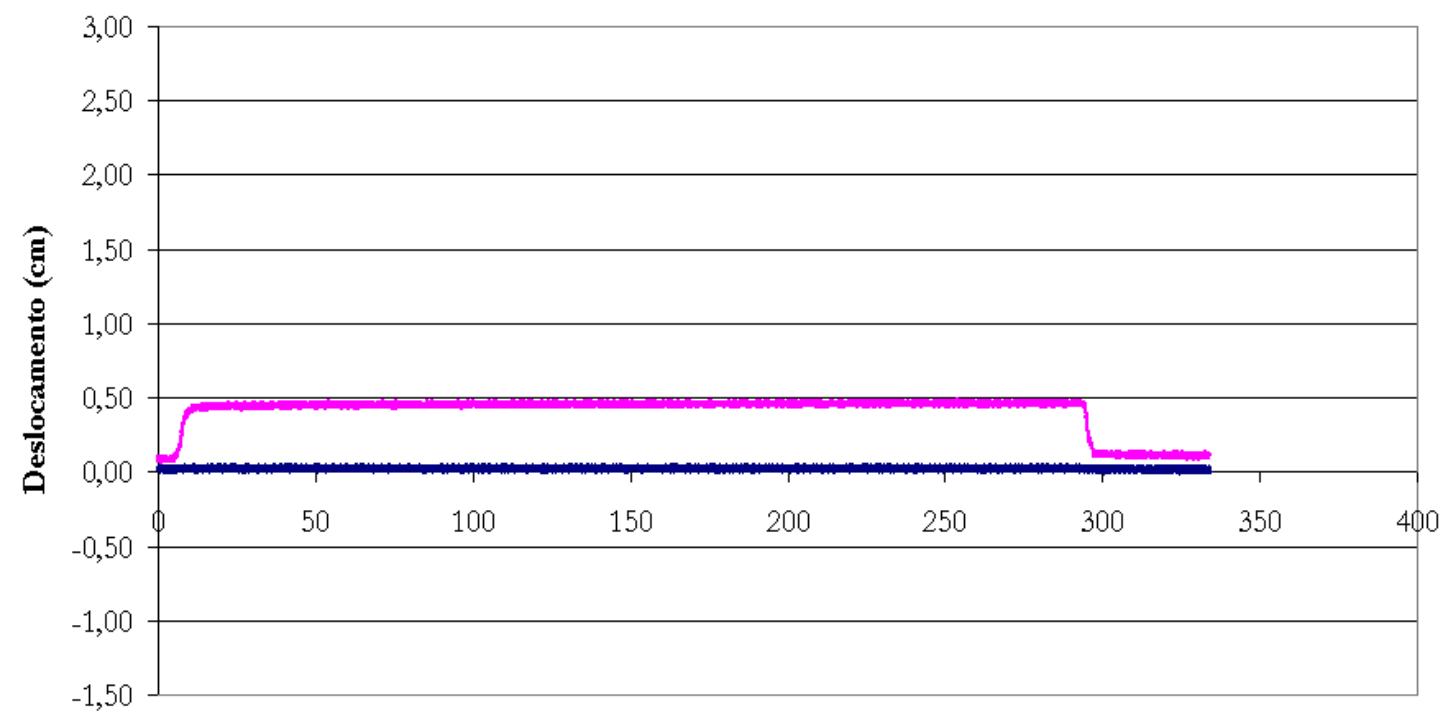

Tempo (s) 
Vala Rasa Compactada - 5,0 ton - Dinâmico

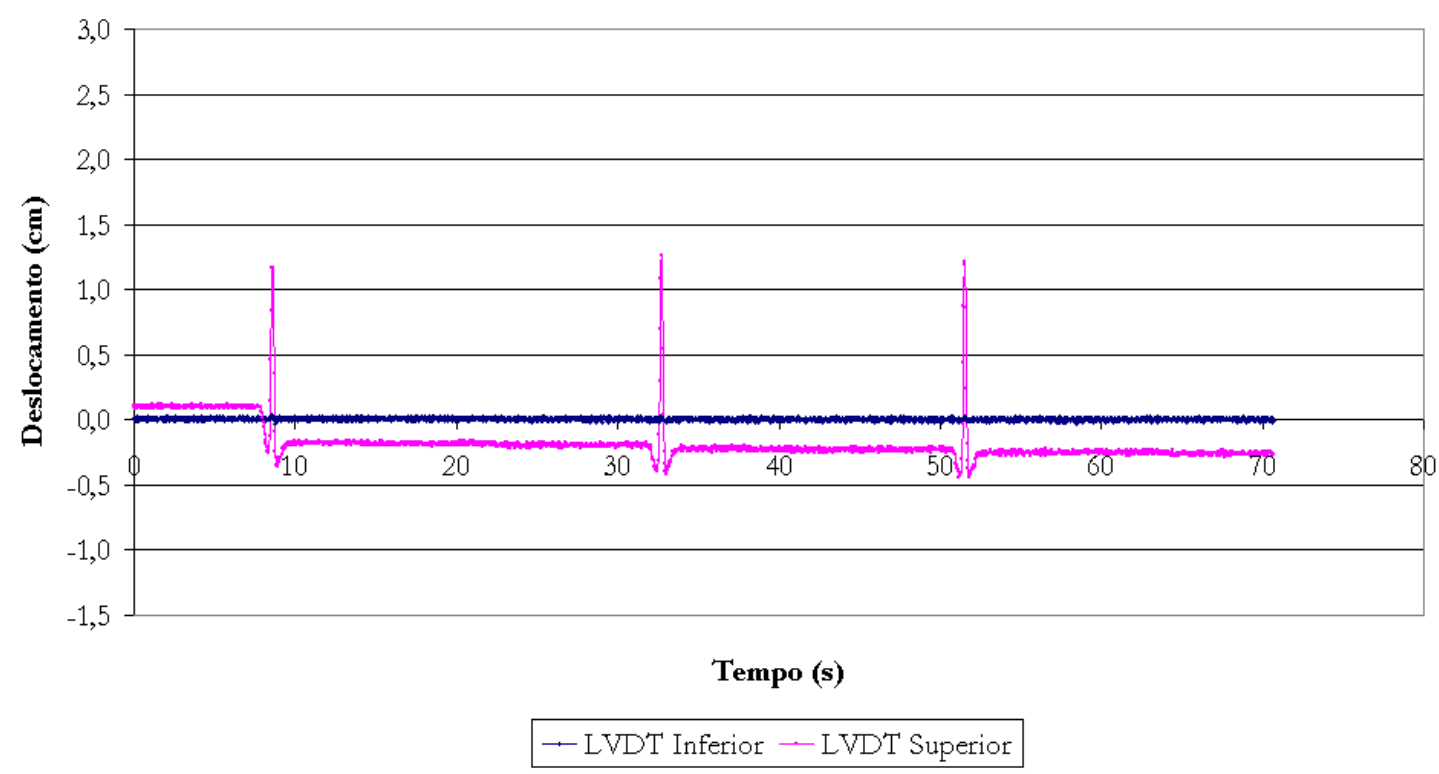

Vala Rasa Compactada - 5,0 ton - Estático 1

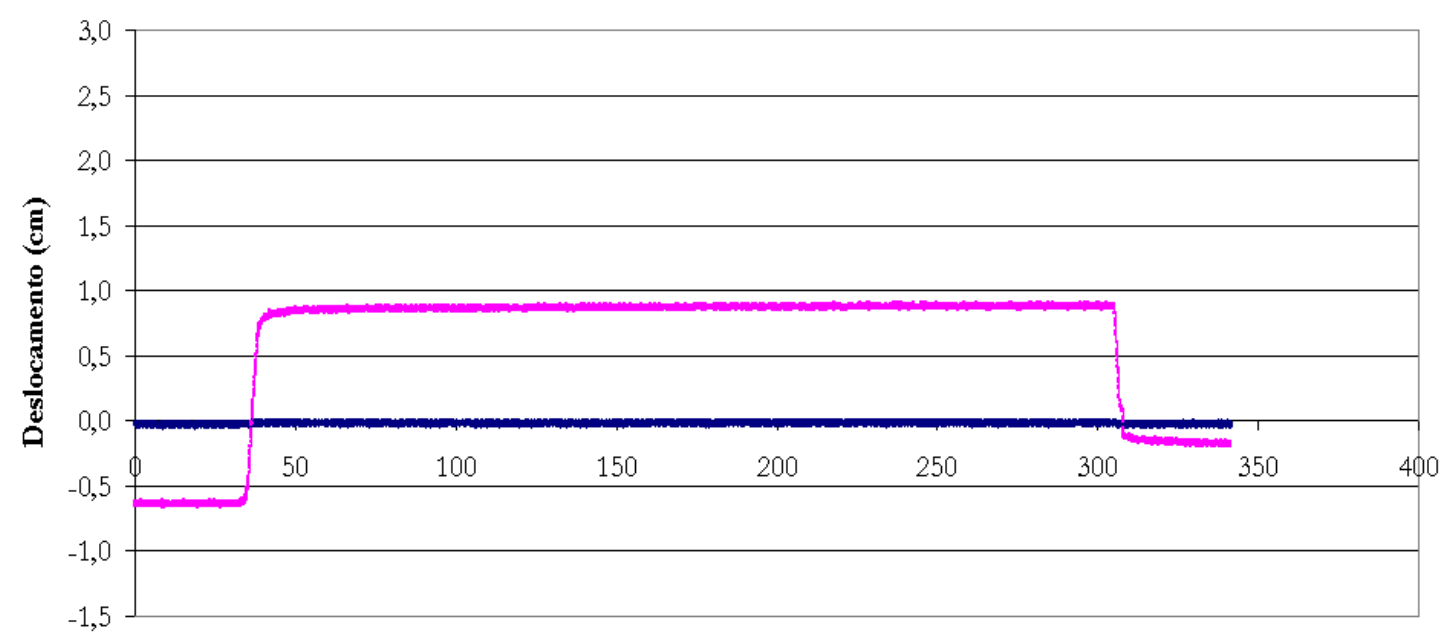

Tempo (s)

$\rightarrow$ LVDT Inferior - LVDT Superior 
Vala Rasa Compactada - 5,0 ton - Estático 2

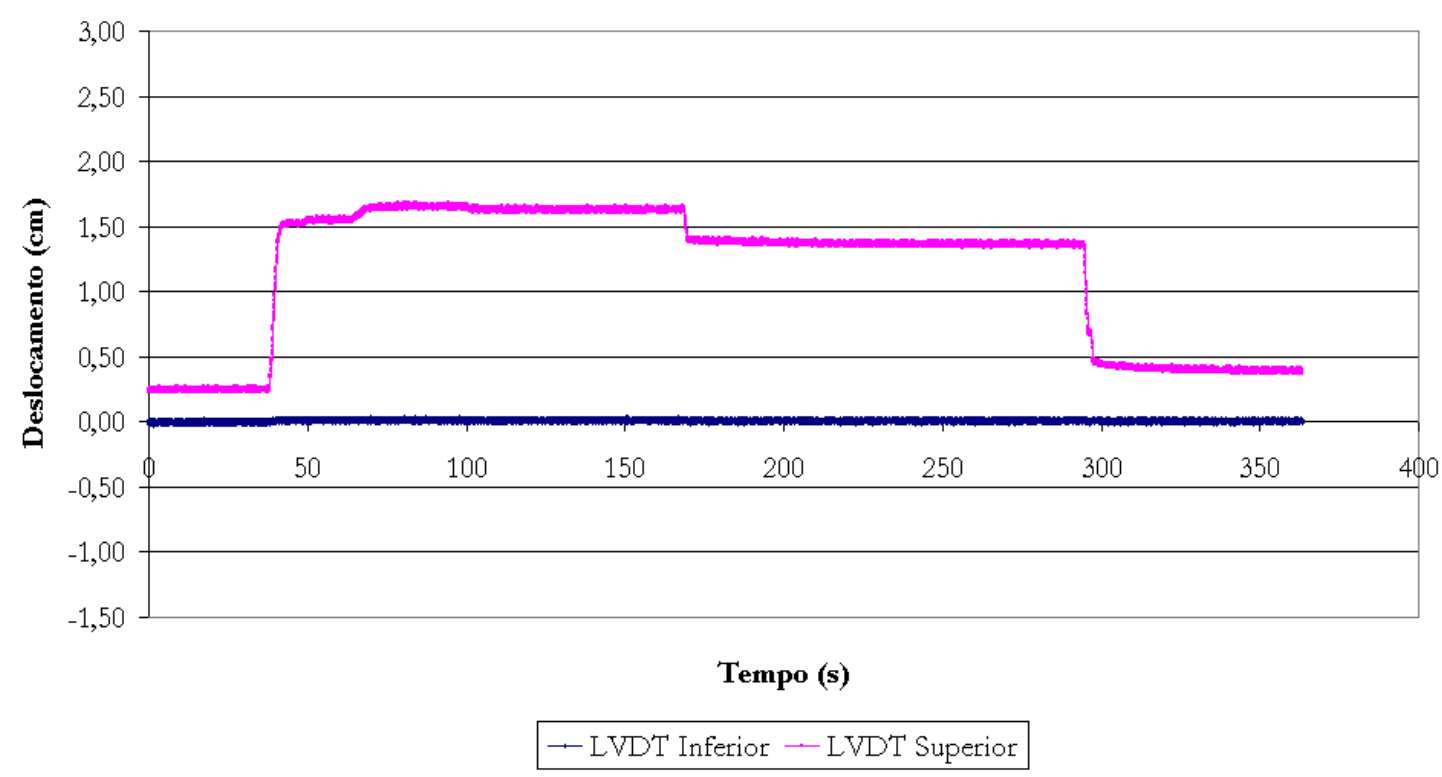

Vala Rasa Compactada - 5,0 ton - Estático 3

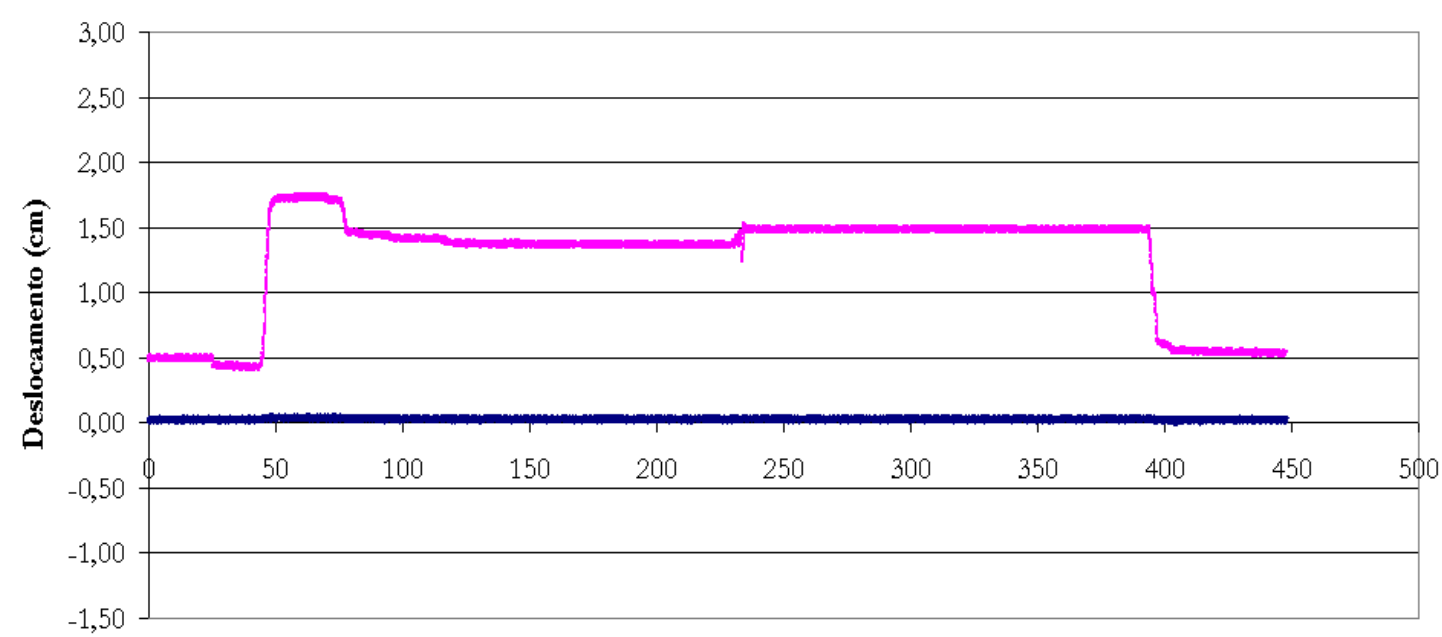

Tempo (s)

$\rightarrow$ LVDT Inferior - - LVDT Superior 
Vala Rasa Compactada - 6,0 ton - Dinâmico

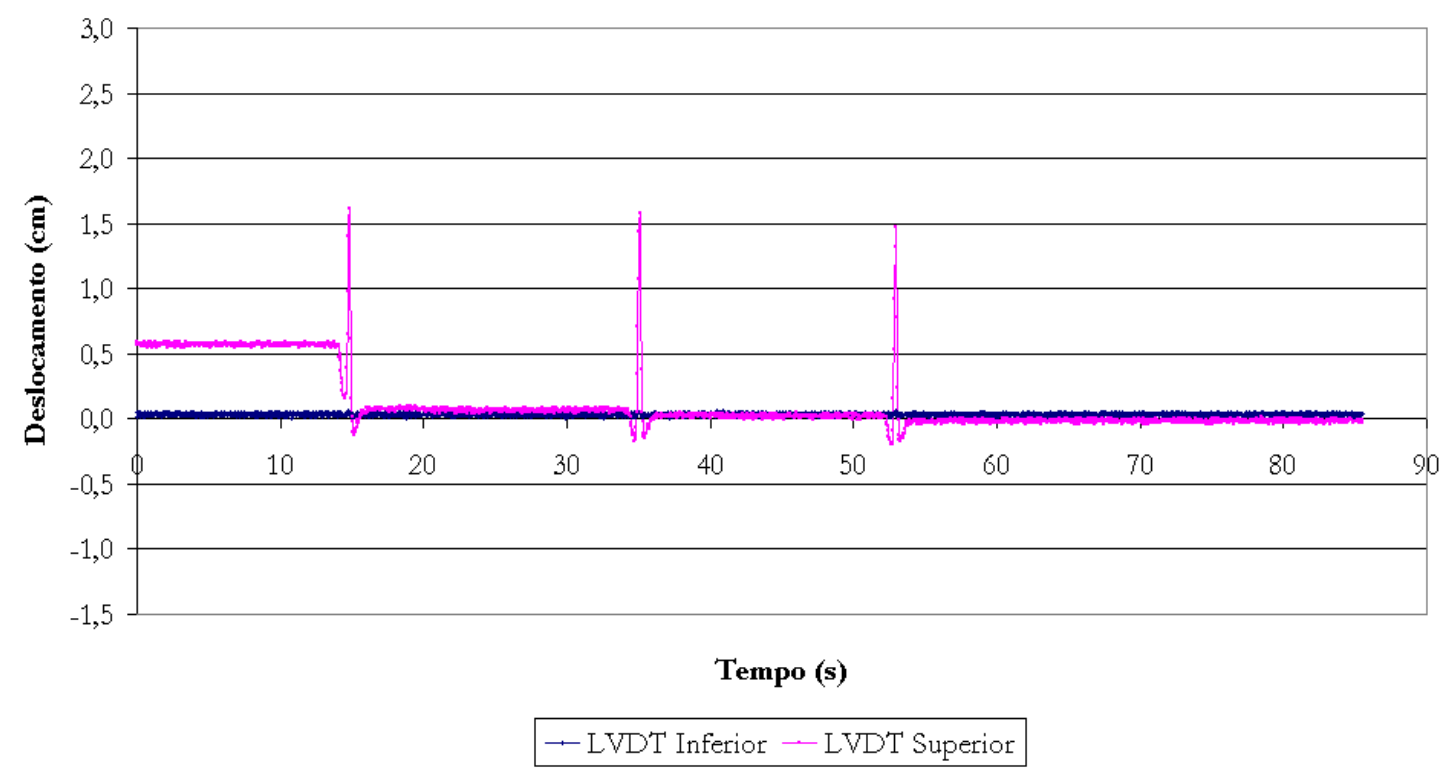

Vala Rasa Compactada - 6,0 ton - Estático 1

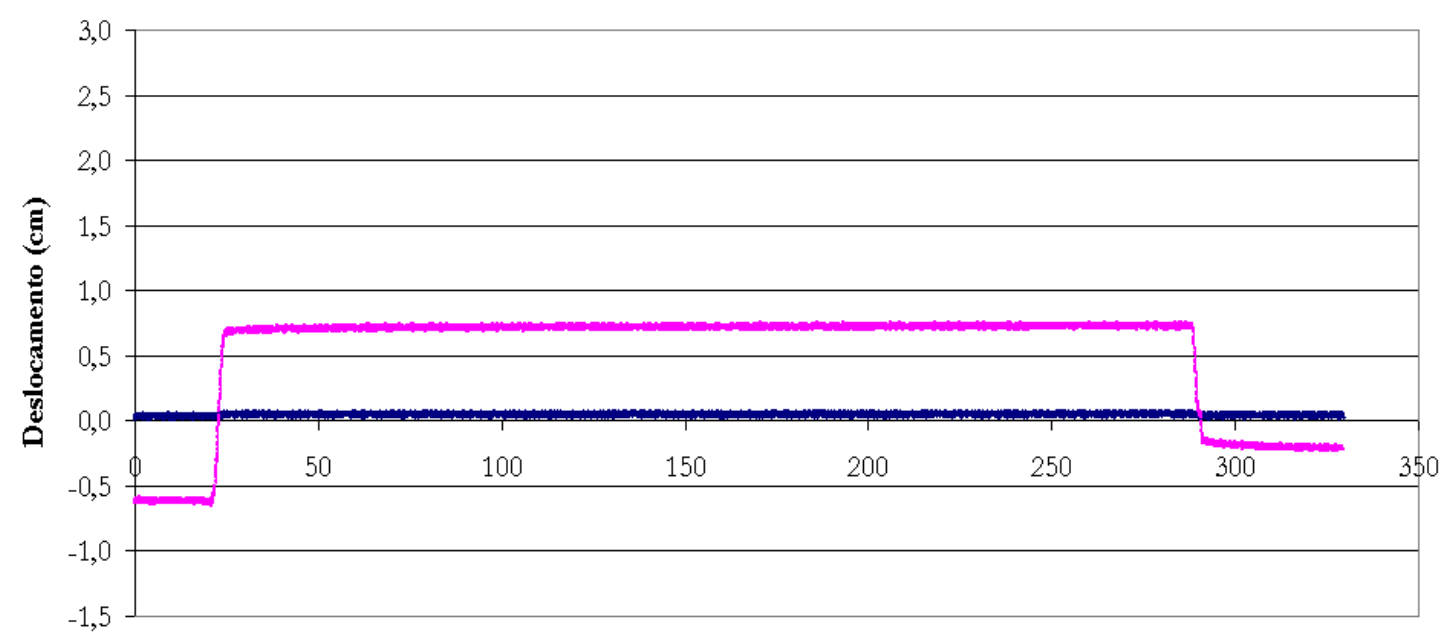

Tempo (s)

$\rightarrow$ LVDT Inferior - LVDT Superior 
Vala Rasa Compactada - 6,0 ton - Estático 2

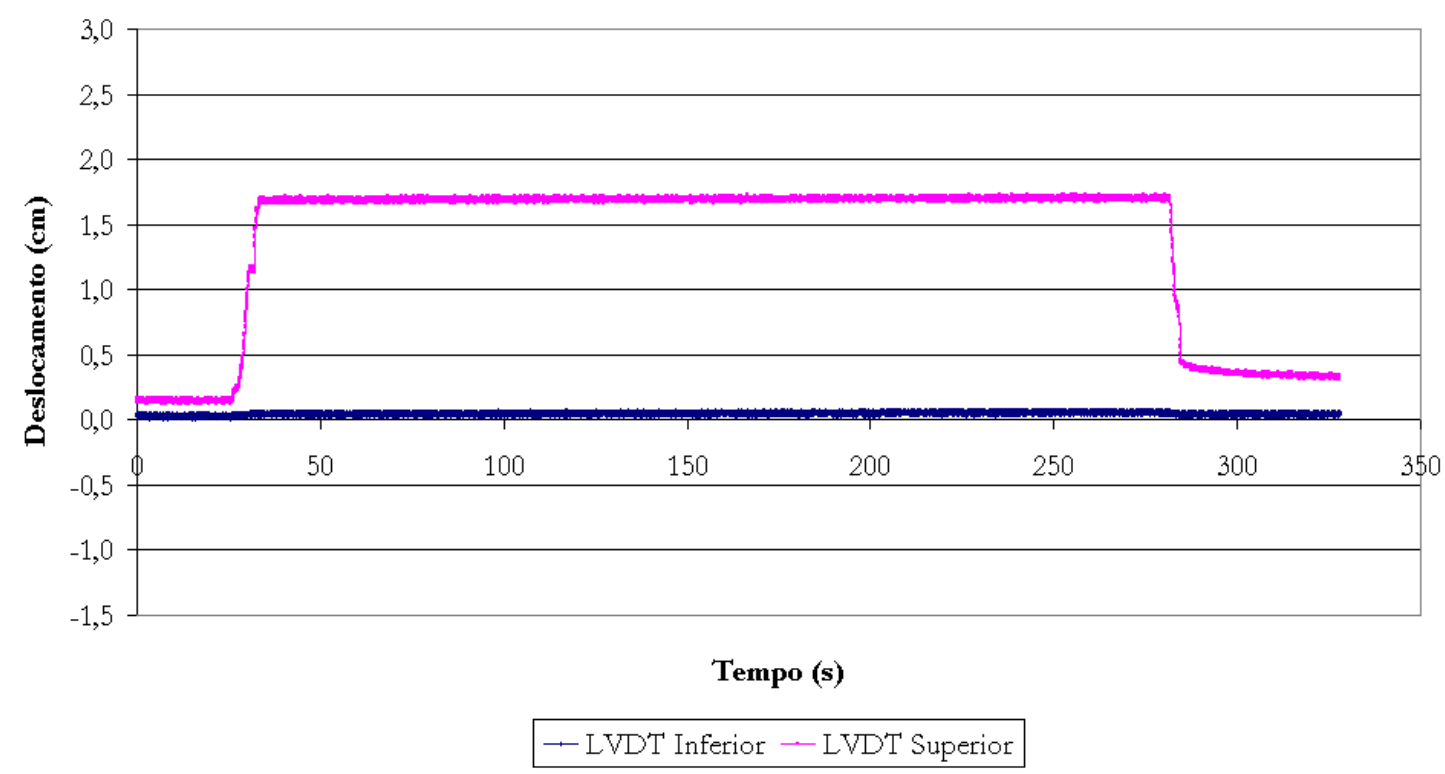

Vala Rasa Compactada - 6,0 ton - Estático 3

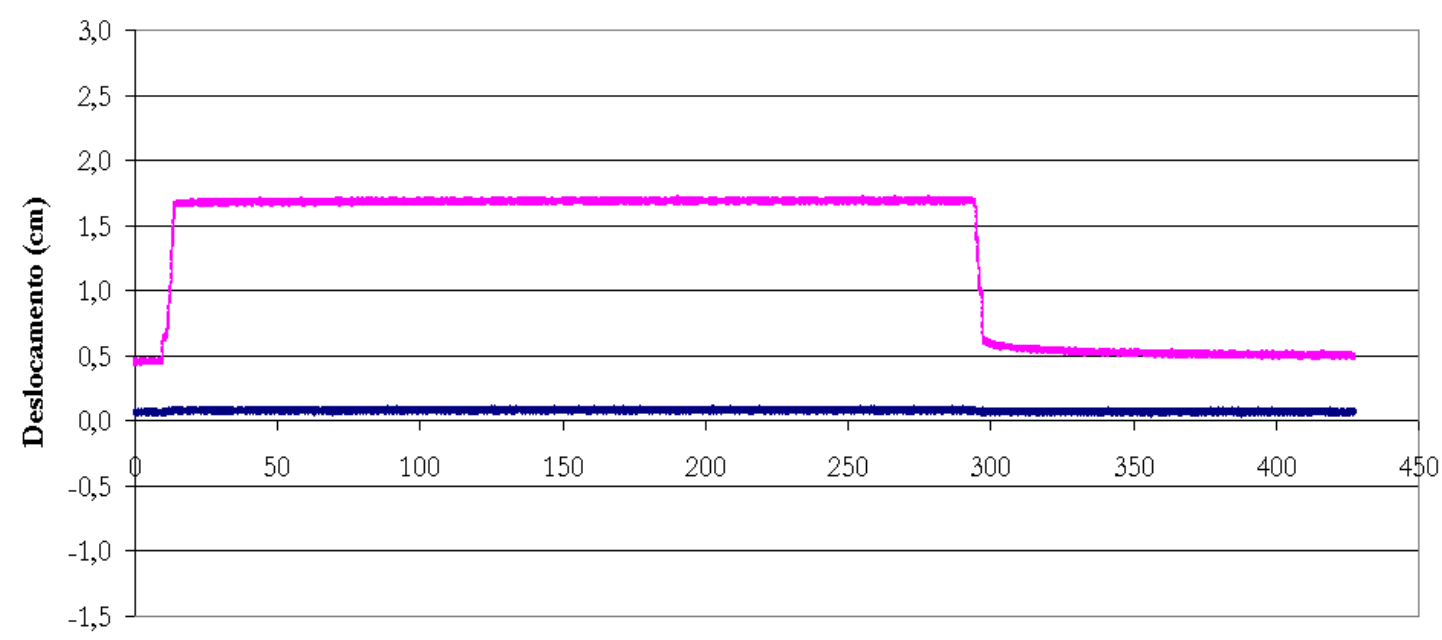

Tempo (s)

$\rightarrow$ LVDT Inferior - LVDT Superior 


\section{ANEXO VIII}

Resultados de Deslocamento da Vala Não Rasa Compactada 
Vala Rasa Não Compactada - 3,0 ton - Dinâmico

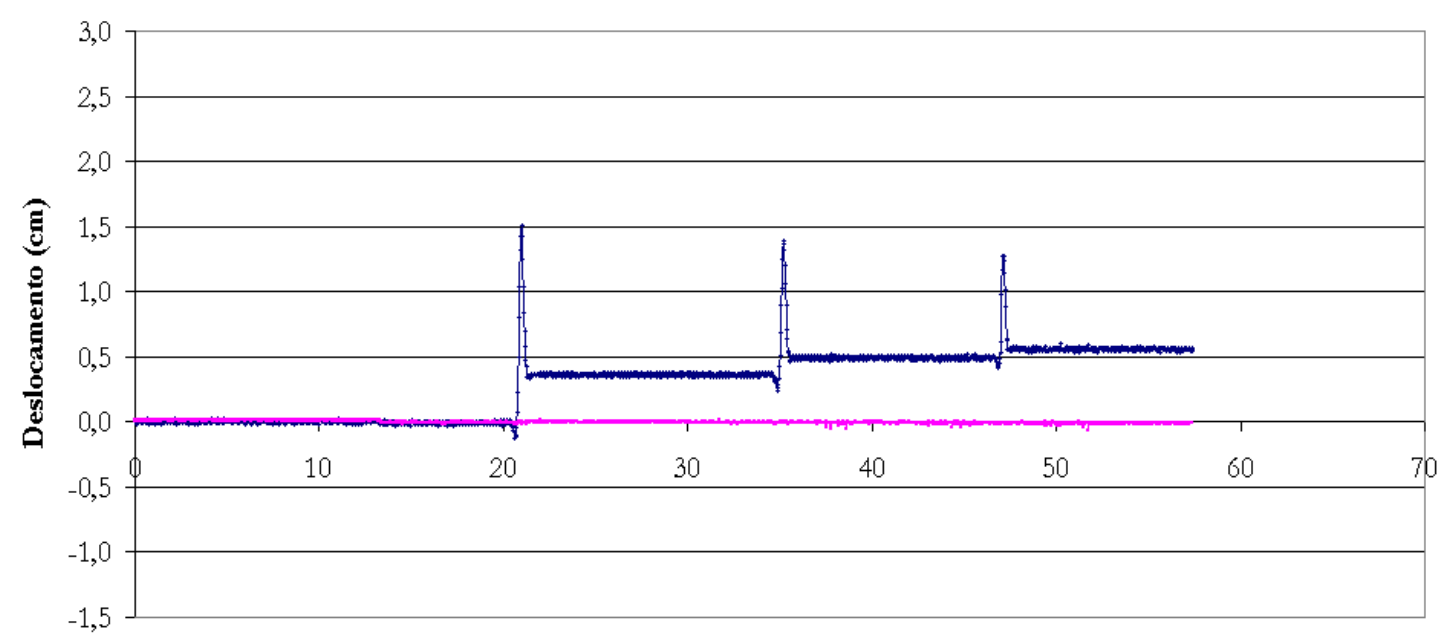

Tempo (s)

$\rightarrow$ LVDT Superior - LVDT Inferior

Vala Rasa Não Compactada - 3,0 ton - Estático 1

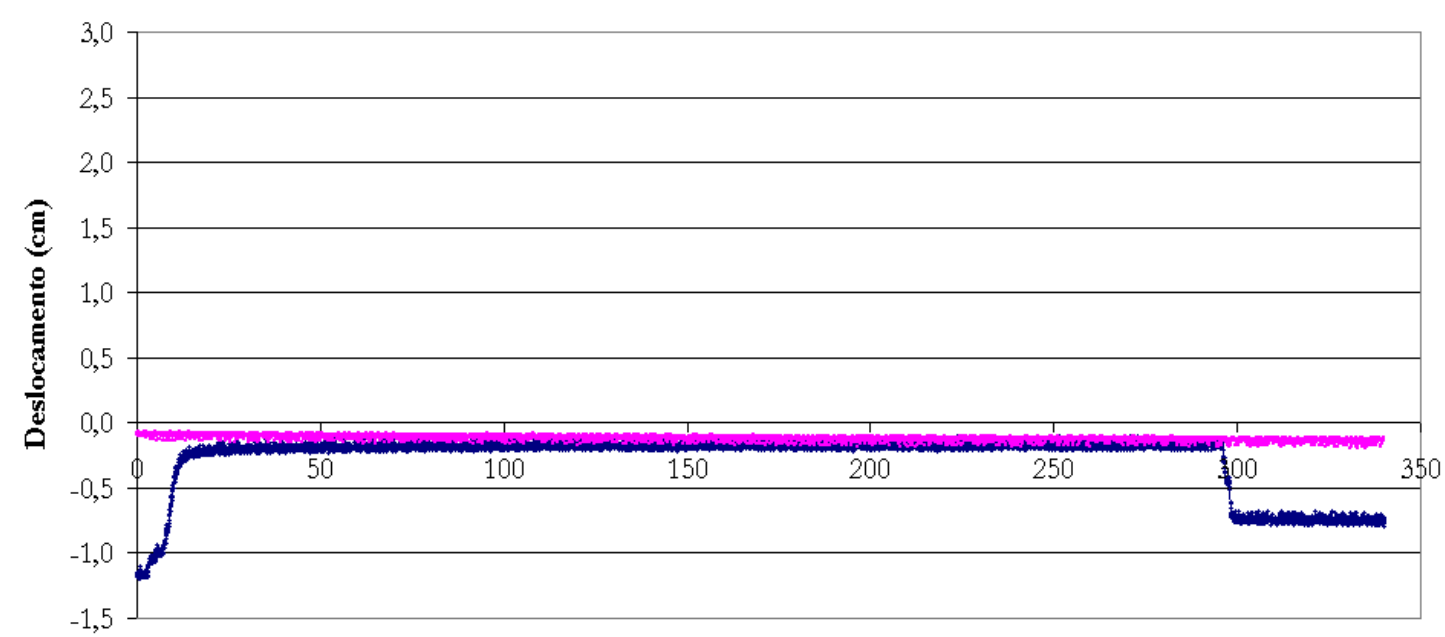

Tempo (s)

$\rightarrow$ LVDT Superior - LVDT Inferior 
Vala Rasa Não Compactada - 3,0 ton - Estático 2

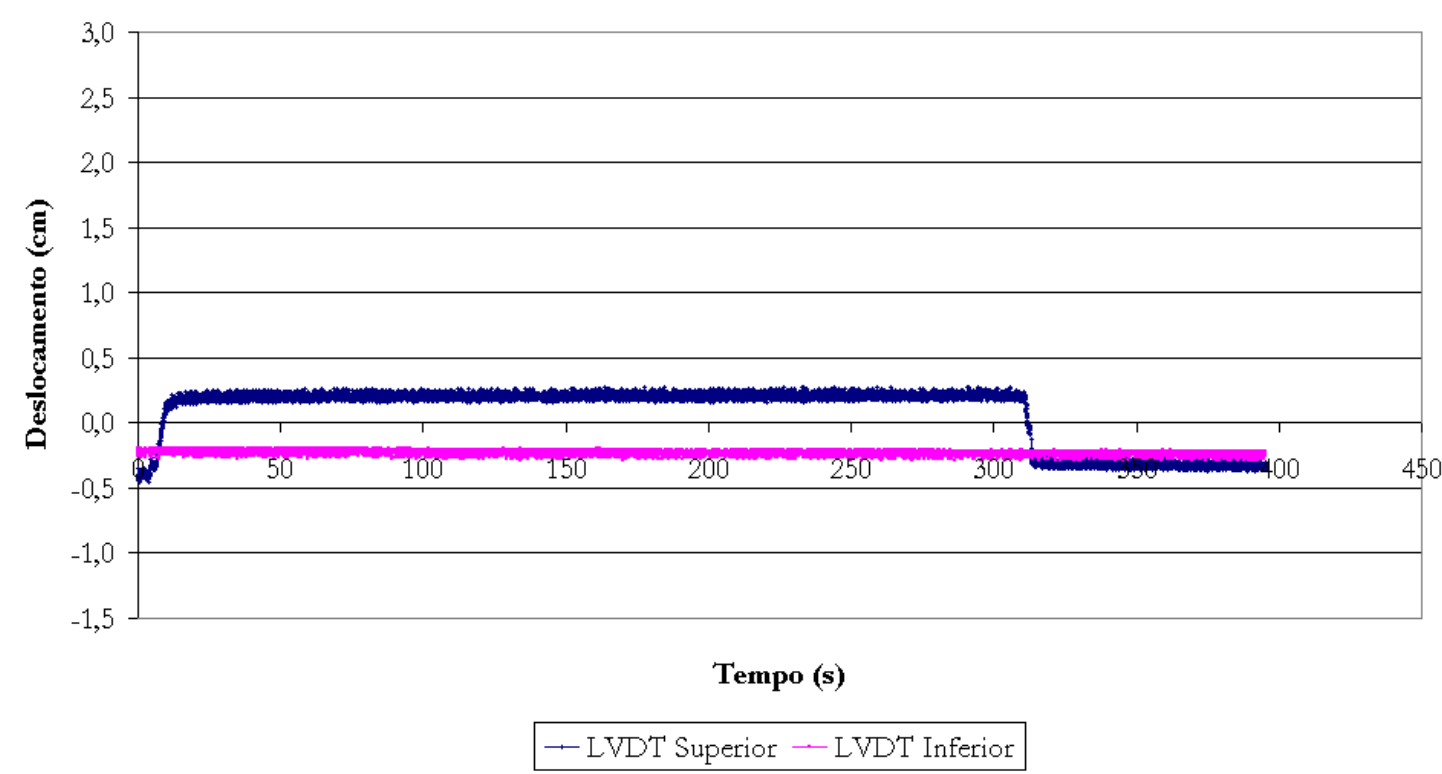

Vala Rasa Não Compactada - 3,0 ton - Estático 3

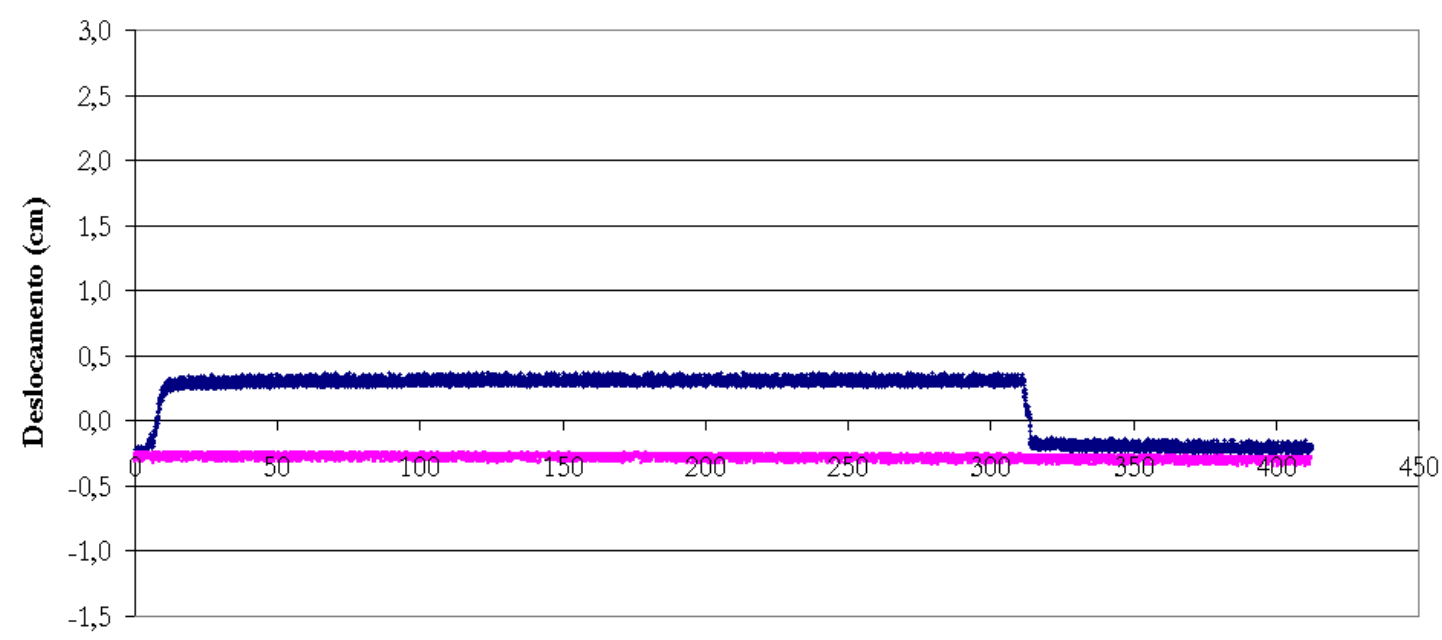

Tempo (s)

$\rightarrow$ LVDT Superior - LVDT Inferior 
Vala Rasa Não Compactada - 4,0 ton - Dinâmico

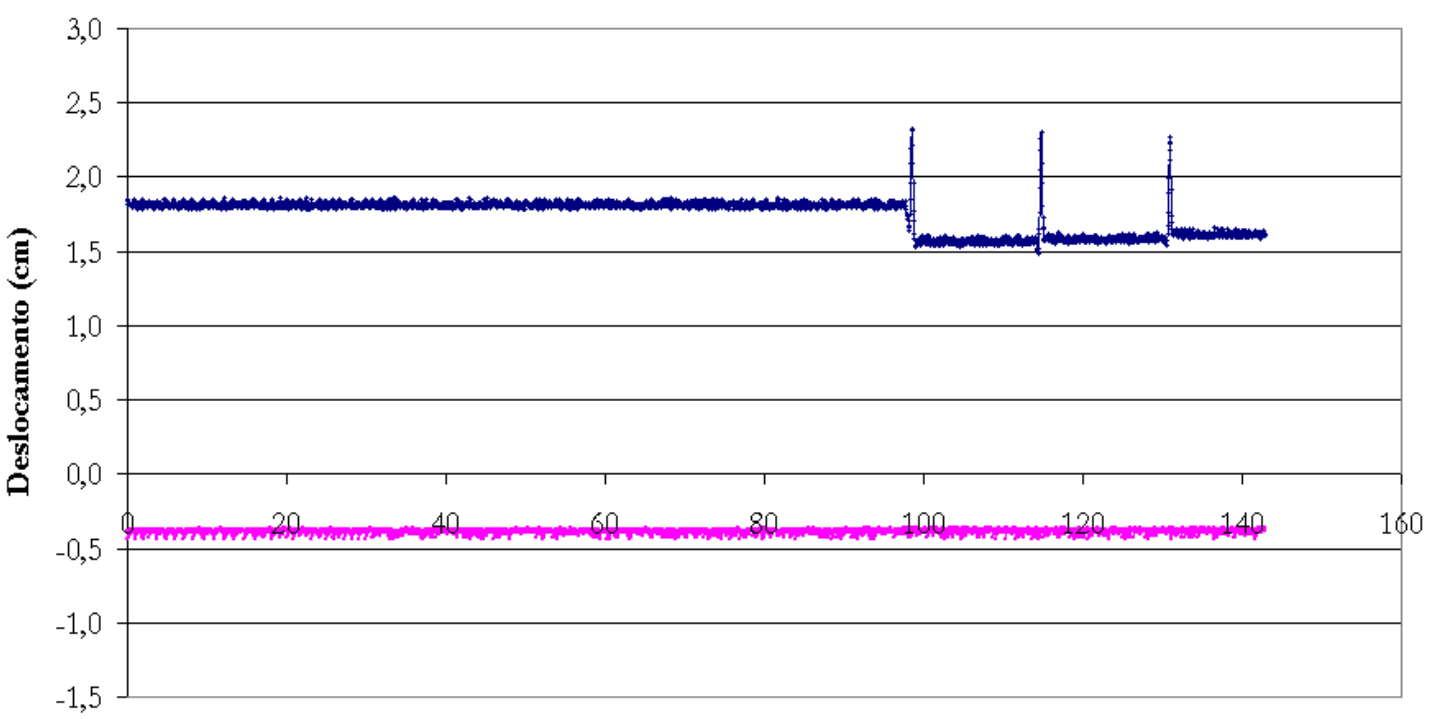

Tempo (s)

$\rightarrow$ LVDT Superior - - LVDT Inferior

Vala Rasa Não Compactada - 4,0 ton - Estático 1

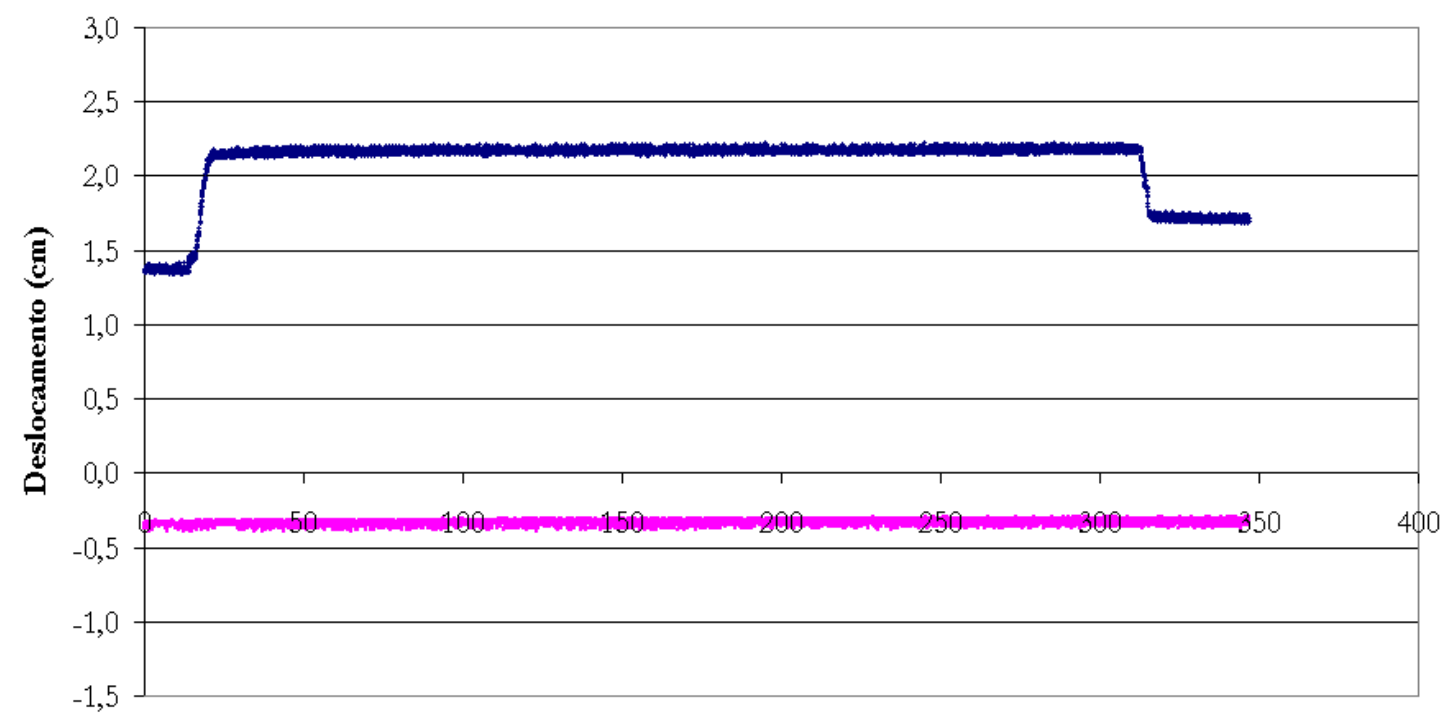

Tempo (s)

$\rightarrow$ LVDT Superior - LVDT Inferior 
Vala Rasa Não Compactada - 4,0 ton - Estático 2

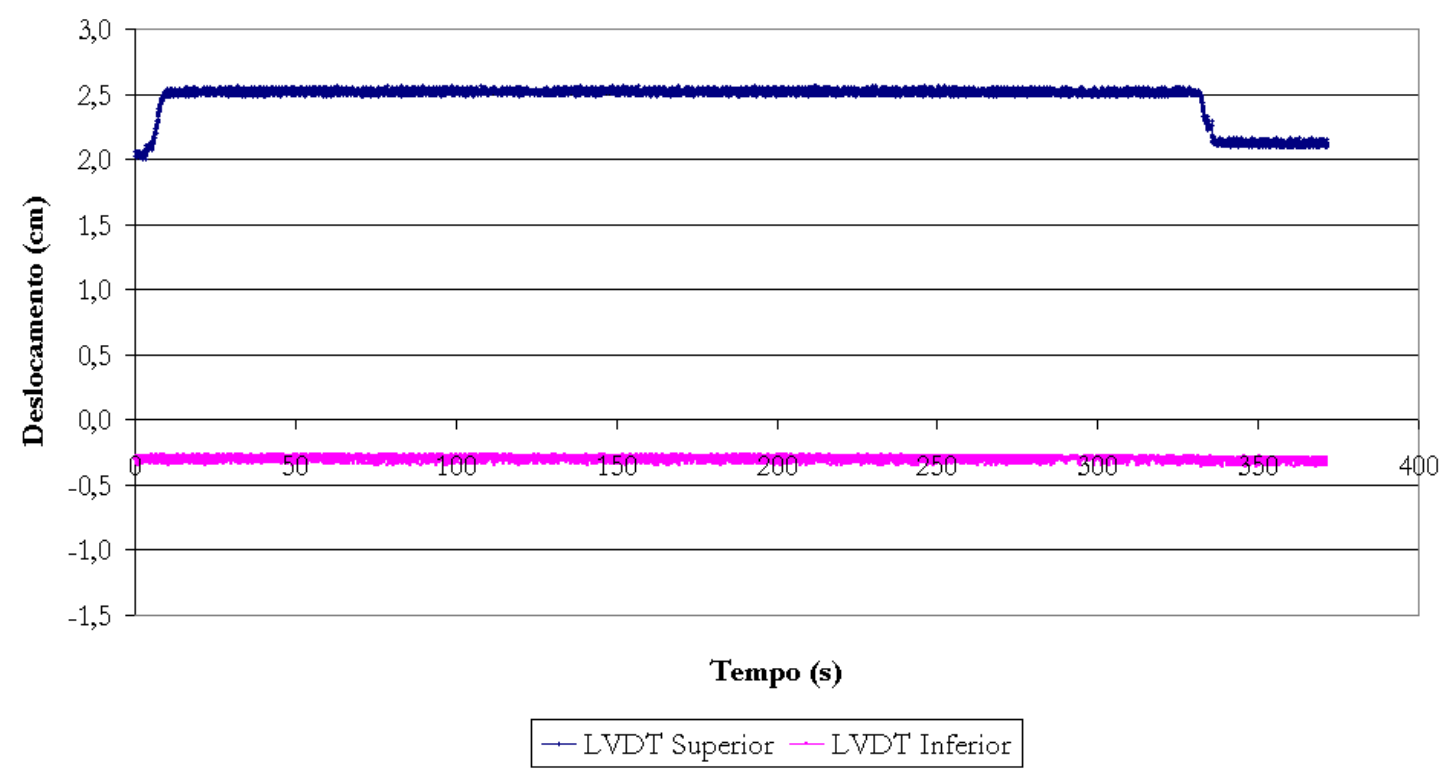

Vala Rasa Não Compactada - 4,0 ton - Estático 3

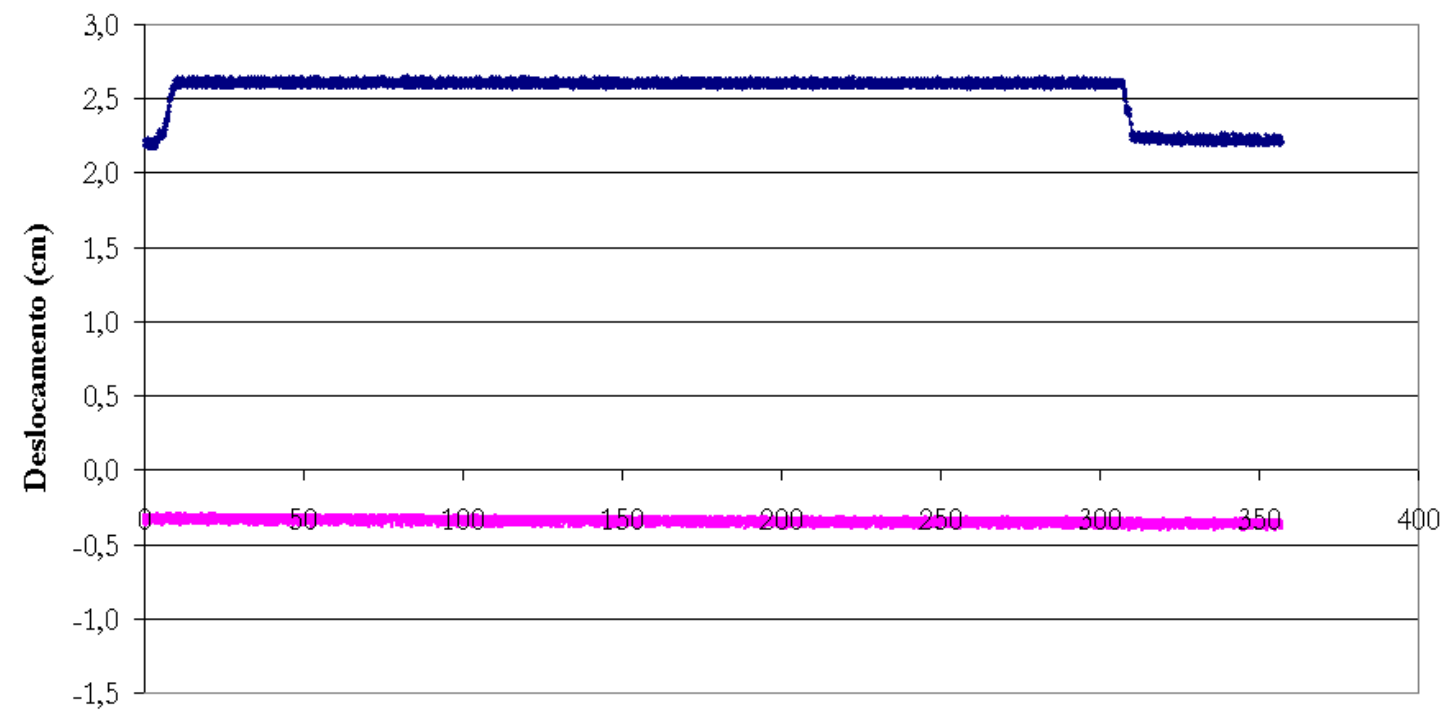

Tempo (s)

$\rightarrow$ LVDT Superior - LVDT Inferior 
Vala Rasa Não Compactada - 5,0 ton - Dinâmico

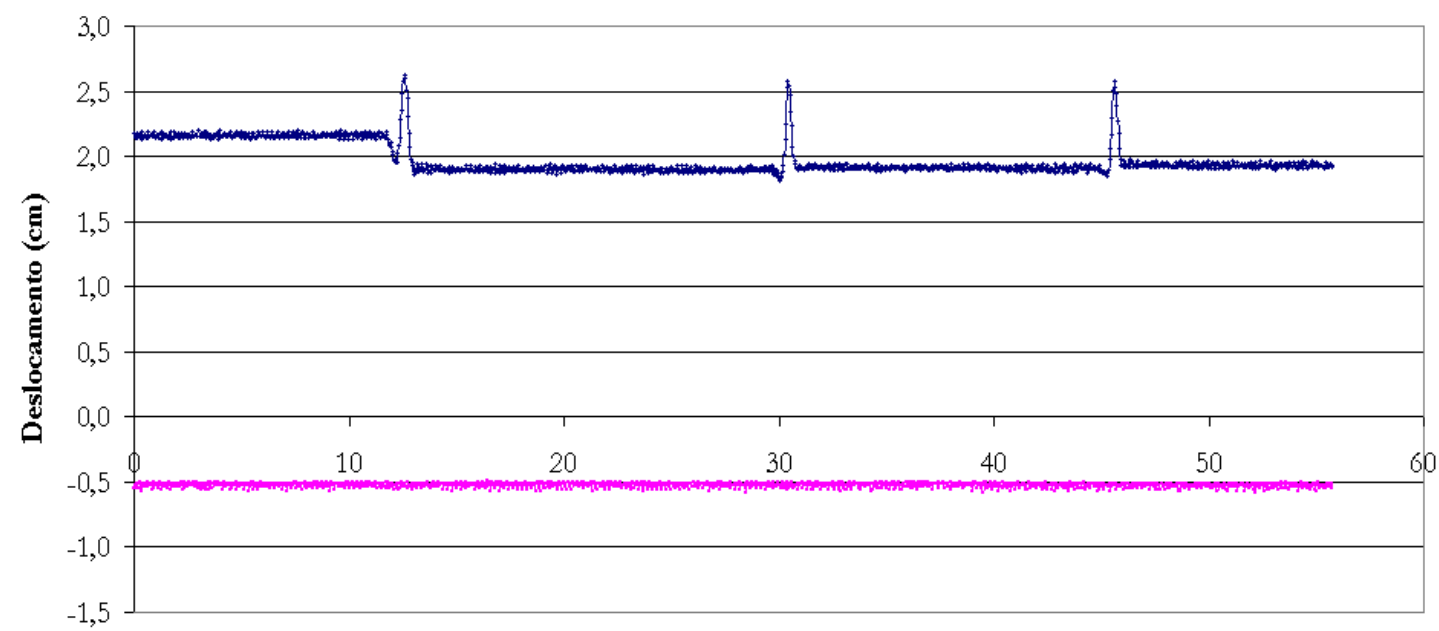

Tempo (s)

$\rightarrow$ LVDT Superior - LVDT Inferior

Vala Rasa Não Compactada - 5,0 ton - Estático 1

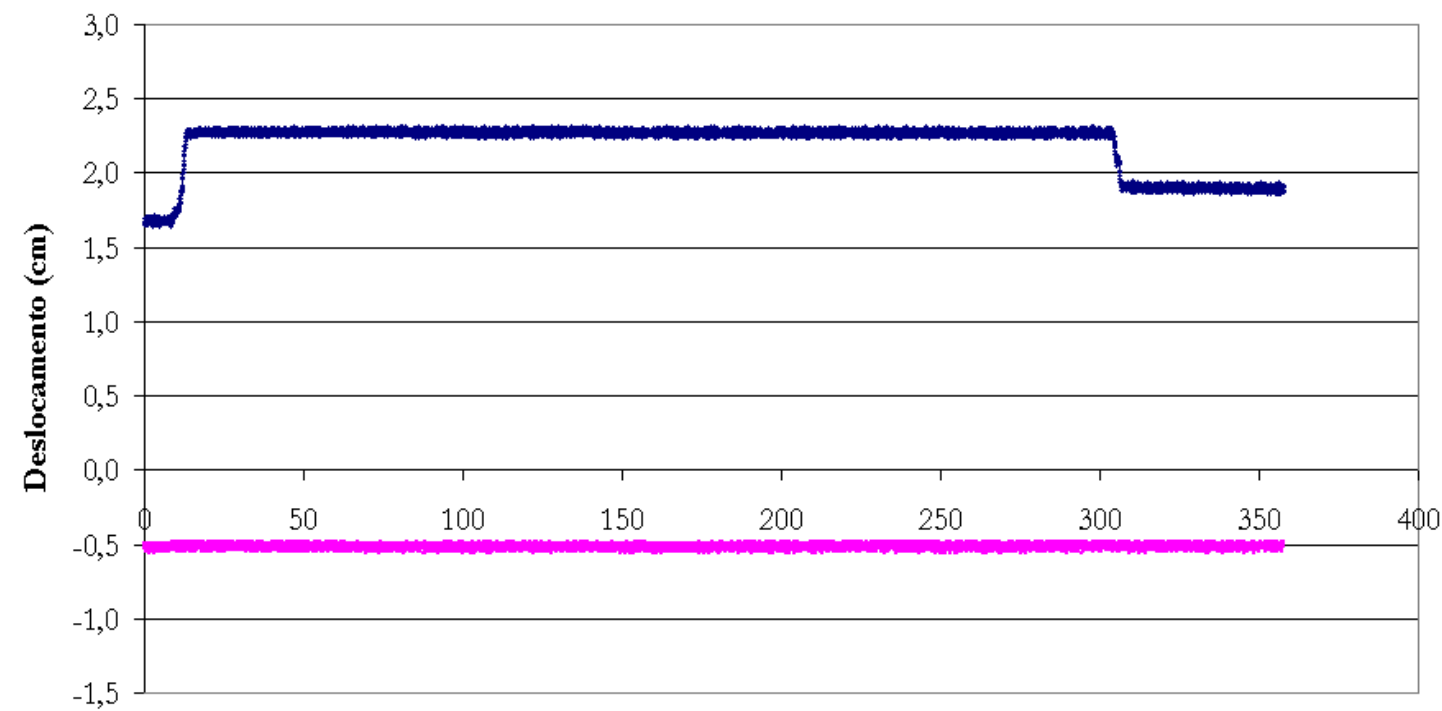

Tempo (s)

- LVDT Superior - LVDT Inferior 
Vala Rasa Não Compactada - 5,0 ton - Estático 2

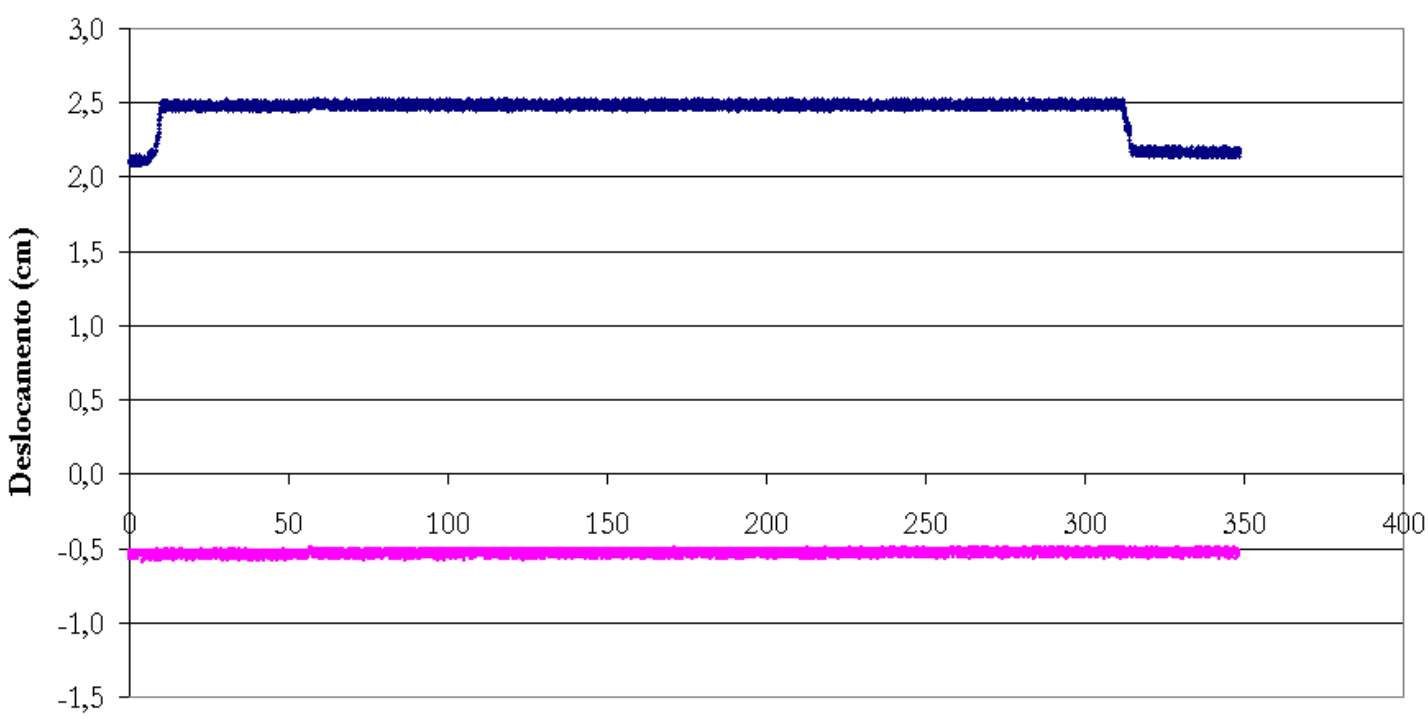

Tempo (s)

$\rightarrow$ LVDT Superior - LVDT Inferior

Vala Rasa Não Compactada - 5,0 ton - Estático 3

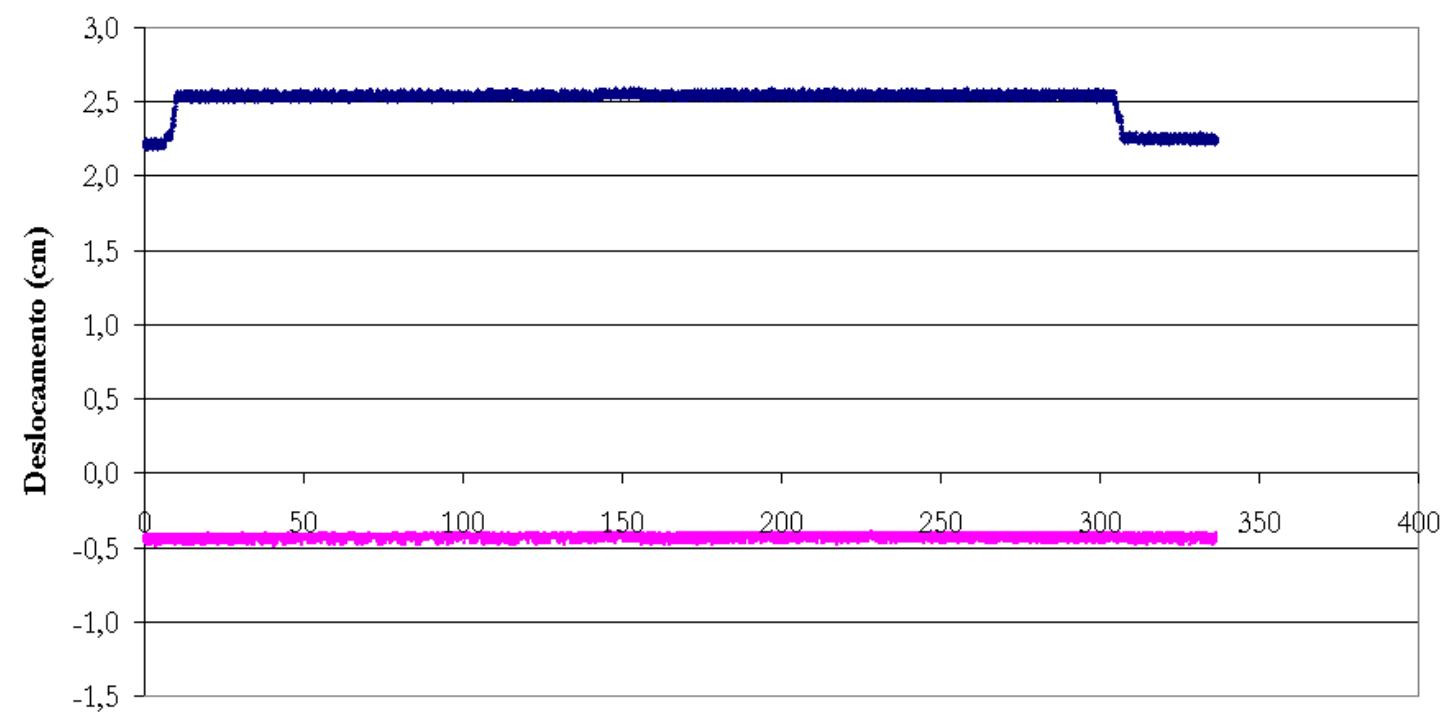

Tempo (s)

- LVDT Superior - - LVDT Inferior 


\section{ANEXO IX}

Resultados de Deslocamento da Vala Profunda Não Compactada 
Vala Profunda Não Compactada - 3,0 ton - Dinâmico

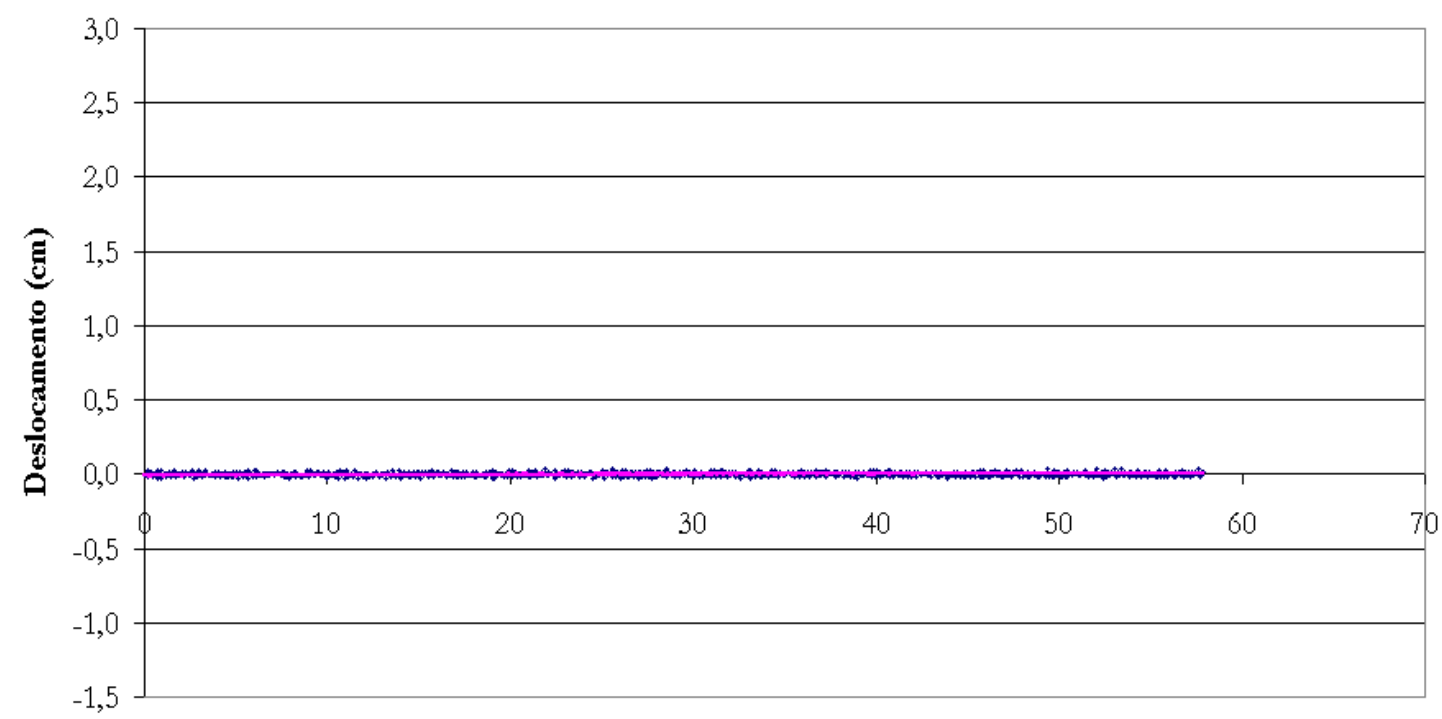

Tempo (s)

$\rightarrow$ LVDT Inferior - LVDT Superior

Vala Profunda Não Compactada - 3,0 ton - Estático 1

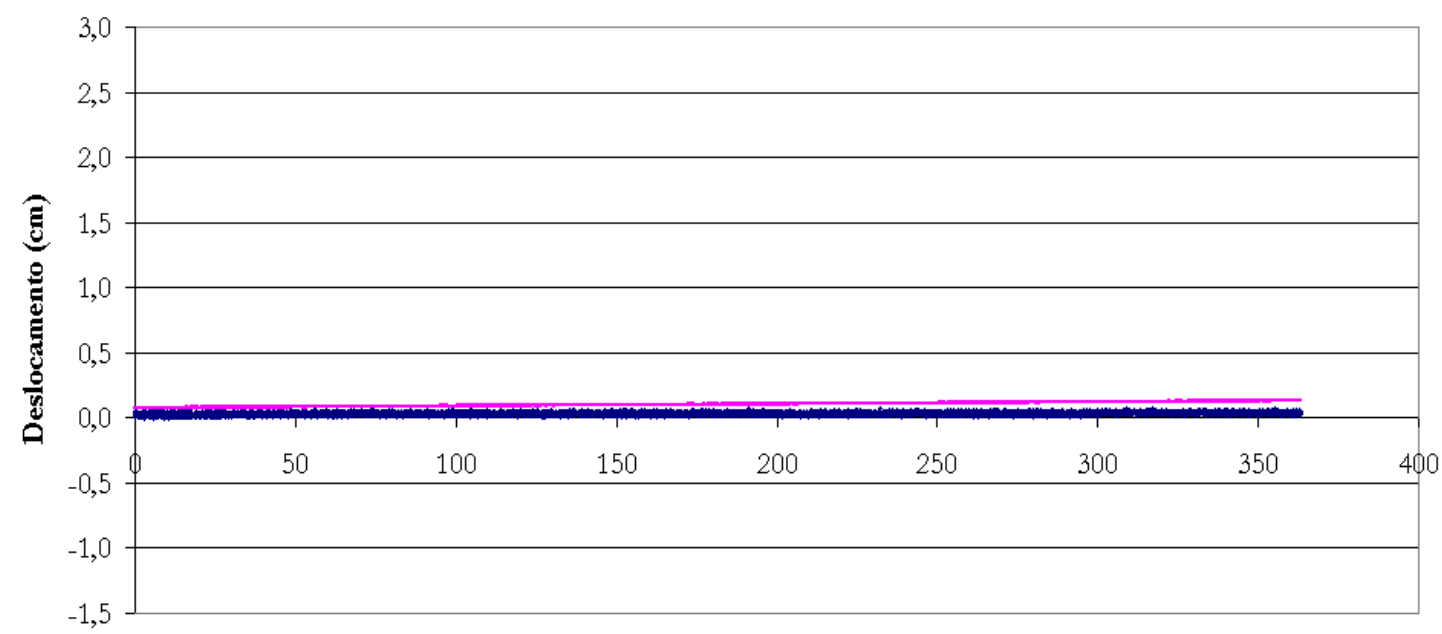

Tempo (s)

- LVDT Inferior - - LVDT Superior 
Vala Profunda Não Compactada - 3,0 ton - Estático 2

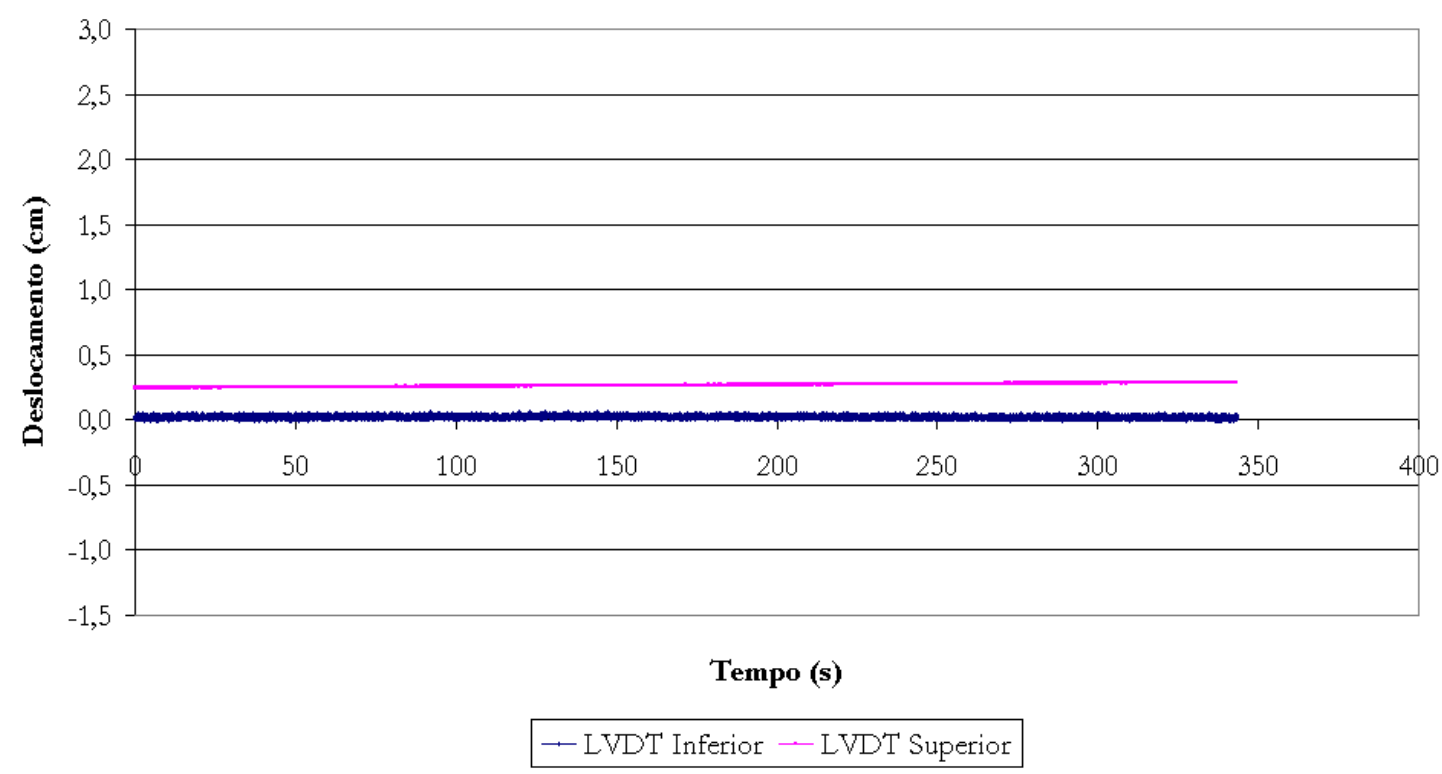

Vala Profunda Não Compactada - 3,0 ton - Estático 3

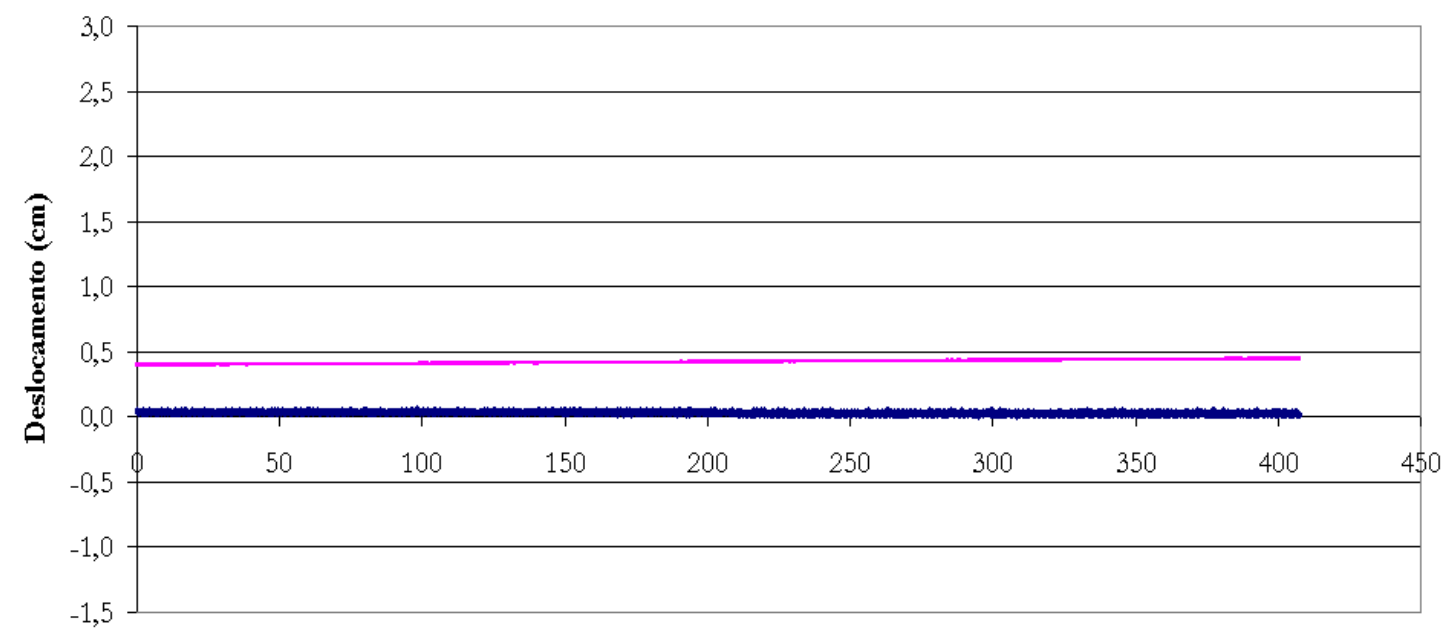

Tempo (s)

- LVDT Inferior - - LVDT Superior 
Vala Profunda Não Compactada - 4,5 ton - Dinâmico

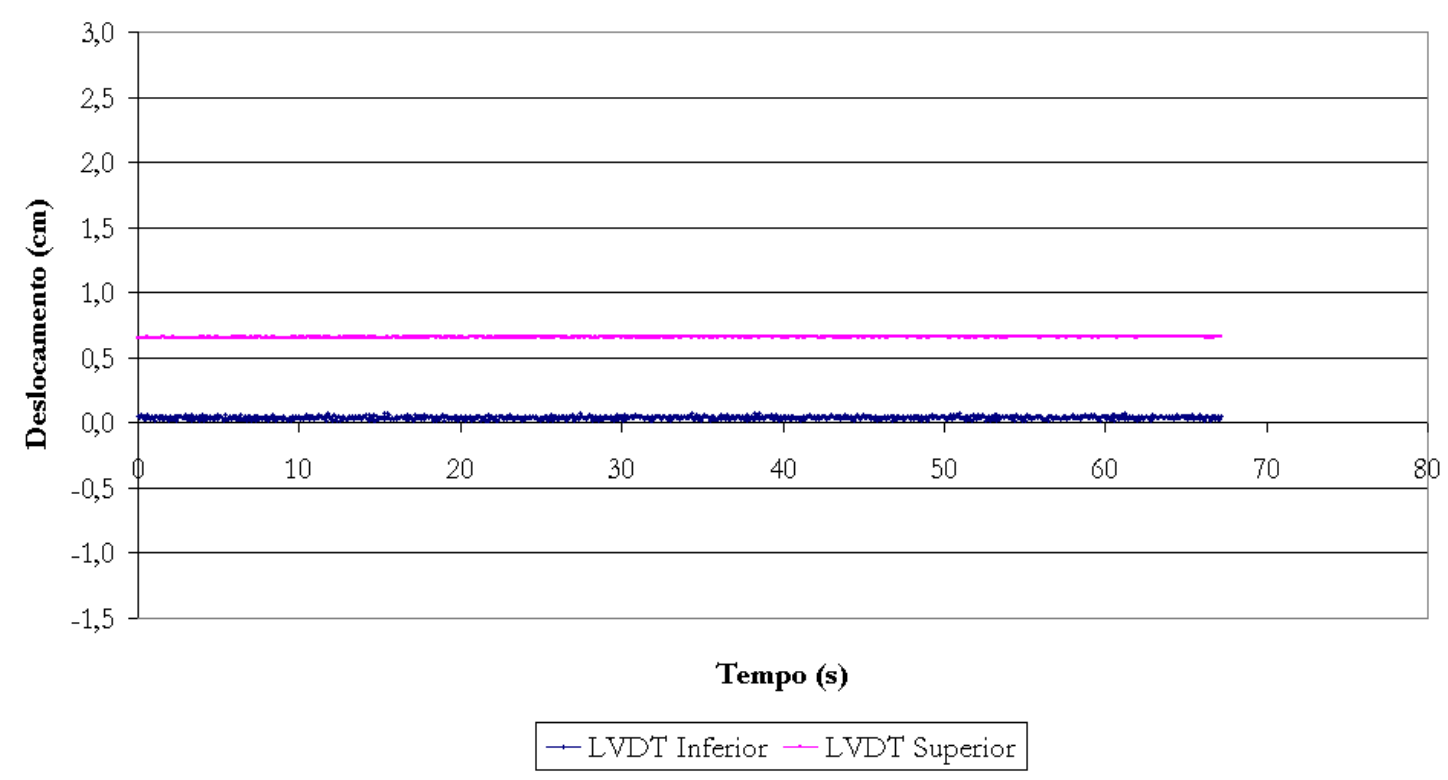

Vala Profunda Não Compactada - 4,5 ton - Estático 1

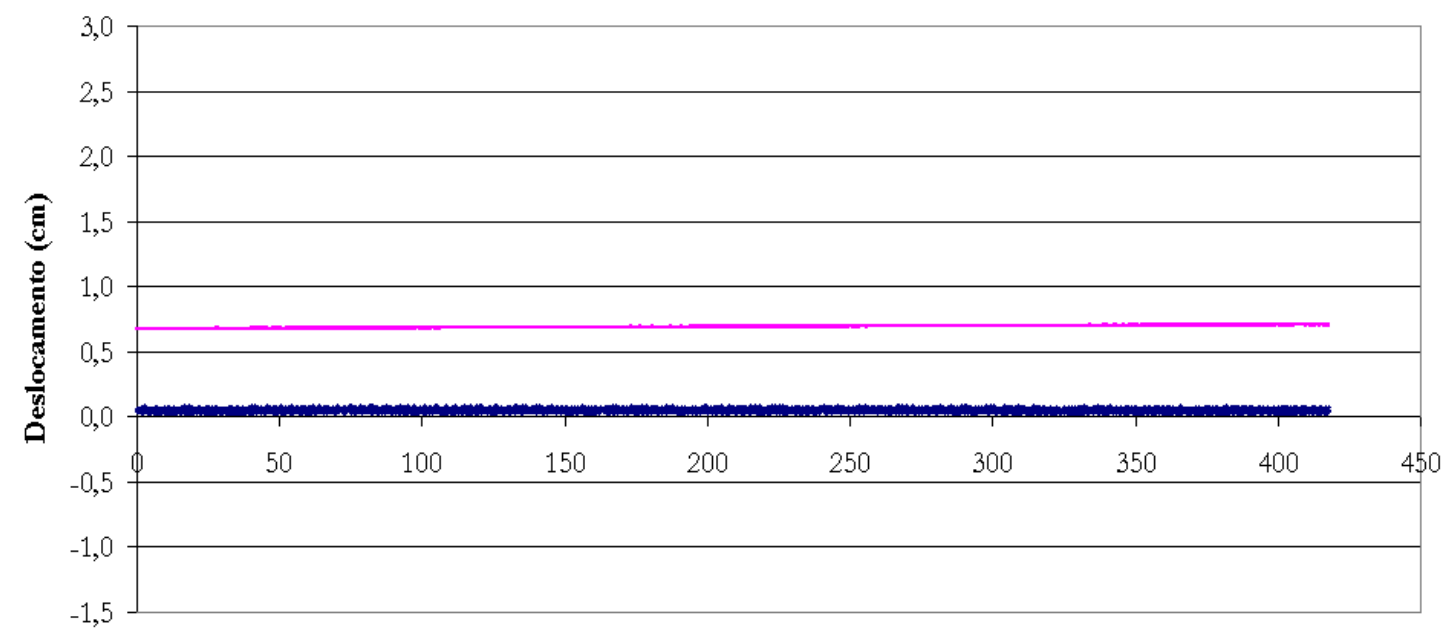

Tempo (s)

$\rightarrow$ LVDT Inferior - LVDT Superior 
Vala Profunda Não Compactada - 4,5 ton - Estático 2

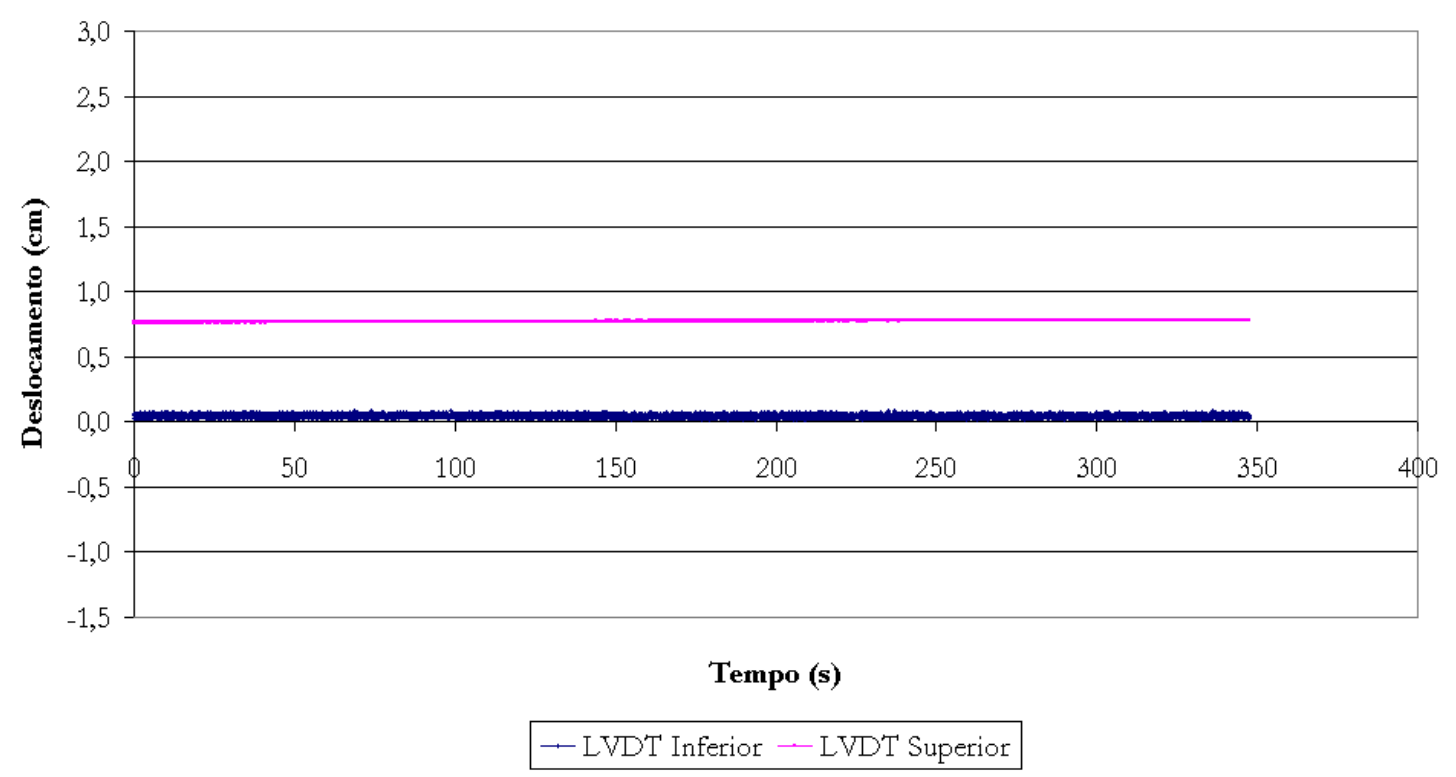

Vala Profunda Não Compactada - 4,5 ton - Estático 3

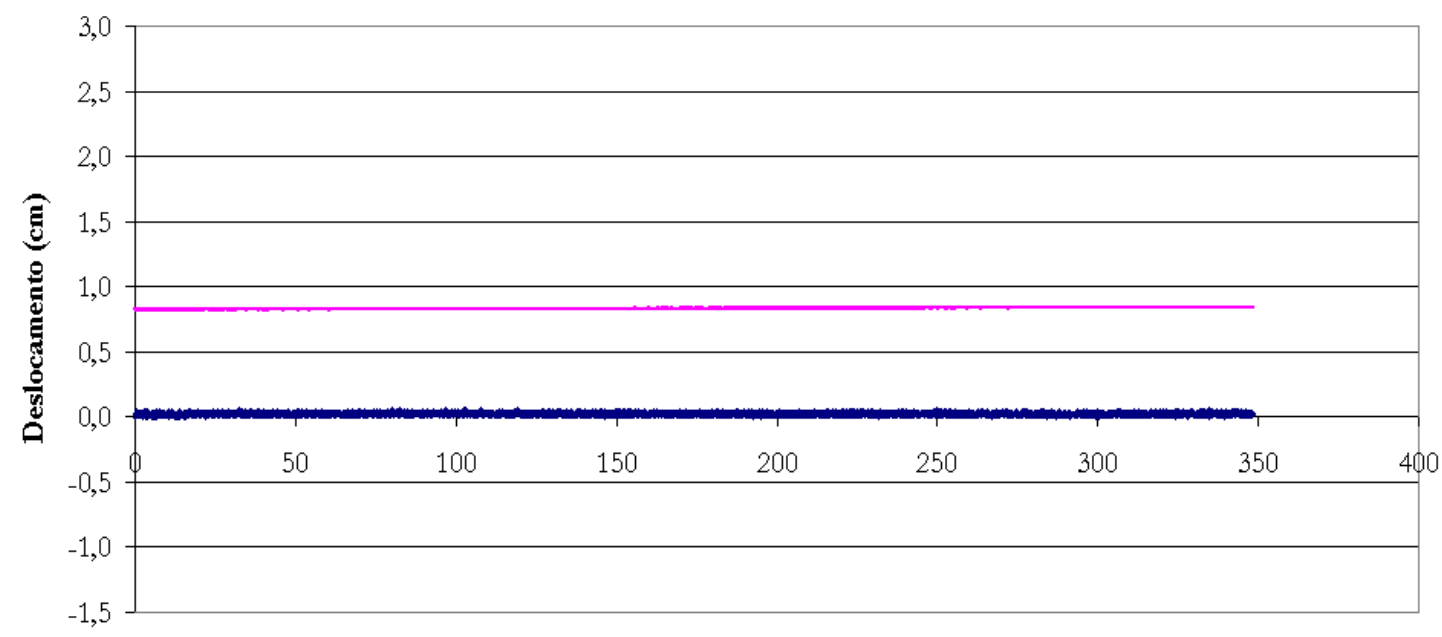

Tempo (s)

- LVDT Inferior - - LVDT Superior 
Vala Profunda Não Compactada - 6,0 ton - Dinâmico

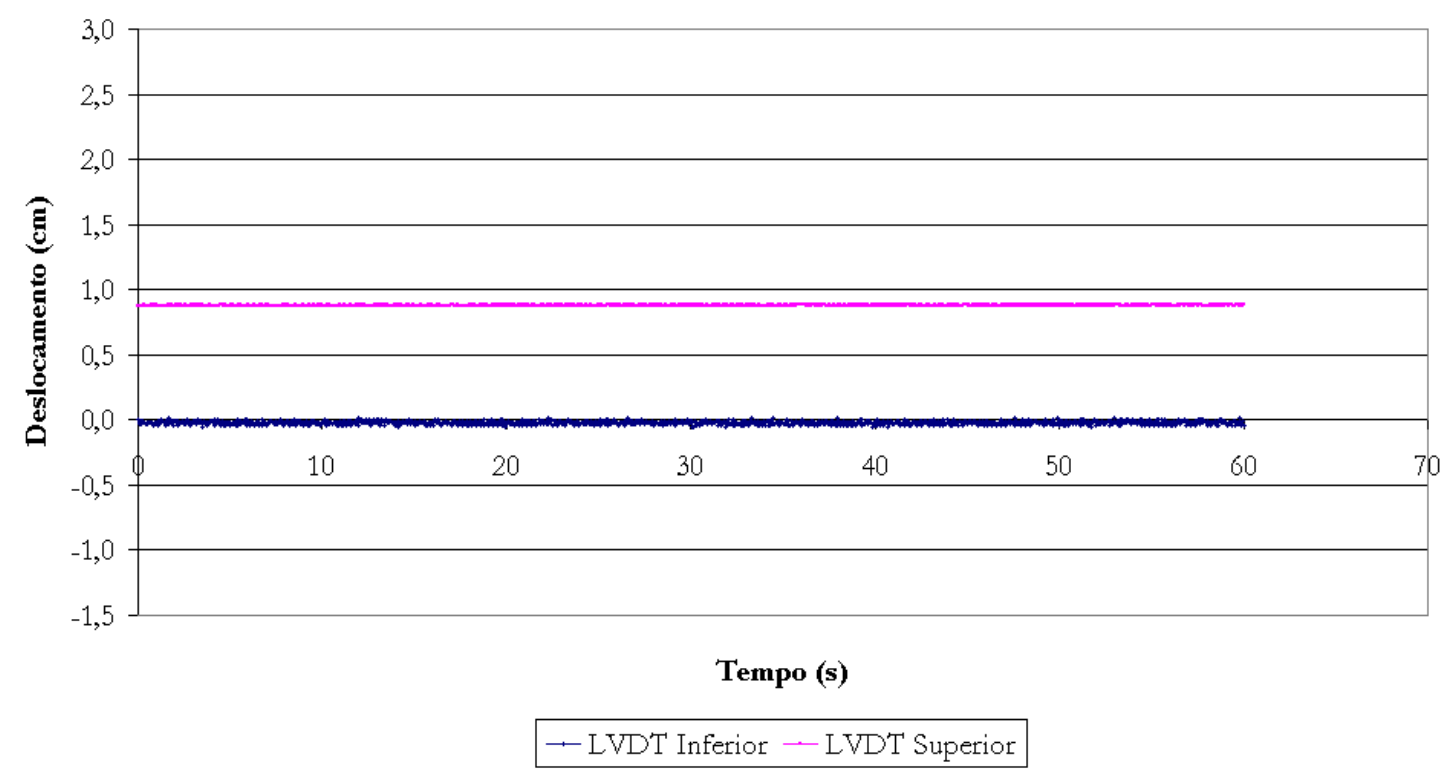

Vala Profunda Não Compactada - 6,0 ton - Estático 1

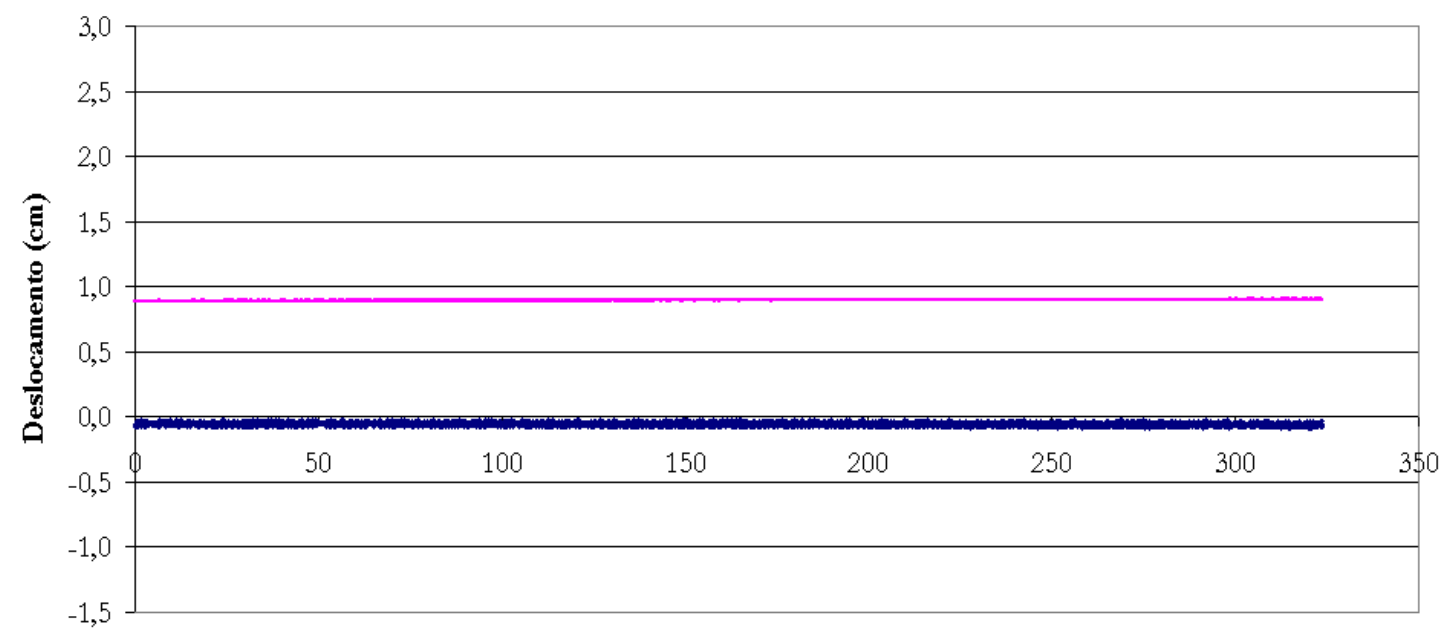

Tempo (s)

$\rightarrow$ LVDT Inferior - - LVDT Superior 
Vala Profunda Não Compactada - 6,0 ton - Estático 2

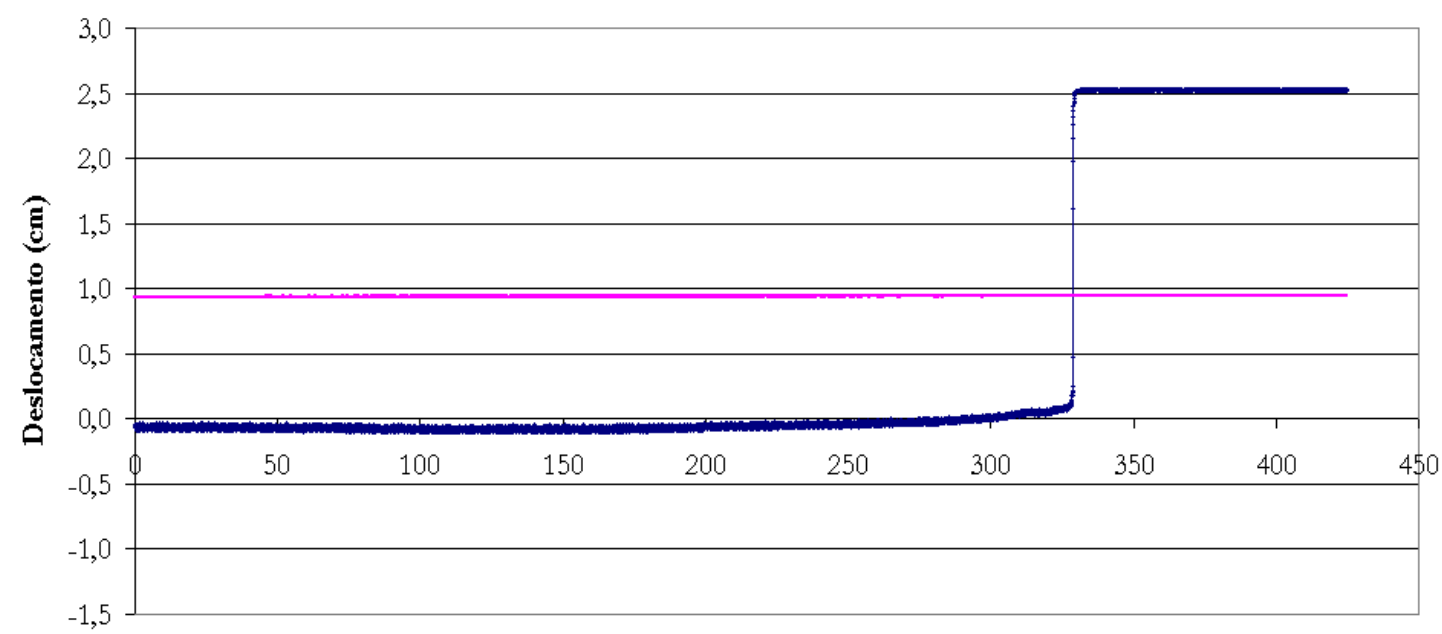

Tempo (s)

$\rightarrow$ LVDT Inferior - - LVDT Superior

Vala Profunda Não Compactada - 6,0 ton - Estático 3

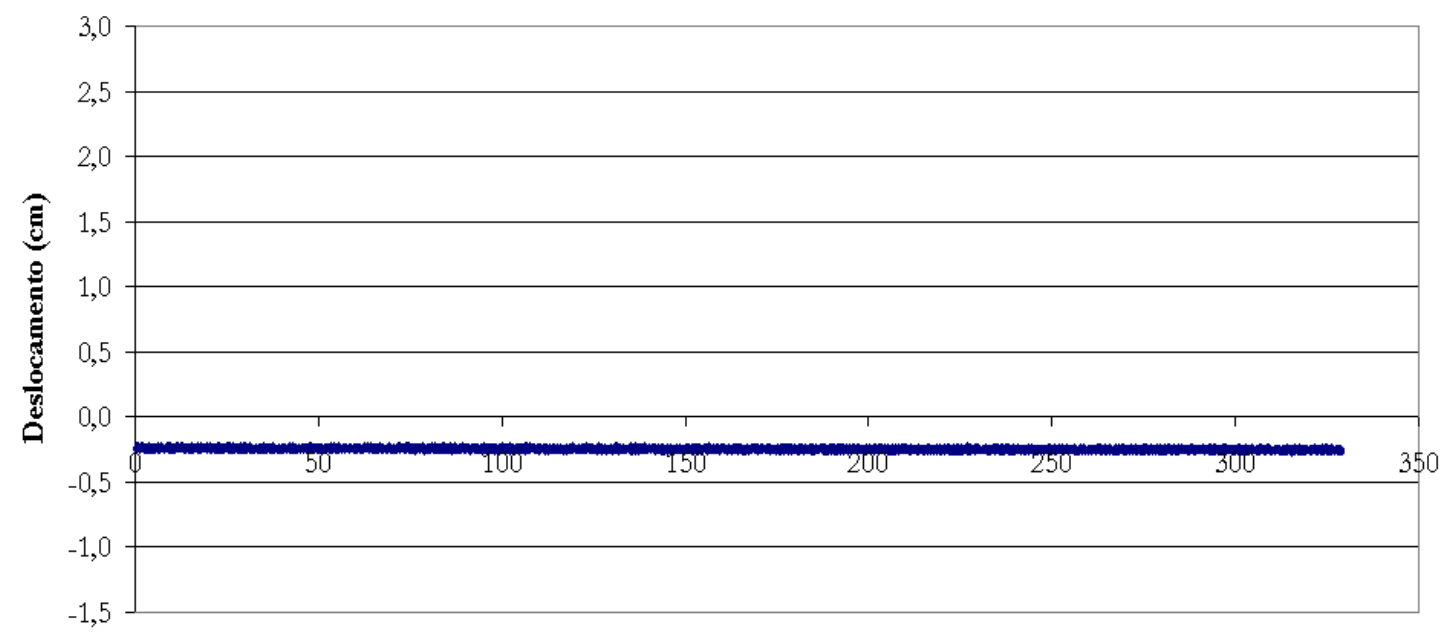

Tempo (s)

$\rightarrow$ LVDT Inferior - - LVDT Superior 